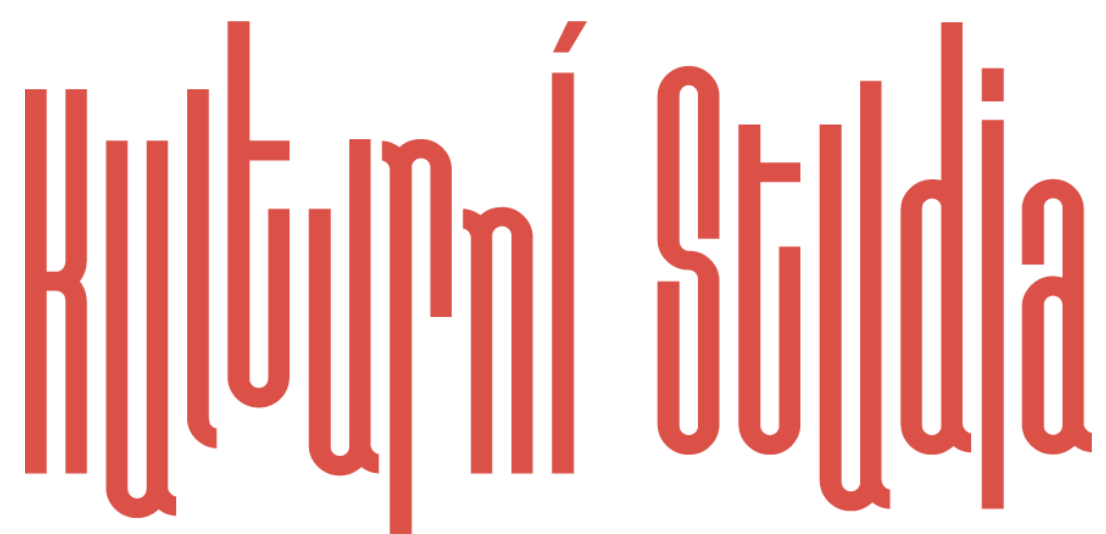

Sedmnácté číslo časopisu Kulturní studia, vychází 1. listopadu 2021 Vydává z. s. Kulturní studia, při oboru Hospodářská a kulturní studia, PEF ČZU 



\title{
150 let antropologie: Tylor, Morgan a Miklucho-Maklaj aneb kultura, komparace a terénní výzkum roku 1871
}

\section{Years of Anthropology: Tylor, Morgan and Miklouho-Maclay or Culture, Comparison and Field Research in 1871}

\author{
Martin Soukup \\ Institut komunikačních studií a žurnalistiky \\ Fakulta sociálních věd Univerzity Karlovy \\ Email: soukup@antropolog.cz
}

DOI: https://dx.doi.org/10.7160/KS.2021.170201

\begin{abstract}
This paper follows up the year 1871; a milestone of hardening anthropology as scientific approach. Tylor has published Primitive Culture; Morgan was signed under the title Systems of Consanguinity and Affinity of the Human Family, Miklouho-Maclay landed on New Guinea in the same year. There is no strict connection between these crucial events. From the historical viewpoint is possible to see (1) rising of focus on diachronic perspective to understand society and culture; (2) a studying of kinship as the key how to understand the both - culture and society; (3) a necessity to perform field research in a particular society and culture.
\end{abstract}

\section{Keywords}

evolution, fieldwork, Tylor, Morgan, Miklouho-Maclay

\section{Klíčová slova}

evoluce, terénní výzkum, Tylor, Morgan, Miklucho-Maklaj

\section{Úvod}

Vydání Tylorovy práce Primitive Culture (1871) se někdy pokládá za okamžik zrodu moderní antropologie jako vědy o člověku, společnosti a kultuře. Ve stejném roce, ovšem na druhé straně Atlantiku, vyšla jiná vlivná práce, bez níž si formování moderní antropologie nelze představit. Morgan toho roku vydal dílo Systémy pokreventství a sešvagření lidské rodiny (1871). Ve stejném roce se Miklucho-Maklaj vylodil na březích Nové Guineje, aby mezi jejími obyvateli provedl vědecké bádání. Od vydání obou děl i počátku novoguinejského 
výzkumu v letošním roce uplyne sto padesát let. Že se všechny tři události vztahují k roku 1871, neznamená, že se jednalo o zlomový moment v dějinách ustanovování norem a forem antropologie jako samostatné disciplíny.

Obě práce otevřely témata, jimiž se lidé spjatí s oborem věnovali sto padesát let, at' již jejich ideje následovali, rozvíjeli, kriticky přehodnocovali, nebo striktně odmítli. Tylorova práce je často interpretována jako jedno ze zakladatelských děl antropologie, protože v ní autor předložil první nehodnotící vymezení kultury jako předmětu antropologického zájmu. Kromě jiného v ní také představil své názory na náboženství, mytologii, jazyk a mnohá další témata. Dílem se pokusil položit základy vědy o kultuře (orig. science) a nabídnul v něm metodu, kterou tato věda měla zkoumat evoluci lidské kultury. Morganova práce otevřela pro antropologii téma př́buzenství, které se stalo jedním z nejdůležitějších ve vývoji antropologického myšlení. Klade si v něm rovněž metodologické otázky, ale pojem kultura pro něj rozhodně nebylo těžištěm jeho úvah. Tylor budoval své spekulace na konstruování představy evoluce kultury lidstva na základě informací z druhé ruky, u kterých jej př́liš nezajímala prostorová distribuce či časové určení. Morgan oproti němu vsadil na metodologicky solidní komparaci administrací dotazníků a jejich zpracováním. Ve rovnání s nimi Miklucho-Maklaj odcestoval na Novou Guineu, aby tam provedl terénní výzkum, jehož výsledky se vztahovaly výhradně k Papuáncům v zálivu Astroláb, nikoli k lidstvu.

Výtisk Morganovy knihy, ze které čerpám, kdysi patřil Herbertu McLean Evansovi, americkému anatomovi a embryologovi, který se podílel na objevu vitaminu E. $\mathrm{S}$ přihlédnutím k tématu této studie v tom lze spatřovat určité symbolické spojení. Vitamin $\mathrm{E}$ je totiž významný antioxidant, který zpomaluje stárnutí buněk. Morganova i Tylorova kniha nezestárly rychle, stejně jako nezastaral Miklucho-Maklajův výzkum, i když můžeme pojmenovat jeho slabiny. Ve studii ukážu, že všichni tři autoři nezávisle na sobě formulovali základy antropologie rámované časem a prostorem, tedy vývojovými proměnami člověka, společností a kultur, respektive jejich prostorovou distribucí. V roce 1871 došlo ke třem antropologicky významným událostem, není mezi nimi přímá souvislost, přesto mají výpovědní hodnotu k otázce vzniku a utváření forem a norem moderní antropologie jako vědy o člověku, společnosti a kultuře. 


\section{Klasický evolucionismus 19. století}

O klasickém evolucionismu vznikla již řada prací, které se bud' snaží ze současné perspektivy vyhodnotit genezi tohoto směru a přínos jeho představitelů pro současnou antropologii, ${ }^{1}$ nebo se snaží zdůraznit dobové hledisko a historické události, které působily na přistup a myšlení jednotlivých autorů. ${ }^{2} \mathrm{~V}$ přehledových textech bývá evolucionismus běžně prezentován jako samostatné paradigma. ${ }^{3}$ Některé publikace řazené do klasického evolucionismu však dělí i bezmála půl století, jak ukazuje rozdíl mezi vročením prvního vydání Bachofenovy práce Mateřské právo (1861) a Westermarckova díla Původ a vývoj morálních myšlenek (1908). Určitě nelze hovořit o nějaké jednotné škole, na druhou stranu autoři řazení do tohoto směru vycházeli z několika předpokladů, které tvoří jistý jednotící teoretický rámec pro směr označovaný klasický evolucionismus. V̌̌echny je spojoval názor, že společnost a kultura lidského druhu prochází evolucí (vývojem) chápanou jako pokrok, který probíhá v jasně vymezitelných vývojových stupních. Někteří autoři se zabývali všeobecným pokrokem kultury lidstva, čímž se zabýval např́íklad John Lubbock v práci Pُ̊ood civilizace (1870). Jiní autoři se zabývali pokrokem ve vybraných doménách lidské společnosti a kultury: právo ${ }^{4}$, manželství ${ }^{5}$, náboženství ${ }^{6}$ či umění.

Přirozeně lze jmenovat mnoho badatelů a vědců mezi průkopníky, kteří přispěli k etablování antropologie jako samostatného vědního oboru. Uvést lze např́íklad Pricharda, Galtona, Müllera a mnohé další. Význam Tylora a Morgana zůstává i tak jen těžko přehlédnutelný, jelikož publikovali texty, které vyjádřili dlouhodobé směřování oboru, na jedné straně důrazem na studium kultury jako předmětu antropologického zájmu, na druhé straně studiem př́ibuzenství, které se stalo slovy Robina Foxe tím, čím se stala „logika pro filozofii a akt pro umění, je to základní disciplína oboru“* Kromě toho, Tylor se stal vůbec prvním profesorem antropologie, ač nikdy neabsolvoval univerzitní studia. Morgan se sice

\footnotetext{
${ }^{1}$ Např. BARNARD, Alan, 2000. History and Theory in Anthropology. Cambridge: Cambridge University Press. HARRIS, Marvin. Rise of Anthropological Theory. New York: Thomas Y. Crowell.

${ }^{2}$ Zejména STOCKING, George, 1987. Victorian Anthropology. New York: The Free Press. PETERMANN, Werner, 2004. Die Geschichte der Ethnologie. Wuppertal: Peter Hammer.

${ }^{3}$ Např. MOORE, Jerry, 2004. Visions of Culture. Walnut Creek: Altamira. ERICKSON, Paul; MURPHY, Liam. A History of Anthropological Theory. Peterborough: Broadview Press.

${ }^{4}$ MAINE, Henry, 1861. Ancient Law. London: John Murray.

${ }^{5}$ MCLENNAN, John. Primitive Marriage. Edinburgh: Adam \& Charles Black. WESTERMARCK, Edvard, 1891. The History of Human Marriage. London: Macmillan.

${ }^{6}$ FRAZER, James George, 1890. The Golden Bough. London: Macmillan. MARRET, Robert, 1911. The

Threshold of Religion. London: Methuen.

${ }^{7}$ HADDON, Alfred Cort, 1895. Evolution in Art. London: Walter Scott.

${ }^{8}$ FOX, Robin, 1970. Kinship and Marriage. Harmondsworth: Penguin Books, s. 10.
} 
musel více věnovat své právní praxi a antropologii měl spíše koníčkem, přesto významně přispěl k etablování antropologie jako samostatné disciplíny. Ve srovnání s nimi zůstává ruský etnograf Miklucho-Maklaj spíše přehlíženou osobností v dějinách oboru, navzdory skutečnosti že se stal průkopníkem samotných základů oboru - terénního výzkumu chápaného jako dlouhodobý a cílevědomý kontakt s příslušníky určité skupiny za účelem jejího poznání a tvorby dat.

U všech tří autorů lze najít přitakání postulátům klasického evolucionismu, jak je vyjmenoval například Václav Soukup, ${ }^{9}$ ale jejich souhrn najdeme již v Tylorově Primitivní kultuře: (1) stadiální charakter vývoje, (2) psychická jednota lidstva, (3) unilineární průběh evoluce, který lze studovat na základě (4) komparace a (5) s využitím konceptu přežitku. ${ }^{10}$ Stejně jako Tylor i Morgan přemýšlel o aliterárních společnostech jako o primitivním reliktu prvotní fáze evoluce lidské kultury. Obdobně Miklucho-Maklaj odcestoval na Novou Guineu, aby tam studoval vzácné a rychle mizející „,primitivní kultury“, které mohou vrhnout jisté světlo na podstatu člověka a vývoj jeho kultury.

\section{„,Věda pana Tylora“: mýtus antropologické definice kultury}

Lee Cronk ${ }^{11}$ uvádí, že Tylorova definice kultury patří k nejcitovanějším antropologům vůbec a odkazují se na ni zvláště autoři učebnic. Význam Tylora jako průkopníka antropologie vědy o kultuře je však přeceňována, podle Stockinga ${ }^{12}$ se pojem kultura začal v antropologii pozvolna prosazovat až po roce 1900 a nebylo to podle něj vlivem Tylora. Význam prvních čtyř řádků prvního svazku Primitive Culture se začal zdůrazňovat mnohem později. Jen letmý pohled do rané reflexe dějin oboru poskytuje nápovědu. Alfred Haddon v práci Dějiny antropologie nepochybně Tylorovi připisoval značné zásluhy, když jeho vyobrazení zařadil na frontispis, ale nespatřoval přínos Tylora pro vznik antropologie ve formulaci konceptu kultury, nýbrž jako „,zakladatele komparativní etnologie““. ${ }^{13}$ Ovšem již na konci třicátých let píše Robert Lowie v díle Dějiny etnologické teorie (1937) o Tylorově „klasické definici kultury“"14 a v publikaci mu věnoval samostatnou kapitolu, ve které se věnoval rozboru jeho př́nosu antropologii. ${ }^{15}$ Zaslouží si dodat, že tentýž autor roku 1917 - shodou okolností v roce

\footnotetext{
${ }^{9}$ SOUKUP, Václav, 2004. Dějiny antropologie. Praha: Karolinum, s. 298.

${ }^{10}$ Srov. TYLOR, Edward Burnett, 1871. Primitive Culture. Sv. 1. London: John Murray.

${ }^{11}$ CRONK, Lee, 1999. That Complex Whole. Boulder: Westview Press, s. 4.

${ }^{12}$ STOCKING, George, 1982. Race, Culture, and Evolution. Chicago: Chicago University Press, s. 201.

${ }^{13}$ HADDON, Alfred Cort, 1910. History of Anthropology. London: Watts \& Co, s. 129.

${ }^{14}$ LOWIE, Robert, 1937. The History of Ethnological Theory. New York: Rinehart \& Company, s. 12.

15 Tamtéž, s. 68 a dále.
} 
Tylorovy smrti - ve svém díle Kultura a etnologie napsal, že „kultura je ve skutečnosti jediným a výlučným předmětem zájmu etnologie““, ${ }^{16}$ ovšem učinil tak bez odkazu na Tylora.

Že se antropologie stala - alespoň do doby kritiky v polovině osmdesátých let 20. století - vědou o kultuře, přesněji o různých kulturách, je zásluhou amerických představitelů oboru, nikoli Tylora. Stocking ${ }^{17}$ poukázal na skutečnost, že boasiánské užití konceptu kultury odkazuje na německy psané zdroje a stalo se východiskem pro formování antropologie jako vědy o kultuře. Antropologové se stali specialisty na kulturu, o tom nebylo v polovině 20. století žádných pochyb, jak uvádí Adam Kuper. ${ }^{18}$ Úspěch pojmu kultura ukazuje hojně citovaná práce Kroebera a Kluckhohna (s přispěním Untreinera a Meyera) Kultura: kritické posouzení koncepti̊ a definic (1952). V práci provedli zevrubnou analýzu vývoje pojmu kultura a dosavadních přístupů k tomuto konceptu, shromáždili několik stovek definic a více než sto šedesát z nich zařadili do svého rozboru. Autoři vyzdvihli význam Tylorova počinu pro formování pojmu kultura jako vědecké kategorie: „Stručně řečeno, slovo kultura v jeho moderním technickém a antropologickém významu bylo v angličtině zavedeno Tylorem roku 1871“. ${ }^{19}$ Oba citovaní autoři zastávali názor, že Tylorem navržená definice byla úspěšná z důvodu ,historických asociací, a protože Tylor vymezil obecné důsledky konceptu, a to přesně i dostatečně abstraktně““ ${ }^{20}$ Oba autoři byli toho názoru, že sice Tylor hodně těžil z Klemmovy práce Všeobecné kulturní dějiny lidstva (1843-1952), ale ten nedokázal v deseti svazcích to, co udělal Tylor v Primitivní kultuře - přikovat do názvu své knihy obecný pojem, jenž ,zůstával prostý náznaku pokroku, který v sobě svíral anglický pojem civilizace““. ${ }^{21}$

Historik antropologie George Stocking ukázal, ${ }^{22}$ že Tylorovu citovanou práci rozhodně nelze označit za nějaký bod zlomu ve formování moderní antropologie, jelikož jím navržené pojetí kultury postrádalo atributy spojované s tímto konceptem ve 20. století: historicitu, holismus, relativismus, determinismus. ${ }^{23}$ Tylor totiž pracoval s konceptem kultury v jednotném čísle a stojí na něm i jeho výčtové vymezení pojmu. Nezajímají jej různé podoby znalostí, práva či umění, ale důsledně pokrok ve vědění, právu či umění vůbec. Tylorova definice kultury je sice dostatečně známá, ale pro potřeby této studie je namístě ji zopakovat:

\footnotetext{
${ }^{16}$ LOWIE, Robert, 1917. Culture and Ethnology. New York: Boni and Liveright, s. 5.

${ }^{17}$ STOCKING, George, 1987. Victorian Anthropology. New York: The Free Press. 0-02-931551-4, s. 303.

${ }^{18}$ KUPER, Adam, 2000. Culture. Harvard: Harvard University Press.

${ }^{19}$ KROEBER, Alfred; KLUCKHOHN, Clyde. Culture: A Critical Review of Concepts and Definitions. Peabody Museum of American Archaelogy and Ethnology Papers. 1952, 47(1), s. 9.

${ }^{20}$ Tamtéž, s. 9.

${ }^{21}$ Tamtéž, s. 25

${ }^{22}$ Srov. STOCKING, George, 1982. Race, Culture, and Evolution. Chicago: Chicago University Press.

${ }^{23}$ STOCKING, George, 1982. Race, Culture, and Evolution. Chicago: Chicago University Press, s. 204
} 
„Kultura neboli civilizace, chápaná v jejím širokém antropologickém smyslu, je ten komplexní celek, jenž zahrnuje poznání, víru, umění, morálku, právo, zvyklost a jakékoli jiné schopnosti a návyky, jež člověk získal jako člen nějaké společnosti“‘24. První část definice je celkem jasná, položil naroveň kulturu a civilizaci, čímž přiblížil anglickým čtenářům výraz kultura, který se $\mathrm{v}$ té době $\mathrm{v}$ angličtině sice již používal, ale rozmanitě a rozhodně ne antropologicky nehodnotícím způsobem. Jak jsem naznačil výše, s pojmem kultura se běžně pracovalo v německém jazykovém prostředí, nikoli v jeho pluralistickém pojetí, které se stalo charakteristické pro pozdější vývoj antropologie. Osvícenští autoři Klemm či Herder pokládali kulturu za univerzální lidský jev. Např́iklad Herder chápal kulturu jako míru osvícenosti, která se přirozeně může lišit v různých epochách a zemích. Ale neexistuje národ bez kultury, domníval se Herder. Proto je překvapivé, že na německé osvícenské myslitele navazující Tylor psal o nekulturních národech.

Na díle Primitivní kultura je mnohem důležitější rozvíjený přístup ke zkoumání sociálních a kulturních jevo̊ než samotné vymezení kultury. Tylor si totiž velmi dobře uvědomoval, že existují dva hlavní způsoby, jak vysvětlit výskyt homologických kulturních jevů. Na jedné straně je lze vysvětlit společným původem, tedy difuzí invence z jednoho geografického místa. Výskyt formálně podobných kulturních jevů lze však rovněž vysvětlit nezávislou invencí, tedy že lidé v různých časech a na různých místech dospívají k podobným řešením srovnatelných problémů. $\mathrm{K}$ druhému vysvětlení se přiklonil Tylor, jak plyne $\mathrm{z}$ jeho vstupní kapitoly Primitivní kultury. ${ }^{25}$ Následující vývoj antropologického myšlení osciloval mezi dvěma názory, bud' se dávala přednost časovému hledisku (evoluce), nebo prostorovému (difuze).

\section{Morganova komparativní práce o příbuzenství}

Americký právník Lewis Henry Morgan (1818-1881) a antropolog patří k průkopníkům moderní antropologie. Tento představitel klasického evolucionismu nezůstával pouze v teple pracovny, jak se někdy nespravedlivě píše o reprezentantech tohoto směru. Morgan podnikl terénní výzkumy u Irokézů, o nichž publikoval dvě knižní monografie. ${ }^{26} \mathrm{~V}$ prvním z citovaných děl popsal irokézský příbuzenský systém, jenž pokládal za jejich vlastní

\footnotetext{
${ }^{24}$ TYLOR, Edward Burnett, 1871. Primitive Culture. Sv. 1. London: John Murray, s. 1.

${ }^{25}$ Tamtéž, kapitola 1.

${ }^{26}$ Zvláště MORGAN, Lewis Henry, 1851. League of the Ho-Dé-No-Sau or Iroquosis. Rochester: Sage \& Brother.
} 
invenci. ${ }^{27}$ Následující léto po vydání knihy z roku 1851 se obeznámil s př́buzenským systémem Odžibvejů. K svému překvapení seznal, že se sice pojmy pro označení př́ibuzných liší, ale „klasifikace př́buzných byla stejná“. ${ }^{28}$ Položil si tedy otázku, zda se př́buzenský systém shoduje u všech skupin původních Američanů a zda lze jeho původ odvodit z Asie, odkud zřejmě předci prvních Američanů přišli. Otevřel stejnou otázku jako Tylor, on ovšem na případu příbuzenství: lze shody vysvětlit jako výsledek difuze a lidské migrace či se jedná o výsledek nezávislé invence. ${ }^{29}$ Aby tuto otázku prozkoumal, rozhodl se provést rozsáhlé dotazníkové šetření, jehož cílem bylo získat data o příbuzenských systémech nejen u původních obyvatel Ameriky, ale rovněž z jiných částí světa, konkrétně ze skupin mluvících semitskými, árijskými ${ }^{30}$ a uralskými ${ }^{31}$ jazyky. Celkem zpracoval 119 dotazníků, jež získal od svých spolupracovníků, z toho osmdesát bylo o nativních skupinách Severní Ameriky. Do své analýzy ještě zahrnul další dotazníky z Číny, Malajsie a Oceánie, které však nebyly stejně bohaté na informace jako ty předchozí. Kupříkladu z Oceánie pracoval s daty z Aoatearoa (Nového Zélandu), Samoy a Havaje. Jen málo informací získal z Afriky, ač „byl učiněn pokus získat informace o negroidních národech Afriky, jenž se však ukázal být zcela neúspěšným“. 32

Výsledkem Morganova rozsáhlého výzkumu a badatelské práce se stala publikace Systémy pokrevenství a sešvagření lidské rodiny (1871), která byla po recenzním řízení přijata k vydání roku 1868, zhruba rok po dokončení rukopisu. Vydání se zdrželo kvůli vysokým nákladům spojeným s produkcí knihy, což si vyžádalo k Morganově nelibosti zkrácení textu na přijatelný rozsah. Morgan výtisk knihy obdržel v červenci 1871 a od svého asistenta se dozvěděl, že se jedná o nejnákladnější knihu, jakou dosud Smithsonova instituce vydala. Náklady se vyšplhaly na ohromných 8000 USD, přičemž velmi nákladné byly rozsáhlé tabulky, kolem nichž autor vystavěl text knihy. Vysázet jednu stránku tabulky stálo celých 16 USD. Morgan však vlastní investice na provedení výzkumu, přípravu publikace a ušlý zisk

\footnotetext{
${ }^{27}$ MORGAN, Lewis Henry, 1871. Systems Consanguinity and Affinity of the Human Family. Washington: The Smithsonian Institution, s. 3.

${ }^{28}$ Tamtéž, s. 3.

${ }^{29}$ Tamtéž, s. 4.

${ }^{30}$ Ve skutečnosti se zabývá různými jazyky, které se dnes řadí do různých jazykových rodin: románská, slovanská, indoárijská, keltská a další.

${ }^{31}$ Zde se zabývá skupinami mluvícími jazyky turkickými a ugrofinskými.

${ }^{32}$ MORGAN, Lewis Henry, 1871. Systems Consanguinity and Affinity of the Human Family. Washington: The Smithsonian Institution, s. 462.
} 
z právní praxe odhadl na celých 25000 USD. ${ }^{33}$ To by dnes odpovídalo závratné částce takřka dvanácti milionů korun.

Východiskem pro jeho bádání se stala filologie, jak upozorňuje hned v první větě předmluvy k dílu. Píše, že se „filologie osvědčila být skvělým nástrojem pro klasifikaci národů do rodin na základě jazykových podobností. Srovnání slovní zásoby a gramatických forem ukázalo, že určité jazyky jsou dialekty obecnější řeči.“ Tamtéž dovozuje, že „tyto dialekty zahrnuté pod společný název, obnovily svou původní jednotu jako rodina jazyků‘. Podle Morgana lze tímto způsobem redukovat počet národů světa na celkem malý počet nezávislých. ${ }^{34}$ A právě o to se pokusil svým výzkumem rozdílů a podobností terminologie př́buzenství. Výsledkem analýzy dat získaných rozsáhlým výzkumem, při němž kombinoval dotazníkové šetření a terénní pobyty u skupin původních obyvatel Severní Ameriky, bylo rozlišení tří typů př́buzenských systémů a dále zjištění, že příbuzenské systémy jsou bud' klasifikační, nebo deskriptivní. Příbuzenské systémy arijsko-semitsko-uralský (dnes eskymácký), ganowajský (dnes irokézský) a turánsko-malajský (dnes havajský) lze podle jeho tvrzení seřadit podle evoluční posloupnosti, tedy od civilizovaných k primitivním. Stejně tak tvrdil, že klasifikační systémy (ganowajský a turánsko-malajský) evolučně předcházejí deskriptivním (arijsko-semitsko-uralský). Byl si ovšem vědom, že získaná data zdaleka nepokrývají všechny národy, zvláště upozornil, že „velký počet nižšśch národů zůstává v tabulkách nezastoupený“ 35

Podhodnocení informací o „nižších národech“, jak se na některé lidské populace etnocentricky pohlíželo v 19. století i v podstatné části toho následujícího, má své koloniální důvody. Tehdy totiž západní koloniální nadvláda v mnoha částech světa rozhodně nebyla stabilizovaná. Stačí si třeba uvědomit, že ruský etnograf Miklucho-Maklaj začal žít mezi obyvateli Nové Guineje ve stejném roce, kdy vyšla Morganova i Tylorova práce. Na Nové Guineji i v jiných částech světa nebyla v té době zdaleka vybudována pevná koloniální administrativa, o kterou by se mohli výzkumníci opřít při snaze získat nějaké etnografické informace o kolonizovaném obyvatelstvu. Jen pro představu, Miklucho-Maklaj se vylodil na pobřeží Nové Guineje mnoho let před založením města Port Moresby, které se stalo pevnou oporou koloniálního systému.

\footnotetext{
${ }^{33}$ TRAUTMAN, Thomas, 1987. Lewis Henry Morgan and the Invention of Kinship. Berkeley: University of California Press, s. 1-2.

${ }^{34}$ MORGAN, Lewis Henry, 1871. Systems Consanguinity and Affinity of the Human Family. Washington: The Smithsonian Institution, s. v.

${ }^{35}$ Tamtéž, s. vii.
} 
Morgan své závěry využil v nadcházející práci Pravěká společnost (1877), ${ }^{36}$ ve které představil teorii evoluce lidské kultury od období divošství přes barbarství k civilizaci. I v této práci staví na evolučním hledisku chápaném jako pokrok lidské společnosti a kultury, jenž se objektivně projevuje ve vynálezech, že kontrola ohně předchází domestikaci plodin a zvîráat i výrobě keramiky. ${ }^{37}$ Vyjádřením evoluce se podle Morgana staly také dvě společenská uspořádání - societas a civitas. Zatímco v první se zdůrazňují skupinové vztahy a práva, v druhé formě se klade důraz na ta individuální, čemuž měly odpovídat také př́ibuzenské systémy. V jejich „primitivní“ formě nerozeznávaly individuální otcovství, proto v havajském př́ibuzenském systému označovaly stejným pojmem muže v generaci +1 , když chtěli pojmenovat „otce“. Morgan se domníval, že pokrok spočíval ve zlepšující se schopnosti popsat pokrevenské vztahy a individualizace vztahů, s nimiž měly souviset také primogenitura i dědické principy.

\section{Antropologie a počátky metody terénního výzkumu}

O představitelích klasického evolucionismu se traduje, že pěstovali kabinetní vědu, jelikož upřednostňovali teoretické bádání před tvorbou dat terénním výzkumem. Podsouvá se jim, že jejich závěry byly ničím nepodložené spekulace založené na četbě zpráv, knih či dopisů cestovatelů, námořníků, místodržících, misionářů a jiných zástupců západních koloniálních mocností. O mnohých průkopnících oboru to nepochybně lze říci. Zářným příkladem je James George Frazer (1854-1941), který až na vzácné výjimky neopustil Trinity College v Cambridge a tamější bohatou knihovnu. Vskutku, nikdy se ani náznakem nepokusil uskutečnit terénní výzkum. Z hlediska jeho názorů by to ani nedávalo smysl, chtěl objasnit vývoj lidského myšlení, jak by mu pomohlo k porozumění zákonitostem evoluce lidské kognice strávit několik let např́íklad na Trobriandových ostrovech. Pro něj jednotlivé kultury představovaly vzorky, které mu pomáhaly porozumět lidstvu a jeho vývoji. A jeho bytostný odpor k provádění vlastního terénního výzkumu je známý, ${ }^{38}$ ale podstatu terénního výzkumu velmi oceňoval, jak dokládá i jeho předmluva k Malinowského Argonautům západního Pacifiku (1922), kde vyzdvihl autorův styl práce, kterou založil na „nejjistějších zdrojích osobním pozorování a výpovědích domorodců v jejich vlastním jazyce bez zásahu

\footnotetext{
${ }^{36}$ Česky MORGAN, Lewis Henry, 1954. Pravěká společnost. Praha: Československá akademie věd.

${ }^{37}$ Této myšlence nelze v podstatě nic vyknout. Jak upozornil Matt Ridley žárovku lze jen těžko vynalézt dř́ive než objevit principy elektřiny. Viz RIDLEY, Matt, 2013. Racionální optimista. Praha - Brno: Argo - Dokořán.

${ }^{38}$ HAYS, H., 1979. From Ape to Angel. Westport: Greenwood Press, s. 121.
} 
tlumočníka““ ${ }^{39}$ Zdaleka ne všichni představitelé klasického evolucionismu zvolili čistou práci v pracovně, jako Frazer, ale vydávali se získat nezprostředkovaná data v terénu. Jejich snahy získat data $\mathrm{v}$ terénu jistě nevyjdou dobře při srovnání se standardy antropologického výzkumu, jak se profilovaly na počátku 20. století. Přesto nelze diskutovanému Tylorovi upřít, že prováděl terénní výzkum mezi londýnskými spiritisty, jak z Tylorova terénního deníku zjistil historik antropologie George Stocking. Upřesňuje, že Tylorova koncepce animismu se přímo zrodila v kontextu britského spiritismu, který mu také pomohl formulovat koncepci přežitku. ${ }^{40}$ Ani Morgan se neomezil na čistě teoretické studium. Pracoval nejen mezi Irokézy, ale vydával se také k jiným skupinám původních obyvatel Severní Ameriky, u nichž se zajímal o příbuzenské systémy. Při studiu Irokézů navázal spolupráci s Elym Parkerem, jenž se stal jeho klíčovým spolupracovníkem mezi Irokézy. Přesto nelze Tylora a Morgana označit za terénní antropology v moderním smyslu slova, ač oba získali jisté terénní zkušenosti. Jak Tylor, tak Morgan byli spíše kabinetními typy akademiků.

Z hlediska formující se antropologie došlo roku 1871 ještě k jednomu památnému kroku, který lze označit za moment zrodu empiricky ukotvené antropologie. V novoguinejském zálivu Astroláb se toho roku vylodil ruský etnograf Nikolaj MikluchoMaklaj (1846-1888). V záŕí 1871 si do deníku poznamenal: „kolem 10. hod. dopolední se konečně ukázalo mraky zpola zahalené hornaté pobřeží Nové Guineje“. ${ }^{41}$ Tento badatel $\mathrm{s}$ přírodovědnou orientací a vzděláním, jenž se hlásil $\mathrm{k}$ darwinismu a úzce spolupracoval $\mathrm{s}$ Ernstem Haeckelem (1834-1919), jedním z prvních německých stoupenců darwinismu, se rozhodl žít mezi obyvateli Nové Guineje. Miklucho-Maklaj měl př́rodovědné vzdělání a Novou Guineu si vybral, protože ,ji obývá málo známá rasa Papuánců, jejichž postavení mezi jinými národy není dosud jasné““. ${ }^{22}$ Miklucho-Maklaj rozhodně nebyl školeným etnografem, to $\mathrm{v}$ jeho době nemohl být nikdo, ale svými př́stupy a postupy se zařadil k průkopníkům empiricky informované antropologie. Stalo se tak více než čtyřicet let před tím, než se Malinowski vlivem geopolitické situace stal technicky vzato nepřítelem v Austrálii, což mu umožnilo podniknout jeho slavné výzkumy v Melanésii, ${ }^{43}$ i takřka třicet let před proslulou expedicí cambridgeských antropologů do Torresovy úžiny uspořádanou v roce 1898.

\footnotetext{
${ }^{39}$ FRAZER, James George, 1922. Preface, s. vi-vii. In MALINOWSKI, Bronislaw. Argonauts of the Western Pacific. London: Routledge, s. vii-xiii.

${ }^{40}$ STOCKING, George, 2001. Delimiting Anthropology. Wisconsin: The University of Wisconsin Press.

${ }^{41}$ MIKLUCHO-MAKLAJ, Nikolaj, 1954. Mezi Papuánci. Praha: Orbis, s. 19.

${ }^{42}$ Tamtéž, s. 15.

${ }^{43}$ Srov. YOUNG, Michael, 2004. Bronislaw Malinowski. New Haven: Yale University Press.
} 
Miklucho-Maklaj bezesporu patří k průkopníkům moderní etnograficky informované antropologie. Terénní situace pro něj jistě nebyla snadná. Musel hbitě a bez kompromisů řešit mnoho každodenních záležitostí, které mnohdy představovaly rizika pro jeho život a zdraví. Například 17. listopadu 1871 si zapsal: „Nic nového. Vše jak bylo. Ráno jsem zoologem, prŕírodozpytcem, potom, jsou-li sluhové nemocní, jsem kuchařem, lékařem, lékárníkem, natěračem, krejčím - dokonce i pradlenou. Krátce děvče pro všechno a plné ruce práce. Ačkoli se učím řeči domorodců s velkou trpělivostí, přece jen rozumím ještě velmi málo. Spíše se pouze dovtipuji a hádám, co mi chtějí asi říci. Tím méně dovedu mluvit““. 44

Etnografická genialita Miklucho-Maklaje se projevila hned na začátku jeho prvního novoguinejského pobytu (vrátil se tam opakovaně, naposledy v roce 1883). V zápisku z prvního října se lze dočíst: „Mé postavení bylo trapné: dohovořit jsem se nedovedl - bylo by lépe odejít, avšak přemáhal mě spánek. Domov je daleko. Proč bych se nevyspal zde?“"Ulehl na nové rohoži, kterou tam našel, a vprostřed vesnice usnul, aby se později probudil „,velmi osvěžen“. ${ }^{45}$ Když se začteme do deníků Miklucho-Maklaje, vidíme poctivou etnografickou práci založenou na zúčastněném pozorování, ač v jeho době nebyla tato technika ještě pojmenována, ani běžně uplatňována. Současně však na jeho práci lze vypozorovat také mocenský rozměr antropologie, který se v plné síle ukázal v koloniální nadvládě, ze které antropologie hodně těžila. Miklucho-Maklaj systematicky na Nové Guineji vytvářel ruskou stopu pojmenováním geografických míst - dosud na mapě Nové Guineje najdeme např́íklad Gogolovu řeku - a nepřímo se podílel na vzniku Německé Nové Guineje. Zprostředkoval totiž klíčové informace o obyvatelích a krajině zálivu Astroláb německému ornitologovi Ottu Finschovi (1839-1917). Jeho Bismarck pověřil prozkoumáním Nové Guineje a zhodnocením míst, kde by mohlo vzniknout bezpečné zázemí chystané německé kolonie. Finsch se s Miklucho-Maklajem osobně několikrát setkal a načerpal od něj cenné informace. Ty mu pomohly při osobním setkání s obyvateli „Maklajovy zátoky“, a to včetně znalosti základní slovní zásoby ruského jazyka, kterou si osvojil během expedice na Sibiř a se kterou se setkal

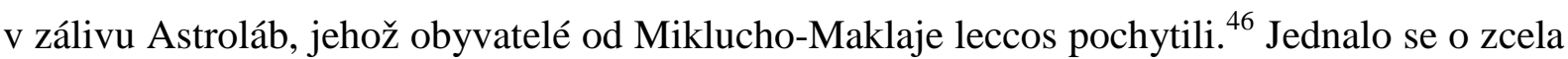
protichůdné aktivity, jelikož Miklucho-Maklaj zamýšlel vytvořit tam samosprávnou oblast a vyvinul značné úsilí, aby se záliv Astroláb nestal součástí Německé Nové Guineje. Jeho telegram Bismarckovi, v němž jej vyzval, aby obyvatelé zátoky měli samosprávu, byl oslyšen.

\footnotetext{
${ }^{44}$ MIKLUCHO-MAKLAJ, Nikolaj, 1954. Mezi Papuánci. Praha: Orbis, s. 49.

45 Tamtéž, s. 31-32.

${ }^{46}$ FINSCH, Otto, 1888. Samoafahrten. Leipzig: F. Hirt, s. 61-62.
} 
Význam Miklucho-Maklaje pro formování moderní antropologie zůstává nemalý, ač o něm standardní př́ručky dějiny antropologického myšlení povětšinou mlčí. ${ }^{47}$ MikluchoMaklaje vedl především vědecký zájem poznat a co možná nejvíce zaznamenat informace o „primitivních národech“, jelikož již nebylo „možno mrhat časem““. ${ }^{4} \mathrm{O}$ celé půlstoletí př̀edběhl Malinowského, když napsal, že by mu přišlo hodné politování „opominutí př́ležitosti poznat blíže původní lidské rasy ... zvláště proto, že tyto rasy - jak známo - při styku s evropskou civilizací rok od roku zanikají. ${ }^{49}$ Malinowski v obdobném duchu otevřel své Argonauty slovy, že „etnologie je ve smutně-směšném neřkuli tragickém postavení“, protože jakmile má vypracované metody a vychované experty, předmět jejího zájmu „vymírá přímo před očima“. 50

\section{Závěr}

Neexistuje žádná historicky prokazatelná vazba mezi vydáním Tylorovy práce, Morganova díla a zahájením výzkumu Miklucho-Maklaje na Nové Guineji. Tylor napsal předmluvu k Primitivní kultuře v březnu 1871, Morganovu práci Smithsonian institut přijal k publikaci již roku 1868, vyšla však po složitých procesech až roku 1871. Miklucho-Maklaj se nalodil na korvetu Vit’az již na sklonku roku 1870 a Nové Guineje dosáhl o bezmála rok později, kdy se v záŕí před posádkou objevily obrysy novoguinejského pobřeží, kde následně ruský vědec prožil několik let mezi domorodci v zálivu Astroláb. „Antropologický rok“ 1871 je tak více narací než objektivním faktem.

Rok 1871 nepochybně přinesl do rodící se antropologie důležitá témata - koncept kultury, zájem o společnosti stavících na prríbuzenství a terénní výzkum. Jinak řečeno, antropologie se začala formovat jako věda o kultuře, začal se prosazovat zájem o pochopení př́ibuzenských vztahů jako základ pro výklad povahy společnosti a kultury. Především dostala impulz stát se empiricky podloženou disciplínou, ač trvalo ještě několik desetiletí, než se prosadily principy terénního výzkumu, které se v disciplíně začaly považovat za samozřejmost - zúčastněné pozorování, zvládnutí místního jazyka a zaznamenat roční cyklus společnosti.

\footnotetext{
${ }^{47}$ Srov. HARRIS, Marvin, 1968. Rise of Anthropological Theory. New York: Thomas Y. Crowell. PETERMANN, Werner, 2004. Die Geschichte der Ethnologie. Wuppertal: Peter Hammer Verlag. SOUKUP, Václav, 2004. Déjiny antropologie. Praha: Karolinum.

${ }^{48}$ MIKLUCHO-MAKLAJ, Nikolaj, 1954. Mezi Papuánci. Praha: Orbis, s. 13

${ }^{49}$ Tamtéž, s. 13.

${ }^{50}$ MALINOWSKI, Bronislaw, 1922. Argonauts of the Western Pacific. London: Routledge, s. xv.
} 


\section{Seznam použitých zdrojů}

BARNARD, Alan. History and Theory in Anthropology. Cambridge: Cambridge University Press, 2000. ISBN 978-0-521-77432-1.

CRONK, Lee. That Complex Whole. Boulder: Westview Press, 1999. ISBN 0-813-33705-4. ERICKSON, Paul; MURPHY, Liam. A History of Anthropological Theory. Peterborough: Broadview Press. ISBN 1-55111-198-5.

FINSCH, Otto. Samoafahrten. Leipzig: F. Hirt, 1888.

FOX, Robin. Kinship and Marriage. Harmondsworth: Penguin Books, 1970.

FRAZER, James George. Preface, In MALINOWSKI, Bronislaw. Argonauts of the Western Pacific. London: Routledge, 1922.

FRAZER, James George. The Golden Bough. London: Macmillan, 1890.

HADDON, Alfred Cort. Evolution in Art. London: Walter Scott, 1895. DOI: 10.5479/sil.120683.39088002611119

HADDON, Alfred Cort. History of Anthropology. London: Watts \& Co., 1910.

HARRIS, Marvin. Rise of Anthropological Theory. New York: Thomas Y. Crowell, 1968.

HAYS, Hoffman Reynolds. From Ape to Angel. Westport: Greenwood Press, 1979. ISBN 0313-21235-X.

KROEBER, Alfred; KLUCKHOHN, Clyde. Culture: A Critical Review of Concepts and Definitions. Peabody Museum of American Archaelogy and Ethnology Papers. 1952, 47(1), s. 3-223, v-vii.

KUPER, Adam. Culture. Harvard: Harvard University Press, 2000. ISBN 0-674-00417-5.

LOWIE, Robert. Culture and Ethnology. New York: Boni and Liveright, 1917.

LOWIE, Robert. The History of Ethnological Theory. New York: Rinehart \& Company, 1937.

MAINE, Henry. Ancient Law. London: John Murray, 1861. DOI: 10.2307/25528207

MALINOWSKI, Bronislaw. Argonauts of the Western Pacific. London: Routledge, 1922.

MARRETT, Robert. The Threshold of Religion. London: Methuen, 1911.

MCLENNAN, John Ferguson. Primitive marriage: an inquiry into the origin of the form of capture in marriage ceremonies. Edinburgh: Adam \& Charles Black, 1865.

MIKLUCHO-MAKLAJ, Nikolaj. Mezi Papuánci. Praha: Orbis, 1954.

MOORE, Jerry. Visions of Culture. Walnut Creek: Altamira, 2004. ISBN 0-7591-0410-7.

MORGAN, Lewis Henry. League of the Ho-Dé-No-Sau or Iroquosis. Rochester: Sage \& Brother, 1851.

MORGAN, Lewis Henry. Pravěká společnost. Praha: Československá akademie věd, 1954.

MORGAN, Lewis Henry. Systems Consanguinity and Affinity of the Human Family. Washington: The Smithsonian Institution, 1871. DOI: 10.5962/bhl.title.29577

PETERMANN, Werner. Die Geschichte der Ethnologie. Wuppertal: Peter Hammer, 2004. ISBN 3-87294-930-6.

RIDLEY, Matt. Racionální optimista. Praha - Brno: Argo - Dokořán, 2013. ISBN 978-80257-0931-3.

SOUKUP, Václav. Dějiny antropologie. Praha: Karolinum, 2004. ISBN 80-246-0337-3.

STOCKING, George. Delimiting Anthropology. Wisconsin: The University of Wisconsin Press, 2001. ISBN 0-299-17450-6.

STOCKING, George. Race, Culture, and Evolution. Chicago: Chicago University Press, 1982. ISBN 0-226-77494-5.

STOCKING, George. Victorian Anthropology. New York: The Free Press, 1987. ISBN 0-02931551-4. 
TRAUTMAN, Thomas. Lewis Henry Morgan and the Invention of Kinship. Berkeley: University of California Press, 1987. ISBN 0-520-05849-6.

TYLOR, Edward Burnett. Primitive Culture. 2 sv. London: John Murray, 1871.

WESTERMARCK, Edvard. The History of Human Marriage. London: Macmillan, 1891.

YOUNG, Michael. Bronislaw Malinowski. New Haven: Yale University Press, 2004. ISBN 0300-10294-1. 


\title{
Women's Veiling: Everyday and Ceremonial Practices of Central- Asian Peoples
}

\author{
Tereza Hejzlarová, Olga Viktorovna Starostina \\ Tereza Hejzlarová, Department of Asian Studies, Faculty of Arts, Palacký University Olomouc, Tř́ída Svobody \\ 26, 77900 Olomouc, Czech Republic \\ Email: tereza.hejzlarova@upol.cz \\ Olga Viktorovna Starostina, Department of Ethnography of the Peoples of the Caucasus, Central Asia and \\ Kazakhstan, Russian Museum of Ethnography, Inzhenernaya 4/1, 191011 St. Petersburg, Russia \\ Email: starostinaov73@mail.ru
}

DOI: https://dx.doi.org/10.7160/KS.2021.170202

\begin{abstract}
The study presents an analysis of traditional forms of clothing serving for women's veiling in Central Asia in the period from the second half of the 19th century to the 20th century, focusing on its occurrence and importance in both everyday and ceremonial practices. The study addresses particular types of veiling, their common features, and differences related to the manner of wearing, as well as the materials and the decorative designs used. An important part of the study is a catalogue representing individual types of clothing from the above determined period from the museum collections of the Russian Museum of Ethnography in St. Petersburg and the National Museum - the Náprstek Museum in Prague.
\end{abstract}

\section{Keywords}

women's veiling, Central Asia, clothing, coat, headdress, veil, headscarf, wedding ceremony

\section{Introduction}

Ethnography-related literature addressing women's clothing of Central Asia, wedding ceremonies, and everyday traditions frequently concern various aspects of women's veiling and certain items of clothing covering individual parts of their bodies. There has been no expert study, however, analysing traditional forms of this type of clothing in relation to both ceremonial and the everyday practices.

In present-day European, Russian, and Central-Asian scientific publications, there are practically no studies addressing the specifics of the existence of various material artifacts in the traditional culture of Central-Asian peoples in relation to women's veiling. The majority of works available in the scientific discourse are written from the perspective of philosophy, 
culturology, or religion. They disregard both the abundance of objects and photographs in museum collections, and archive materials including expedition reports and historical inventory.

The present treatise, which is far from being a comprehensive one, is based on the analysis of collections of two prominent ethnographic museums in Europe: the Russian Museum of Ethnography (about 100,000 objects and photographs from Central Asia), and the National Museum - the Náprstek Museum (about 400 objects and photographs), as well as numerous sources related to the topic that are available on the internet. While investigating the topic, an important aspect is also scientific research of the late 19th century and the 20th century focusing on Central-Asian clothing, specifics of social relationships, women's culture, traditional beliefs, etiquette and ethical standards adopted in the traditional society, as well as Islamic traditions embedded in daily life and ritual practices.

The authors of this study aimed to define the individual types of clothing used for veiling and the manner in which this clothing was worn, as well as to identify common typical features and differences among the individual peoples of Central Asia.

In her study Traditional and Modern Women's Clothing of the Tajikistan Mountains (Traditsionnaya i sovremennaya odezhda zhenshchin gornogo Tadzhikistana), Z. A. Shirokova ${ }^{1}$ presented a classification of clothing worn over the head which may be, with some reservations and additions, applied to a similar type of clothing that was used in Central Asia among the Uzbeks, the Kyrgyz, the Kazakhs, the Karakalpaks, the Turkmens and the Tajiks. This classification allows for making a distinction between the individual types of clothing based on their form, but also for determining the specifics of the particular type of clothing with regard to the manner in which it was worn, its occurrence and the importance derived from a particular tradition. This study does not analyse the emergence and development of this type of clothing; this issue having been investigated in detail by O. A. Sukhareva. ${ }^{2}$

\section{Classification of Women's Veiling Clothing}

The particular type of clothing may be divided into four groups. The first group involves large headscarves that cover either the woman's entire body or only her face or part of it, such as

\footnotetext{
${ }^{1}$ SHIROKOVA, Zinaida Aleksandrovna, Traditsionnaya i sovremennaya odezhda zhenshchin gornogo Tadzhikistana, Dushanbe, Donish 1976, p. 84.

${ }^{2}$ SUKHAREVA, Ol'ga Aleksandrovna: Opyt analiza pokroev traditsionnoy «tunikoobraznoy» sredneaziatskoy odezhdy v plane ikh istorii i evolyutsii. Sukhareva, O. A. (otv. red.) Kostyum narodov Sredney Azii: istorikoetnografitcheskie otcherki. Moskva, Nauka 1979, p. 77-102.
} 
those worn at wedding ceremonies by the Mountain Tajiks, the Turkmen, and some groups of nomadic Uzbeks and Kazakhs. The second group consists of veils covering the face that were part of wedding dresses of some groups of the Mountain Tajiks, the Turkmen Yomuts, the southern Kyrgyzs and the Uyghurs. The third group involves coats worn on the head used especially by women in the settled rural environment of Central Asia; they also served as everyday clothing for men and children. Much less common are cases of women's coats of a specific fit, such as munisak (kaltacha). The fourth group involves a special type of coat worn on the head with numerous specific features unique for this type of clothing. These coats were used exclusively by women and their distinctive feature are narrow false sleeves that are tied together. Such coats were regarded as a common part of a woman's appearance in Mountain Tajikistan and Turkmenistan. This group also incorporates a long coat called paranja typical especially for women living in urban areas of Central Asia (the Uzbeks, the Tajiks and the Jews). It needs to be noted that this treatise does not focus on all parts of clothing.

\section{Group One - Headscarves}

A large headscarf is one of the most universal items of clothing used for veiling in order to hide a woman from sight. Used without any exception by all Central-Asian peoples, it is a square or rectangular piece of cloth. The manner of its wearing and utilization as part of everyday or ceremonial clothes depends on the traditions of a particular ethnographic, territorial and local group.

In the traditional culture of the Kazakhs and the Kyrgyzs, it was not usual to cover a woman's face and body (with the exception of southern Kyrgyzstan). It wass common that a young woman avoided her husband's relatives, in contrast to settled peoples; in their traditional culture, young women covered themselves with headscarfs and various coats. Wedding rituals of Central-Asian nations, however, required the veiling of the bride in the period after entering into marriage, when leaving for the husband's home, and in the first days in her new home. The bride was veiled until the ceremony of "face uncovering". Up until then, the Kyrgyz and Kazakh newly married women were veiled with a large white cotton headscarf that was placed over the headdress and covered their body down to their knees. ${ }^{3}$

The special status of brides and newly married women within the Tajik culture as well as among settled Uzbeks was also manifested in other details. As with the Kazakhs and the

\footnotetext{
${ }^{3}$ KISLYAKOV, Nikolay Andreevitch: Otcherki po istorii sem'i i braka u narodov Sredney Azii i Kazakhstana. Leningrad: Nauka, 1969, p. 113, 120.
} 
Kyrgyzs, they wore large white scarves over their heads. These were made from silk or muslin and covered their face, chest, shoulders and back. The young women took off these scarves after the wedding night in the husband's house. Within wedding ceremonies, the white colour was considered the colour of good luck; for this reason, the clothes of both the bride and the groom had to contain white fabric. ${ }^{4}$ Paranjas $^{5}$ were not worn to wedding ceremonies, with some rare exceptions, in all probability because they were considered casual clothes that did not have any deeper roots in the history of traditional clothing. ${ }^{6}$

A similar utilization of a large white headscarf was recorded in the period from the second half of the $19^{\text {th }}$ century to the $20^{\text {th }}$ century among the Mountain Tajiks in Kulyab and Karategin, where the clothes worn on the head, such as paranjas, did not appear at all. ${ }^{7}$

In many areas of Central Asia, a headscarf was used within wedding ceremonies as a veil to cover the face. It was accompanied by a specific headdress, a paranja, or another type of coat worn over the head. Tajik women from Kulyab and the Mascho and Hissar basins always wore, for example, a white silk headscarf under their coat called chodar $^{8}$ - the headscarf was diagonally folded and worn in such a way that the front part covered the woman's face and neck. Turkmen and Karakalpak women used scarves to cover only the lower part of their faces, and these were combined with coats called chyrpy (zhegde) ${ }^{9}$ worn on the head. ${ }^{10}$

Women from rural areas of Uzbekistan and Tajikistan wore headscarves not only at wedding ceremonies, but even in daily life in order to hide their faces from strangers (especially men).

Every inhabitant of the husband's village or guzar (the neighbourhood) was also considered a stranger by the newly married woman. The woman was gradually introduced to other people at family and local celebrations and eventually stopped veiling her face in their presence. Girls and women of childbearing potential covered their faces when meeting inhabitants from other villages, travellers and particularly people of a different religion. They

\footnotetext{
${ }^{4}$ SHIROKOVA, Zinaida Aleksandrovna: Traditsionnaya i sovremennaya odezhda zhenshchin gornogo Tadzhikistana, Dushanbe, Donish 1976, p. 128.

5 For more detailed information on paranja, see Group Four.

${ }^{6}$ SUKHAREVA, Ol'ga Aleksandrovna: Istoriya sredneaziatskogo kostyuma: Samarkand (2ya polovina XIXnatchalo XX v.). Moskva, Nauka 1982, p. 50.

${ }^{7}$ SHIROKOVA, Zinaida Aleksandrovna: Traditsionnaya i sovremennaya odezhda zhenshchin gornogo

Tadzhikistana, p. 133.

8 For more detailed information on the chodar coat, see Group Four.

9 For more detailed information on the chyrpy and zhegde coats, see Group Four.

${ }^{10}$ KISLYAKOV, Nikolay Andreevitch: Otcherki po istorii sem'i i braka u narodov Sredney Azii i Kazakhstana, p. $124,134$.
} 
turned their back or their side towards such people and covered their faces with the edge of the scarf. ${ }^{11}$

Young married women of the Turkmen Ersari, Nokhurli, Murchali, and Teke tribes wore a scarf called gynach, a triangular scarf sewn from several stripes of wine-red locally manufactured silk with two of its edges decorated with a wide knitted ribbon with a diamond and triangular pattern in white, yellow, and green interconnected with white and yellow stripes. The edges were frequently decorated with fringes made from black, wine-red or green silk. This type of headscarf was worn over borik or takya caps. On some headscarves, the right tip called yashmak was slightly frilled and rounded. In such cases, the right tip was pulled over the face from right to left - from the nape to the left ear, where it was tucked or pinned to a headdress with a special pin. In this way, the woman's mouth and neck were veiled. In some cases, women could hold the tip of the scarf in her teeth.

Women also carefully veiled their chest, neck, and often even chin - an item of clothing serving this purpose was called lachak. This part of the headdress was worn by some Tajik and Kyrgyz women, as well as by nomadic and Khorezm Uzbek women. Lachak was a small scarf, usually white, that was diagonally folded and tied at the top of the head in order to fit tightly to the face and cover the chest. ${ }^{12}$ Instead of lachak, married Kazakh and Karakalpak women wore a special headdress called kimeshek, similar to a hood.

\section{Group Two - Veils}

As stated above, the tradition of veiling the face of a bride and a newly married woman is universal for most inhabitants of Central Asia; the reason is the common belief in the sacral vulnerability of women in certain stages of their lives.

The veils completely covered the face, the neck and the upper part of the chest. This type of veil was part of the wedding dress of some groups of the Mountain Tajiks, the Uzbeks, the Kyrgyzs and the Uyghurs. There are also typical ways of the ceremonial utilization of these veils: a newly married woman took the veil for the first time in the house of her parents after the Muslim wedding ceremony nikah immediately preceding her departure for the husband's home. Her face was veiled throughout this time. People in the Samarkand

\footnotetext{
${ }^{11}$ SHIROKOVA, Zinaida Aleksandrovna: Traditsionnaya i sovremennaya odezhda zhenshchin gornogo Tadzhikistana, p. 81.

${ }^{12}$ LYUSHKEVITCH, Fanya Davidovna: Odezhda tadzhikskogo naseleniya Bukharskogo oazisa v pervoy polovine XX v. Sbornik Muzeya antropologii i etnografii. T. 34, Leningrad 1978, p. 138.
} 
region, apart from covering the bride's face, also used suzane ${ }^{13}$ embroideries that either veiled the bride, or were carried over her head. Suzane for the wedding purpose was created by the bride's family with the embroidery serving as an amulet to protect the bride from the evil powers and from the evil eye. ${ }^{14}$ The new wife even had her veil on during the wedding feast in the husband's house (with the exception of the wedding night) and until the ceremony of "face uncovering". This ceremony occurred amongst all the nations of Central Asia with only subtle differences. In the morning following the wedding night, when the woman's virginity had been proven, the relatives and the most respectable women from the village, aul, or town district gathered in the husband's house. The wife was brought to them with her face veiled. In the Kyrgyz and Kazakh cultures, the right of uncovering the face and seeing the young woman's face for the first time belonged to the most respectable woman, a mother of many children. In the Tajik and Uzbek cultures, it was usually a boy related to the bride's motherin-law. This magical process provided the woman with fertility; according to traditional beliefs of inhabitants of Central Asia, fertility was considered necessary for the happiness and prosperity of the family. The woman was subsequently visited by guests who were allowed to uncover the veil for a moment and look into her face. The woman was given presents representing a payment for "face uncovering". Following this ceremony, the veil was taken off, and among settled inhabitants it was not used any longer. It was preserved as family heritage for the next generation of brides, which is indicated by the evidence of frequent home repairs apparent on veils in the collection of the Russian Museum of Ethnography, as well as by accounts of local inhabitants gathered within scientific expeditions.

Kyrgyz and Uyghur women of childbearing potential also took on the veil during the migration to spring pastures, which was perceived to be an event of similar meaning as the wedding, and within the ceremonies of a nomadic year cycle it represented the notion of marriage to nature.

Decorated veils did not appear in all areas of Central Asia. In Tajikistan, the face-veil part of the bride's wedding clothing was called ruband, but that was limited to Darvaz and Garm. According to K. I. Antipina, ${ }^{15}$ the veil called bet kalka, which belonged to the clothing

\footnotetext{
${ }^{13}$ The term suzane (suzani) is also used in a wider sense as an umbrella term for embroidered fabrics used within the household of settled inhabitants. As dowry fabrics for the needs of a particular family, they were embroidered by Uzbek and Tajik women in towns and bigger villages. The term of the entire group of embroidery, suzane is derived from the Persian word súzán meaning a needle.

${ }^{14}$ SUKHAREVA, Ol'ga Aleksandrovna: K istorii razvitiya samarkandskoy dekorativnoy vyshivki. Literatura $i$ iskusstvo Uzbekistana. Kn. 6. Tashkent, 1937, p. 119-134.

${ }^{15}$ ANTIPINA, Klavdiya Ivanovna: Osobennosti material'noy kul'tury i prikladnogo iskusstva yuzhnykh kirgizov. Frunze, Izd-vo AN Kirg. SSR 1962, p. 256.
} 
of southern Kyrgyzs, was adopted from the Mountain Tajiks. The authors of this study believe, however, that notwithstanding the similarity in form, semantics of the embroidery, and the form of utilization, bet kalka could not have been adopted directly from Mountain Tajik people, because the area where rubands were used is separated from southern Kyrgyzstan with four mountain ridges and valleys where such veils were not used. This element of woman's clothing may also be found among Uyghur women in Kashgar and in the Fergana Valley.

The central motif of the embroidery on the veils is a tree and birds; these are depicted with a various degree of stylization. Rubands worn by the Mountain Tajiks are the most typical ones: their composition of the central field contains a tree with two birds (cocks or peacocks) on the sides. The Kyrgyz veils are decorated with a geometric pattern depicting a swastika - a symbol that some researchers attribute not only to the sun, but also to a bird. ${ }^{16}$ The tree is a complex polysemic motif. On the one hand, it may be interpreted as a model of the world where the treetop represents the sky and the Upper World, the stem represents the earth, and the roots represent the Underworld, the land of the dead. ${ }^{17}$ On the other hand, this motif symbolized an ancient deity - the Mother Goddess - the originator of all living things, who represented fertility and wielded the realm of the dead and the element of water. The motif of the bird, according to traditional beliefs of Central-Asian nations, correlated the solar symbolism and was a powerful amulet, in addition to bringing good luck and wealth to the house of the young couple.

Some common features are also shared by the peshkurpe veil that was part of the wedding dress of the Turkmen Yomuts. It was worn by a newly married woman when leaving for the husband's house and also served for the "face uncovering" ceremony. The embroidery on the veil represents a tree with long curved branches that the Turkmens related to the cult of the Goddess of Fertility - the patroness of women. ${ }^{18}$ In contrast, there are differences in the manner of wearing the veil and its colour and form. Unlike other veils, peshkurpe was made from red silk in the shape of a trapezoid, and was worn in such a way that it covered the young woman's mouth, neck and chest.

\footnotetext{
${ }^{16}$ BOBRINSKIY, Aleksey Aleksandrovitch: O nekotorykh simvolitcheskikh znakakh obshchikh pervobytnoy ornamentike vsekh narodov Evropy i Azii. Moskva, T-vo tip. A. I. Mamontova 1902, p. 9.

${ }^{17}$ KISLYAKOV, Nikolay Andreevitch: Materialy po drevnim verovaniyam gornykh tadzhikov. Strany i narody. Vyp. XXVI., Kn. 3. Moskva, Nauka 1989, p. 256.

${ }^{18}$ MOROZOVA, Anna Stepanovna: Golovnye ubory turkmen (po kollektsiyam GME). Tr. In-ta istorii, arkheologii i etnografii Turkmenskoy SSR. T. VII. Moskva, 1963, p. 112.
} 


\section{Group Three - Coats}

Numerous travellers and researchers have reported that settled inhabitants of Central Asia often used various types of coats as headdresses. Mr. and Mrs. Nalivkin, who lived in the area for several decades and studied the customs and lifestyle of local people, stated the following: "It is common in many places that women from the rural environment do not wear their own coats on their heads; instead, they take a coat of one of their children, and always place it with the inside of the armhole on the top of their head." 19

Young woman, who still did not have any children, could wear her husband's coat or her own.

Coats worn on the head included for instance yagtak worn by the Uzbek Karluk women in the west of the Kashkadarya region in Uzbekistan and in southern Tajikistan, or sargirak worn by Tajik women belonging to certain groups from the Kashkadarya region. There were also coats that were worn on heads by some groups while in others they served their original purpose. This type includes for instance jeylak, which was worn on the head by the Uzbek Kungrat women.

For Turkmen women, such a type of coat was called kurte; on some occasions they wore it in a common way while on others they put it on their heads. ${ }^{20}$ This coat was most widely used among the Turkmen Teke women who decorated it with complex embroidery on the chest, sleeves, and along the edges. The chest embroidery consisted of the motif of a stylized branch with flowers and leaves in a diamond shape. The sleeves were decorated with zoomorphic motifs, most often with ram horns - these were attributed a strong protective function. The edges of the coat were lined with the motif of a polygonal chain with three-leaf clover and flower buds. Kurte coats were most frequently made from red (kyzyl kurte) or green (yashyl kurte) silk fabric. Along with Teke women, it was also worn on the head by women of the Turkmen Goklen, Salor and Nokhurli tribes. Women wore them when leaving the house or even at home in the presence of strange men. ${ }^{21}$

Among Uzbek and Tajik women, an especially widely used type of coat was munisak (mursak, kaltacha), typically with its slightly frilled fabric under the sleeves, inserted gussets

\footnotetext{
${ }^{19}$ NALIVKIN, Vladimir Petrovitch - Nalivkina, Mariya Vladimirovna: Otcherk byta zhenshchiny tuzemnogo naseleniya Fergany. Kazan': Tipografiya Imperatorskogo universiteta 1886, p. 96.

${ }^{20}$ LOBATCHEVA, Nina Petrovna: K istorii sredneaziatskogo kostyuma (zhenskie golovnye nakidki-khalaty). Sovetskaya etnografiya, № 6, 1965, p. 36-38.

${ }^{21}$ VASIL'EVA, Galina Petrovna: Turkmeny - nokhurli. In TOLSTOV, S. P., ZHDANKO, T. A. (otv. red.) Sredneaziatskiy etnografitcheskiy sbornik, t. XXI. Moskva, Nauka 1954, p. 161., MOROZOVA, Anna Stepanovna: Traditsionnaya narodnaya odezhda turkmen. In LOBATCHEVA, N. P., SAZONOVA, M. V. (otv. red.) Traditsionnaya odezhda narodov Sredney Azii i Kazakhstana. Moskva, Nauka 1989, p. 66.
} 
on the sides to widen the coat, a lining, and the hems decorated with a knitted ribbon. It was typically made from expensive silk fabrics or from brightly coloured velvet. Munisak was the main component of women's outerwear from the 1870 s to $1890 \mathrm{~s}$, when it was also used for wedding ceremonies. The dowry could include two to ten, in wealthy families even eighteen, munisaks from expensive as well as less expensive fabrics. This coat also served as a gift for the bride from the husband's parents. In central Tajikistan, the Oasis of Bukhara, Penjikent, and the Samarkand region it was common that when a girl turned twelve, she was dressed in a festive coat munisak (kaltacha) for the first time. ${ }^{22}$ This feast took place in order to celebrate the first "muljar" - the end of the first twelve-year cycle. For the girl, this meant a transition to the next age category, so she could get married. In the Samarkand region, there was a distinctive feast called "kaltachapushon" 23 that was also related to the transition of a girl into the next age category; its name referred to the above-described coat. In the 1920s, munisak was only infrequently used for wedding ceremonies, and was gradually replaced with other types of coats. It later entirely lost its original function and its utilization was preserved only in funerary rituals where it was used to cover the bodies of the dead. ${ }^{24}$ Munisak for young women was made from the most expensive and brightly coloured fabrics, mostly from brocade, silk or velvet. In the $19^{\text {th }}$ century in Tashkent and Samarkand, young women wore it on their heads for several years following their wedding not only when leaving the house but even at home, because a woman's face could not be seen by the father-in-law and brothers-inlaw until her first child was born. ${ }^{25}$

\section{Group Four - Coats with False Sleeves}

Very narrow sleeves that were usually decoratively tied together and placed on the back were the distinctive feature of this group of coats. Sleeves of such coats had lost their original function and served only as a decorative element. This type of coat was labelled with various names and was used by women belonging to certain groups of the Uzbeks, the Tajiks, the Turkmens and the Karakalpaks.

\footnotetext{
${ }^{22}$ LYUSHKEVITCH, Fanya Davidovna: Odezhda tadzhikskogo naseleniya Bukharskogo oazisa v pervoy polovine XX v. Sbornik Muzeya antropologii i etnografii. T. 34, Leningrad 1978, p. 136.

${ }^{23}$ SUKHAREVA, Ol'ga Aleksandrovna: Istoriya sredneaziatskogo kostyuma: Samarkand (2ya polovina XIXnatchalo XX v.). Moskva, Nauka 1982, p. 39.

${ }^{24}$ BIKZHANOVA, Murshida Abdullovna: Odezhda uzbetchek Tashkenta XIX - natchala XX v. Sukhareva, O. A. (otv. red.) Kostyum narodov Sredney Azii: istoriko-etnografitcheskie otcherki. Moskva, Nauka 1979, p. 138140 .

${ }^{25}$ SUKHAREVA, Ol'ga Aleksandrovna: Istoriya sredneaziatskogo kostyuma: Samarkand (2ya polovina XIX natchalo $X X$ v.), p. 38.
} 
Chyrpy (purenjek, elek) was sewn by Turkmen women from home-made silk fabrics. Young women wore chyrpy from dark-green silk, older women from yellow silk and old women from white silk. The surface of the entire coat was decorated with embroidery. A richly decorated chyrpy was worn by brides and young women as festive clothing. Coats for daily utilization were less decorated. The decorations depicted various floral motifs; an exceptional type with regard to the motif as well as composition was the Teke chyrpy embroidery. The ornament depicted a sprout surrounded with a number of palmettes. ${ }^{26}$ Its structure and importance were similar to that of the ornament decorating the veils of the Turkmen Teke, described in greater detail above.

The Turkmen Nokhurli called this type of coat elek. Its fit was similar to the Teke chyrpy, but it was made from red silk fabric with white and black stripes. Instead of embroidery, the front part of elek was decorated with silver plates of various shapes, usually sewn to the black fabric. The sleeves were very long, their edges were decorated with fringes, and they were tied together with a chain made from coins. Apart from elek, the Nokhurli also wore purenjek, which differed with its very simple or no embroidery and a ribbon on the hems of the coat. ${ }^{27}$

Purenjek was part of the ritual headdress of the Turkmen Yomut women. It was made from green silk without lining, and also had very long narrow sleeves tied together in the back with a chain. A wide long collar was always decorated with embroidery with the motif of a branch with stylized leaves and flowers. The purenjek or the Turkmen Saryk women was of the same style, but was primarily made from red and green velvet. It was not decorated with embroidery, but instead with silver decorations with carnelians sewn onto the collar. Similarly to the Yomut women, the Saryk women also wore purenjek on festive occasions following their wedding until the birth of their first child. ${ }^{28}$

The Uzbeks from the northern Khorezm and the Karakalpaks called this type of coat zhegde. Among the Karakalpaks, zhegde was worn by women from the age of fifteen until the end of their life. There are two main types of zhegde - one for young women, the other for old ones. The coat for young women was made from colourful fabric, most frequently wine-red fabric (kyzyl zhegde); its collar was always made from red and black fabric decorated with

\footnotetext{
${ }^{26}$ MOROZOVA, Anna Stepanovna: Traditsionnaya narodnaya odezhda turkmen. In LOBATCHEVA, N. P., SAZONOVA, M. V. (otv. red.) Traditsionnaya odezhda narodov Sredney Azii i Kazakhstana, p. 83.

${ }^{27}$ VASIL'EVA, Galina Petrovna: Turkmeny - nokhurli. In TOLSTOV, S. P., ZHDANKO, T. A. (otv. red.) Sredneaziatskiy etnografitcheskiy sbornik, p. 163.

${ }^{28}$ MOROZOVA, Anna Stepanovna: Traditsionnaya narodnaya odezhda turkmen. In LOBATCHEVA, N. P., SAZONOVA, M. V. (otv. red.) Traditsionnaya odezhda narodov Sredney Azii i Kazakhstana, p. 66.
} 
embroidery with tambour and buttonhole stitch. For old women, the coat was made from white fabric (ak zhegde) and the embroidery was made with cross stitch. Apart from the above described two main types, there were also other types of zhegde distinguished according to the colour of the fabric and the quality of manufacturing. Zhegde was sewn and embroidered by the bride with the help from the wives of her older brothers for both herself and her husband's mother. In the late 1920s, this coat was worn as ceremonial and festive clothing. It was gradually replaced in daily use with a large headscarf tied around the turban; by the middle of the $20^{\text {th }}$ century, zhegde was entirely replaced with it. These coats were preserved, however, in almost every house as a family heirloom and were also part of the dowry. ${ }^{29}$

Casual clothing of the Uzbek and Tajik women from urban areas paranja was worn together with a dense rectangular net called chachvan made from black horsehair, which covered the woman's face. Wearing paranja and chachvan complied with the norms of Islam, which required the woman's body and face to be veiled. Paranja was originally made from blue or grey cotton fabric, but at the end of the $19^{\text {th }}$ century, rich families also had their coats made from local as well as imported silk and satin with Chinese patterns, imported from Kashgar. In some cases, paranja could also be decorated with embroidery. ${ }^{30}$ A girl was given her first paranja at the age of nine. When married, she was given one or two, in wealthier families up to four paranjas from expensive fabric. Dressing, undressing, and wearing the coat was subject to strict rules. When leaving her house, a woman covered her face with chachvan when walking through the gate. This custom was rooted in the people's negative relationship to the black colour which was believed to bring bad luck. This phenomenon has also been recorded as part of the wedding ceremony, where the bride wearing her paranja had her face covered with white fabric instead of the black chachvan when taken to her husband's house, since the white colour was believed to bring good luck. When a woman visited someone else's house, she took off her chachvan, while her paranja was taken off by her female host. When leaving the host's house, she was dressed in her coat by the host family. ${ }^{31}$

\footnotetext{
${ }^{29}$ LOBATCHEVA, Nina Petrovna: Karakalpakskie golovnye nakidki. In LOBATCHEVA, N. P., SAZONOVA, M. V. (otv. red.) Traditsionnaya odezhda narodov Sredney Azii i Kazakhstana. Moskva, Nauka 1989, p. 171$172,181$.

${ }^{30}$ BIKZHANOVA, Murshida Abdullovna: Odezhda uzbetchek Tashkenta XIX - natchala XX v. In SUKHAREVA, O. A. (otv. red.) Kostyum narodov Sredney Azii: istoriko-etnografitcheskie otcherki, p. 142.

${ }^{31}$ SUKHAREVA, Ol'ga Aleksandrovna: Istoriya sredneaziatskogo kostyuma: Samarkand (2ya polovina XIX natchalo $X X$ v.), p. 44.
} 
In Tashkent at the beginning of the $20^{\text {th }}$ century, this item of clothing was also part of the funerary equipment of dead women. ${ }^{32}$

The manner of wearing paranja varied considerably. Female inhabitants of Tashkent wore it high on top of their heads, while Namangan women pulled it on their forehead. ${ }^{33}$ Some women from urban areas tied the edges tight with silk ribbons sewn onto the lower part of the collar, or fastened them with buckles. Paranja, usually of inconspicuous colours, blurring the women's age characteristics that are of high importance for traditional society, was not part of the ancient traditional women's clothing. Bright velvet and silk coats, reflecting the owner's age and social status, began to emerge to a greater extent as late as the early $20^{\text {th }}$ century. In addition, it is important to remark that paranja was not a common item of daily clothing for women from rural areas. For instance, in Tajikistan, it was worn in Hissar, Karatag, and the administrative centres Kulyab, Karategin, and Darvaz, because these areas were inhabited by wives of Bukharan officers. ${ }^{34}$ In contrast, it could sometimes be part of the wedding dress: for instance, in the area of the upper Zeravshan River, paranja was worn as part of wedding ceremonies.

It also has to be added that paranja did not occur only among Muslim inhabitants of Central Asia, but also among the Bukharan Jews, even though neither their religion, nor the traditions of ancient Jewish clothing required Jewish women to cover their face and body in the presence of strangers. Paranja was part of outdoor clothes within the Muslim community and enabled the maximum possible blurring of a woman's appearance; this also applied to Jewish women who lived permanently among worshipers of the Islam. ${ }^{35}$

Women living in the villages of central Tajikistan (Hissar, Karatag, and Dushanbe) wore their traditional coats on their heads when staying within their own village, but when travelling farther or when visiting a town, they always preferred wearing a paranja. This was in all probability for the reason that the common daily coat was perceived as part of the local clothing, not appropriate for the town-related traditions that required the woman's entire body to be veiled. The common coats worn on the head were about one metre long, so they only covered the body down to the upper part of the thighs. A characteristic feature of such coats

\footnotetext{
${ }^{32}$ BIKZHANOVA, Murshida Abdullovna: Odezhda uzbetchek Tashkenta XIX - natchala XX v. In SUKHAREVA, O. A. (otv. red.) Kostyum narodov Sredney Azii: istoriko-etnografitcheskie otcherki, p. 141.

${ }^{33}$ NALIVKIN, Vladimir Petrovitch, NALIVKINA, Mariya Vladimirovna: Otcherk byta zhenshchiny tuzemnogo naseleniya Fergany, p. 96.

${ }^{34}$ SHIROKOVA, Zinaida Aleksandrovna: Traditsionnaya i sovremennaya odezhda zhenshchin gornogo

Tadzhikistana, p. 82.

${ }^{35}$ EMEL'YANENKO, Tat'yana Grigor'evna: Traditsionnyy kostyum bukharskikh evreev. Sankt-Peterburg, Peterburgskoe vostokovedenie 2012, p. 177.
} 
was that the woman's face was never entirely covered. Women commonly held the edges of the coat with their hands so as to cover the lower part of their faces, while the eyes were never covered. In Karategin, Kulyab and Darvaz, these coats were also considered an integral part of women's casual clothing. ${ }^{36}$

A custom of Tajiks from the Mascho District was that before the bride left her home, an older respectable woman dressed her in a chodar, a long coat with false sleeves analogical to paranja. Every village had its own preferences related to the colour and decorations for this part of the wedding dress, but the semantic meaning of motifs (peacocks, flowers, plant sprouts) was the same - the embroidered motifs were believed to bring the young family good luck. Women always wore a big white silk headscarf under chodar. It was folded diagonally in such a way that the front part veiled the face and the neck. Chodar was not part of the property of every family, so it was passed from one family to another where necessary. If a girl lived in another village, the coat was brought to her by the family of her future husband from their own village. This symbolized the young woman's affiliation to a certain kinship group. ${ }^{37}$ There are two major differences between paranja and other coats worn on the head. While paranja was intended to veil the woman completely, both her face and her body, the coats covered the back and sides of her body but her face and the front of her body were not covered entirely. A very popular custom was wearing the coat in such a way so that details of the clothing were visible (the headdress, the dress, and the outerwear). This enabled the identification of the woman's age, which was very important for the local traditional culture. Other important factors were the colour of the coat and the material from which it was made. In contrast, paranja almost entirely eliminated all indicators of age, and since it was originally made especially from blue or grey cotton fabric, the townswomen were completely depersonalized.

\section{Conclusion}

The analysis of traditional forms of the particular type of clothing in relation to ceremonial and everyday practices demonstrates that women's veiling was manifested to the greatest extent within wedding ceremonies, where headscarves and veils were most widely used, as well as coats with false sleeves and less commonly even normal coats. A specific type of

\footnotetext{
${ }^{36}$ SHIROKOVA, Zinaida Aleksandrovna: Traditsionnaya i sovremennaya odezhda zhenshchin gornogo Tadzhikistana, p. 82.

${ }^{37}$ Data from a field research conducted by O. V. Starostina in Mascho District, Sughd Region, acquired in 2018 from accounts of local old women who had been told by their mothers about their wedding. Chodar is used in this area in the same way even at present.
} 
clothing is paranja, which was used for wedding ceremonies only infrequently; it served rather as an item of outdoor clothes of women in the urban environment. In daily life, women used especially headscarves and normal coats for veiling. The coats gradually became a rather festive and ceremonial type of clothing. Apart from wedding ceremonies, they were also used for funerary ceremonies - they were worn in the period of mourning, or were used to cover the body of the dead woman; this applies to munisak, which almost disappeared from wedding ceremonies at the beginning of the 20th century and was used as funerary clothes. Coats with false sleeves also gradually became primarily festive and ceremonial clothes. An example may be the Karakalpak coat zhegde, which had been replaced in the middle of the $20^{\text {th }}$ century in everyday utilization by a large headscarf tied around the turban.

We agree with O. A. Sukhareva, who assumes that the tradition of women's veiling, which is typical for many peoples of Central Asia, is related to the ancient custom of protecting women in certain stages of their lives when they might be harmed by evil powers. ${ }^{38}$ As already mentioned, women's veiling was most remarkably manifested within wedding ceremonies. The wedding ceremony belongs to rites of passage, the same as ceremonies related to birth and death. Within it, a woman's departure from her parents' home is considered a symbolic death and the arrival to the family of her husband symbolizes the birth of a new family member. Over the course of the entire period from entering marriage to the wedding night (in case of some nations even until the birth of the child), the young woman finds herself in an undefined stage - already dead and not born yet. In accordance with this state, her connection to the realm of spirits (the dead) is significantly strengthened. In addition, she also loses the sacral protection from her family, and has not yet acquired the protection from her husband's family. For this reason, the woman needs special protection in the form of a great number of jewels and amulets, and both her face and her body need to be hidden from the outer world, where she is particularly vulnerable and prone to the evil eye and various demonic beings.

Veiling of women in Central Asia was also a social phenomenon connected to the practice of the bride avoiding her husband's male relatives, and it reflected the woman's status within the family. The religious reasons resulting from the influence of Islam probably gained influence later, and gave rise to clothes such as paranja.

\footnotetext{
${ }^{38}$ SUKHAREVA, Ol'ga Aleksandrovna: Istoriya sredneaziatskogo kostyuma: Samarkand (2ya polovina XIX natchalo XX v.), p. 40-41.
} 
When analysing the specifics of veiling items of clothing related to the woman's age, it is possible to identify the following aspects: Such clothing started to be used at an earlier age in the case of women from Central-Asian urban areas, the Uzbek women, and the Tajik women. As stated above, a girl wore her first paranja at the time of her sexual maturation i.e. the time when she entered the age group of brides, which corresponded to the Islamic ethical standards ${ }^{39}$ and the Shariah law widely spread among the urban inhabitants. In contrast, settled rural populations and nomads, who were undoubtedly also Muslims, primarily followed adat - standards of customary law and ethics. In these cultural traditions, women's veiling started with wedding ceremonies and lasted for all of the woman's childbearing age until her transition to the age category of old women.

\footnotetext{
${ }^{39}$ Koran. 24:31, 33:59
} 


\section{Catalogue}

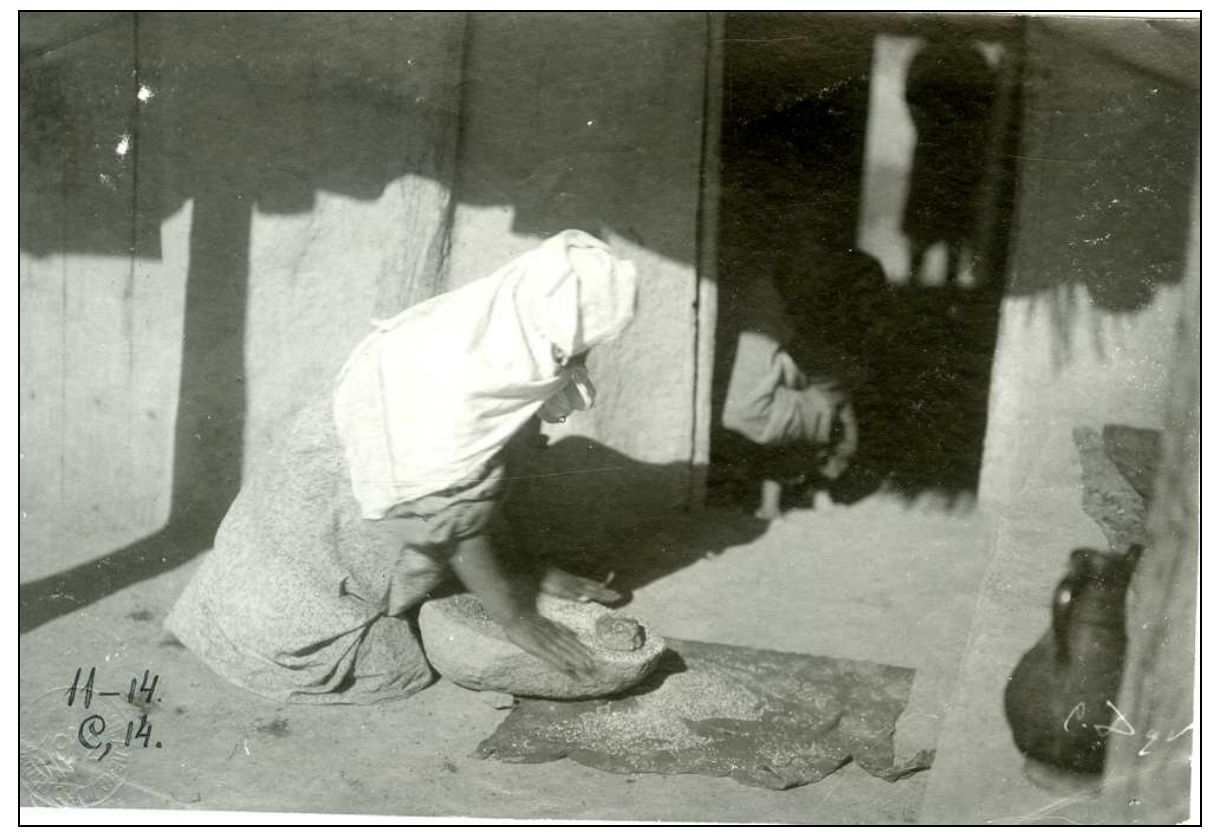

Fig. 1. Woman with a mealing stone (demonstrates how to wear a scarf covering the body to the waist). Tajiks, 1901, Syr Darya Region. Inv. No. 11-14, Russian Museum of Ethnography.

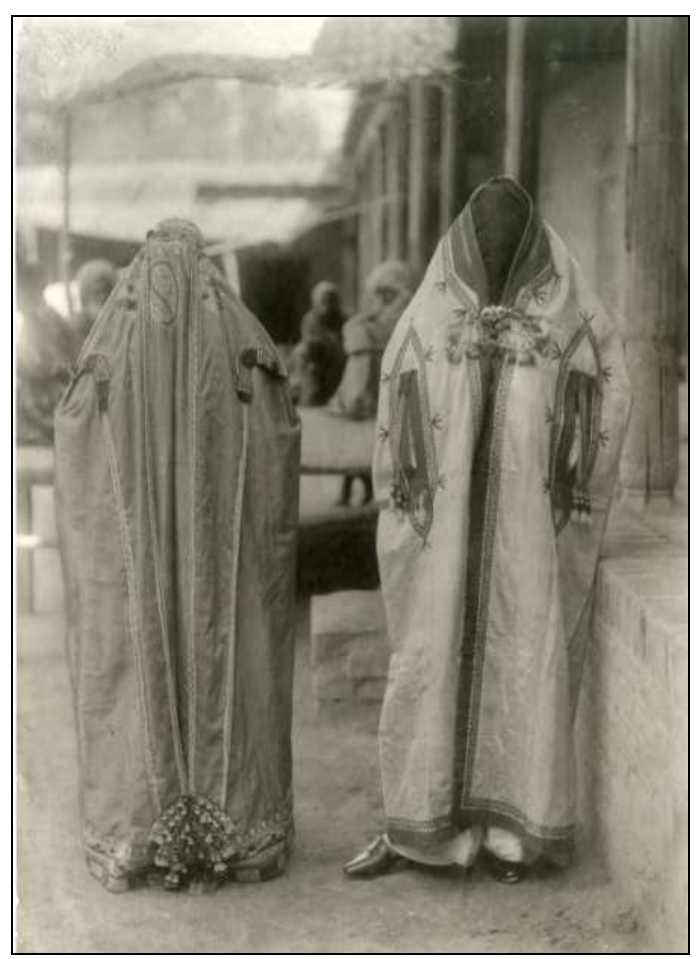

Fig. 2. Townswomen in paranjas. Uzbeks, Tajiks, 1901, Emirate of Bukhara. Inv. No. 48-343, Russian Museum of Ethnography. 


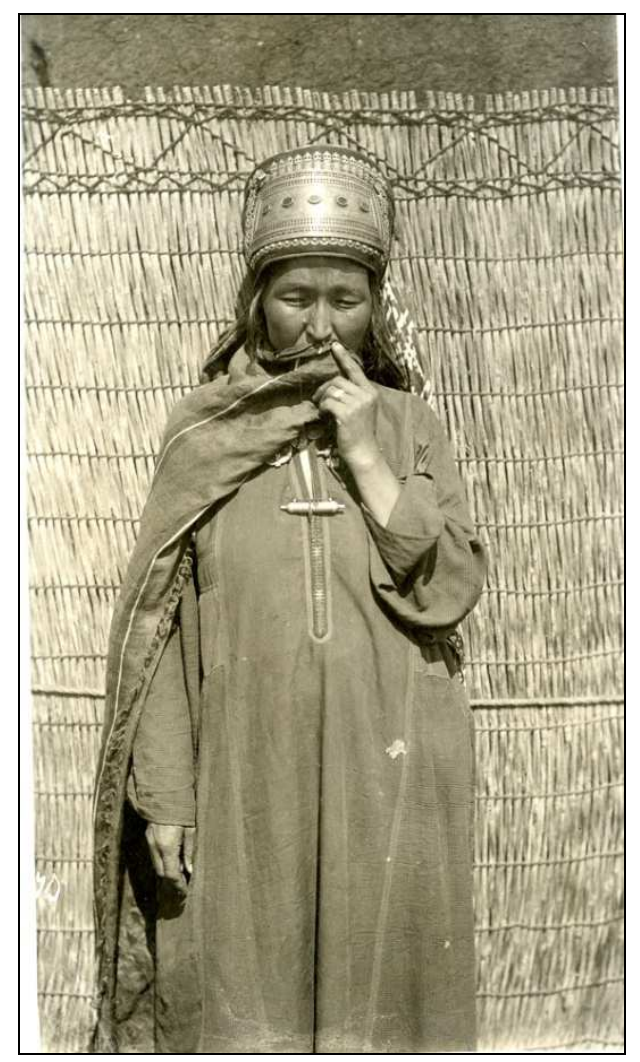

Fig. 3. Married woman, Turkmens, 1900-1901, Trans-Caspian Region. Inv. No. 40-45, Russian Museum of Ethnography.

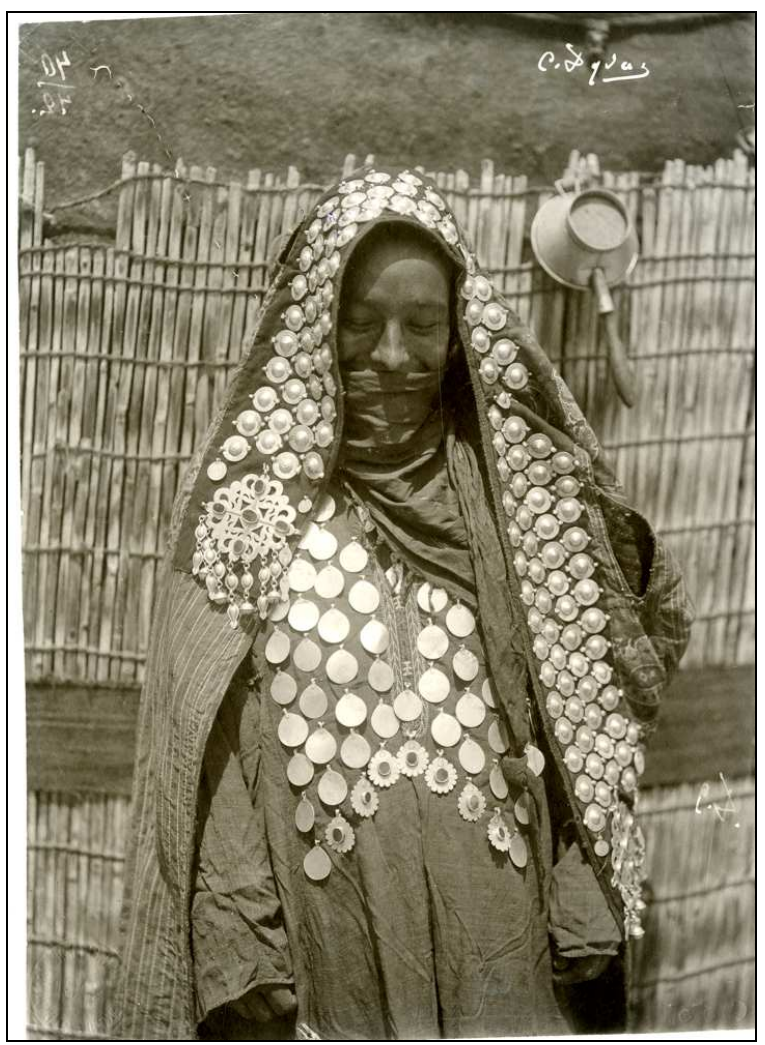

Fig. 4. Woman with a coat with false sleeves. Turkmens, 1900-1901, Trans-Caspian Region. Inv. No. 40-42, Russian Museum of Ethnography. 


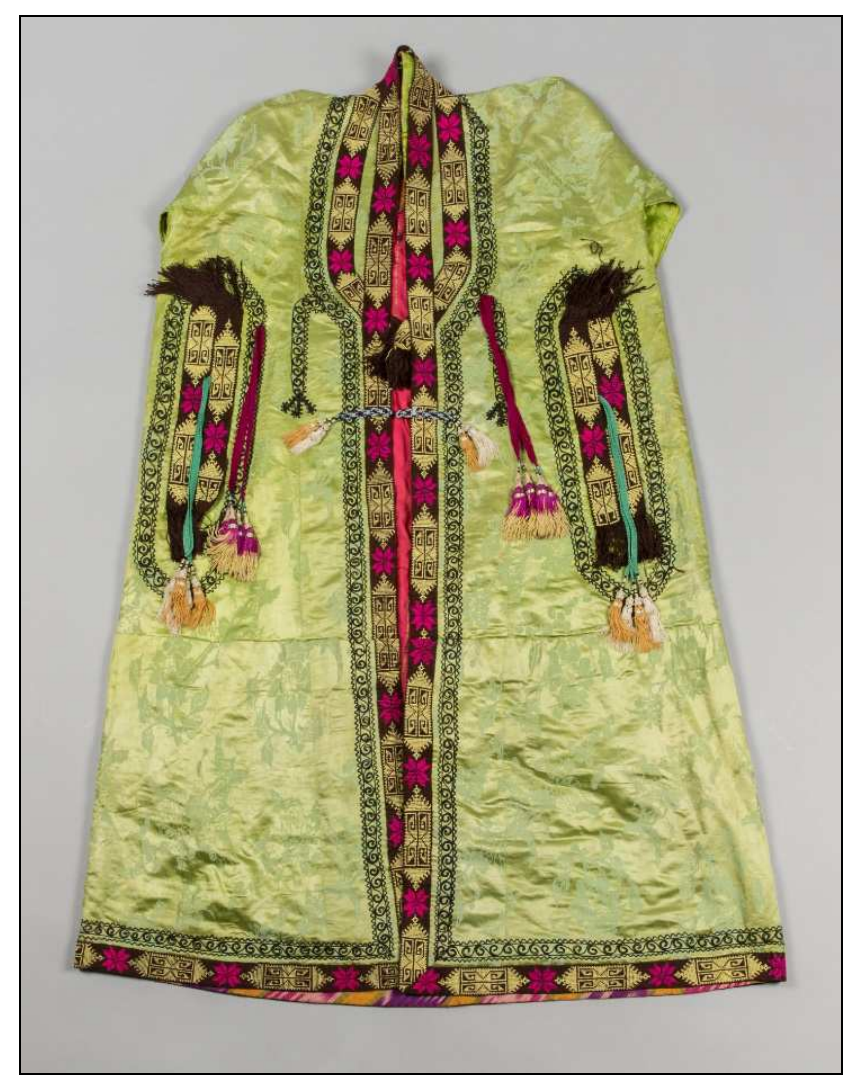

Fig. 5. Paranja coat. Uzbeks, early 20th century, Tashkent. Silk, satin, silk embroidery, l. 147 cm, w. 202 cm. Inv. No. 12850-3, Russian Museum of Ethnography.

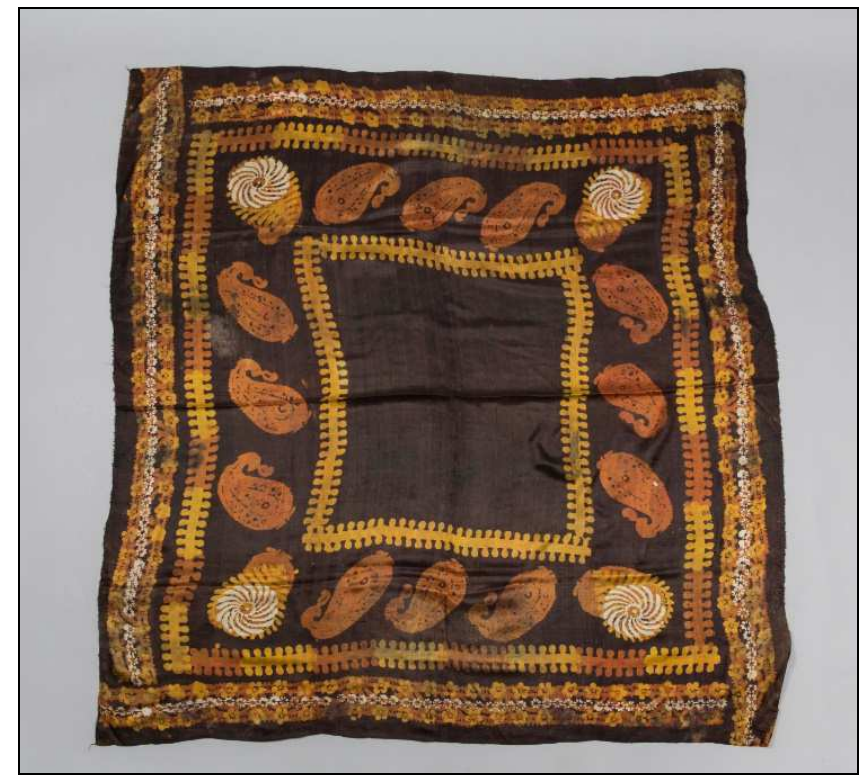

Fig. 6. Headscarf. Uzbeks, last third of the 19th century, Bukhara. Silk, $1.135 \mathrm{~cm}$, w. 188 cm. Inv. No. 20151, Russian Museum of Ethnography. 


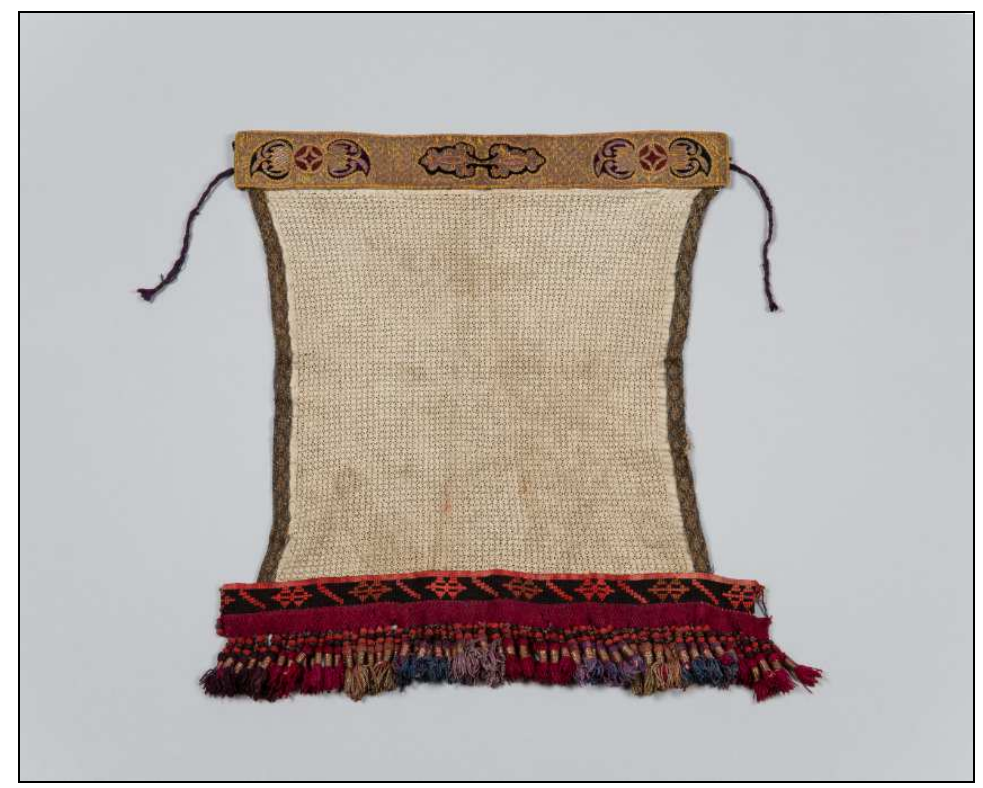

Fig. 7. Veil. Kyrgyzs, late $19^{\text {th }}$ century - early $20^{\text {th }}$ century, Southern Kyrgyzstan. Cotton, silk, gold embroidery, 1. 41 cm, w. 36.5 cm. Inv. No. 13098-3, Russian Museum of Ethnography.

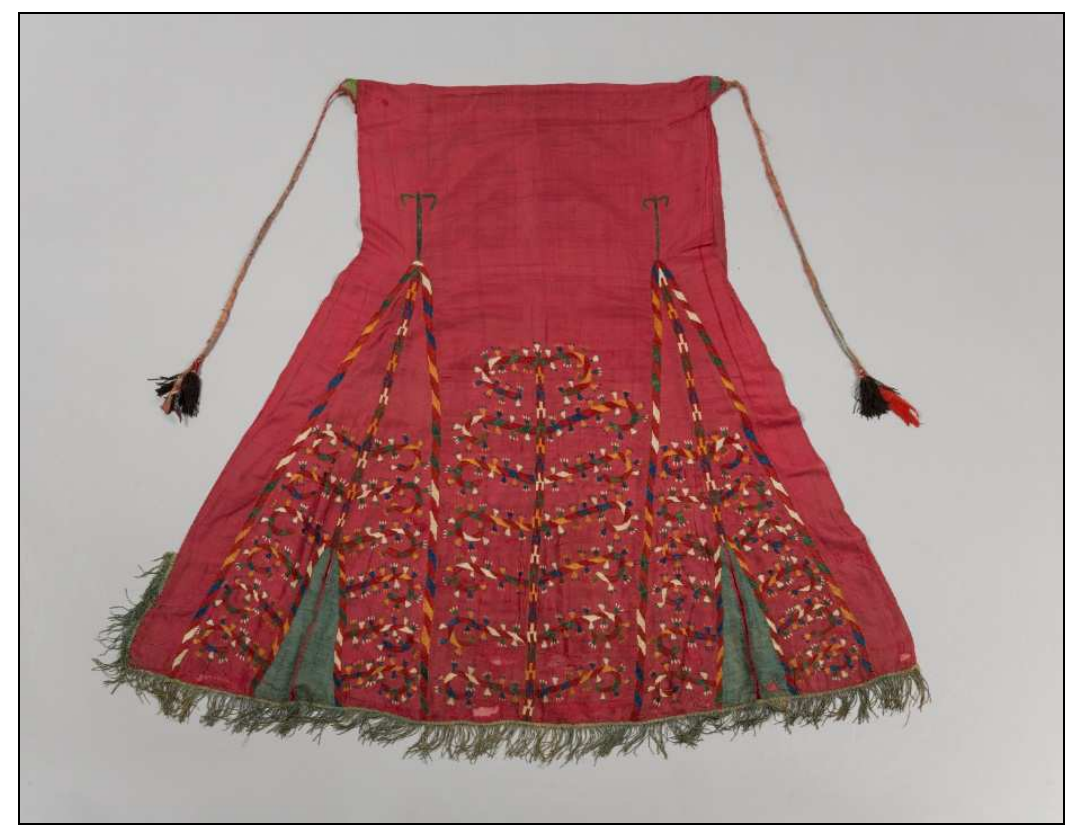

Fig. 8. Veil. Turkmens, late 19th century, Trans-Caspian Region. Silk, silk embroidery, l. 134 cm, w. 108 cm. Inv. No. 8762-22579, Russian Museum of Ethnography. 


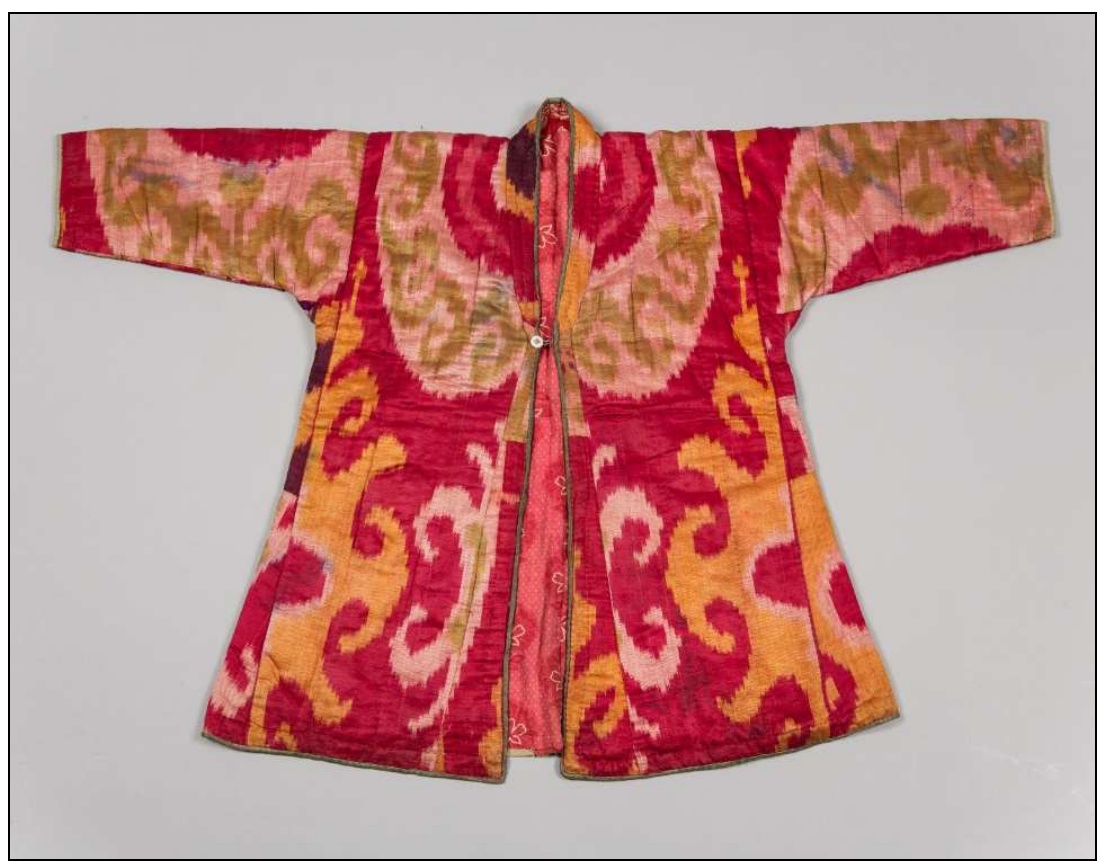

Fig. 9. Children's coat. Tajiks, late 19th century, Samarkand. Semi-silk and cotton fabric, $1.58 \mathrm{~cm}$, back w. 36 cm. Inv. No. 58-9, Russian Museum of Ethnography.

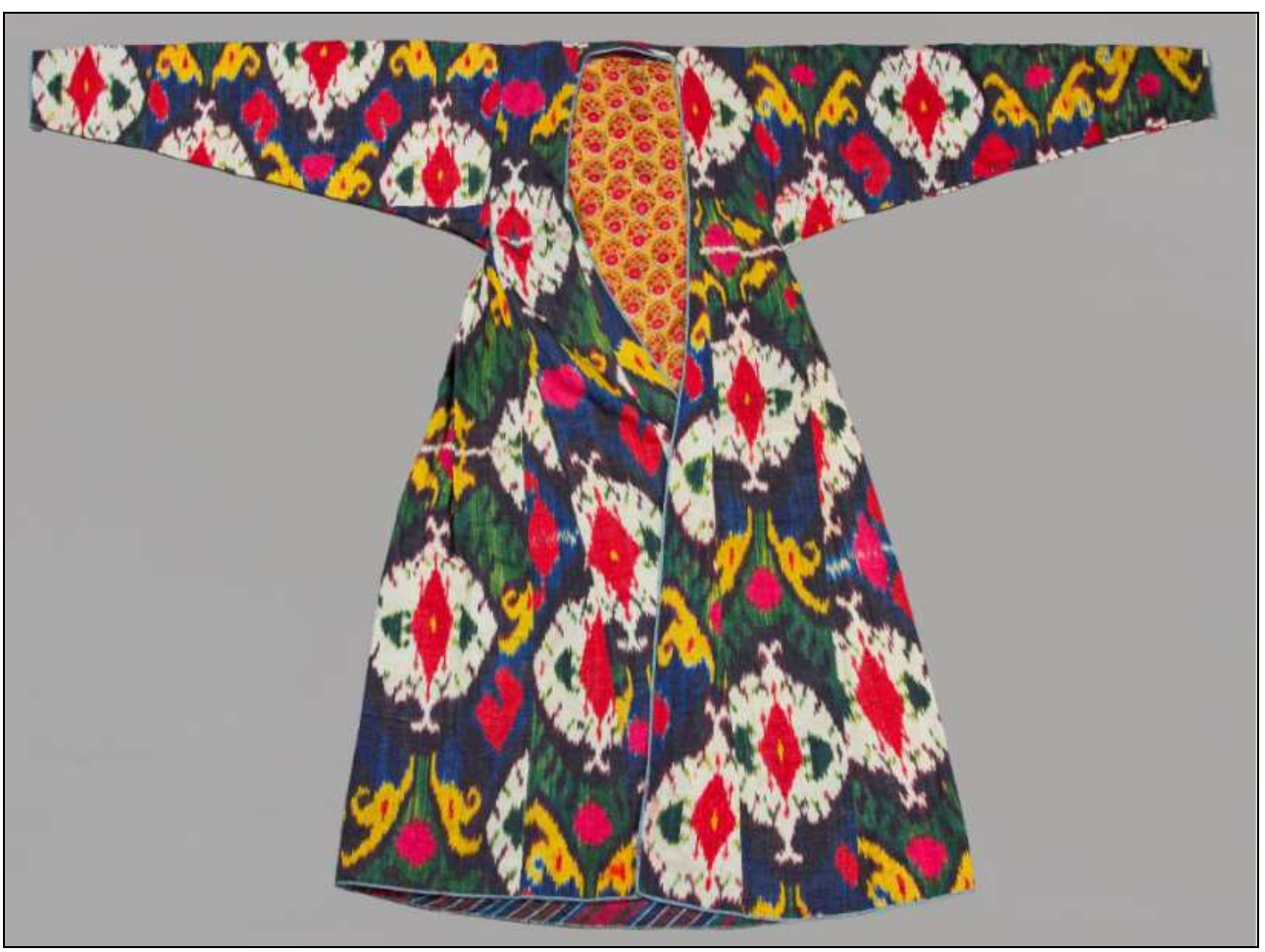

Fig. 10. Kaltacha coat, Tajiks, late 19th century, Emirate of Bukhara. Semi-silk fabric, $1.129 \mathrm{~cm}, \mathrm{back}$ w. 45. Inv. No. 59-3, Russian Museum of Ethnography. 


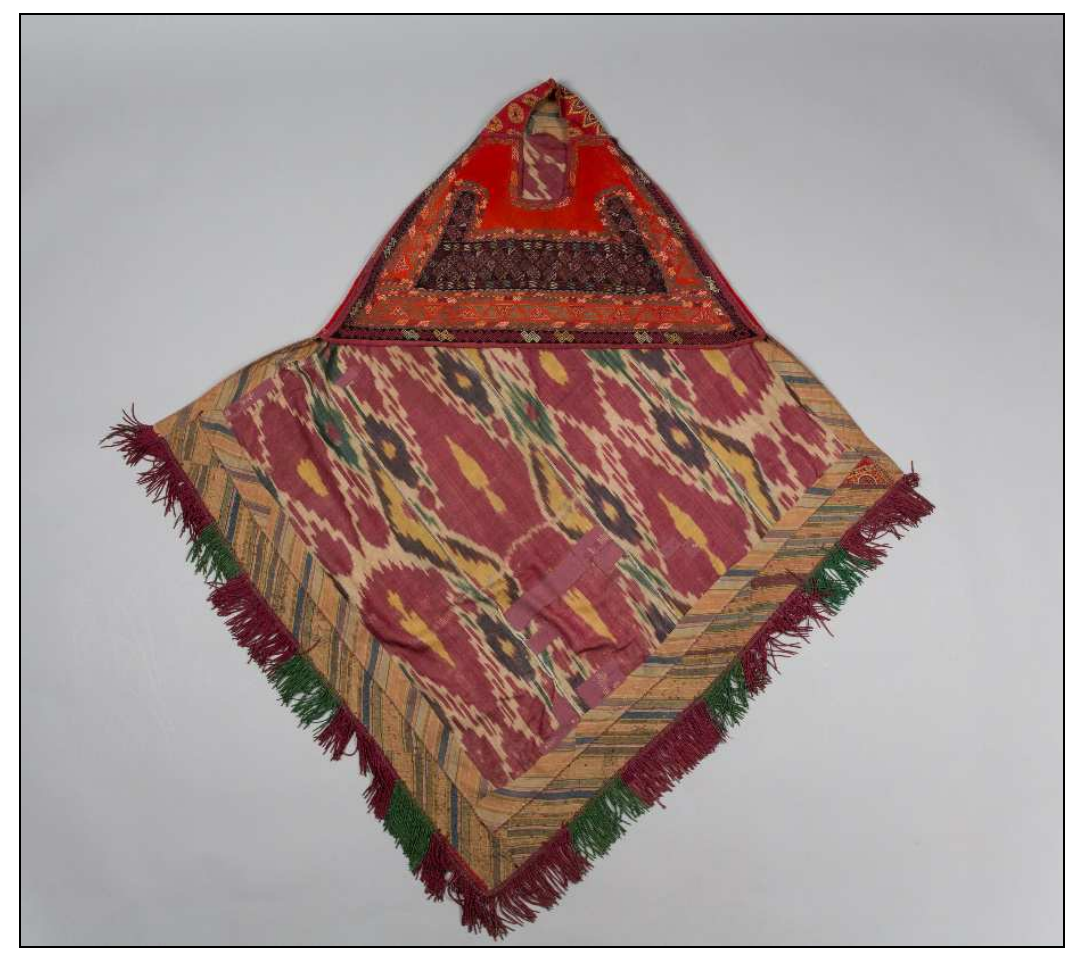

Fig. 11. Kimeshek headdress, Karakalpaks, 1910s, Amu Darya Delta. Broadcloth, silk, silk embroidery, Inv. No. 7128-87, Russian Museum of Ethnography.

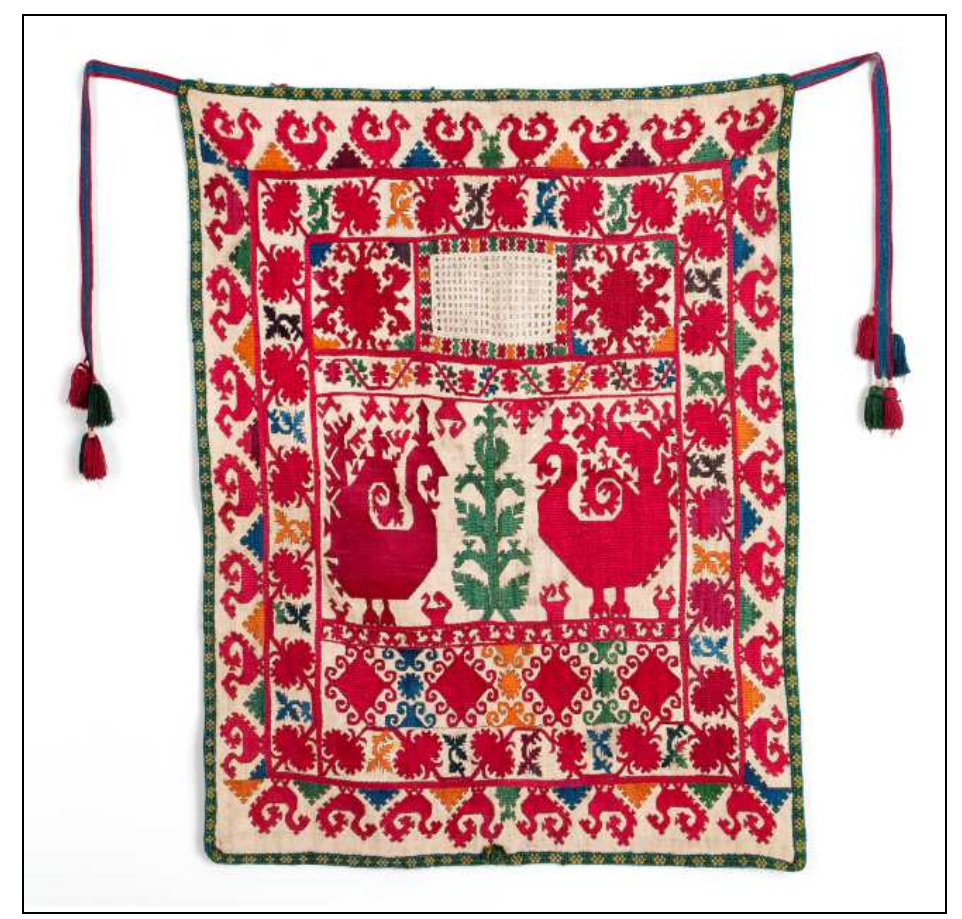

Fig. 12. Ruband wedding veil. Tajiks, Darvaz. Late $19^{\text {th }}$ century. Cotton, silk embroidery, satin stitch, $71 \times$ 56 cm. Inv. No. A 18 379, National Museum - Náprstek Museum. 


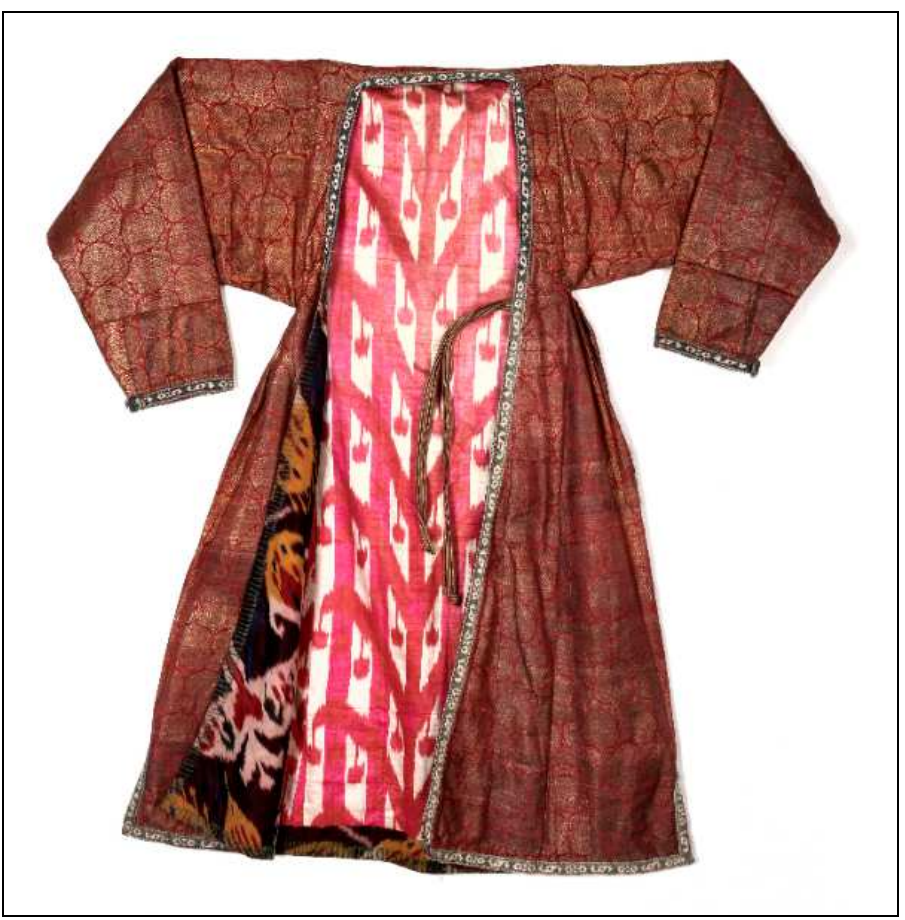

Fig. 13. Munisak coat. Uzbeks, Samarkand. Late $19^{\text {th }}-$ early $20^{\text {th }}$ century. Silk brocade, silk ikat lining, l. 132 cm. Inv. No. A 18 432, National Museum - Náprstek Museum.

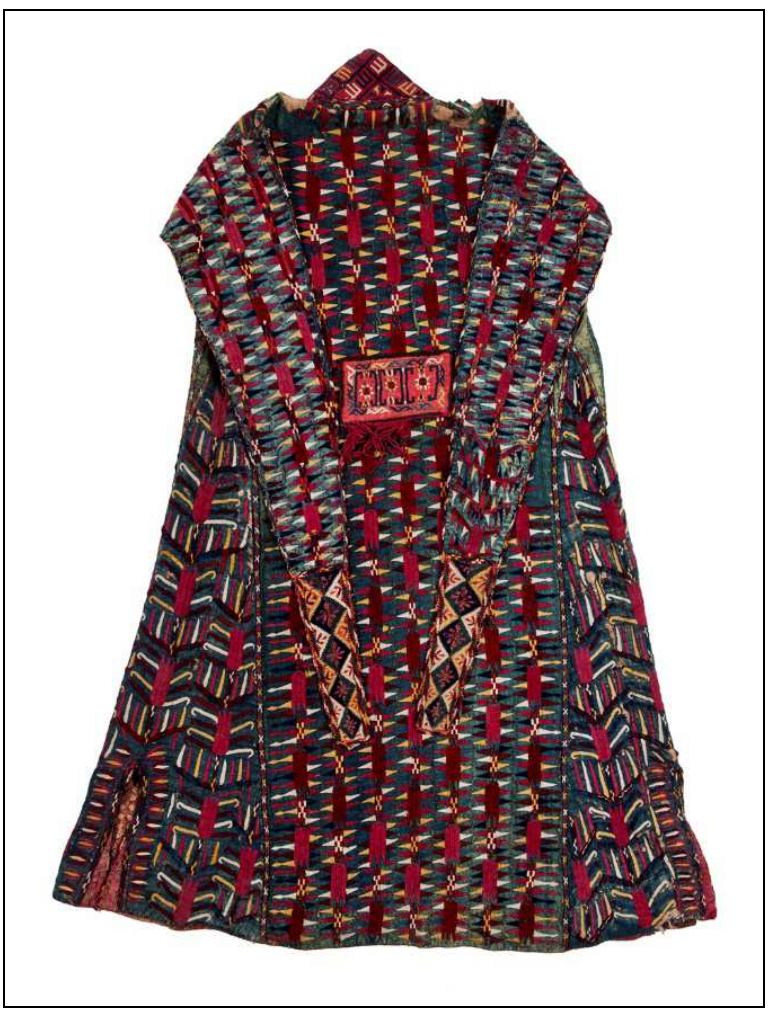

Fig. 14. Chyrpy coat, Teke Turkmens, 1840s. Cotton, silk embroidery, I. $110 \mathrm{~cm}$. Inv. No. A31638, National Museum - Náprstek Museum. 


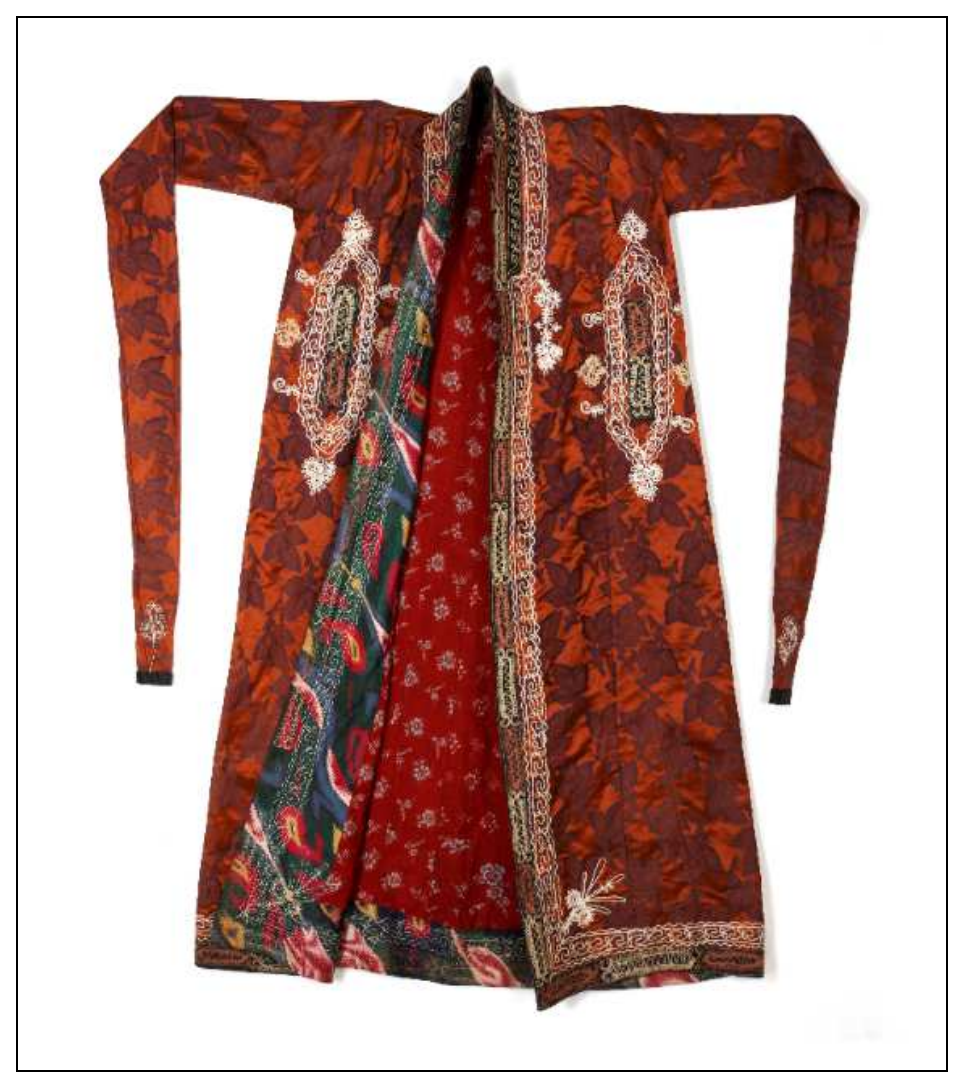

Fig. 15. Paranja coat. Uzbekistan. Early $\mathbf{2 0}^{\text {th }}$ century. Silk, cotton lining, machine silk embroidery, tambour stitch, l. 139 cm, w. 44 cm. Inv. No. 22 744, National Museum - Náprstek Museum. 


\section{References}

ANTIPINA, Klavdiya Ivanovna: Osobennosti material'noy kul'tury i prikladnogo iskusstva yuzhnykh kirgizov. Frunze, Izd-vo AN Kirg. SSR 1962.

BIKZHANOVA, Murshida Abdullovna: Odezhda uzbetchek Tashkenta XIX - natchala XX v. Sukhareva, O. A. (otv. red.) Kostyum narodov Sredney Azii: istoriko-etnografitcheskie otcherki. Moskva, Nauka 1979, p. 133-151.

BOBRINSKIY, Aleksey Aleksandrovitch: O nekotorykh simvolitcheskikh znakakh obshchikh pervobytnoy ornamentike vsekh narodov Evropy i Azii. Moskva, T-vo tip. A.I. Mamontova 1902.

EMEL'YANENKO, Tat'yana Grigor'evna: Traditsionnyy kostyum bukharskikh evreev. SanktPeterburg, Peterburgskoe vostokovedenie 2012.

KISLYAKOV, Nikolay Andreevitch: Materialy po drevnim verovaniyam gornykh tadzhikov. Strany i narody. Vyp. XXVI., Kn. 3. Moskva, Nauka 1989, p. 249-268.

KISLYAKOV, Nikolay Andreevitch: Otcherki po istorii sem'i i braka u narodov Sredney Azii i Kazakhstana. Leningrad, Nauka 1969.

LOBATCHEVA, Nina Petrovna: K istorii sredneaziatskogo kostyuma (zhenskie golovnye nakidki-khalaty). Sovetskaya etnografiya, № 6, 1965, p. 34-49.

LOBATCHEVA, Nina Petrovna: Karakalpakskie golovnye nakidki. Lobatcheva, N. P. Sazonova, M. V. (otv. red.) Traditsionnaya odezhda narodov Sredney Azii $i$ Kazakhstana. Moskva, Nauka 1989, p. 169-181.

LYUSHKEVITCH, Fanya Davidovna: Odezhda tadzhikskogo naseleniya Bukharskogo oazisa v pervoy polovine XX v. Sbornik Muzeya antropologii i etnografii. T. 34, Leningrad 1978, p. 123-144.

MOROZOVA, Anna Stepanovna: Golovnye ubory turkmen (po kollektsiyam GME). Tr. In-ta istorii, arkheologii i etnografii Turkmenskoy SSR. T. VII. Moskva, 1963, p. 81-118.

MOROZOVA, Anna Stepanovna: Traditsionnaya narodnaya odezhda turkmen. Lobatcheva, N. P. - Sazonova, M. V. (otv. red.) Traditsionnaya odezhda narodov Sredney Azii $i$ Kazakhstana. Moskva, Nauka 1989, p. 39-89.

NALIVKIN, Vladimir Petrovitch - Nalivkina, Mariya Vladimirovna: Otcherk byta zhenshchiny tuzemnogo naseleniya Fergany. Kazan': Tipografiya Imperatorskogo universiteta 1886.

SHIROKOVA, Zinaida Aleksandrovna: Traditsionnaya i sovremennaya odezhda zhenshchin gornogo Tadzhikistana, Dushanbe, Donish 1976.

SUKHAREVA, Ol'ga Aleksandrovna: Istoriya sredneaziatskogo kostyuma: Samarkand (2ya polovina XIX - natchalo XX v.). Moskva, Nauka 1982.

SUKHAREVA, Ol'ga Aleksandrovna: K istorii razvitiya samarkandskoy dekorativnoy vyshivki. Literatura i iskusstvo Uzbekistana. Kn. 6. Tashkent, 1937, p.119-134.

SUKHAREVA, Ol'ga Aleksandrovna: Opyt analiza pokroev traditsionnoy «tunikoobraznoy» sredneaziatskoy odezhdy v plane ikh istorii i evolyutsii. Sukhareva, O. A. (otv. red.) Kostyum narodov Sredney Azii: istoriko-etnografitcheskie otcherki. Moskva, Nauka 1979, p. 77-102.

VASIL'EVA, Galina Petrovna: Turkmeny - nokhurli. Tolstov, S. P. - Zhdanko, T. A. (otv. red.) Sredneaziatskiy etnografitcheskiy sbornik, t. XXI. Moskva, Nauka 1954, p. 82215. 


\title{
«Скрывание» женщины: Повседневная и обрядовая практика у народов Средней Азии
}

\author{
Тереза Гейзларова / Tereza Hejzlarová, Ольга Викторовна Старостина \\ Тереза Гейзларова, Кафедра азиатских исследований, Философский факультет, Университет имени \\ Палацкого, Тршида Свободы 26, 77900 Оломоуц, Чешская Республика \\ Email: tereza.hejzlarova@upol.cz. \\ Ольга Викторовна Старостина, Отдел этнографии народов Кавказа, Средней Азии и Казахстана, \\ Российский этнографический музей, Инженерная 4/1, 191011 Санкт-Петербург, Россия. \\ Email: starostinaov73@mail.ru
}

DOI: https://dx.doi.org/10.7160/KS.2021.170202ru

\section{Резюме}

Статья посвящена анализу традиционных форм «закрывающих» элементов костюма и их связи с ритуальными и повседневными практиками народов Средней Азии в период со второй половины XIX до XX века. В исследовании рассматриваются конкретные виды «закрывающих» элементов костюма, их общие черты и различия, связанные с манерой ношения, а также используемые материалы и узоры. Важной частью исследования является каталог, представляющий отдельные виды одежды указанного периода из музейных собраний Российского этнографического музея в СанктПетербурге и Национального музея - Музея имени Напрстека в Праге.

\section{Ключевые слова}

закрывание женщин, Средняя Азия, одежда, халаты, наголовные накидки, лицевые занавески, платки, свадебные обряды

\section{Введение}

В этнографической литературе, посвященной женскому костюму народов Среднеазиатско-Казахстанаского региона, свадебным обрядам и традициям повседневности, нередко рассматривались вопросы связанные как с различными аспектами «закрывания» женщины, так и с некоторыми элементами костюма, предназначенными для скрытия тех или иных частей ее тела. Однако, обобщающих работ, в которых проводился бы анализ традиционных форм данных элементов костюма и их связи и ритуалом и повседневными практиками, до настоящего времени не проводился. В современных европейских, российских и среднеазиатских научных работах практически не встречаются исследования, посвященные особенностям 
бытования различных материальных артефактов в традиционной культуре народов Средней Азии и Казахстана, касающихся скрывания женщины. Большинство известных в научном сообществе работ носят философский, культурологический или религиоведческий характер и не учитывают, с одной стороны обширную материальную базу музейных памятников и фотоколлекций, а с другой, накопленные за последнее столетие архивные материалы, выключающие экспедиционные отчеты, дневники собирателей и описи к музейным собраниям. Предложенная статья, которая является далеко не исчерпывающей, базируется на основе анализа собраний двух этнографических музеев Европы - Российского этнографического музея (около 100000 предметов и фотографий по этнографии народов среднеазиатско - казахстанского региона) и Музея имени Напрстка (около 400 предметов и фотографий по этнографии народов среднеазиатско - казахстанского региона), а также многочисленных источников, касающихся данной темы, доступных в сетевых ресурсах. Значительную роль в разработке данной темы имеет и научные исследования конца XIX - XX веков, посвященные среднеазиатскому костюму, особенностям социальных отношений, женской культуре, традиционным верованиям, поведенческим и этическим нормам, принятым в традиционном сообществе, а также исламским традициям, включенным в культуру повседневности и обрядовые практики.

В данном исследовании авторы предприняли попытку установить связи между конкретными видами «закрывающей» одежды и способами ее бытования, а также выявить общие черты и отличия, характерные для данного явления у народов Средней Азии и Казахстана.

3. А. Широкова в своей работе «Традиционная и современная одежда женщин горного Таджикистана» разработала классификацию головных накидок ${ }^{1}$, которую, с некоторыми оговорками и дополнениями, на наш взгляд, возможно применить к подобного рода предметам, бытовавшим на территории Средней Азии среди узбеков, киргизов, каракалпаков, туркмен и таджиков. Данная классификация позволяет не только выделить группы предметов по принципу кроя, но и определить особенности их манеры ношения, бытования и семантический смысл, определяемые той или иной традицией. В представленной работе не рассматривается возникновение и генезис

\footnotetext{
${ }^{1}$ Широкова 3.А Традиционная и современная одежда женщин горного Таджикистана. - Душанбе, 1976 C. 84
} 
наголовных накидок различного кроя, так как этот вопрос был подробно рассмотрен О. А. Сухаревой².

\section{Классификация женской «закрывающей» одежды}

Женскую «закрывающую» одежду можно разделить на четыре группы. К первой группе относятся большие наголовные платки, которые закрывают всю фигуру женщины, или только лицо, или его часть, как, например во время свадебных обрядов у горных таджиков, туркмен, некоторых групп кочевых узбеков и казахов. Вторая группа лицевые занавески, бытовавшие в свадебном женском костюме и костюме молодух и распространенные среди некоторых групп горных таджиков, туркмен-йомудов, южных киргизов и уйгуров. К третьей группе относятся халаты, используемые женщинами наиболее широко среди оседлого сельского населения Средней Азии и являющиеся одновременно повседневной плечевой одеждой детей и мужчин. Значительно реже фиксируются случаи использования женских халатов особого кроя, таких как калтача, камзул, чопон. В четвертой группе объединены халатообразные накидки имеющие ряд характерных признаков, присущих только данному виду одежды. Эти накидки являются исключительно женским предметом костюма с сильно зауженными рукавами, соединенными между собой. Они воспринимались как часть повседневного образа женщины в Горном Таджикистане и Туркмении. К этой же группе следует отнести и длинную наголовную накидку паранджа, характерную, преимущественно для горожанок Средней Азии (узбечек, таджичек, евреек). Следует отметить, что в работе не рассматривается весь костюмный комплекс.

\section{Первая группа - платки}

Большой головной платок является одним из самых универсальных элементов одежды, которые используются для скрывания женщины от посторонних глаз. Он бытует в костюме всех без исключения народов Среднеазиатско-Казахстанского региона и представляет собой квадратный или прямоугольный кусок ткани, преимущественно белого цвета. Манера его ношения и использование в повседневном или обрядовом костюме зависит от конкретной традиции, принятой у того или иного народа, этнографической, территориальной и узколокальной группы.

\footnotetext{
${ }^{2}$ Сухарева О.А. Опыт анализа покроев традиционной «туникообразной» среднеазиатской одежды в плане их истории и эволюции. Костюм народов Средней Азии. - М.:Наука, 1979. - С. 77-102
} 
В традиционной культуре казахов и киргизов не существует обычая закрывания лица и фигуры женщины (за исключением областей южной Киргизии). Избегание, связанное с семейно-брачными отношениями, касаются только поведенческих запретов на общение молодухи с родственниками мужа, в отличие от оседлых народов, в традиционной культуре которых для скрывания молодухи используются платки и разнообразные накидки. Но в свадебных ритуалах народов Средней Азии и Казахстана скрывание молодой после бракосочетания, во время переезда в дом мужа и первых дней еe пребывания там, до совершения обряда смотрения лица, считается необходимым. Весь этот период новобрачная у киргизов и казахов покрыта большим белым хлопчатобумажным головным платком ${ }^{3}$, который в несложенном виде набрасывается на головной убор и закрывает ее фигуру до колен.

Особый статус девушки - невесты и новобрачной у равнинных таджиков и оседлых узбеков подчеркивался дополнительными деталями. Так же как у казахов и киргизов на ее голову набрасывали большой белый несложенный платок из шелка или кисеи, закрывавший лицо, грудь, плечи и всю спину, который молодая снимала после первой брачной ночи в доме супруга. В свадебных обрядах белый цвет считался приносящим счастье, поэтому белые ткани были обязательны в одежде новобрачных ${ }^{4}$. На брачные церемонии паранджу ${ }^{5}$ не надевали, что, вероятно, было связано с представлением об этом наголовном халате как об исключительно уличной одежде, не имевшей в истории традиционного костюма глубоких исторических корней ${ }^{6}$.

Аналогичное использование большого белого головного платка во второй половине XIX - XX вв. наблюдалось среди горных таджиков Куляба и Каратегина ${ }^{7}$, где не бытовали наголовные накидки и паранджа.

В ряде районов Средней Азии во время брачных церемоний платки использовали в качестве лицевого покрывала, которое было дополнено головной накидкой, халатом или паранджой. Так, например таджички Куляба, Матчинской и Гиссарской долин под наголовную накидку чодар 8 обязательно надевали белый шелковый большой платок, который складывали по диагонали и затем набрасывали на голову таки образом, чтобы

\footnotetext{
${ }^{3}$ Кисляков Н.А. Очерки по истории семьи и брака у народов Средней Азии и Казахстана. Л.: Наука, 1969 - C. 113,120

${ }^{4}$ Широкова 3.А. Традиционная и современная одежда женщин горного Таджикистана - С. 128

${ }^{5}$ Для получения более подробной информации о паранджи см. Четвертую группу.

${ }^{6}$ Сухарева О.А. История среднеазиатского костюма: Самарканд (2я половина XIX - начало XX в.). Москва, 1982 - С. 50

${ }^{7}$ Широкова 3.А. Традиционная и современная одежда женщин горного Таджикистана. - Душанбе, 1976 - C. 133.

${ }^{8}$ Для получения более подробной информации о чодаре см. Четвертую группу.
} 
передняя часть закрывала лицо и шею девушки. У каракалпаков и туркмен платок также набрасывали только на лицо ${ }^{9}$ и носили с наголовными накидками чырпь (жегде). ${ }^{10}$

В Узбекистане и Таджикистане помимо свадебных церемоний головные платки использовались сельскими женщинами в повседневной жизни для скрывания лица от посторонних (преимущественно мужчин). При этом, для молодухи практически все жители кишлака или гузара (квартала) мужа считались посторонними. Постепенно, знакомясь во время семейных и общинных праздников, а также посиделок с родственниками и соседями, женщина переставала прикрывать от них лицо. Девушки и женщины фертильного возраста продолжали закрывать лицо при встрече с жителями других поселков, торговцами, путешественниками и, особенно, с иноверцами обеих полов. Они становились спиной или боком к встречному человеку и прикрывали лицо краем головного платка ${ }^{11}$.

Молодые замужние эрсаринки, нохурли, мучарли и текинки носили платок гыйнач, которая представляет собой большую треугольную косынку, сшитую из нескольких полос бордового шелка местного кустарно производства, по двум сторонам которого проходит широкая тканая кайма в виде ромбов и треугольников белого, желтого и зеленого цветов, заключенных между бело-желтыми полосами. По краю косынки, как правило, пришивали бахрому из скрученного шелка черного, бордового или зеленого цвета. Ее набрасывали сверху на головной убор борик или тахью. На некоторых косынках правый конец платка, называемый ящмак, слегка присобирали и скругляли. В этом случае правый конец проводили от затылка справа на лево к уху, где он подтыкался или закреплялся специальной булавкой к головному убору. Таким образом, рот и шея женщины оказывались закрытыми. В некоторых случаях женщина могла держать угол платка во рту, зажав его между зубов.

Женщины также тщательно закрывали грудь, шею, часто подбородок, для чего служили специальные повязки «лячек». Эта деталь головного убора была зафиксирована в костюме некоторых групп таджичек, киргизок, кочевых и хорезмских узбечек. «Лячек» представлял собой небольшой, обычно белый платок, сложенный по диагонали, угол платка закрывал грудь, а концы, плотно облегая лицо, завязывались на

\footnotetext{
${ }^{9}$ Кисляков Н.А. Очерки по истории семьи и брака у народов Средней Азии и Казахстана. Л.: Наука, 1969 - С. 124,134

${ }^{10}$ Для получения более подробной информации о чырпы и жегде см. Четвертую группу.

${ }^{11}$ Широкова 3.А. Традиционная и современная одежда женщин горного Таджикистана. - Душанбе, 1976 - C. 81
} 
темени $^{12}$. Замужние казашки и каракалпачки вместо этого платка использовали специальный нижний головной убор кимешек, напоминавший капюшон с отверстием для лица.

\section{Вторая группа - лицевые занавески}

Как отмечалось выше, традиция закрывания лица невесты и новобрачной для большинства народов Среднеазиатско-Казахстанского региона является универсальной, что объясняется общими представлениями о сакральной уязвимости женщины в переходный период ее жизни.

Лицевые занавески полностью закрывали лицо, шею и верхнюю часть груди. Этот вид лицевых покрывал входил в свадебный костюм некоторых групп горных таджиков, узбеков, киргизов и уйгуров. Наблюдаются и общие черты в обрядовом использовании лицевых занавесок. Впервые она надевалась в доме родителей новобрачной, после обряда мусульманского бракосочетания никах и непосредственно перед переездом молодой в дом мужа. Во все время следования свадебного поезда лицо ее было закрыто. В Самаркандской области, помимо закрывания лица, использовали декоративные вышивки сюзане ${ }^{13}$, которыми покрывали сверху новобрачную или несли над ее головой. Сюзане, изготовлявшиеся к свадьбе стороной невесты, служили магическим оберегом для молодых от злых духов, заговора людей и сглаза ${ }^{14}$. Молодая оставалась в лицевой занавеске и во время свадебных торжеств в доме мужа (за исключением первой брачной ночи) вплоть до совершения обряда «смотрения лица новобрачной».

Этот обряд, с некоторыми незначительными отличиями фиксируется у всех народов Средней Азии и Казахстана. Утром, после первой брачной ночи и проверки невинности женщины, в одной из комнат дома новобрачного собираются родственницы семьи и наиболее уважаемые в кишлаке, ауле или городском квартале женщины, к которым и приводят молодую с закрытым лицом. У киргизов и казахов право первой приоткрыть лицо молодой женщине имеет наиболее уважаемая и

\footnotetext{
12 Люшкевич Ф.Д. Одежда таджикского населения Бухарского оазиса в первой половине XX в. Люшкевич Ф. Д. Одежда таджикского населения Бухарского оазиса в первой половине XX в. // Сборник Музея антропологии и этнографии. Т. 34, Л., 1978 - С. 138.

${ }^{13}$ Термин сюзане также используется в более широком смысле как обобщающий термин для вышитых тканей, используемых в домах оседлых жителей. В качестве приданого их вышивали узбекские и таджикские женщины в городах и крупных селах. Термин сюзане, происходит от персидского слова súzán, означающего иглу.

${ }^{14}$ Сухарева О.А. К истории развития самаркандской декоративной вышивки // Литература и искусство Узбекистана. - Кн. 6 - Ташкент - С. 119-134
} 
многодетная женщина, таджиков и узбеков это делает мальчик из числа родственников свекрови. Таким магическим образом новобрачной передавалась плодовитость, которая, согласно традиционным представлениям народов СреднеазиатскоКазахстанского региона, считалась необходимой для счастья и процветания семьи и рода. Далее к новобрачной подходили другие приглашенные, приподнимали лицевую занавеску, смотрели на молодую и одаривали ее подарками, символизировавшими плату за «смотрения лица». После совершения обряда у оседлого населения лицевая занавеска снималась и хранилась как семейная реликвия до следующего поколения невест, что подтверждается следами многочисленных бытовых реставраций на коллекционных предметах РЭМ и свидетельствами местного населения, собранными во время научных экспедиций.

Киргизские и уйгурские женщины фертильного возраста одевали ее также во время первой весенней перекочевки, которая по семантическому восприятию считалась аналогичной свадьбе, и в контексте обрядов годового цикла воплощала идею брака с природой.

Орнаментированные лицевые занавески бытовали не во всех районах Среднеазиатско-Казахстанского региона. В Таджикистане распространение данного элемента свадебного костюма, называемого рубанд, ограничивалось нижними кишлаками Дарваза и верхними кишлаками Гарма. Лицевая занавеска бет калка, входившая в женский костюм южных киргизов, по мнению К. И. Антипиной, была заимствована у горных таджиков ${ }^{15}$. Несмотря на близость формы, семантического значения орнаментации и особенностей бытования, на наш взгляд, бет калка не могла быть прямым заимствованием, так как место бытования рубанда отделено от Южной Киргизии четырьмя горными хребтами и долинами, в которых не бытуют лицевые занавески.

Данный элемент женского костюма бытовал также среди уйгурок Кашгара и Ферганской долины.

Центральным орнаментальным мотивом вышивки на лицевых занавесках являются изображения дерева и птиц, выполненные с различной степенью стилизации. Наиболее показательными являются горнотаджикские рубанды, центральное поле которых представляет собой композицию, состоящую из древовидного побега с двумя

\footnotetext{
${ }^{15}$ Антипина К.И. Особенности материальной культуры и прикладного искусства южных киргизов. Фрунзе: Изд-во АН Кирг. ССР, 1962. - С. 256
} 
фигурами птиц, изображающих петухов или павлинов, по сторонам. Лицевая занавеска киргизов орнаментирована геометрическим узором в виде свастики - символа, который некоторые исследователи связывают не только с изображением солнца, но и птицы ${ }^{16}$. Изображение древа - сложный полисемантический знак, осмыслявшийся, с одной стороны, как модель мира, в которой крона отражала небо и верхний мир, ствол землю, а корни - нижний мир, мир мертвых ${ }^{17}$. С другой стороны, этот мотив символизировал древнее божество - Богиню-Мать - прородительницу всего живого, которая олицетворяла плодородие и имела власть над миром мертвых и водной стихией. Мотив птицы, согласно традиционному мировоззрению народов Средней Азии и Казахстана, соотносился с солярной символикой и являлся мощным оберегом, приносившим, кроме того, счастье и богатство в дом молодых.

Некоторые общие черты в бытовании и орнаментации обнаруживает также лицевое покрывало пешкурпе, входившее в свадебный женский костюм туркменйомудов. Его надевали на новобрачную во время переезда в дом мужа и использовали в обряде смотрения лица молодой жены. Вышивка на покрывале представляет собой древо с длинными загнутыми ветвями, которое, по представлениям туркмен, было связано с культом Богини Плодородия - покровительнице женщин ${ }^{18}$. Однако, существуют и различия, проявляющиеся в манере ношения, цвете и форме. В отличие от других лицевых покрывал она имела трапециевидную форму, изготавливалась из красного шелка и одевалась таким образом, чтобы закрыть рот, шею и грудь новобрачной.

\section{Третья группа - халаты}

Многие путешественники и исследователи отмечали, что наиболее часто у оседлых народов Средней Азии в качестве головной накидки использовали верхнюю наплечную одежду различных видов. Так, например, супруги Наливкины, прожившие в регионе несколько десятков лет и изучавшие нравы и быт местных жителей, писали, что «во многих местностях у кишлачных женщин принято набрасывать не свой халат, а халатишко одного из детей, при чем на голову всегда накладывается внутреннее

\footnotetext{
${ }^{16}$ Бобринский А.Ф. О некоторых символических знаках общих первобытной орнаментике всех народов Европы и Азии. М., 1900-1902. - С. 9.

${ }^{17}$ Кисляков Н.А. Материалы по древним верованиям горных таджиуов // Страны и народы. - Вып. XXVI., Кн. 3. М., 1989. - С. 256.

${ }^{18}$ Морозова А.С. Головные уборы туркмен: по коллекциям ГМЭ // ТИИАЭ АН Туркм. ССР. М., 1963. C. 112 .
} 
отверстие какого-нибудь из рукавов» ${ }^{19}$. Если у молодой женщины еще не было детей, то она могла накинуть на голову халат своего мужа или же свой халат, камзол или жакет.

Среди халатов, которые надевали на голову, следует отметить также, ягтак узбечек-карлучек, проживавшх западной части Кашкадарьинской области Узбекистана и на юге Таджикистана, или саргирак, бытовавший у таджикских женщин некоторых групп Кашкадарьинской области. Существовали также халаты, некоторые из которых выполняли функцию головного убора и другие, которые сохраняли свою первоначальную функцию. Речь идет, например, о халате джейлак, который узбечкикунгратки начали носить на голове.

Женщины-туркменки носили курте, который надевали или обычным способом, или на голову. ${ }^{20}$ Наиболее распространен он был у текинок, которые украшали его богатой вышивкой на полах, рукавах и по подолу. Вышивка, располагавшаяся на груди представляла собой стилизованную ветку с цветами и листьями ромбовидной формы, рукава украшали зооморфные мотивы - чаще всего бараньи рога - символ плодородия. Края халата окаймляла ломаная линия с трилистниками и бутонами. Курте шили чаще всего из красного (кызыл курте) или зеленого (яшыл курте) шелка. Кроме текинок данный вид закрывающей одежды носили также и гокленки, салырки и нохурки. Женщины одевали его поверх головного убора, выходя из дома, или в доме в случае присутствии чужих мужчин ${ }^{21}$.

Помимо мужских и детских халатов, узбечки не редко носили халат мунисак (мурсак, калтача). Характерной особенностью этого вида верхней плечевой одежды являлась присборенная ткань в подмышечной области под рукавами, пришитые клинья по бокам, расширяющие его, и, в некоторых случаях, тканая лента, украшающая подол. В шестидесятых - девяностых годах XIX века мунисак являлся, прежде всего, основным видом женской верхней одежды, а также входил в обязательную часть приданого (от двух до десяти штук, в богатых семьях и до восемнадцати мунисаков из дорогих и обычных тканей). Данный вид халата также являлся обязательным даром

\footnotetext{
${ }^{19}$ Наливкин В., Наливкина М. Очерк быта женщины оседлого туземного населения Ферганы. - С. 96

${ }^{20}$ Лобачева, Н. П. К истории среднеазиатского костюма (женские головные накидки-халаты) // Советская этнография, 1965, № 6. - С. 36-38.

${ }^{21}$ Васильева, Г. П. Туркмены-нохурли // Толстов, С. П. - Жданко, Т. А. (отв. ред.) Среднеазиатский етнографический сборник, т. ХХІ. Москва, 1954 С. - 161, Морозова, А. С. Традиционная народная одежда туркмен // Лобачева, Н. П. - Сазонова, М. В. (отв. ред.) Традиционная одежда народов Средней Азии и Казахстана. Москва, 1989 - С. 66.
} 
родителей жениха невесте. В Центральном Таджикистане, Бухарском оазисе, Пенджикенте и Самаркандской области, когда девочке исполнялось 12 лет, на нее впервые надевали старинный праздничный халат «мунисак», «калтача» 22 . Это торжество происходило по поводу первого «мулджар»- окончания 12-летнего цикла. Девочка переходила в следующий возрастной класс и могла выходить замуж. В Самарканде существовал особый праздник «калтачапушон» ${ }^{23}$, также связанный с переходом девочки в возрастную группу девушек, название, которого происходило от названия вышеописанной старинной одежды.

В двадцатые годы XX века мунисак в свадебных обрядах практически перестал бытовать и был заменен другими халатами. Позже он потерял свое первоначальное значение в качестве наплечной и наголовной одежды и его стали использовать лишь при погребальных обрядах, набрасывая этот халат на тело покойной ${ }^{24}$. Мунисак молодых женщин шили из самых дорогих тканей ярких цветов - прежде всего из шелка или бархата. В XIX веке жительницы Ташкента и Самарканда надевали мунисак на голову еще в течение нескольких лет после замужества не только выходя из дома, но и в доме, так как показывать свое лицо перед свекром и деверьями до рождения первого ребенка не допускалось ${ }^{25}$.

\section{Четвертая группа - халатообразные накидки}

Главной особенностью халатов данной категории являются узкие рукава, которые скреплялись на спине. Рукава данных халатов потеряли свою первоначальную функцию и, таким образом, представляли собой лишь декоративный элемент. Они имели различные названия и были широко распространены среди женщин некоторых групп узбеков, таджиков, туркмен, каракалпаков.

Чырпы (пуренжек, елек) туркменок шили из шелковой ткани домашнего изготовления. Молодые женщины носили темно-зеленые или черные чырnы, пожилые - желтые, а представительницы возрастной группы «старухи» - белого цвета. Вся поверхность халата украшалась богатой вышивкой. Этот вид наголовной одежды

\footnotetext{
22 Люшкевич Ф. Д. Одежда таджикского населения Бухарского оазиса в первой половине XX в. // Сборник Музея антропологии и этнографии. Т. 34, Л., 1978 - С. 136.

${ }^{23}$ Сухарева, О. А. История среднеазиатского костюма: Самарканд (2я половина XIX - начало XX в.). Москва, 1982 - С. 39.

${ }^{24}$ Бикжанова, М. А. Одежда узбечек Ташкента XIX - начала XX в. // Сухарева, О. А. (отв. ред.) Костюм народов Средней Азии: историко-етнографические очерки. Москва, 1979 - С. 138.

${ }^{25}$ Сухарева, О. А. История среднеазиатского костюма: Самарканд (2я половина XIX - начало XX в.). Москва, 1982 - С. 38.
} 
одевали невесты и молодые женщины в качестве праздничной одежды. Повседневные чырпьл были украшены значительно скромнее. Среди различных узоров растительного характера и композиций выделяется вышивка на чырnы текинок. Орнамент вышивки представлял собой древовидный побег, окруженный многочисленными пальметтами ${ }^{26}$, и по своей структуре и семантическому значению был аналогичен узору, украшавшему текинскую лицевую занавеску, подробно описанную выше.

У туркмен-нохурли данный тип халата, называемый елек, по крою был аналогичен чырnы текинок, но шили его из шелковой ткани красного цвета с белыми и черными полосами. Вместо вышивок елек украшали серебряными бляшками округлых форм, нашитыми на передние полы. Рукава халата были очень длинные, по краям украшенные бахромой и соединялись между собой цепочкой с монетами. Кроме елека туркмен-нохурли носили также пуренжек, отличавшийся скромной вышивкой или не имеющем ее вовсе ${ }^{27}$.

Пуренжек являлся частью ритуального головного убора туркмен-иомутов, который изготавливали из шелка зеленого цвета без подкладки, с длинными и узкими рукавами, соединенными на спине цепочкой. Широкий воротник наголовного халата всегда украшали вышивкой, представлявшей собой ветку со стилизованными листьями и цветами. Сарычки носили пуренжек аналогичного кроя, но из красного и зеленого бархата. Вместо вышивки, на сарыкскую женскую наголовную одежду нашивали серебряные украшения со вставками из сердолика, располагавшиеся по обе стороны ворота. Как и иомутки, сарычки носили пуренжек в праздничные дни вплоть до рождения первого ребенка ${ }^{28}$.

У узбеков Северного Хорезма и каракалпаков этот тип халата называли жегде. Выделяются два основных вида жегде - для молодых женщин и для пожилых. Халат молодых женщин шили из цветных тканей, чаще всего бордового цвета (кызылл жегде). На ворот и передние части пол нашивали широкую полосу из красного или черного сукна, украшенную вышивкой тамбурным и петельчатым швом. Халат пожилых женщин шили из белой ткани (ак жегде) и вышивали крестом. Кроме выше указанных двух основных видов существовали и другие, которые отличались по цвету и качеству

\footnotetext{
${ }^{26}$ Морозова, А. С. Традиционная народная одежда туркмен // Лобачева, Н. П. - Сазонова, М. В. (отв. ред.)

Традиционная одежда народов Средней Азии и Казахстана. Москва, 1989 - С. 83.

${ }^{27}$ Васильева, Г. П. Туркмены-нохурли // Толстов, С. П. - Жданко, Т. А. (отв. ред.) Среднеазиатский етнографический сборник, т. XXI. Москва, 1954 - С. 163.

${ }^{28}$ Морозова, А. С. Традиционная народная одежда туркмен // Лобачева, Н. П. - Сазонова, М. В. (отв. ред.) Традиционная одежда народов Средней Азии и Казахстана. Москва, 1989 - С. 66.
} 
ткани. Готовясь к свадьбе, невеста шила и вышивала жегде не только для себя, но и для матери жениха. Эту работу она делала с помощью родственниц - жен своих старших братьев. В конце двадцатых годов XX века жегде служил в качестве обрядовопраздничной одежды. В первой половине XX века из повседневного ношения его постепенно вытеснял большой платок, который повязывали поверх высокого головного убора. Тем не менее, данный халат сохранялся почти в каждой семье как семейная реликвия и являлся также обязательной частью приданого ${ }^{29}$.

Уличной одеждой узбекских и таджикских женщин-горожанок была паранджа, которую носили с чачваном - прямоугольной сеткой, сплетенной из черных конских волос, которая закрывала лицо женщины. Ношение паранджи и чачвана соответствовало исламским нормам, согласно которым лицо и тело женщины должно быть полностью закрыто от посторонних глаз. В середине XIX века, с начала распространения этого вида наголовной одежды в традиционной городской культуре Средней Азии, паранджу изготавливали из хлопчатобумажной серой ткани. В конце XIX века в богатых семьях шили данные халаты из местного и привозного шелка и атласа со сотканным китайским узором, который ввозился из Кашгара. Паранджу также украшали вышивкой. ${ }^{30}$ Первую паранджу получила молодая женщина в возрасте 9 лет. Невеста получила на свадьбу еще одну или две паранджи, в богатых семьях даже четыре из дорогих тканей. Ношение, надевание и снимание паранджи должно следовать правилам.

Чачван одевался под паранджу и завязывался сзади специальными тесемками на головной убор, сверху набрасывали паранджу и за тем откидывали чачван назад. Когда выходили из ворот, то его накидывали на лицо. Основой для этого обычая является негативное отношение к черному цвету чачвана, который, согласно традиционным представлениям, мог накликать несчастье. Это явление было можно заметить на свадьбе, когда невесту, закрытую паранджой, везли в дом жениха, ее лицо закрывали вместо чачвана белой тканью, которая должна была привлекать счастье. В редких случаях использовали чачван, изготовленный из белого конского волоса. Приходя в чужой дом, женщина сама снимала чачван, а паранджу ей снимала хозяйка дома, проявляя, таким образом, уважение к гостье. При уходе паранджу также надевали

\footnotetext{
29 Лобачева, Н. П. Каракалпакские головные накидки // Лобачева, Н. П. - Сазонова, М. В. (отв. ред.) Традиционная одежда народов Средней Азии и Казахстана. Москва, 1989 - С. 171-172, 181.

${ }^{30}$ Бикжанова, М. А. Одежда узбечек Ташкента XIX - начала XX в. // Сухарева, О. А. (отв. ред.) Костюм народов Средней Азии: историко-етнографические очерки. Москва, 1979 - С. 142.
} 
хозяева дома ${ }^{31}$. В начале XX века была паранджа в Ташкенте введена в похоронные обряды ${ }^{32}$.

Значительно варьировалась манера ношения паранджи: ташкентские жительницы набрасывали ее верхний край высоко на темя, в Намангане надвигали низко на лоб ${ }^{33}$, некоторые горожанки плотно завязывали передние полы с помощью шелковых шнуров, пришитых к нижней части ворота или скрепляли их ювелирными застежками. Паранджа, обычно серого цвета, как элемент, нивелирующий столь важные для традиционного общества возрастные характеристики женщин, не являлся частью старинного традиционного женского костюма. Только в начале XX века начинают появляться яркие бархатные и шелковые халаты - накидки, отражавшие возрастные и социальные характеристики его владелицы. Следует также отметить, что паранджа не была характерна для повседневного костюма сельских жительниц, ее носили в Гиссаре, Каратаге и административных центрах Куляба, Каратегина и Дарваза, где проживали жены бухарских чиновников ${ }^{34}$. Однако, она иногда могла являться частью свадебного костюма. Так, например, в верховьях Зеравшана паранджа использовалась в брачных ритуалах.

Хотелось бы отметить также, что паранджа бытовала не только среди мусульманского населения Средней Азии, но и в костюме бухарских евреев, хотя ни религия, ни традиции древнего еврейского костюма не требовали, чтобы еврейки скрывали от посторонних лицо и фигуру. Она являлась частью «внешнего» уличного костюма, предназначенного для мусульманского окружения ${ }^{35}$ и позволяла максимально нивелировать образ женщины- иудейки постоянно проживавшей среди представителей исламской религии.

Женщины, живущие в кишлаках Центрального Таджикистана (Гиссар, Каратаг, Душанбе) накидки-халаты носили только в пределах своего кишлака, но если они отправлялись на дальние расстояния или в город, то всегда предпочитали паранджу. Таким образом наголовный халат вероятно воспринимался частью местного

\footnotetext{
${ }^{31}$ Сухарева, О. А. История среднеазиатского костюма: Самарканд (2я половина XIX - начало XX в.). Москва, 1982 - С. 44.

${ }^{32}$ Бикжанова, М. А. Одежда узбечек Ташкента XIX - начала XX в. // Сухарева, О. А. (отв. ред.) Костюм народов Средней Азии: историко-етнографические очерки. Москва, 1979 - С. 141.

${ }_{33}$ Наливкин В., Наливкина М. Очерк быта женщины оседлого туземного населения Ферганы. - Казань, 1886 - С. 96

${ }^{34}$ Широкова 3.А. Традиционная и современная одежда женщин горного Таджикистана. - Душанбе, 1976 - C. 82 .

${ }^{35}$ Емельяненко Т.Г. Традиционный костюм бухарских евреев. - СПб, 2012 - С. 177
} 
традиционного костюма, не вполне уместный для городской традиции, которая декларировала полное закрытие всей женской фигуры. Халат-накидка имел длину около метра и соответственно закрывал фигуру только до верхней части бедер. Характерной особенностью манеры ношения такой накидки являлось то, что лицо женщины никогда не было полностью закрыто. Придерживая одну из пол халата рукой женщины прикрывали нижнюю часть лица, глаза же всегда оставались открытыми. В Каратегине, Кулябе и Дарвазе халатообразные накидки также считались обязательными элементами женской уличной одежды ${ }^{36}$.

У таджиков Матчинского района был обычай, что перед отъездом новобрачной из своего дома пожилая уважаемая женщина надевала на невесту наголовную накидку чодар, которая представляет собой доходящий до середины голени халат с ложными рукавами, известный в научной литературе под термином «паранджа». В каждом кишлаке существовали свои цветовые и орнаментальные предпочтения для данного элемента свадебной одежды, однако семантический смысл орнаментов (павлины, цветы, растительные побеги) был общим и являлся благопожеланием молодой семье. Под чодар обязательно надевали белый шелковый большой платок, который складывали по диагонали и затем набрасывали на голову таки образом, чтобы передняя часть закрывала лицо и шею девушки. Чодар имелся не в каждой семье и передавался из одного дома в другой по необходимости. Если девушка жила в другом кишлаке, то семья будущего мужа привозила наголовный халат из своего поселка, так как он должен был демонстрировать принадлежность молодой к определенной семейно-родственной группе. ${ }^{37}$ Таким образом, можно выделить два принципиальных отличия паранджи и наголовного халата. Первая предназначалась для полного закрытия женщины, ее фигуры и лица, халат прикрывал женщину сзади и по бокам, оставляя приоткрытым лицо, переднюю часть фигуры. Соответственно модно было увидеть детали костюма (головной убор, платье верхнюю одежду), которые маркировали возрастные особенности женщины, что было важно в рамках местной традиционной культуры. Немаловажную роль играл цвет и материал головной накидки-халата. Тогда как паранджа практически полностью нивелировала возрастные признаки, а благодаря тому, что шили ее преимущественно из

\footnotetext{
${ }^{36}$ Широкова 3.А. Традиционная и современная одежда женщин горного Таджикистана. - Душанбе, 1976 - C. 82

${ }^{37}$ Данные полевого исследования, проведенного О. В. Старостиной в Матчинском районе Согдийской области, получены в 2018 году из рассказов местных пожилых женщин, которым матери рассказали о своей свадьбе. Чодар используется в этой области точно так же и в настоящее время.
} 
серой хлопчатобумажной ткани происходило полное обезличивание женщиныгорожанки.

\section{Заключение}

Анализ традиционных форм данного вида одежды в связи с обрядовыми и повседневными практиками показывает, что «скрывание» женщины в наибольшей степени проявлялось в рамках свадебных церемоний, где наиболее широко использовались платки и лицевые занавески, а также халатообразные накидки и даже обычные халаты. Особую роль играет паранджа, которая редко применялась в свадебных обрядах и использовалась скорее как уличная одежда женщин в городской среде. В повседневной жизни женщины использовали, прежде всего, платки и халаты. Халаты постепенно стали скорее праздничным и ритуальным видом одежды. Кроме свадебных обрядов, они применялись и в погребальных ритуалах - их одевали в период траура или использовали для покрытия тела умершей женщины; это относится к мунисаку, который в начале XX века почти исчез из свадебных обрядов и использовался как погребальная одежда. Халатообразные накидки также постепенно становились преимущественно праздничной и обрядовой одеждой. Примером может служить каракалпакская халатообразная накидка жегде, которая в середине XX века в повседневном употреблении была заменена большим платком, повязанным вокруг чалмы.

Согласимся с О. А. Сухаревой, которая предполагает, что традиция «закрывания» женщины, характерная для многих народов Средней Азии, связана с древним обычаем защиты женщин в переходные периоды ее жизни, когда ей могли повредить злые духи ${ }^{38}$. Как уже отмечалось, «скрывание» женщин наиболее ярко проявлялось в свадебных обрядах. В свадебных ритуалах, относящихся к переходным обрядовым действиям аналогичным родильным и погребальным, уход девушки из семьи родителей рассматривается как символическая смерть, а появление в семье мужа как рождение нового члена семьи. Все время с момента бракосочетания в доме отца и до первой брачной ночи (a, у некоторых народов до рождения ребенка) молодая находится в неопределенном статусе - она уже умерла и еще не родилась. Соответственно, ее связь с миром духов (мертвых) значительно усиливается. Кроме

\footnotetext{
${ }^{38}$ Сухарева, О. А. История среднеазиатского костюма: Самарканд (2я половина XIX - начало XX в.). Москва, 1982 - С. 40-41.
} 
того, она теряет сакральную защиту своей семьи, а защиту семьи супруга еще не приобретает, поэтому женщина нуждается в особой защите, которая обеспечивается как большим количеством украшений, оберегов, амулетов, так и закрытием ее лица и фигуры от внешнего мира, в котором она особенно уязвима для сглаза, джиннов и различных демонических существ.

«Скрывание» являлось особенно социальным знаком, который связан с обычаем избегания невестой родни мужа мужского пола. Это отражало положение женщины в семье. Позже, под влиянием ислама, пробились религиозные предписания, благодаря которым появилась одежда паранджа.

При анализе особенностей возрастного бытования скрывающей одежды возможно выделить следующие аспекты. Для жительниц среднеазиатских городов, узбечек и таджичек, характерно более ранее начало ее использования. Как отмечалось выше, первую паранджу девушка одевала в период полового созревания, то есть вступления в возрастную группу невест, что соответствовала нормам исламской этики $^{39}$ и шариату, которые получили широкое распространение среди городского населения. Сельское оседлое население и кочевники, которые, безусловно, также являлись мусульманами, следовали адату - нормам обычного права и этики принятым в той или иной местности и также были включены в исламскую культуру, но значительно превалировали. В данных культурных традициях скрывание женщины начиналось с брачных церемоний и продолжалось на протяжении всего фертильного возраста до перехода в возрастную группу старух.

\footnotetext{
${ }^{39}$ Коран. 24:31, 33:59.
} 


\section{Каталог}

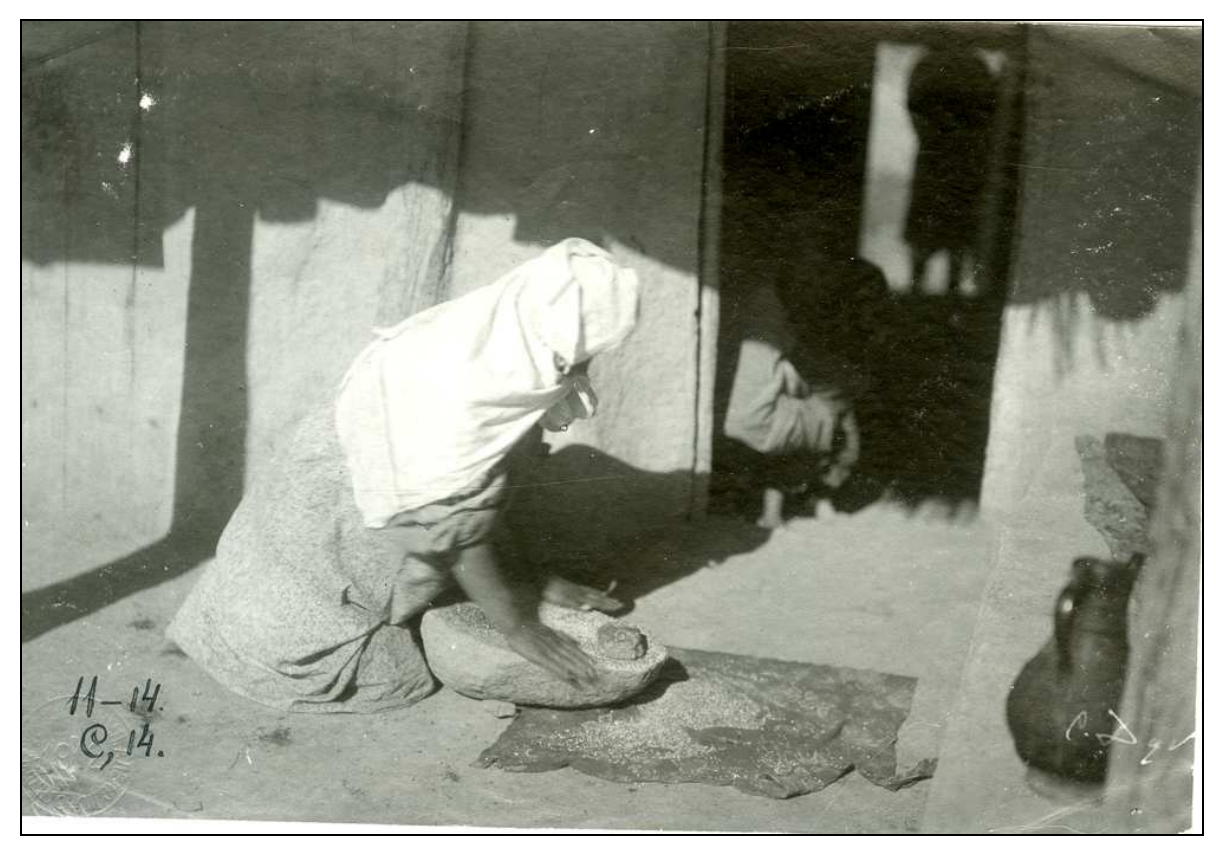

Рис. 1 Женщина с зернотёркой (демонстрирует манеру наматывания верхнего платка, закрывающего фигуру до пояса). Таджики, 1901 г., Сырдарьинская область. Инв. № 11-14, Российский этнографический музей.

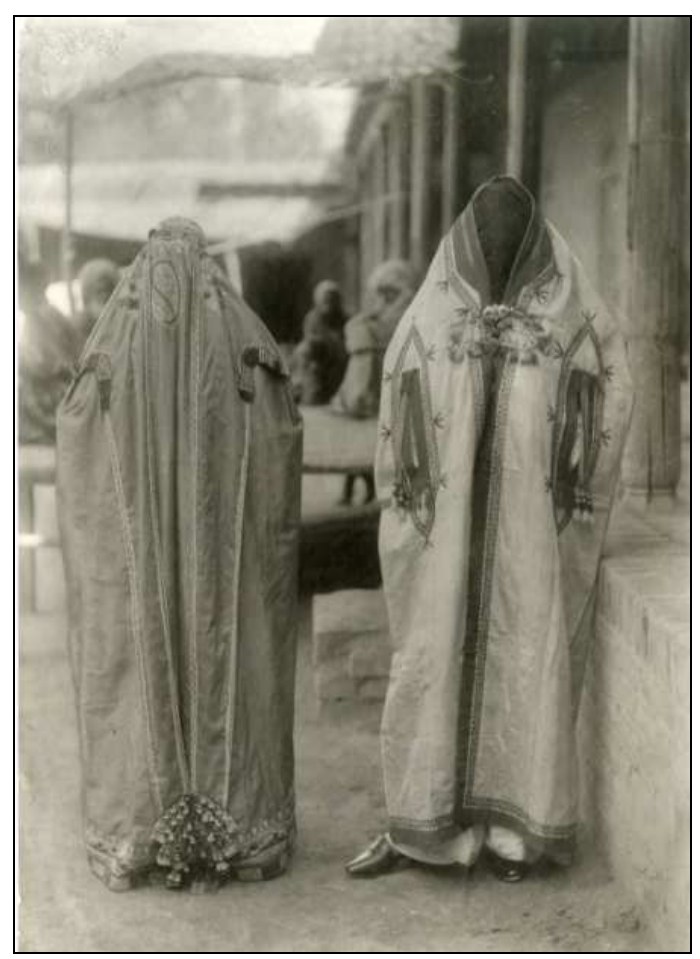

Рис. 2 Горожанки в паранджах. Узбеки, таджики, 1901 г., Бухарский эмират. Инв. № 48-343, Российский этнографический музей. 


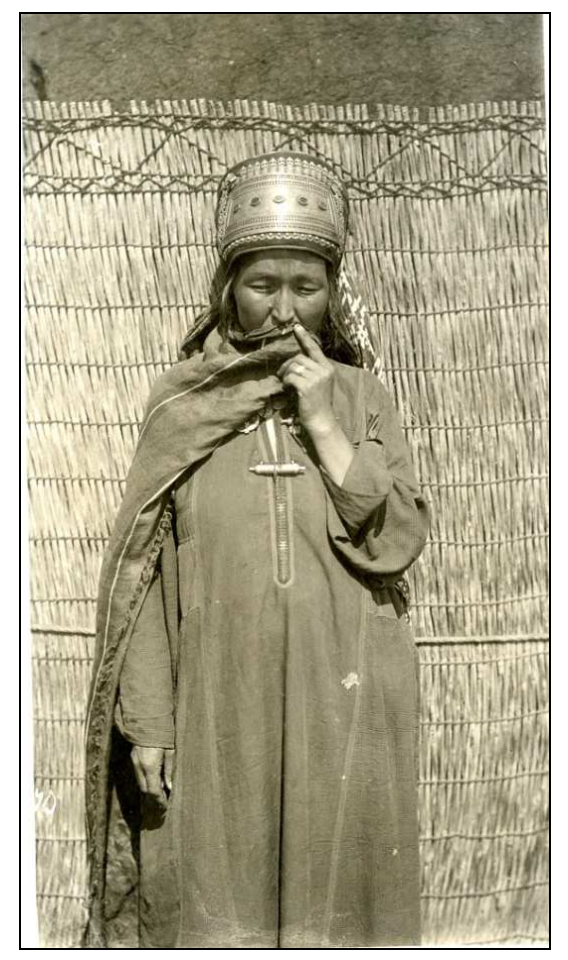

Рис. 3 Замужняя женщина (демонстрирует манеру закрывания рта платком). Туркмены, 1900-1901 гг. Закаспийская область. Инв. № 40-45, Российский этнографический музей.

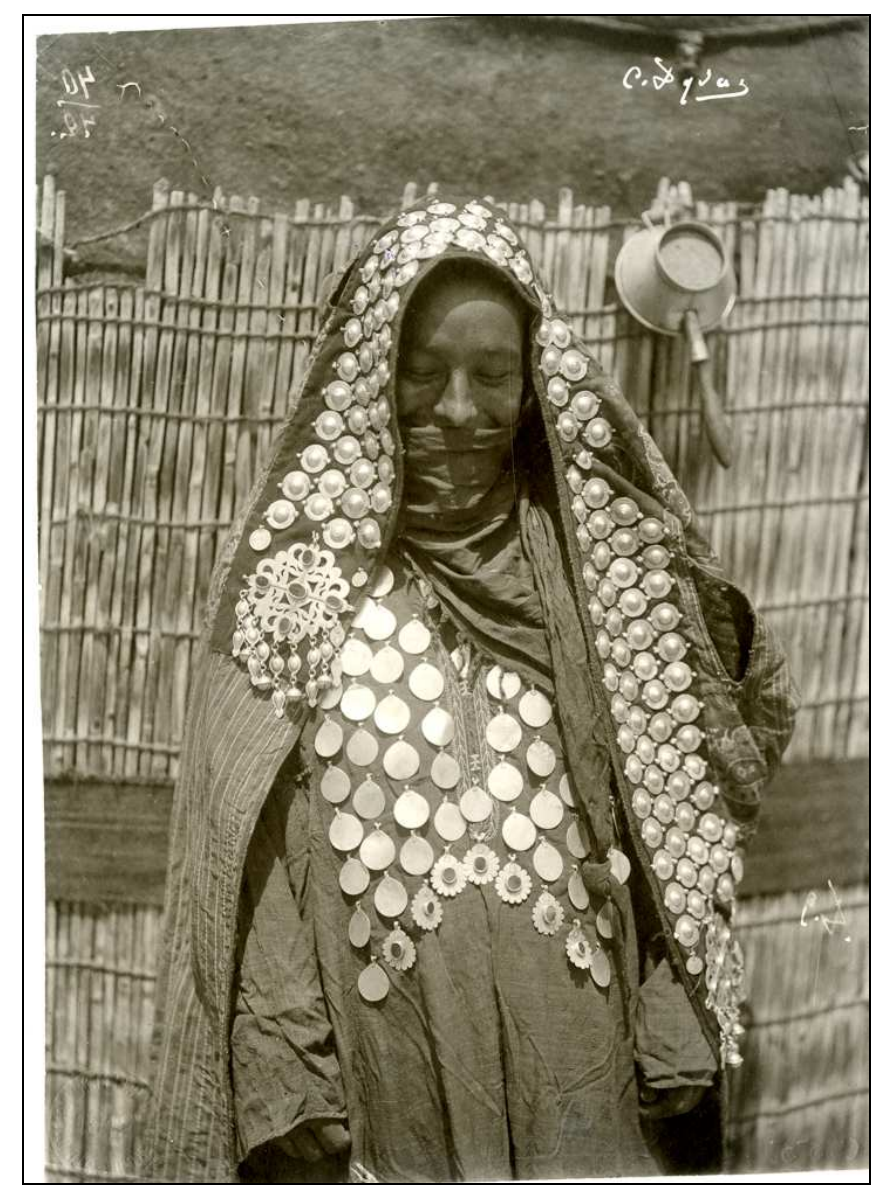

Рис. 4 Женщина в наголовной накидке. Туркмены, 1900-1901 гг. Закаспийская область. Инв. № 4042, Российский этнографический музей. 


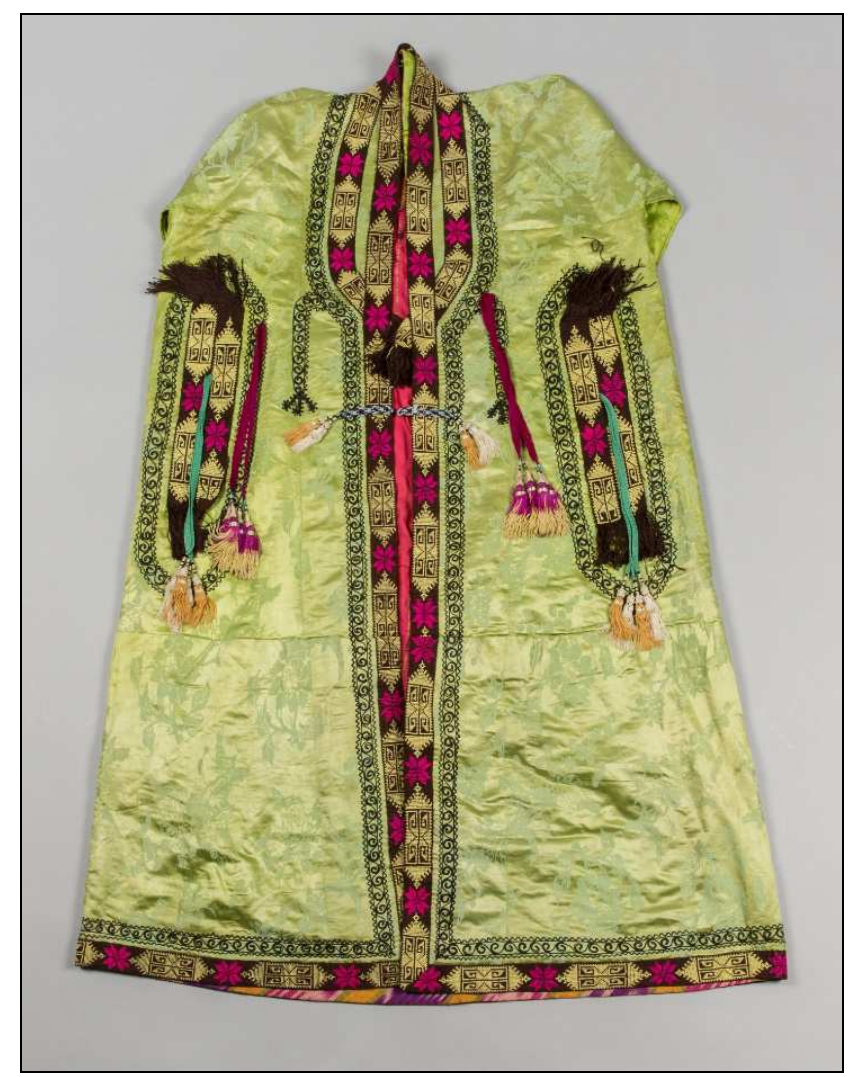

Рис. 5 Паранджа. Узбеки, начало ХХ века, Ташкент. Шелк, атлас, вышивка шелком, д. 147 см, ш. 202 см. Инв. № 12850-3, Российский этнографический музей.

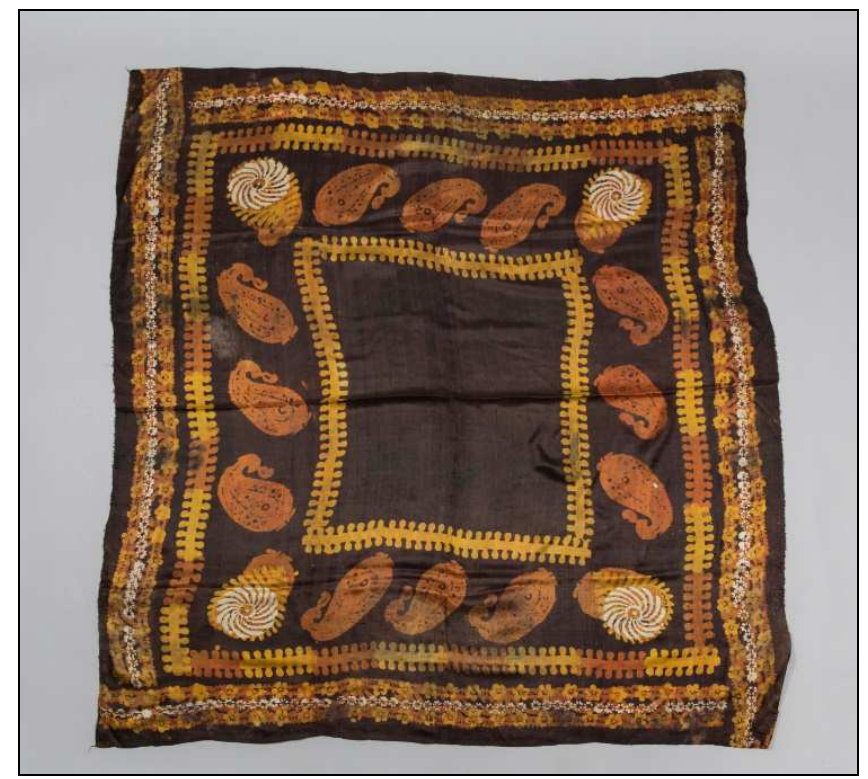

Рис. 6 Платок головной. Узбеки, последняя треть ХІХ в., Бухара. Шелк, д. 135 см, ш. 188 см. Инв. № 20-151, Российский этнографический музей. 


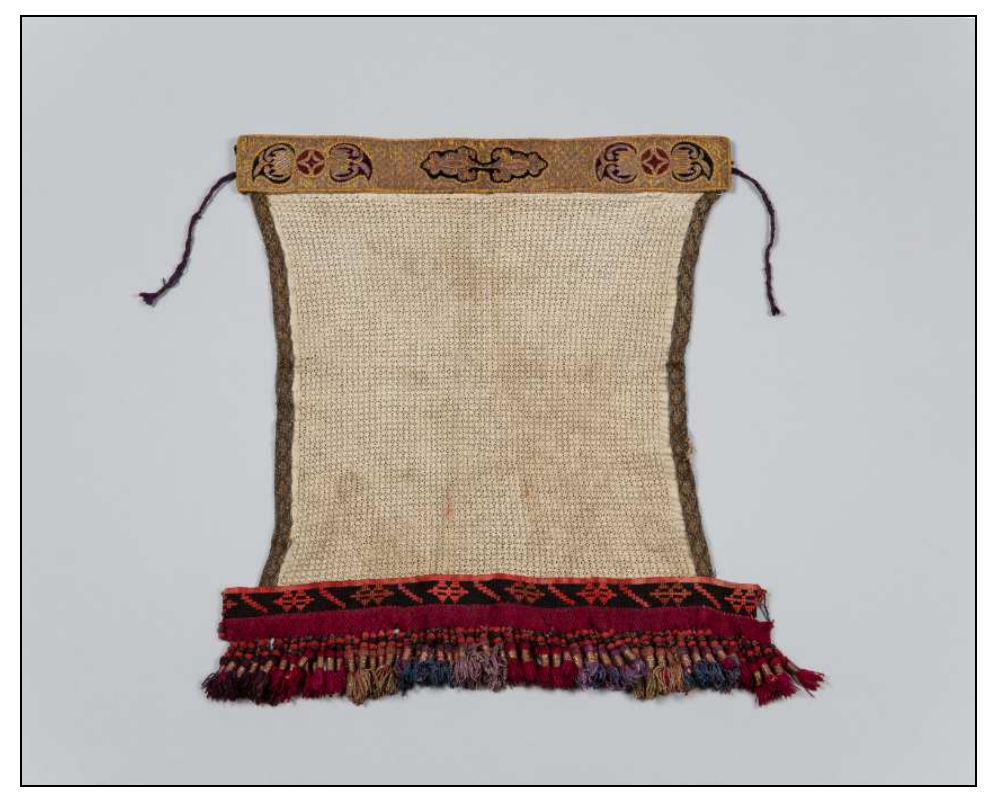

Рис. 7 Лицевая занавеска. Кыргызы, конец XIX - начало XX в., Южный Кыргызстан. Хлопок, шелк, золотое шитье, Д. 41 см, ш. 36,5 см. Инв. № 13098-3, Российский этнографический музей.

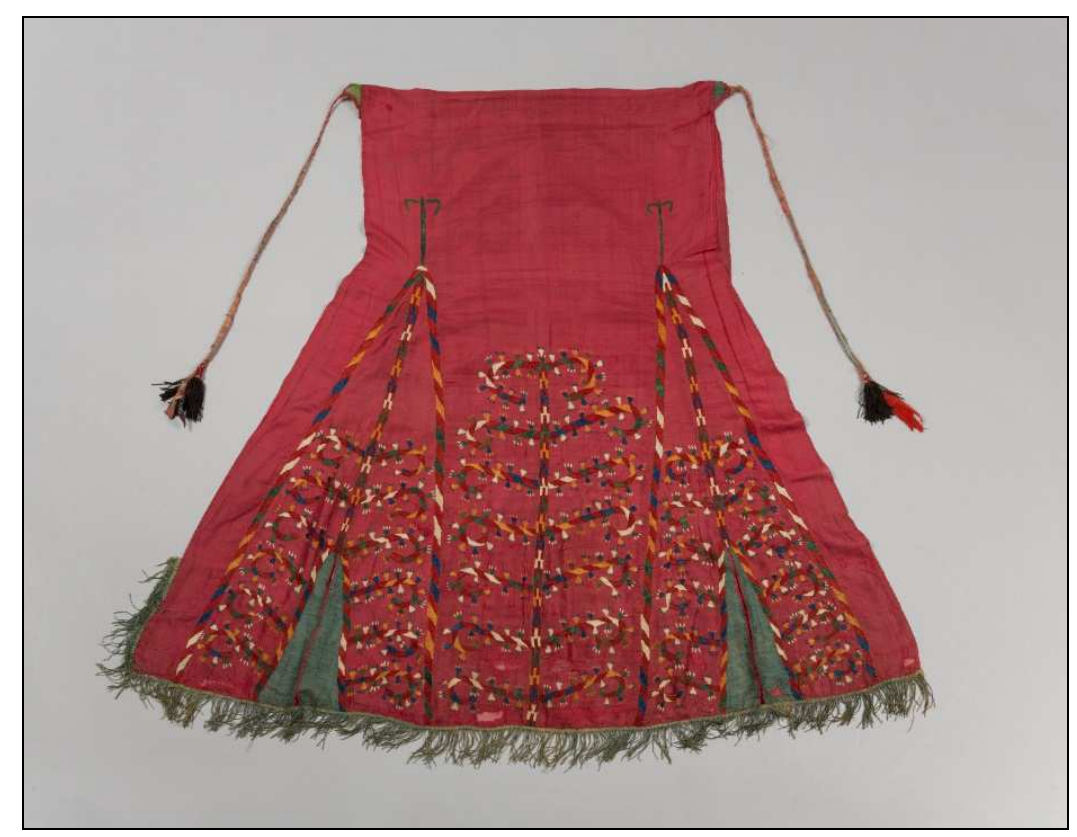

Рис. 8 Лицевая занавеска. Туркмены, конец XIX в., Закаспийский регион. Шелк, вышивка шелком, д. 134 см, ш. 108 см. Инв. № 8762-22579, Российский этнографический музей. 


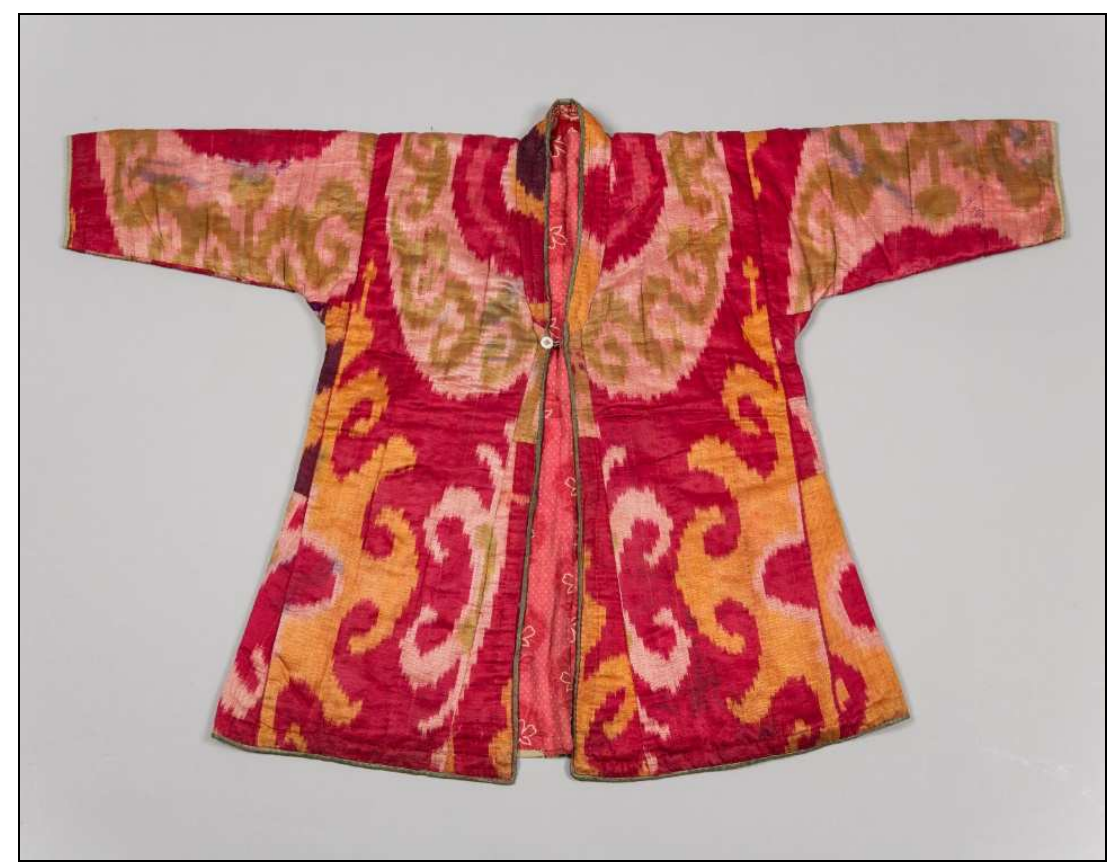

Рис. 9 Халат детский. Таджики, конец XIX в., Самарканд. Полушелковая и хлопчатобумажная ткань, д. 58 см, Ш. спинки 36 см. Инв. № 58-9, Российский этнографический музей.

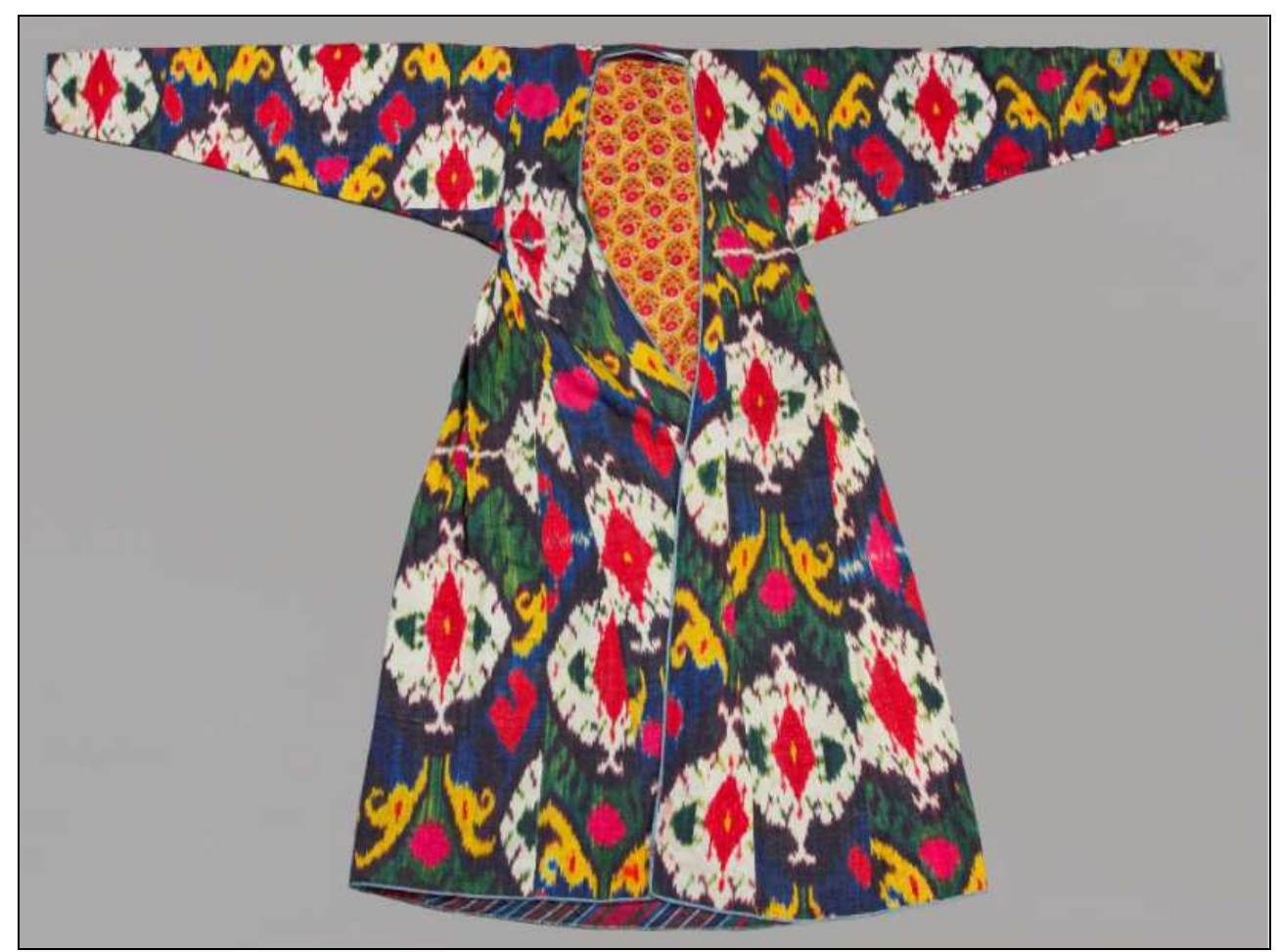

Рис. 10 Халат калтача. Таджики, конец ХIX века, Бухарский эмират. Полушелковая ткань, д. 129 см, ш. спины 45 см. Инв. № 59-3, Российский этнографический музей. 


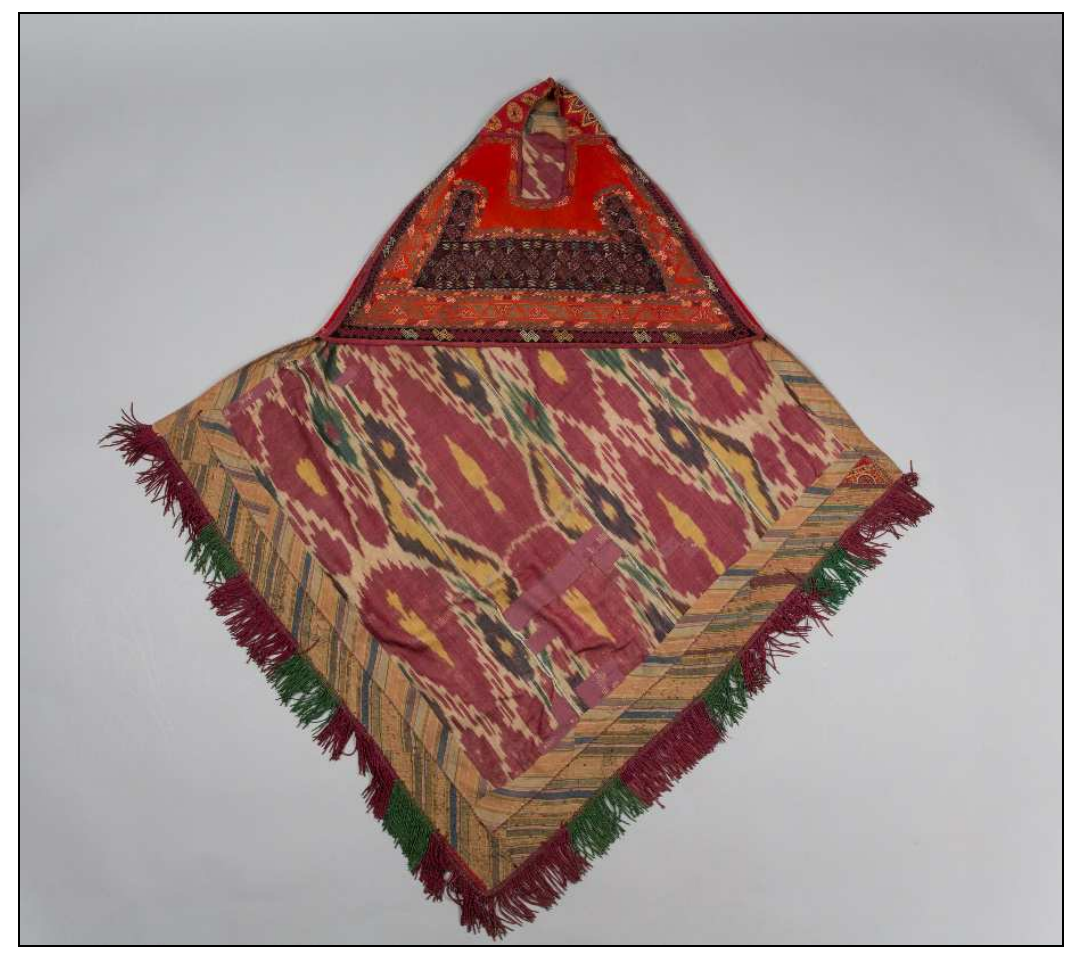

Рис. 11 Женский нижний головной убор кимешек. Каракалпаки, 1910 гг. Дельта Амударьи. Сукно, шелк, вышивка шелком, инв. № 7128-87, Российский этнографический музей.

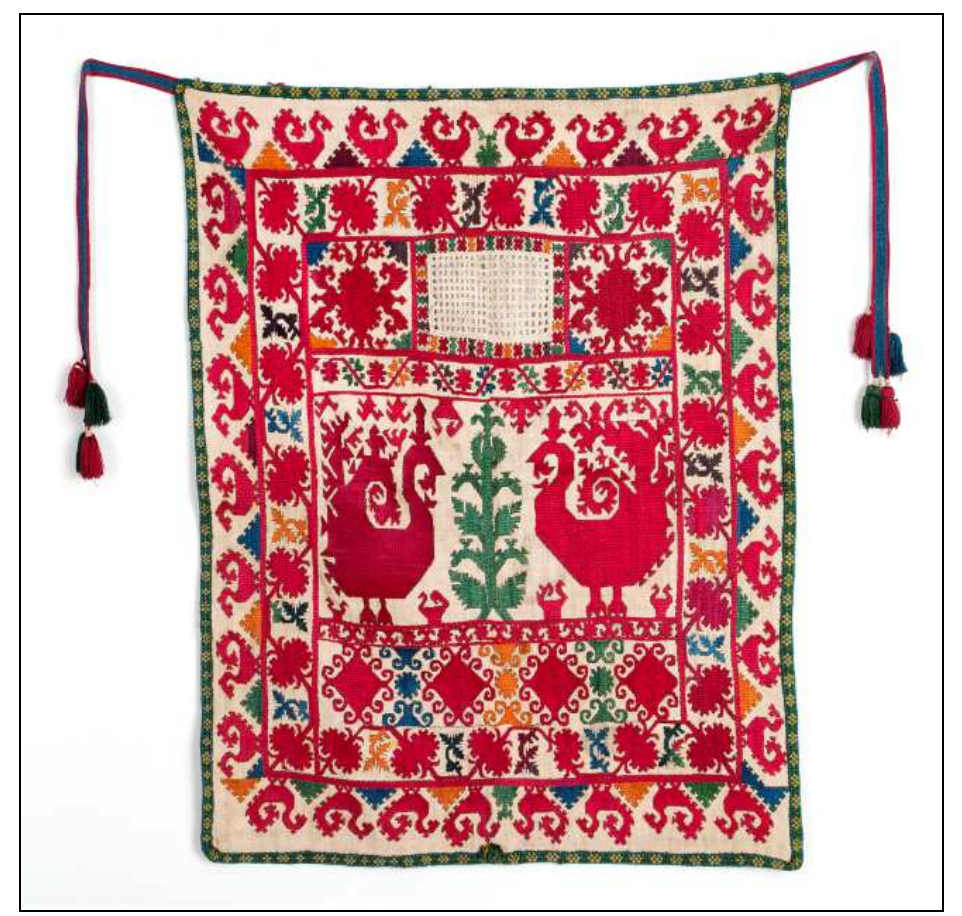

Рис. 12 Лицевая занавеска рубанд. Таджики, Дарваз. Конец ХІХ века. Хлопок, вышивка шелком, 71 x 56 cм. Inv. No. А 18 379, Национальный музей - Музей Напрстека. 


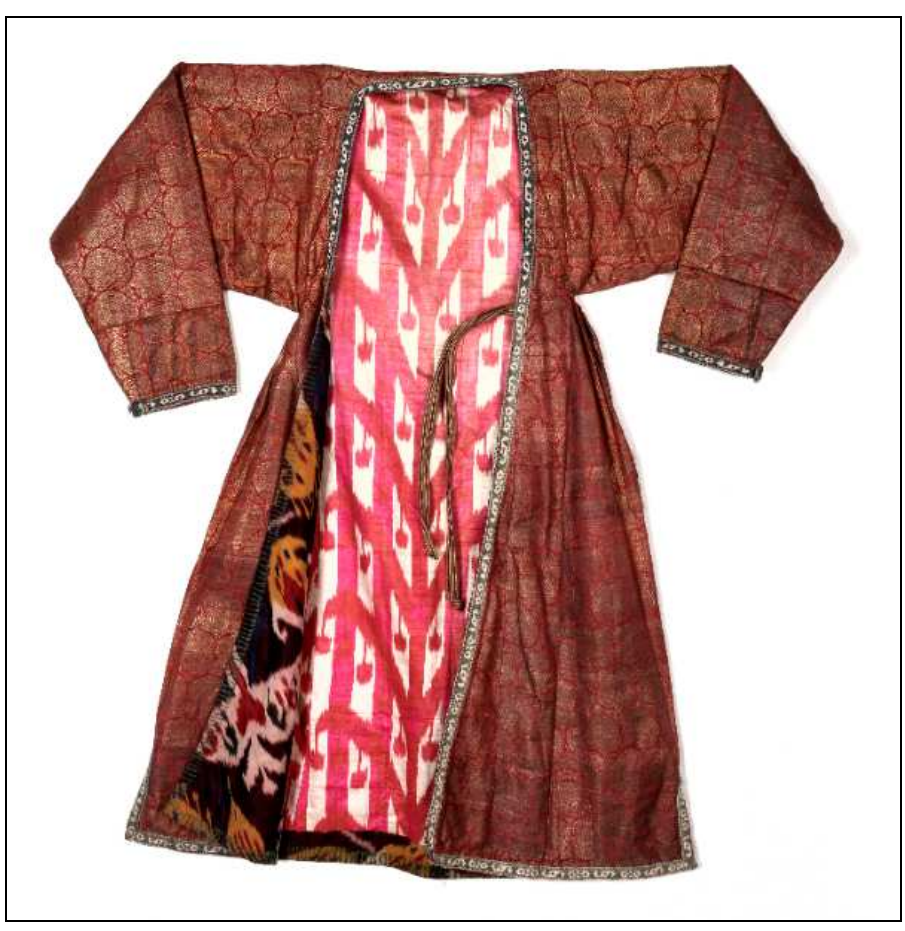

Рис. 13 Халат мунисак. Узбеки, Самарканд. Конец XIX - начало XX века. Шелковая парча, подкладка из шелкового иката, д. 132 см. Инв. № А 18 432, Национальный музей - Музей Напрстека.

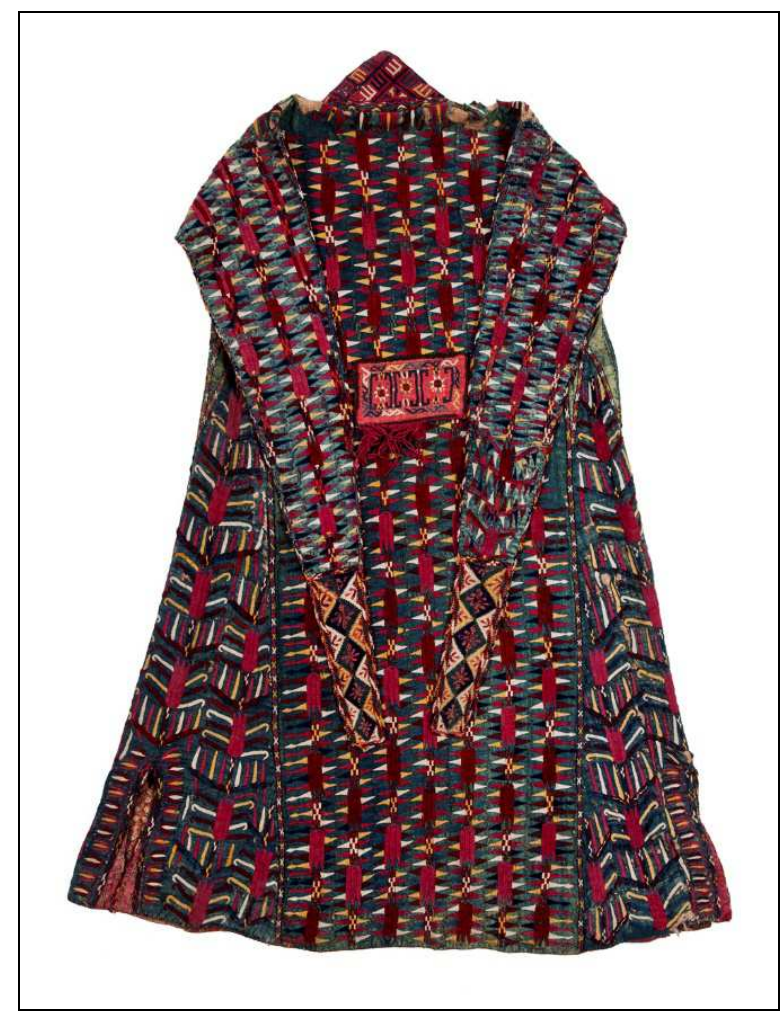

Рис. 14 Наголовная накидка чырпы. Туркмены-текинцы, 1840 гг. Хлопок, вышивка шелком, д. 110 см. Инв. № A31638, Национальный музей - Музей Напрстека. 


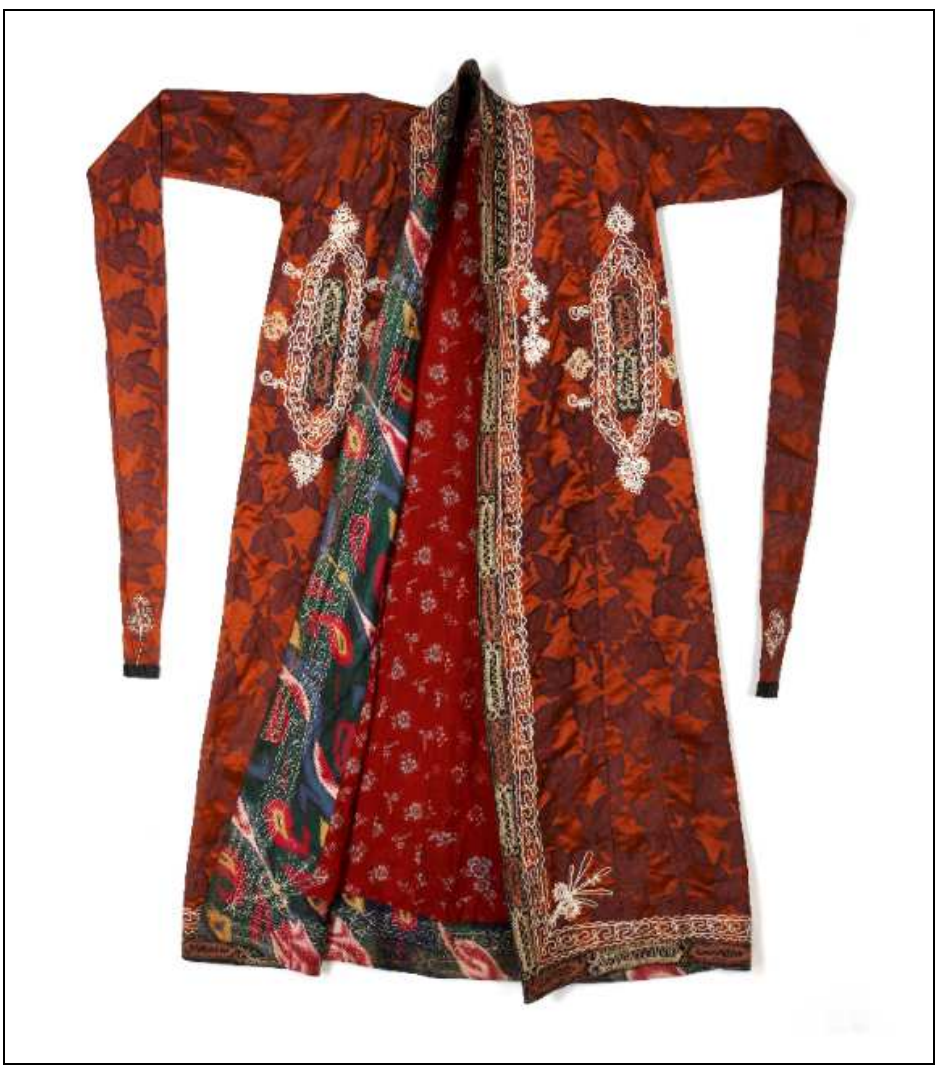

Рис. 15 Паранджа. Узбекистан. Начало ХХ века. Шелк, хлопковая подкладка, машинная вышивка шелком, тамбурный шов, Д. 139 см, ш. 44 см. Инв. № 22 744, Национальный музей - Музей Напрстека. 


\section{Использованные источники}

АНТИПИНА, Клавдия Ивановна. Особенности материальной культуры и прикладного искусства южных киргизов. Фрунзе: Изд-во АН Кирг. ССР, 1962.

БОБРИНСКИЙ, Алексей Александрович. О некоторых символических знаках общих первобытной орнаментике всех народов Европы и Азии. Москва: Т-во тип. А. И. Мамонтова, 1902.

БИКЖАНОВА, Муршида Абдулловна. Одежда узбечек Ташкента XIX - начала XX в. In CУХАРЕВА, О. А. (отв. ред.) Костюм народов Средней Азии: историкоетнографические очерки. Москва: Наука, 1979, с. 133-151.

ВАСИЛЬЕВА, Галина Петровна. Туркмены - нохурли. Толстов, С. П. - Жданко, Т. А. (отв. ред.) Среднеазиатский етнографический сборник, т. XXI. Москва: Наука, 1954, c. $82-215$.

ЕМЕЛЬЯНЕНКО, Татьяна Григорьевна. Традиционный костюм бухарских евреев. Санкт-Петербург: Петербургское востоковедение, 2012.

КИСЛЯКОВ, Николай Андреевич. Очерки по истории семьи и брака у народов Средней Азии и Казахстана. Ленинград: Наука, 1969.

Материалы по древним верованиям горных таджиков. Страны и народы. Вып. XXVI., Кн. 3. Москва: Наука, 1989, с. 249-268.

ЛОБАЧЕВА, Нина Петровна. К истории среднеазиатского костюма (женские головные накидки-халаты). Советская этнография, № 6, 1965 с. 34-49.

Каракалпакские головные накидки. Лобачева, Н. П. - Сазонова, М. В. (отв. ред.) Традиционная одежда народов Средней Азии и Казахстана. Москва: Наука, 1989. c. $169-181$.

ЛЮШКЕВИЧ, Фаня Давидовна. Одежда таджикского населения Бухарского оазиса в первой половине XX в. Сборник Музея антропологии и этнографии. Т. 34, Ленинград, 1978, с. 123-144.

MOРОЗОВА, Анна Степановна. Головные уборы туркмен (по коллекциям ГМЭ). Тр. Ин-та истории, археологии и этнографии Туркменской ССР. Т. VII. Москва, 1963 c. 81-118.

Традиционная народная одежда туркмен. Лобачева, Н. П. - Сазонова, М. В. (отв. ред.) Традищионная одежда народов Средней Азии и Казахстана. Москва: Наука, 1989, c. 39-89.

НАЛИВКИН, Владимир Петрович, НАЛИВКИНА, Мария Владимировна. Очерк быта женщины туземного населения Ферганы. Казань: Типография Императорского университета, 1886.

СУХАРЕВА, Ольга Александровна. К истории развития самаркандской декоративной вышивки. Литература и искусство Узбекистана. Кн. 6. Ташкент, 1937, с.119134.

Опыт анализа покроев традиционной «туникообразной» среднеазиатской одежды в плане их истории и эволюции. Сухарева, О. А. (отв. ред.) Костюм народов Средней Азии: историко-етнографические очерки. Москва: Наука, 1979, с. 77-102.

История среднеазиатского костюма: Самарканд (2я половина XIX - начало XX в.). Москва: Наука, 1982.

ШИРОКОВА, Зинаида Александровна. Традиџионная и современная одежда женщин горного Таджикистана. Душанбе: Дониш, 1976. 


\title{
Political invention of the World Nomad Games in Kyrgyzstan
}

\author{
Arzuu Sheranova \\ Corvinus University of Budapest, Doctoral School of International Relations and Political Science, Hungary \\ Email: arzuu.sheranova@stud.uni-corvinus.hu
}

DOI: https://doi.org/10.7160/KS.2021.170203

\begin{abstract}
This paper examines 'invention' of a new 'tradition', that is of nomadic games in Kyrgyzstan blessed by its prehistoric past of nomadism. Since 2012 the Kyrgyz government had introduced the World Nomad Games (the WNGs) in Kyrgyzstan. The country hosted three spectacular games in the northern oblast of the country - Yssyk-Kul. Hundreds of sportsmen worldwide took part in these events and thousands of tourists rushed into the country to watch the games. In fact, Kyrgyz nomadic games are more than just a revival of old nomadic traditions, but they are political inventions. Using Hobsbawm's framework of 'invented traditions' (1983), I examine the World Nomad Games as invented tradition. I argue that the Kyrgyz leadership invented tradition of nomadic games to tackle with contemporary issues, such as a need for attraction of foreign investment and promotion of tourism. As I illustrate the WNGs project was a timely response to improve the country image after a series of political instabilities the country underwent in its recent history.
\end{abstract}

\section{Keywords}

invented traditions, games, nomad, nomadic, the World Nomad Games, foreign investment, tourism, Kyrgyzstan

\section{Introduction}

The early years of Kyrgyzstan's independence were marked by large national projects, such as Manas epic's 1000-year anniversary celebration in 1995, Osh city's 3000-year anniversary in 2000, and Kyrgyzstan's 2200-year anniversary in 2003. After a nearly a decade of 'silence', it was only in 2012, when Kyrgyzstan again invested into spectacular mass events under the slogan of nomadism. Almazbek Atambaev's leadership introduced to the world the World Nomad Games ${ }^{1}$ during the Summit of the Turkic Council in 2012, and the Turkic Council member-states unanimously supported this idea. It was only on $19^{\text {th }}$ of May 2014 when the Kyrgyz government issued a decree announcing preparations for the first WNGs. The decree

\footnotetext{
${ }^{1}$ In Kyrgyz Duinoluk Kochmondor Oiundary, in Russian Vsemirnye Igry Kochevnikov (in brief VIK).
} 
outlined the Organization Committee of the WNGs and other responsible bodies. It was decided that the nomad games project would 'sell' to international spectators Kyrgyz nomadic history, nomadic culture and traditions. Thus the World Nomad Games offered three main thematic components: sports games, a cultural part and a scientific part. Overall, the project was aimed at promotion of international tolerance and diversity. These games claimed to be a nomadic alternative of the World Olympic Games, with 37 kinds of nomadic sports, starting from hunting and horse riding, and finishing with arm-wrestling and intellectual games.

There is a large literature on cultural performances and sports. Major group of existing scholarship examines theatre and performances as politically active and points out to their ability to affect national identities. ${ }^{2}$ For instance, a volume edited by Nadine Holdsworth states that "theatre is part of an ongoing dialogue, a constant re-imagining of what the nation is, constitutes and means in any given moment." (emphasis original) ${ }^{3}$ This collection of essays illustrates how theatre and performances present and contest ideas about nation and national identity:

"The theatre, taking place in a communal public arena, can be one of the ways that members of a nation contribute to public discourse, a national conversation, which opens up the possibility for reflection and debate."

Helen Gilbert's remarks are also strong in this sense:

"Always ... theatre becomes, at formative moments in the ongoing narrative of nationhood, a means by which communities register, reiterate and/or contest modes and models of national belonging."

As Billig put the power of performances or theatres in inducing a national identity lays in overstatement of the word 'we' and 'us' as people belonging to one nation'. Likewise Hurley ${ }^{7}$ in her study observed that performances become 'national' due to 'representational' and 'emotional' 'labors'. She wrote that representational labors which induce nationness are performances which are based on largely accepted existing beliefs or ideas about a nation. Emotional labors are those performances which also generate and experience strong shared emotions and feelings of unity. This is especially true in small nations like Scotts and

\footnotetext{
${ }^{2}$ see Gounaridou 2005, Hurley 2011, Holdsworth 2014

${ }^{3}$ HOLDSWORTH, Nadine. Theatre and National Identity. Re-imagining Conceptions of Nation. New York: Routledge, 2014, p. 3.

${ }^{4}$ HOLDSWORTH, Nadine. $c . d$., Introduction.

${ }^{5}$ HOLDSWORTH, Nadine. $c . d$., p. 2.

${ }^{6}$ EDENSOR, Tim. National Identity, Popular Culture and Everyday Life. Berg: Oxford, 2002, p.11.

${ }^{7}$ HURLEY, Erin. National Performance: Representing Quebec from Expo 67 to Céline Dion. Toronto: University of Toronto Press, 2011.
} 
Catalans who see theatre as a way of expressing their national distinctiveness vis-à-vis big nations ${ }^{8}$.

In his seminal work Smith wrote that "distinctive ethnic histories, ethnic myths and territorial associations"9 are key resources of modern nationalism. National heroes, national myths and national histories are sources of deep feelings of dignity (ibid.). Theatres and performances representing these 'deep' motifs might serve as powerful tools for the emergence of nationalism. As Smith put nations glorify their 'golden age' or are proud of an "era distinguished for its collective dignity and external prestige"10. Golden ages are important because they inspire and motivate national 'regeneration':

"This is important, exactly because most nationalisms, viewed from inside, start out from a sense of decline, alienation and inner exile, and go on to promise renewal, reintegration and restoration to a former glorious state." 11

And they emphasize a feeling of 'collective destiny':

"The road that the community expects to take in each generation is inspired and shaped by its memories of former heroic ages. Their values and symbols form the basis and spur to heroic feats of communal self-sacrifice in the future, a future that can become as glorious and fulfilling as the days of old." ${ }^{2}$

In post-Soviet space too theatre and performances were used to build new ideologies and nationalisms. For instance, Laura Adams ${ }^{13}$ examines how the Uzbek state used so-called 'spectacles' on national celebrations to construct a new nation. For Adams it was striking to observe that the same officials who were involved in building communism during the Soviet era were involved in building a new Uzbek nation after the Soviet collapse ${ }^{14}$. In the age of nationalism, nations which do not possess rich ethno-histories, lack beliefs of religious election or do not have shared myths or sacred lands had to 'invent' them. ${ }^{15}$ Post-Soviet Central Asian states were not exceptions to this rule. During a period of early independence, the leaders of these countries re-wrote national histories, invented national myths and

\footnotetext{
${ }^{8}$ BLANDFORD, Steve. ed. Theatre and Performance in Small Nations. Bristol: Intellect, 2013.

${ }^{9}$ SMITH, Anthony. Myths and Memories of the Nation. New York: Oxford University Press, 1999, p. 255.

${ }^{10}$ SMITH, Anthony. c. d., p. 263.

${ }^{11}$ SMITH, Anthony. c. d., p. 264.

12 Ibidem

${ }^{13}$ ADAMS, Laura. The Spectacular State: Culture and National Identity in Uzbekistan. Durham: Duke University Press, 2010.

${ }^{14}$ Ibidem

${ }^{15}$ SMITH, Anthony. c. d.
} 
heroes ${ }^{16}$. Theatres and performances among many other forms such as festivals, celebrations and sports also become key events of expressing distinctive national identities ${ }^{17}$. For some states, however, these big spectacular events were more than a mere nation-building efforts. They served to address a much broad umbrella of national issues, namely economic and political ones. As I illustrate further in the paper, in Kyrgyzstan, WNGs were also projects aimed at promotion of tourism and foreign investment. Using, Hobsbawm's framework of 'invention of tradition' I argue that the Kyrgyz leadership 'invented' these games in order to address present-day issues.

I start my paper by discussing Hobsbawm's framework of invented traditions and explain why the World Nomad Games are better explained as invented tradition. Then I give a brief information and statistics about the World Nomad Games. Later, I recap certain modern domestic needs which led to creation of nomadic sports and I analyze president Atambaev's keynote speech delivered during the opening of the first nomadic games through content analysis to find out more about the official narratives of the invented tradition of nomadic games. Finally, I conclude by reflecting on a broader implication of the WNGs in Kyrgyzstan and in the region. Namely, I comment about increasing 'trend of nomadism' among citizens and use of 'nomadism brand' by other states.

\section{Invented traditions and Invention of the World Nomad Games}

In their influential volume called "The invention of tradition" Eric Hobsbawm and Terence Ranger ${ }^{18}$ present number of examples of inventing traditions and rituals in Europe and Africa. Hobsbawm writes that traditions "which appear or claim to be old are often quite recent in origin and sometimes invented" ${ }^{\prime 19}$. The authors use a term 'invented tradition' in the following meaning:

"It includes both 'traditions' actually invented, constructed and formally instituted and those emerging in a less easily traceable manner within a brief and dateable period - a matter of a few years perhaps - and establishing themselves with great rapidity. $" 20$

\footnotetext{
${ }^{16}$ see Akaev 2002, March 2002, Horak 2005, Kokaisl and Kokaislová 2009, Blakkisrud and Nozimova 2010, Jacquesson 2021.

${ }^{17}$ Adams and Rustemova 2009, Adams 2010.

${ }^{18}$ HOBSBAWM, Eric; RANGER, Terence eds. The Invention of Tradition. New York: Cambridge University Press, 1983.

${ }^{19}$ HOBSBAWM, Eric; RANGER, Terence eds. $c$. d., p. 1.

${ }^{20}$ Ibidem
} 
'Invented tradition' is symbolic in its nature and it is aimed to indoctrinate or encourage "certain values and norms of behaviour" among societies through an act of "repetition". ${ }^{21}$ According to Hobsbawm 'invented traditions' are "responses to novel situations which take the form of reference to old situations, or which establish their own past by quasi-obligatory repetition". 22 Inventing traditions is "a process of formalization and ritualization, characterized by reference to the past". ${ }^{23}$

Why do ruler need traditions? Hobsbawm observes that it is the "constant change and innovation of the modern world" that pushes the governments to "attempt to structure at least some parts of social life within it as unchanging and invariant". ${ }^{24}$ In other words, it is a wish of the rulers to maintain some 'traditions' static and fixed, not impacted by modern patterns, which make the rulers interested in keeping traditions. Hobsbawm notes increase of inventing of traditions in the era of a "rapid transformation of society" because the transformation or modernization abolishes "the social patterns for which 'old' traditions had been designed". ${ }^{25}$ Very important is to highlight application of "ancient materials" in inventing traditions "of a novel type for quite novel purposes". ${ }^{26}$ For example, among novel traditions for novel purposes Hobsbawm lists national symbols, such as flags, anthems which are new inventions. $^{27}$

As per Hobsbawm there are three kinds of purposes of inventing traditions: a) founding national cohesion or nation-building, b) institution-building or legitimizing institutions, c) socialization. ${ }^{28}$ Hobsbawm points application of "history as a legitimator of action and cement of group cohesion". ${ }^{29} \mathrm{He}$ observes that political actors, various movements and factions historically used to invent fake or semi-fake historic past, not only for nationalism purposes. By history Hobsbawm means "the people's past," "heroes and martyrs," and "memories". 30

Hobsbawm's work deserves a more detailed attention here because it lays down a conceptual framework of the paper, in particular it stresses a deliberate nature of inventions. In other words, Hobsbawm points to instrumental function of invention of tradition. Most of

\footnotetext{
${ }^{21}$ HOBSBAWM, Eric; RANGER, Terence eds. $c . d$.

${ }^{22}$ HOBSBAWM, Eric; RANGER, Terence eds. c. d., p. 2.

${ }^{23}$ HOBSBAWM, Eric; RANGER, Terence eds. $c$. $d$., p. 4.

${ }^{24}$ HOBSBAWM, Eric; RANGER, Terence eds. $c$. $d$., p. 2.

${ }^{25}$ HOBSBAWM, Eric; RANGER, Terence eds. c. d., p. 4.

${ }^{26}$ HOBSBAWM, Eric; RANGER, Terence eds. $c$. $d$., p. 6.

${ }^{27}$ HOBSBAWM, Eric; RANGER, Terence eds. $c$. $d$.

${ }^{28}$ HOBSBAWM, Eric; RANGER, Terence eds. $c$. $d$., p. 9.

${ }^{29}$ HOBSBAWM, Eric; RANGER, Terence eds. $c$. d., p. 13.

${ }^{30}$ HOBSBAWM, Eric; RANGER, Terence eds. c. d., p. 13.
} 
rituals and traditions which are perceived as ancient are not ancient indeed claims Hobsbawm. He states that invention of traditions is more a political act and they are "deliberate" and "systematic" $" 31$, invented traditions serve certain social and political objectives. ${ }^{32}$ His chapter illustrates the $19^{\text {th }}$ century Europe which under social transformation from empires into republics underwent 'mass-generation of traditions' such as: public ceremonies, production of monuments, anniversaries, commemorations, rituals and public festivities. According to Hobsbawm, these innovative 'devices' or traditions were needed for newly introduced modern states in order to obtain political loyalty: "the state ... raised unprecedented problems of how to maintain or even establish obedience, loyalty and cooperation of its subjects or members, or its own legitimacy in their eyes. ${ }^{, 33}$ Especially 'new states' were lacking political legitimacy. $^{34}$

Kyrgyzstan being a relatively 'new state' which underwent series of political instabilities in 2005 and 2010 needed a tradition of nomadism for rather practical or economic purposes, namely for promotion of tourism and branding the country. Originally, the term "World Nomad Games" was coined during the scholarly-practical conference titled "National physical culture and national sports games: current situation and prospects of future development" which was held in Bishkek in 2007 under the support of the Kyrgyz State Academy of physical culture and sport. The idea of nomadic games belonged to Askhat Akibaev, the head of Ethno-games confederation. ${ }^{35}$ Akibaev proposed the concept of "World Nomad Games" as a means of promoting national (ethnic) sports on the international level. For the Kyrgyz leadership, the idea of World Nomad Games was more than just a promotion of ethno-sport abroad. In particular, the President's Apparatus wanted to make the WNGs Kyrgyzstan's 'business card' (in Russian vizitnaia kartochka). ${ }^{36}$ In addition, there were also other public opinions who shared the view that the WNGs should be associated with Kyrgyzstan and should not be passed to other countries, like the Olympic Games are. For example, the former minister of culture of Kyrgyzstan, Sultan Raev suggested to host the WNGs only in Kyrgyzstan in order to make the WNGs a new national brand of Kyrgyzstan. This idea was shared by then deputy-head of Ministry of culture, tourism and information of

\footnotetext{
${ }^{31}$ HOBSBAWM, Eric; RANGER, Terence eds. c. $d$., p. 282.

${ }^{32}$ HOBSBAWM, Eric; RANGER, Terence eds. c. d., p. 307.

${ }^{33}$ HOBSBAWM, Eric; RANGER, Terence eds. c. d., p. 265.

${ }^{34}$ HOBSBAWM, Eric; RANGER, Terence eds. $c$. $d$.

${ }^{35}$ World Ethnogames Confederation: О проекте Всемирные Игры Кочевников [About the project World Nomad Games], n.d., https://weconfederation.com/wec/vik (accessed 14 January 2021).

${ }^{36}$ Ibidem
} 
the Kyrgyz Republic, Azamat Zhamankulov. For instance, in 2016, during the meeting of the Council on Tourism in the Commonwealth of Independent States (CIS) ${ }^{37}$ Zhamankulov said:

"We have to have a kind of annual brand-event [in Kyrgyzstan] about which tourist are aware and plan their trips accordingly. There are many similar events in the world which are associated with one country. For instance, we watch carnivals from Brazil but not the USA. Bullfighting is held only in Spain, and many tourists go there to watch them. The World Nomad Games should become a similar brand-event."38

Similarly, in 2016 during the press-conference after the first World Nomad Games Sapar Isakov, the deputy-head of the President's Apparatus, stated the following:

"The entire world has learned about such a small and democratic country as Kyrgyzstan. The games pushed a genuine interest in all countries in the world. Each country has its ethnic games. A decision was made to hold them [the World Nomad Games] once in two years and only in Kyrgyz land." ${ }^{, 39}$ (emphasis are mine)

Askhat Akibaev, the author of World Nomad Games, currently the head of Ethnogames confederation, later also emphasized that the WNG is ethno-sport tourist festival and is a touristic brand of Kyrgyzstan. ${ }^{40}$ He noted the following:

"World Nomad Games - is our product. For instance, Kazakhstan arranged Great games of the steppes. While nomad games - are ours. One does not need to prepare for these games for eight years. They are more democratic games. Olympics - is for rich [countries]. There are more than 200 countries in the world - and only very few can afford Olympics. But in the format of world ethno-games each country can be represented. It is a new format [of games], each country can display own settlement [culture] - wigwams, urts, tents. We have to demonstrate diversity and beauty of each nation." ${ }^{41}$ (emphasis are mine)

Finally, Sapar Isakov during the interview for a media outlet stated that the World Nomad Games became Kyrgyzstan's brand:

"the World nomad games should be held twice a year only in Kyrgyzstan ... I think that the initiative about holding World nomad games will be written in golden letters

\footnotetext{
${ }^{37}$ CIS established in 1991 by the initiative of former Soviet states: Armenia, Azerbaijan, Belarus, Kazakhstan, Kyrgyzstan, Moldova, Russia, Tajikistan, Turkmenistan, Ukraine, Uzbekistan.

38 Sputnik Kyrgyzstan: Глава департамента туризма: Игры кочевников должны остаться в Кыргызстане [Head of the tourism department: Nomad games should remain in Kyrgyzstan], 8 July 2016, https://ru.sputnik.kg/culture/20160708/1027457694.html (accessed 15 January 2021).

${ }^{39}$ Sputnik Kyrgyzstan: Исаков: Игры кочевников будут проводиться только в Кыргызстане [Isakov: Nomad Games will be held only in Kyrgyzstan], 8 September 2016, https://ru.sputnik.kg/society/20160908/1029088777.html (accessed 15 January 2021).

40 RIA Novosti: На Всемирные игры кочевников в Киргизии пригласили представителей 40 стран [Representatives of 40 states were invited for World nomad games in Kyrgyzstan], 21 June 2016, https://ria.ru/20160621/1449422477.html (accessed 12 January 2021).

${ }^{41}$ Ibidem
} 
in the history of our state. In addition, I can say for sure that this initiative will be written in the history of world development and global peace. To document this event and to mention about it in the history of the UN, Kyrgyzstan suggested about this idea during the 71-st General assembly of the UN Kyrgyzstan." ${ }^{, 2}$ (emphasis are mine)

Thus, for the Kyrgyz leadership, nomadism became an opportunity to create a new national brand and a new country image, which the country lost in the course of series of coups in 2005 and 2010, and the bloody inter-ethnic conflict in Osh. Since turmoil in 2005 Kyrgyzstan became internationally known as the country of political instabilities which put at risk a potential of international investment and tourism. Apart from these major country image-related issues, Atambaev's rule also lacked a popular support. First Atambaev's policies, namely his decision about the entrance to the Eurasian Economic Union ${ }^{43}$ (the EaEU) in 2015 was largely criticized by local entrepreneurs and farmers. Kyrgyz agricultural products were blocked on the borders with Kazakhstan preventing their further export to Russia. As noted by the head of the business association "Jash Ishkerler Assotsiatsiasy" local entrepreneurs faced a big loss within the EaEU because of new bureaucratic regulations, such as certification of products. ${ }^{44}$ Finally, during the presidency of Atambaev international relations of Kyrgyzstan with several countries had worsened because of Atambaev's 'emotional' speeches addressed to presidents of Kazakhstan, Uzbekistan, Turkey and Tajikistan. ${ }^{45}$ As a result, the Kyrgyz leadership needed a new grand project to 'overshadow' an umbrella of existing national issues, such as improving the national image of the country tourism and foreign investment, improving complicated international relations with neighbouring states. A timing was right and accurate to invent and invest into the project of the World Nomad Games -games inspired by its prehistoric past of nomadism. Before we move on to discuss in detail the President Almazbek Atambaev's opening speech at the first World Nomad Games, in the following section I briefly present related information on the first WNGs.

\footnotetext{
${ }^{42}$ Cabar: Сапар Исаков о Вторых Всемирных играх кочевников [Sapar Isakov about the Second World nomad games], 11 October 2016, https://www.for.kg/news-383021-ru.html (accessed 22 January 2021).

${ }^{43}$ The Russian-led union was established in 2015, other member-states are Russia, Kazakhstan, Belarus and Armenia.

44 Azattyk: Кыргызстан и ЕАЭС: плюсы и минусы четырехлетнего пребывания в организации

[Kyrgyzstan and the EaEU: pros and cons of four-years membership in the organization], 30 August 2019, https://rus.azattyk.org/a/kyrgyzstan-economy-eurazes/30137604.html (accessed 7 February 2021).

${ }^{45}$ See the video here to watch Atambaev's impolite speeches addressed to the presidents of neighbouring states. Source: AzattyqTV, https://rus.azattyq.org/a/kyrgyzstan-atambaev-rezkie-vyskazyvania/28873846.html
} 


\section{Kyrgyzstan's new 'business card': The first World Nomad}

\section{Games}

The first WNG were held in September 9-14 ${ }^{\text {th }}$ in 2014 and attracted 583 sportsmen from 19 countries. $^{46} 1,200$ people were involved into the mass performances under World Nomad Games. Ten kinds of ethno-sport games were played. ${ }^{47}$ International TV broadcasting channels ${ }^{48}$ from 40 countries with auditory of 230 million people reported about the WNG from Cholpon-Ata city. The opening ceremony of the first WNG lasted for two hours and included 14 theatrical performances. The ceremony was staged at the city hippodrome. Performances reflected the history of nomadic Kyrgyz, the epic Manas, and national songs and dances. After the WNG's official opening sports tournaments lasted for six days. Tournaments were split into two locations: the city hippodrome for horseback games and the historical cultural centre "Ruh-Ordo" for intellectual games. Simultaneously in Kyrchyn ethno-village a special nomadic programme was organized. 150 decorated boz ui representing all regions of Kyrgyzstan were installed in Kyrchyn and displayed national traditions and customs. Various festivals, such as "Nomad folk"49 and "Dastarkon" valley. In addition, "Ruh-Ordo" centre hosted an exhibition of nomadic craftsmen, "Ethno Fashion" fashion show and "Ordo-Sakhna" folk theatre. Kyrgyzstan spent 200 million KGS for the organization of the first WNG. In addition, around 11 million KGS were spent for the reconstruction of old city hippodrome. Entrance to the tournaments and to other festivals and events under the first WNG were free of charge, except for opening and closing ceremonies. The closing ceremony was accompanied with a laser-show and a concert featuring local and international singers and dancers. Kyrgyzstan took a leading position in the first WNG. In total Kyrgyzstan earned 55 medals (16 gold, 20 silver and 19 bronze). Kazakhstan took the second place with total 28 medals (10 gold, 9 silver and 9 bronze). Turkmenistan earned in total 6 medals ( 3 gold and 3 bronze) and received the third place. The total prize fund

\footnotetext{
${ }^{46}$ Afghanistan, Austria, Azerbaijan, Belarus, Brazil, France, Germany, Kazakhstan, Kyrgyzstan, Lithuania, Mongolia, Russia, South Korea, Sweden, Tajikistan, Turkey, Turkmenistan, USA, Uzbekistan. For more details about the first WNG visit: http://worldnomadgames.com/ru/page/VIK-2014/

${ }^{47}$ Alysh (wrestling with belts), alaman baige (horse racing for a long distance), jorgo salysh (horse-racing on footsteps-horses), Kazakh kurosh (Kazakh wrestling), Kyrgyz kurosh (Kyrgyz wrestling), kok boru (a horseback team game with a headless goat), kunan chabysh (horse racing of three-year old horses), ordo (Kyrgyz national game in the knucklebones), toguz korgool (Kyrgyz national intellectual table game), er enish (horseback wrestling).

${ }^{48} 250$ international journalists from foreign TV broadcasting channels such as BBC, CNN, The Guardian, Washington Post, Al Jazeera and others broadcasted WNG from Cholpon-Ata.

${ }^{49}$ A nomadic music festival

${ }^{50}$ A nomadic food festival
} 
consisted of 16 million KGS. Following the success of the first World Nomad Games in 2014, the Kyrgyz leadership decided to hold these games once in two years. Consequently, the games were held again in 2016 and 2018. However, during the closing event in 2018 then President Sooronbai Jeenbekov declared that these games will be transferred like the Olympic Games from one participating state to another, and announced Turkey as the second destination. At the moment, the games scheduled for 2020 were rescheduled by Turkey because of the Covid-19 pandemic.

\section{Official narratives of the Nomad Games: Atambaev's keynote speech at the opening ceremony of the first World Nomad Games in 2014}

In this part of the paper, I examine President Atambaev's speech delivered on September $9^{\text {th }}$ 2014 during the opening ceremony of the first WNGs. ${ }^{51}$ As noted earlier the opening speech of Atambaev provides an official account on the invented tradition of nomad games. The official account versus the real-world accounts mentioned in the section two of the paper (namely a need for improving the national image of the country to develop tourism and foreign investment, improving complicated international relations with neighboring states) is especially noteworthy.

Opening speech of Atambaev consisted of three main parts delivered in turn in Kyrgyz and Russian languages. In the first part of the speech, Atambaev welcomed the guests and the spectators and thanked the presidents of Kazakhstan, Turkey and Azerbaijan for supporting the initiative on the WNGs which he proposed during the Bishkek summit in 2012. Atambaev noted that the WNG was a great event in the life of Kyrgyzstan and the country was very proud of it. Then Atambaev paused on who nomads were:

"The nomads stayed at the beginning of the human civilization history, and are nations which had a distinctive contribution to humankind's development. We are responsible for studying lives of our ancestors and nomadic philosophy. The ones who know own roots and their past can find a way to the future."

Then Atambaev emphasized about a special relationship between Kyrgyzstan and nomads, he said:

\footnotetext{
${ }^{51}$ To access a full text of Atambaev's keynote speech at the first WNG visit the following link: President.kg: Выступление Президента Кыргызской Республики Алмазбека Атамбаева на открытии I Всемирных игр кочевников [Speech of President of the Kyrgyz Republic Almazbek Atambaev during the opening of the I World nomad games], 9 September 2014, http://president.kg/ru/sobytiya/novosti/2276_vistuplenie_prezidenta_kirgizskoy_respubliki_almazbeka_atamba eva_na_otkritii_i_vsemirnih_igr_kochevnikov (accessed 27 January 2021).
} 
"It is not just a concurrence that the beginning of nomad games is taking place in Kyrgyzstan. The Kyrgyz nation - is the one of those who founded the nomadic civilization, it is one of nations which led it [the nomadic civilization], it is rich in history and traditions and customs."

Concluding the first part of the speech Atambaev highlighted that a better future was only in unity and cooperation between the countries:

"Let us together build a future by remembering heritage of our ancestors and their sacred words! Let the God to bright our way! Only in unity with kin nations and partner states we can pass this path! We have a common background. Similar to the Father Manas who "made a nation from split tribes," let us make our lives together with other nations and kin nations!"

In the next part of his speech Atambaev called the WNG - a unique game because of its new format. He described in brief that the games had unique spectacular events. The president noted that most of modern sports emerged from ancient war tournaments. Atambaev believed that sports would unite nations, strengthen friendship and harmony between the nations. Then Atambaev again paused to speak about nomadic civilization and its importance:

"Many states had disappeared from the world map for the last centuries. Many nations had vanished. However, the spirit of nomadic civilization is going on. Its strength - is its ability be in a harmony with the nature and ever-changing world. This is in particular is important in our century - the century of transformations and globalization. Nomadic nations had always respected their past, had remembered own ancestors, they had generated legends about own heroes and passed them from one generation to another. Thus, for Kyrgyz nation a spiritual power comes from the millennial epic Manas, other nations also have own great heroes and works. Even if our history is not reflected in ancient stone cities, it lives in our hearts, in memory of peoples. It is important for us to remember our past, remember our roots. We have many things in common. We have common roots. I am sure that our future is also one!"

In the second part of his speech Atambaev emphasized importance of cooperation and friendship in the following way:

"Today we - the descendants of nomadic nations, are responsible for reviving in our hearts spirits of our fathers and mothers, souls and are responsible for reviving civic feelings. Let us learn to live in peace, let us stop conflicts, let us remember our history and roots, and only then we can have a bright and great future. It seems that the ancient and the present eras are facing each other in the shores of a sacred YssykKol! These games will disseminate to the world the history, talents, culture and nature of nomadic nations, and will improve our unity and exercises our peace." 
In the third part of his speech Atambaev turned to Kyrgyz citizens and noted that the World Nomad Games are a special occasion which would improve tourism and development of the Yssyk-Kol region and advertise Kyrgyzstan worldwide, therefore, he asked the citizens to be helpful in making the games successful:

"World Nomad games which we are launching today will certainly develop tourism to our country, especially will contribute to Yssyk-Kol oblast's development. It is the best advertisement of Kyrgyzstan to the world! Therefore, for the sake of our country, we ask you not do breach public order, respect our guests and let us hold [the games] on a high level."

Afterwards, Atambaev turned to participating sportsmen and wished them a good luck. He reminded them that they were descents of great nomads such as - Attila, Oguz Khan, Manas, Chenghiz Khan and Babur. He closed his speech by praying for a successful event, praying for prosperity, unity and peace for all, and declared the games open.

In the Table 1. below I identified five key themes in the keynote speech of the President Atambaev which provide a glimpse into official narrative of the invention of the nomadic tradition. These themes cover: nomadic civilization, nomadic heritage, Kyrgyz and nomadism, future (international) and future (domestic). Atambaev explained importance of the WNGs to the Kyrgyz nation both by economic benefits for the country and by nomadic spiritual judgements as descents of a great nomadic civilization. Atambaev stressed the spiritual rationale behind the WNGs by noting that Kyrgyzstan was not just a first random place to host these games, but it was a sacred nomadic land with a great history, unique culture and past and the Kyrgyz nation was one of founders of nomadic civilization and nomadic culture. Economic rationale behind the WNGs was noted by the President Atambaev too because the event would attract tourists and improve Kyrgyzstan's international prestige making attractive country for investing. Atambaev saw these games as a means of international cooperation and partnership, and a prosperous future, he hoped that the WNGs would boost economic partnership with other states and increase international investment to Kyrgyzstan. To do so Atambaev attempted several times to highlight other states about their common nomadic background and (potentially) their common future. For that very reason Atambaev was also eager to hold the games annually and even declared the games annual in front of international guests, international mass media during the opening ceremony (although later it was decided to hold the WNGs once in two years but not annually). Thus the official reasoning of importance of the WNGs communicated to the nation was economic and spiritual ones (as a spiritual duty of nomadic descents). The central themes raised in the 
speech support these claims: first, Atambaev reminded who were nomads, then he noted about nomadic heritage and mentioned about responsibility/duty of nomadic descents [also Kyrgyz nomads] and, finally, Atambaev discussed a future of nomadic states and the country's future, in particular how the WNGs would contribute to a better future.

Table 1. Central themes in Atambaev's speech during the I WNGs in 2014

\begin{tabular}{|c|c|}
\hline Central themes: & Key words and phrases (rephrased and summarized): \\
\hline Nomadic civilization & $\begin{array}{ll}\text { - } & \text { founders of human civilization } \\
\text { - } & \text { had a contribution to mankind's development } \\
\text { - } & \text { the spirit of nomadic civilization goes on } \\
\text { - } & \text { nomads can stay in harmony with the nature } \\
\text { - } & \text { great nations }\end{array}$ \\
\hline Nomadic heritage & $\begin{array}{ll}\text { - } & \text { nomadic philosophy } \\
\text { - } & \text { we are responsible as descents to revive and remember } \\
\text { - } & \text { to know our past and our roots } \\
\text { - } & \text { legends from one generation to another } \\
\text { - } & \text { to respect and remember the ancestors and the past }\end{array}$ \\
\hline Kyrgyz and nomadism & $\begin{array}{l}\text { - Kyrgyz are among the nations which founded, headed } \\
\text { nomadic civilization } \\
\text { - } \text { Kyrgyz have a rich nomadic culture and traditions }\end{array}$ \\
\hline Future (international) & $\begin{array}{l}\text { - we have a future if we know our past, if we remember } \\
\text { our past } \\
\text { - } \text { we have a better future if we [nomads] unite and } \\
\text { cooperate } \\
\text { - } \text { we can pass the path only in unity } \\
\text { - } \text { we have a common background/roots and future } \\
\text { - } \quad \text { unity of nations, friendship and harmony } \\
\text { - } \quad \text { to learn to live in peace } \\
\text { - } \quad \text { to stop conflicts }\end{array}$ \\
\hline Future (domestic) & $\begin{array}{l}\text { - } \text { development of tourism } \\
\text { - } \text { development of regions } \\
\text { - } \quad \text { the country's advertisement on the global level (the } \\
\text { WNGs is great, unique event) } \\
\text { - Kyrgyz are proud of the WNGs } \\
\text { - } \quad \text { improvement of the country image }\end{array}$ \\
\hline
\end{tabular}


In this manner, the invention of the World Nomad Games in Kyrgyzstan was a calculated political decision rather a pure cultural or social event. The Kyrgyz leadership invested in nomadism because it believed it will create a new national brand and a new country image, both of which are important for attracting foreign investments and tourism. The country lost its prestige as a stable country due to series of political coups in 2005 and 2010 which were followed by violence, looting and seizure of foreign businesses.

\section{Conclusion}

I examined the World Nomad Games in Kyrgyzstan as a deliberate 'invented tradition' by the country's leadership. I argued that the nomadic games were revived in order to tackle with contemporary issues, such as a need for attraction of foreign investment and promotion of tourism. In my paper I illustrated that the WNGs project was a timely response to improve the country image after a series of political instabilities in its recent history which undermined Kyrgyzstan's international image and challenged it as a tourist and investment destination.

Two final remarks are essential to be mentioned here. First, the invention of the World Nomad Games led to increase of 'trend of nomadism' in Kyrgyzstan. Nomadism became associated with local businesses because they used official symbol of the World Nomad Games in producing T-shirts, souvenirs and other items which were sold to tourists and were used by local population. In addition, many new private tourist companies were opened in Kyrgyzstan after the WNGs which proudly present a special 'nomadic' programme, such as horse-riding, demonstration of hunting falcons, tasting nomadic cuisine, etc. Second point relates to the use of 'nomadism brand' by other states. The Kyrgyz government managed to successfully present idea of nomad games not only on national, but also on international level because nomadic sport and culture became increasingly popular outside Kyrgyzstan after a presentation of the WNGs. For instance, the Saudi Arabia expressed its interest in promoting nomadic culture. In 2019 the Saudi Arabia launched its International Ethno-festival "Nomad Universe" where more than 2,200 people from 95 states took part ${ }^{52}$. Similar to the WNGs, the Arabic ethno-festival combined both nomadic sport activities and nomadic cultural activities. Another important international development in promotion of nomadic culture which occurred after the WNGs was the initiative of UNESCO to hold the first World Ethno-sport

\footnotetext{
${ }^{52}$ World Ethnogames Confederation: Международный этнофестиваль «Вселенная Кочевников» [International ethno-festival "Nomad Universe"], n.d., https://weconfederation.com/wec/nu (accessed 13 January 2021).
} 
Games in 2021. Among the countries which applied for hosting UNESCO's World Ethnosport Games are Kazakhstan, Turkey, Canada and South Korea. ${ }^{53}$

\section{Acknowledgement}

The present publication is the outcome of the project „From Talent to Young Researcher project aimed at activities supporting the research career model in higher education", identifier EFOP-3.6.3-VEKOP-16-2017-00007 co-supported by the European Union, Hungary and the European Social Fund.

\footnotetext{
${ }^{53}$ Azattyk: Казахстан подал заявку на проведение первой этноолимпиады [Kazakhstan applied for hosting the first ethno-Olympics], 4 June 2018, https://rus.azattyk.org/a/29269689.html (accessed 16 January 2021).
} 


\section{References}

ADAMS, Laura L.; RUSTEMOVA, Assel. Mass Spectacle and Styles of Governmentality in Kazakhstan and Uzbekistan. Europe-Asia Studies, 2009, 61.7: 1249-1276. DOI: 10.1080/09668130903068798

ADAMS, Laura. The Spectacular State: Culture and National Identity in Uzbekistan. Durham: Duke University Press, 2010. DOI: 10.2307/j.ctv11318c6

AKAEV, Askar. Kyrgyzskaya gosudarstvennost i narodnyi epos Manas. Bishkek: Uchkun, 2002.

BLAKKISRUD, Helge; NOZIMOVA, Shahnoza. History writing and nation building in postindependence Tajikistan. Nationalities Papers, 2010, 38.2: 173-189. DOI:10.1080/00905990903517835

BLANDFORD, Steve. ed. Theatre and Performance in Small Nations. Bristol: Intellect, 2013.

EDENSOR, Tim. National Identity, Popular Culture and Everyday Life. Berg: Oxford, 2002.

GOUNARIDOU, Kiki. ed. Staging Nationalism: Essays on Theatre and National Identities. Jefferson, NC: McFarland \& Company, 2005.

HORÁK, Slavomír. The ideology of the Turkmenbashy regime. Perspectives on European Politics and Society, 2005, 6.2: 305-319. DOI: 10.1080/15705850508438920

HOBSBAWM, Eric; RANGER, Terence eds. The Invention of Tradition. New York: Cambridge University Press, 1983.

HOLDSWORTH, Nadine. Theatre and National Identity. Re-imagining Conceptions of Nation. New York: Routledge, 2014. DOI: 10.4324/9780203366219

HURLEY, Erin. National Performance: Representing Quebec from Expo 67 to Céline Dion. Toronto: University of Toronto Press, 2011. DOI: 10.3138/9781442686342

JACQUESSON, Svetlana. On Folklore Archives and Heritage Claims: the Manas Epic in Kyrgyzstan. Asian Theatre Journal, 2021, 64.4: 425-454. DOI: 10.1163/1568520912341542

KOKAISL, Petr; KOKAISLOVÁ, Pavla. The Kyrgyz - Children of Manas. Kыргыздар Манастын балдары. Praha: Alterra, 2009. ISBN 978-80-254-6365-9. DOI: 10.13140/RG.2.1.3566.2168

MARCH, Andrew F. The Use and Abuse of History: 'National Ideology' as Transcendental Object in Islam Karimov's 'Ideology of National Independence'. Central Asian Survey, 2002, 21.4: 371-384. DOI: 10.1080/0263493032000053190

SMITH, Anthony. Myths and Memories of the Nation. New York: Oxford University Press, 1999. 


\title{
The Baloch Insurgency in Pakistan and the Chinese Connection
}

\author{
Shakoor Ahmad Wani \\ Islamic University of Science \& Technology, Awantipora, Jammu and Kashmir 192122, India \\ Email: shakoor.ahmad@live.in
}

DOI: https://doi.org/10.7160/KS.2021.170204

\begin{abstract}
Shakoor Ahmad Wani teaches International Relations at Islamic University of Science and Technology, Awantipora, Kashmir. He holds a PhD in South Asian Studies from the School of International Studies, Jawaharlal Nehru University, New Delhi, India.
\end{abstract}

\begin{abstract}
This article examines the interplay between big ticket investment projects financed by the Chinese capital and ethno-nationalism in the province of Balochistan. It argues that the growing Chinese presence in Balochistan has provided a new impetus to an already simmering Baloch nationalist resistance. Balochistan has profuse natural resource wealth, yet its riches have not benefited its people. The Baloch are one of the most deprived communities in Pakistan. Successive central governments have exploited the province's resources in the name of development to the detriment of its inhabitants. The advent of CPEC (ChinaPakistan Economic Corridor) has exacerbated Baloch grievances. They believe that megadevelopment projects like Gwadar port would impinge adversely on local demography by attracting a huge influx of economic migrants and render the Baloch minority in their own land. The insurgent groups view China as a 'partner in crime' and have responded by selectively targeting Chinese assets and personnel. The article analyses the nature of resistance to Chinese presence and the changing modus of insurgent groups. It argues that Islamabad's attempts to deter the attacks by intensifying the militarisation of the province are counterproductive as they reinforce Baloch opposition to CPEC.
\end{abstract}

\section{Keywords}

CPEC, Balochistan, Gwadar port, Demography, Exclusion

\section{Introduction}

Balochistan has remained in the throes of a smouldering insurgency for nearly two decades. Animated by a historic set of grievances, including political neglect, economic marginalisation and resource exploitation, Baloch militants have waged periodic armed struggles against an authoritarian and extractive state. Balochistan has abundant natural resource wealth but its benefits have not accrued to its people. Its resources, in particular, natural gas, have contributed billions of dollars to the state exchequer and powered industries 
in Karachi and Central Punjab but the province continues to be most penurious. The socioeconomic indicators are abysmal. The province has the lowest literacy rates in the country and lacks basic civic amenities like clean water, electricity and health infrastructure. ${ }^{1} 71$ per cent of households in Balochistan are classified as poor compared to a national average of 37 per cent. $^{2}$

The multi-billion dollar investments by China in the mineral sector, Gwadar Port and now the China-Pakistan Economic Corridor (CPEC) have accentuated perceptions of exploitation. Even before CPEC, China was involved in different projects in the province like Gwadar port and the copper and gold mining project in Chagai District. With CPEC, Chinese involvement has seen a rapid upswing. The Baloch nationalists are anxious that massive Chinese investments would increase resource theft, engender socio-economic disruptions and upend the demographic balance in the province. They fear that the influx of outsiders in large numbers induced by projects like Gwadar port, estimated to run into several million, could turn the Gwadar city into the next Karachi -a metropolis where migrants outnumber the native population. A single Karachi, in a vast but sparsely populated Balochistan would mean that the Baloch would be reduced to a minority in what they regard as their historic homeland. This has spawned intense consternation and resentment against what they perceive as a 'PakChina neo-colonial project' to expropriate their resources.

The Baloch have responded with fear and violence and escalated an already simmering insurgency. Initially, the insurgents blew up gas pipelines and other energy infrastructure purveying resources to other parts of Pakistan, gradually burgeoning Chinese investments and personnel became the target. Sporadic attacks on Chinese personnel have intensified Islamabad's effort to dominate the region through the extensive militarisation of the geography. This has resulted in a sharp spike in the cases of enforced disappearances and extra-judicial killings.

The worsening human rights abuses by security forces and diminutive media attention has prompted the Baloch separatists to gain greater visibility for their cause by escalating costs for Pakistan and China. For too long the simmering insurgency remained confined within the precincts of Balochistan. This is beginning to change, as insurgent groups, in

\footnotetext{
${ }^{1}$ The World Bank. Balochistan Mining and Regional Integration Policy Dialogue Paper, 2013. https://www.pakistanmdtf.org/images/stories/project-documents/BalochistanReport2013.pdf, p. 28.

${ }^{2}$ JAVED, Umair; NABI, Ijaz. Heterogeneous fragility: The case of Pakistan. Commission on State Fragility, Growth and Development, 2018. https://www.theigc.org/wp-content/uploads/2018/04/Pakistan-report.pdf, p. 25.
} 
particular, the Baloch Liberation Army (BLA) recalibrate their strategies to expand the theatre of conflict.

This article examines Chinese investments in Balochistan and its interaction with the Baloch nationalism. It argues that CPEC and Gwadar port in particular has heightened local perceptions of exploitation and expropriation. The Baloch fear the socio-economic disruptions wrought by mega projects and have thus mounted fierce resistance. The first section places Baloch nationalism in a historical context and argues that the current resistance against Chinese projects is informed by a history of resource exploitation by an extractive central government. The second section examines various motives that underlie Chinese investments in Balochistan. The third section analyses the causes behind the Baloch opposition to Chinese investments and argues that increasing attacks against Chinese interests have led to an intense military crackdown and this has reinforced opposition to CPEC. The fourth section focuses on the Majeed Brigade - a distinctly anti-Chinese insurgent faction that sprang up as a reaction to growing Chinese presence in Balochistan. This new group has adopted a hitherto novel modus operandi and expanded the theatre of the conflict by undertaking action outside the provincial boundaries. The last section summarises the arguments and concludes with some comments about making the Baloch equal stakeholders in the CPEC.

\section{Roots of the Baloch Discontent}

Balochistan is one of the four federating units of Pakistan. It is the largest province by area but least populated, home to around six per cent of the country's population. Ethnolinguistically, it is Pakistan's most diverse province. The Baloch are the dominant ethnic group followed by Pashtuns and other smaller minorities like Punjabis, Hazaras, Sindhis etc. Tribalism forms the basis of social structure in Balochistan. There are 17 major Baloch tribal groupings and some 400 sub-groupings, with each group or sub-group headed by a Sardar (chieftain) who wields considerable influence over the tribe. ${ }^{3}$

The Baloch have fiercely guarded their political independence throughout their history. From invading Afghans to the imperial British, they have resisted intruding forces. After falling at the hands of the British in 1839, Balochistan enjoyed a quasi-sovereign status. The Khan (Chief) of Kalat - the largest princely state in Balochistan, was afforded considerable leeway in the administration of internal affairs in return for protection of imperial trade routes

\footnotetext{
${ }^{3}$ JETLY, Rajshree. Baluch ethnicity and nationalism (1971-81): an assessment. Asian Ethnicity, 2004, 5.1: 726, p. 10.
} 
and access to Afghanistan. For the British, Balochistan was an economic wasteland but was valued for its strategic significance.

The roots of current nationalist resistance against Islamabad can be traced to the later phase of the British colonial period. As British withdrawal neared its end, the then Khan of Kalat, Mir Ahmad Yar Khan, supported by a coterie of young Baloch nationalists organised under the Kalat National State Party (KSNP) speeded up their activities to create an independent Balochistan. Khan opposed accession to Pakistan at the time of partition and officially declared independence on 12 August 1947.

However, Pakistan disregarded Baloch opposition and coerced Kalat into accession. After an initial revolt against the forced incorporation was quelled by the Pakistan military, Baloch leaders faced with a fait accompli and acutely conscious of their weak position "acquiesced to subsumption into Pakistan." Leaders at the forefront of the Baloch struggle for independence recalibrated their struggle to fight for a federal Pakistan that granted considerable autonomy to its ethno-linguistic minorities. ${ }^{5}$ The ruling class disdained claims of ethnic difference by smaller ethnic groups and superimposed a centralised state structure. This centralised state system "turned into militaristic, authoritarian [regime] that imposed a kind of 'native' colonialism on the non-dominant groups." Consequently, the nascent Baloch nationalism that emerged before the partition of the Indian subcontinent became a potent force after Pakistan rode roughshod over their ethno-regional aspirations.

The failure to evolve stable democratic institutions and the dawn of military authoritarianism saw Balochistan erupt into a series of uprisings between 1958 and 1962 against the central rule. ${ }^{7}$ The bloodiest confrontation took place during the regime of Zulfiqar Ali Bhutto. Although a democratically elected leader, Bhutto shared many of the authoritarian tendencies with his predecessors and displayed a penchant for a strong unitary centre. He was disdainful of demands for greater provincial autonomy by smaller ethno-linguistic groups and hostile to provincial governments ruled by opposition parties. ${ }^{8}$ The country's first elections based on the adult franchise in 1970 had brought the National Awami Party (NAP) to power

\footnotetext{
${ }^{4}$ TITUS, Paul; SWIDLER, Nina. Knights, not pawns: Ethno-nationalism and regional dynamics in post-colonial Balochistan. International Journal of Middle East Studies, 2000, 32.1: 47-69, p. 48.

${ }^{5}$ SHEIKH, Salman Rafi. The Genesis of Baloch Nationalism: Politics and Ethnicity in Pakistan, 1947-1977. New York: Routledge, 2018, p. 140-141.

${ }^{6}$ KHAN, Adeel. Politics of Identity: Ethnic Nationalism and the State in Pakistan. New Delhi: Sage, 2005, p. 31.

${ }^{7}$ WANI, Shakoor A. The New Baloch Militancy: Drivers and Dynamics. India Quarterly, 2021, 77(3) 479-500, p. 481.

${ }^{8}$ HARRISON, Selig. In Afghanistan's Shadow: Baluch Nationalism and Soviet Temptations. Washington, D.C.: Carnegie Endowment for International Peace, 1981, p. 156.
} 
in Balochistan, led by fiery nationalist Sardar Ataullah Khan Mengal. Bhutto gave short shrift to the provincial government and barely nine months later (1 May 1972 to 12 February 1973) the province had its first popularly elected government overthrown on the dubious charges of plotting a secessionist conspiracy to dismember the country. ${ }^{9}$

Mengal's unceremonious dismissal plunged the province into a protracted armed struggle between a mélange of Baloch militant groups and government forces. The conflict dragged on for four years from 1973-77 resulting in the death of several thousand Baloch until a coup by General Zia-ul-Haq ousted Bhutto from office. ${ }^{10}$ Zia adopted a less confrontational approach, offering amnesty to incarcerated leaders and economic aid to the province. Zia's method of coercion, co-optation and economic largesse helped forestall the retrogression to violence for more than a decade. His accidental death in a plane crash in 1988 ushered in a decade of democracy, 1988-1999. Throughout this period, Balochistan remained largely calm with moderate nationalist parties partaking in the revived democratic process. Pakistan's relapse into military authoritarianism with the seizure of power by General Pervez Musharraf in 1999, coincided with the resurgence of militant nationalist resistance.

At the top of Musharraf's agenda in 1999 was to prop up "Pakistan's sick economy" and to this end, he "focused primarily on mega-projects and infrastructural development."11 Balochistan with its abundant resource wealth was an ideal location. China was to play a pivotal in financing many of the big ticket projects like Gwadar Port and Reko Deq coppergold project. Musharraf's big push on mega-development projects was fiercely resisted by locals who feared being dispossessed of their land and resources. ${ }^{12}$ Reeling under years of severe socio-economic deprivation and political marginalisation, the Baloch are wary of Islamabad's promises of development which brings little benefit to the local population. The military's attempt to suppress local resistance and establish greater control over the resources and territory provided the necessary conditions for the revival of insurgency in Balochistan. ${ }^{13}$

\footnotetext{
${ }^{9}$ HAQQANI, Hussain. Pakistan: Between Mosque and Military. Lahore: Vanguard, 2005, p. 94.

${ }^{10}$ Ibidem, p. 151

${ }^{11}$ BONI, Filippo. Civil-military relations in Pakistan: a Case Study of Sino-Pakistani Relations and the Port of Gwadar. Commonwealth \& Comparative Politics, 2016, 54(4): 498-517, p. 504.

${ }^{12}$ GRARE, Frederic. Pakistan: The Resurgence of Baluch Nationalism. The Carnegie Papers, 2006, No. 65, Washington, DC: Carnegie Endowment for International Peace, p. 5.

${ }^{13}$ AKHTAR, Aasim Sajjad. Balochistan versus Pakistan. Economic and Political Weekly, 2007, 42(45/46): 7379, p. 75.
} 


\section{What is China doing in Balochistan?}

The centrepiece of Chinese interests in Pakistan is Gwadar port. For centuries, Gwadar's natural harbours have attracted fishermen and traders shuttling between Southeast Asia, Middle East and Africa. It's potential as the deep seawater port was first noted by the British engineers in the 1920s, but nothing was done until Musharraf announced the plan to build a port in Gwadar with Beijing's assistance in March 2002. ${ }^{14}$ Phase one of the port was completed in 2006 with China contributing \$198 million of the total \$248 million budget and leased to the Port of Singapore Authority (PSA) in 2007 for 40 years. ${ }^{15}$

Gwadar provides economic and strategic value to both Pakistan and China. Located at the mouth of the Persian Gulf, a key route for global oil supplies, it is projected to serve as a regional hub for transit and transhipment of goods for Afghanistan, Central Asia, and the Middle East. Gwadar is home to a naval base that affords Islamabad with strategic depth. During the 1971 war, the country's major naval base at Karachi was subjected to blockade and a threat of the blockade loomed large during the Kargil war in 1999. ${ }^{16}$

For decades, China and Pakistan have had a close strategic relationship, often described with such lyrical epithets as 'higher than the mountains' and 'deeper than the oceans.' However, the extent of cooperation in the political and military domains did not extend to economic relations. This began to change with Musharraf's policies of liberalisation. A free trade agreement between China and Pakistan was signed in 2006 and implemented in 2007. ${ }^{17}$ China invested heavily in Gwadar port, Saindak gold and copper mines in Balochistan and finally, CPEC, the single largest source of foreign direct investment in Pakistan. A flagship of China's Belt and Road Initiative (BRI), CPEC involves a 3,000-km network of roads, railways and pipelines connecting Kashgar in the Xinjiang region of China with Gwadar in Balochistan. It pledges an investment exceeding $\$ 60$ billion that is expected to address the widening gaps in the energy and infrastructure requirements in Pakistan. In cashstrapped Pakistan, CPEC has been hailed as a game-changer. ${ }^{18}$

\footnotetext{
${ }^{14}$ SCHMIDLE, Nicholas. Waiting for the Worst: Baluchistan, 2006. Virginia Quarterly Review, 2007, 83(2).

${ }^{15}$ JETLY, Rajshree. The politics of Gwadar Port: Baluch nationalism and Sino-Pak relations. The Round Table, 2021, 110(4): 432-447, p. 435.

${ }^{16}$ HAIDER, Ziad. Baluchis, Beijing, and Pakistan's Gwadar Port. Georgetown Journal of International Affairs, 2005, 6(1): 95-103, p. 98.

${ }^{17}$ AHMED, Zahid Shahab. Impact of the China-Pakistan Economic Corridor on Nation-Building in Pakistan. Journal of Contemporary China, 2018, p. 5.

${ }^{18}$ RIZVI, Hasan A. The China-Pakistan Economic Corridor: regional cooperation and socio-economic development. Strategic Studies, 2014, 34(4): 1-17.
} 
Existing scholarship on CPEC examines various factors underlying Chinese interests in Gwadar port notwithstanding the volatile security in the province. It underlines the strategic and economic significance of Gwadar port for the Chinese, which has been described as "China's important energy transfer station" and "China's new energy channel."19 Some studies suggest that CPEC can reduce the cost of western and central China's international trade with Central Asia, the Middle East, Europe and Africa and allow China to save as much as US\$2 billion every year if it were to use CPEC to import 50 per cent of its current volume of oil supplies. $^{20}$

For others Gwadar's commercial viability is suspect and that China's investments are driven by strategic motives. ${ }^{21}$ Gwadar's proximity to the Persian Gulf offers the Chinese navy a potential "permanent, reliable facility for ships needing support points close to the Middle East, North Africa or East Africa." 22 It also offers China an alternate route for energy supplies from the Middle East to China, allowing Beijing to reduce its dependence on the Strait of Malacca and thus alleviate what has been called the 'Malacca dilemma.' Nearly 85 per cent of China's oil imports pass through this single chokepoint making it vulnerable to an eventual blockade by the United States. ${ }^{23}$ Even from the Pakistan's perspective Gwadar's economically viability is in doubt and its main import may lie in its strategic significance. The main industrial clusters in the country are primarily based in Gujranwala, Lahore and Faisalabad and these areas are closest to Karachi port and not Gwadar. ${ }^{24}$

It is also argued that investments in Gwadar are a part of China's 'Open up the West' strategy to reduce socioeconomic inequality between China's underdeveloped western region and its relatively developed coastal provinces. By developing a large scale transportation infrastructure, Gwadar could provide China's landlocked western provinces access routes to exploit trade and investment opportunities with the wider world. Through this strategy,

\footnotetext{
${ }^{19}$ DUCHÂTEL, Mathieu. The Terrorist Risk and China's Policy toward Pakistan: strategic reassurance and the 'United Front'. Journal of Contemporary China, 2011, 20(71): 543-561.

HARTPENCE, Mathias. The Economic Dimension of Sino-Pakistani Relations: an overview. Journal of Contemporary China, 2011, 20(71): 581-599.

YANG, Jian; RASHID A Siddiqi. About an 'All-Weather' Relationship: security foundations of Sino-Pakistan relations since 9/11. Journal of Contemporary China, 2011, 20(71): 563-579.

${ }^{20}$ ESTEBAN, M. The China-Pakistan Corridor: A Transit, Economic or Development Corridor?" Strategic Studies, 2016, 36(2): 63-74, p. 68.

${ }^{21}$ SMALL, Andrew. The China-Pakistan Axis: Asia's New Geopolitics. New York: Oxford University Press, 2015, p. 102.

${ }^{22}$ Ibidem, p. 103.

${ }^{23}$ MARKEY, Daniel S.; WEST, James. Behind China's Gambit in Pakistan. Council on Foreign Relations, 2016. https://www.cfr.org/expert-brief/behind-chinas-gambit-pakistan.

${ }^{24}$ BONI, Filippo. Civil-military relations in Pakistan: a Case Study of Sino-Pakistani Relations and the Port of Gwadar. Commonwealth \& Comparative Politics, 2016, 54(4): 498-517, p. 512.
} 
Beijing envisages to pacify Xinjiang - China's restive westernmost province, home to a separatist movement, by promoting the economic revitalisation of the region by linking it to markets in South Asia, Middle East and Europe through road and railway networks. CPEC is also motivated by China's need to prop up a long-time ally struggling with political and economic instability. A stable and economically thriving Pakistan would be disinclined to provide safe havens for Uighur militants. An economically strong Pakistan would simultaneously be a formidable counterweight to a rising India and thus act as a strategic hedge. $^{25}$

CPEC has presented Pakistan with a much longed-for opportunity to reboot its economy and infrastructure. It is the largest foreign direct investment in the history of Pakistan and is almost one-fifth of its GDP. However, many are sceptical about the equitable distribution of benefits from the proposed projects. Ethnic divisions are deep-rooted in Pakistan and they overlap with inter-provincial disparities and this has made CPEC an object of intense contestation among the provinces and different interest groups. Smaller provinces like Balochistan and Khyber Pakhtunkhwa (KP) have sparred with Islamabad over the allocation of investments. Opposition parties have accused the central government of discrimination and claimed that the distribution of routes, services, industrial parks, and special economic zones denies some provinces access to investment opportunities and only benefits Punjab -Pakistan's most populous province containing more than half the country's total population. ${ }^{26}$ The discontent against CPEC is most potent in Balochistan where on the one hand moderate pro-federation politicians accuse Islamabad of preferential treatment and on the other hand militant groups outrightly reject the corridor as a neo-colonial project.

\section{Militarisation and Resistance to Chinese Presence}

Since Beijing began investing heavily in Balochistan, Baloch separatists have increasingly turned their attention to China, which they perceive to be hand in glove with Islamabad in the exploitation of resources and the militarisation of their spaces. They decry that profitable resources are being siphoned off with the 'development' projects in Balochistan following a familiar pattern of exclusion, misappropriation and skewed revenue distribution ratio. The Saindak Project, presently the largest operating copper and gold mine in Pakistan, is a case in

\footnotetext{
${ }^{25}$ RITZINGER, Louis. The China-Pakistan Economic Corridor: Regional Dynamics and China's Geopolitical Ambitions. The National Bureau of Asian Research, 2015.

${ }^{26}$ MARKEY, Daniel S.; WEST, James. Behind China's Gambit in Pakistan. Council on Foreign Relations,

2016. https://www.cfr.org/expert-brief/behind-chinas-gambit-pakistan.
} 
point. The Chinese enterprise, the Metallurgical Corporation of China (MCC) has been operating the profitable Saindak mines since 2001 but with little oversight and accountability. ${ }^{27}$ A working paper submitted to the Senate functional committee reveals that copper extracted at Saindak from 2003 to 2013 was sold for around \$1.6 billion. Pakistan and China pocketed the lion's share while Balochistan received a meagre $\$ 9$ million. ${ }^{28}$ The Saindak project has been called a daylight robbery; there is no tally of how much silver, gold and copper was separated since the mines become operational in $2002 .^{29}$ The lopsided revenue sharing notwithstanding, even secondary benefits like the uplift of the local area, including employment opportunities, have evaded the locals. As two scholars observe that "the Chinese, following their well-honed management approach to such mega-projects, are highly self-sufficient and have not engaged local labor in these efforts." 30

No other project impinged on Baloch nationalism as much as Gwadar port did. ${ }^{31}$ Projected as the next utopia akin to Dubai and Shenzen, the port presents the tragic story of exclusion, expropriation and dispossession for the local population. In 2013 leasing rights for the port were transferred to China Overseas Port Holding Company-Pakistan (COPHC) under the CPEC agreement after PSA failed to meet its investment pledges and decided to withdraw. The agreement grants COPHC 91 per cent of the profits and Islamabad nine per cent over the next 40 years while denying Balochistan any revenue. Moreover, the port was constructed on a prime fishing ground located along the East Bay, where the majority of the locals depend on the fishing industry for their livelihood. Access to the sea was also restricted due to security concerns causing their steady displacement. ${ }^{32}$ With CPEC throwing a renewed spotlight on Gwadar port, displacement of fishermen has accelerated and more land is being expropriated by the federal government to make way for development. ${ }^{33}$ Land grabbing in

\footnotetext{
${ }^{27}$ Until 2012 when the share of the province was enhanced as required by the eighteenth constitutional amendment, according to the terms of the contract the federal government and the MCC received 48 per cent and 50 per cent revenue respectively, leaving a pittance of 2 per cent for Balochistan. MCC was to pay $\$ 500,000$ per month to Pakistan for 10 years and 50 per cent of the total revenue from the mineral sale, Balochistan was to receive a meagre $\$ 0.7$ million per year as royalty. Fazl-e-Haider. Syed. "Expansion of Saindak copper project", Dawn, 31 Oct 2005, https://www.dawn.com/news/163609.

${ }^{28}$ The Express Tribune. Saindak Copper and Gold Project: Centre refuses to hand over ownership till 2018. Nov 24, 2014, at https://bit.ly/2TrDwMe.

${ }^{29}$ NOTEZAI, Muhammad Akbar. The Saindak Files. Dawn, Jan 7, 2018. https://www.dawn.com/news/1381378.

${ }^{30}$ FAIR, Christine; HAMZA, Ali. Rethinking Baloch Secularism: What the Data Say. Peace and Conflict Studies, 2017, 24(1), Article 1, p. 11.

${ }^{31}$ WANI, Shakoor A. The Changing Dynamics of the Baloch Nationalist Movement in Pakistan: From

Autonomy toward Secession. Asian Survey, 2016, 56(5); 807-832, p. 810.

${ }^{32}$ International Crisis Group. China-Pakistan Economic Corridor: Opportunities and risks. Asia Report N ${ }^{\circ} 297$, 2018, p. 20.

${ }^{33}$ KOVRIG, Michael. National Ambitions Meet Local Opposition along the China-Pakistan Economic Corridor. International Crisis Group, 2018. https://bit.ly/2tKFl8v
} 
Gwadar has become another contentious issue after civil and military elites from other provinces appropriated lands owned by locals who possessed no ownership documents. Military, navy, coastguards all acquired prime land at Gwadar at throwaway prices. ${ }^{34}$ Moreover, locals have not benefited from employment opportunities created by CPEC as China brings along its own labour and also the local human resource is too underdeveloped to compete with outsiders. ${ }^{35}$ Gwadar, branded as the futuristic port city still lacks basic amenities like clean water, schools and hospitals for local inhabitants.

Once fully developed, Gwadar port city is projected to attract millions of migrants according to some official estimates. It will reshape the demographics of Gwadar city led by an influx of economic non-Baloch migrants. According to an estimate, the population of the Gwadar city currently around 90,000 is constantly increasing and the city is likely to have a population of over two million within the next two decades, with the majority being from other provinces of Pakistan. ${ }^{36}$ There are also reports that gated colonies will be built exclusively for Chinese professionals in Gwadar. Some reports even estimate that the Chinese will outnumber the native population by $2048 .{ }^{37}$ While these reports may or may not turn into a reality, they nonetheless play upon Baloch anxieties about demographic change and reinforce resistance to Gwadar Port. This resentment has led to the targeted attacks on Chinese personnel and labourers working on various China funded projects in Balochistan. While the Chinese have been targeted in Balochistan since the 2001 attack in Sibi district, they have come increasingly under attack as their presence and investments in the region grew in number. Between 2001 and 2017, a study found 13 such attacks in which 60 people were killed, mostly labourers working on Chinese projects but also some Chinese nationals. ${ }^{38}$

However, instead of addressing the local discontent over exploitation, inequitable resource sharing and apprehensions about demographic change, Islamabad has responded

\footnotetext{
${ }^{34}$ KAPLAN, Robert. Pakistan's fatal shore. The Atlantic Monthly, 2009, 72. http://www.theatlantic.com/magazine/archive/2009/05/pakistans-fatal-shore/307385/

${ }^{35}$ KAKAR, R. China Pakistan Economic Corridor (CPEC) and Balochistan. In Maheen Hassan \& Umer Akhlaq M. (Eds), Balochistan: Challenges \& opportunities, 2018, Islamabad: UNDP, p. 14-15.

${ }^{36}$ AHMED, Zahid Shahab. Impact of the China-Pakistan Economic Corridor on Nation-Building in Pakistan. Journal of Contemporary China, 2018, p. 10.

${ }^{37}$ CHAUDHURY, Dipanjan Roy. As part of CPEC, 'Chinese only'colony coming up in Pakistan. Economic Times, 2018, 21.

YOUSAFZAI, Fawad. Chinese to outnumber Baloch natives by 2048. The Nation, 04 Aug, 2018. https://bit.ly/2hrYbbZ

${ }^{38}$ JAWAD, Syed. Terrorising the Belt and Road: A critical analysis of security threats to Chinese nationals and businesses in Pakistan. China Pakistan Management Initiative, LUMS Working Paper Series, 2017. http://shorturl.at/gmnHO
} 
with increased security surveillance and control. ${ }^{39}$ Some other conciliatory options were also tried to create a more conducive environment for Chinese investments. For instance, the parliamentary committee established by the Musharraf government in 2004 and the Aghaz-eHuqooq-e-Balochistan package (Urdu for Beginning of Rights in Balochistan) in 2009 attempted to accommodate Baloch grievances through institutional structures. However, these efforts were half-hearted and the reforms were never fully implemented. Contrary to the popular demands for the greater provincial control over Gwadar port and a halt to the construction of military cantonments, Musharraf government approved the construction of three new army cantonments in some of the most sensitive districts in the region, namely Sui, Gwadar and Kohlu. This further indicates government's willingness to militarily dominate the region to provide greater security to Chinese nationals working in the area. ${ }^{40}$

The military 'solutions' continue to be the preferred way over arduous democratic compromises to deal with the security issues in Balochistan. A 15,000-strong force was created to protect Chinese interests in Pakistan. ${ }^{41}$ The federal government also planned to build a 24-km fence to physically seal off parts of Gwadar to protect CPEC related investments from insurgent attacks. The decision was later reversed following a public outcry. ${ }^{42}$ It is telling that Chinese authorities appear to be more sensitive to local resentment than Islamabad. They built a school and promised some $\$ 500$ million assistance for the construction of a hospital, a college and projects to supply the city with drinking water. ${ }^{43}$ Chinese analysts have also suggested that Beijing must build up local support by establishing contacts with local communities to better accommodate local interests in order to ensure the success of CPEC. ${ }^{44}$ Some reports suggested that Beijing was holding talks with Baloch rebels to protect its investments in the province. ${ }^{45}$ However, such efforts did not yield desired results as evidenced by subsequent attacks against Chinese interests and workers.

\footnotetext{
${ }^{39}$ KOVRIG, Michael. National Ambitions Meet Local Opposition along the China-Pakistan Economic Corridor. International Crisis Group, 2018. https://bit.ly/2tKFl8v

${ }^{40}$ BONI, Filippo. Civil-military relations in Pakistan: a Case Study of Sino-Pakistani Relations and the Port of Gwadar. Commonwealth \& Comparative Politics, 2016, 54(4): 498-517, p. 504.

${ }^{41}$ AKINS, Harrison. China in Balochistan: CPEC and the Shifting Security Landscape of Pakistan. Howard H. Baker Jr. Center for Public Policy, Policy Brief 4:17, 2017, University of Tennessee., p. 10.

${ }^{42}$ ZAFAR, M. CM halts work on Gwadar fencing project. The Express Tribune, 2020. https://tribune.com.pk/story/2277928/cm-halts-work-ongwadar-fencing-project

43 ADENEY, Katherine; BONI, Filippo. How Pakistan and China negotiate. Washington DC: Carnegie Endowment for International Peace, 2021, p. 20-21.

${ }^{44}$ NOTEZAI, M. Akbar. Why Balochs Are Targeting China. The Diplomat, 2018. https://hediplomat.com/2018/11/why-balochs-are-targeting-china/

${ }^{45}$ BOKHARI, Farhan \& Stacey, Kiran. China woos Pakistan militants to secure Belt and Road projects. Financial Times, 2018. https://www.ft.com/content/063ce350-1099-11e8-8cb6-b9ccc4c4dbbb
} 
In the midst of pervasive militarisation and growing disenchantment with exclusionary 'development', the appeal of separatism is finding greater resonance among the increasingly disillusioned population. The anxiety over an impending threat to the demographic balance has engendered a radical ethnic consciousness among the Baloch who perceive the pattern in the influx of outsiders as "ethnic swamping." 46 As a result, the struggle to restore ownership over the province's resources has become a cornerstone of the Baloch armed resistance.

\section{The Majeed Brigade: The Formation of an anti-China Front}

The Majeed brigade was formed to target security forces and Chinese personnel and investments in the region. Since its formation, Baloch militants have not hesitated to take their fight outside the territorial precincts of Balochistan by carrying out attacks against carefully chosen targets outside the province. This strategy has somewhat lifted the Baloch resistance from the abyss of obscurity in which the province remains perennially shrouded and forced its inclusion in the national and international discourse. In December 2011, members from the Majeed Brigade carried out what was the first suicide attack since the onset of insurgency in the mid-2000s. A car laden with explosives targeted the alleged head of a Pro-Pakistan militia-Shafeeq Mengal at his residence in Quetta. The blast killed more than 10 people but Shafiq and his family escaped unhurt. ${ }^{47}$

The Majeed Brigade remained dormant until 2017, when Aslam Baloch rose through the ranks to become the commander-in-chief of the BLA. ${ }^{48}$ Aslam repurposed the group as a near China-exclusive outfit and under his leadership, the group carried out some of the most high profile attacks on Chinese personnel and businesses who Aslam believed were "looting resources in Balochistan in the name of mega projects". ${ }^{49}$ In August 2018, the Brigade targeted a bus carrying Chinese engineers in Dalbandin. The suicide attack injured three Chinese engineers and five other people. Although the suicide attack was a limited success, it was nevertheless a symbolic display of Aslam's commitment to the group's objective to drive the Chinese away, he had assigned his elder son as the suicide bomber.

A more daring attempt to hurt China was made a few months later when members of the Brigade launched an attack against the Chinese consulate in Karachi in which seven

\footnotetext{
${ }^{46}$ LIEVEN, Anatol. Pakistan: A Hard Country, New York: Public Affairs, 2011.

${ }^{47}$ MASOOD, Salman. Car Bombing, Claimed by Separatists, Kills 10 in Pakistan. The New York Times, Dec 30, 2011. https://shorturl.at/alJTZ

${ }^{48}$ The Balochistan Post. Aslam Baloch-The Baloch General. 11 Feb 2020 at https://shorturl.at/otFNQ

${ }^{49}$ AAMIR, Adnan. The Balochistan Insurgency and the Threat to Chinese Interests in Pakistan. China Brief: A Journal of Analysis and Information, 2019, 19(4).
} 
people were killed including the three attackers. A pre-recorded video warned Chinese investors to stop exploiting the resources of Balochistan, or else the attacks would continue. ${ }^{50}$ A few weeks later, Aslam Baloch was killed in a suicide bombing attack in Kandahar, Afghanistan. The commander's death was a severe blow to the fledgling group, whose organisation and structure remain nebulous. His death, however, did not deter the group from launching further attacks and some months later, Balochistan's only five star hotel, the Pearl Continental in Gwadar, where the Chinese businessmen are known to stay, was attacked by the group. Four hotel employees and one security personnel were killed. The recent attack on Pakistan Stock Exchange in June 2020 too had a Chinese angle. In 2016, China became the anchor investor in the stock market and secured management control by acquiring 40 per cent of its shares in a transaction valued at $\$ 85$ million. The shares are held by Shanghai Stock Exchange, Shenzhen Stock Exchange and China Financial Futures Exchange. Another five per cent of shares held by a local company are also linked to Chinese investment. ${ }^{51}$

All the above attacks by Majeed Brigade have had a high visibility impact but were unable to exact significant damages on the opponent. The attackers have failed to engage the adversary for longer hauls and some of the attacks have been neutralised in a flash. This brings to fore the group's poor organisational capacity, lack of preparedness, training and resources. Above all, it points towards the absence of serious external assistance or a guiding hand that could make the group more effective and lethal and thus seems to belie the claims by the Pakistan government that these attacks are handiwork of foreign intelligence agencies.

Yet the recurring attacks have exposed the vulnerability of Chinese personal and inhibited their mobility within the province. They are unable to move freely and must travel with security squads. The attacks have increased the security costs of CPEC. In addition to the 15,000 strong security division created to protect Chinese personnel, Chinese firms working in Pakistan have also hired private security guards thus sharply increasing the security costs of CPEC. ${ }^{52}$ The attacks on Chinese by Baloch separatists as well as by extremist groups like Tehrik-i-Taliban Pakistan (TTP) - which have begun to increasingly target Chinese personal due to Beijing's persecution of the Uyghur Muslims in the Xinjiang region, have raised question marks on the future of Gwadar port.

\footnotetext{
${ }^{50}$ Ibidem

${ }^{51}$ BAQIR S. Syed. Analysis: BLA out to bleed Pakistan economy, Chinese interests. Dawn, June 30, 2020. https://shorturl.at/duxQ3

52 AAMIR, Adnan. The Balochistan Insurgency and the Threat to Chinese Interests in Pakistan. China Brief: A Journal of Analysis and Information, 2019, 19(4).
} 
There are already changes underway and Gwadar seems to be losing its importance as a mega-investment hub. Saudi Arabia has decided to shift a proposed oil refinery to Karachi from Gwadar. In 2019, Riyadh had committed to invest $\$ 10 \mathrm{bn}$ in an oil refinery and petrochemical complex at Gwadar. The decision to withdraw stemmed from the infrastructural shortcomings of Gwadar, which Pakistan and China have failed to address in the past six years. ${ }^{53}$ With security in Balochistan showing no signs of improvement, China may well be turning its back on Gwadar port city. As the recent MoU signed between Pakistan and China for the Karachi Coastal Comprehensive Development Zone indicates, the focus and investments might be shifting towards Karachi and away from Gwadar. ${ }^{54}$ While China may remain invested in Gwadar port for strategic reasons, the development of a futuristic port city will remain a pipe dream, as unending turmoil makes sustained investments in infrastructure unfeasible.

\section{Conclusion}

Balochistan is currently into the second decade of a simmering low intensity insurgency that commenced in the mid-2000s. Although Baloch nationalism is informed by historically consistent demands for greater self-rule, the contemporary conflict is characterised by such dominant themes as, expropriation, marginalization, and dispossession. The Baloch are increasingly conscious of the riches their land possesses and yet find themselves among the most deprived in the country. For decades, Balochistan was the largest producer of natural gas in the country and Pakistan relied heavily on it for its domestic consumption. However, most of the energy produced there bypasses Balochistan to supply the state's most industrialized and populous provinces, Punjab and Sindh. Even the royalties allocated by the federal government to the province were until recently the lowest among the gas-producing provinces of Pakistan. Similarly with the development of Gwadar Port, purported to transform the coastal region of Gwadar into the next Dubai, the local population again find themselves bereft of any potential benefits. As one think tank report aptly summarises, that "instead of developing a sleepy fishing village into a bustling commercial hub as pledged by Islamabad

\footnotetext{
53 AAMIR, Adnan. Pakistan's Gwadar loses lustre as Saudis shift \$10bn deal to Karachi. Financial Times, 23 June 2021. https://www.ft.com/content/88cfe78b-517f-41d9-97d1-9f7f540f517c

${ }^{54}$ AAMIR, Adnan. Pakistan and China unveil ambitious plan to develop Karachi coast. Nikkei Asia, 5 October 2021. https://asia.nikkei.com/Spotlight/Belt-and-Road/Pakistan-and-China-unveil-ambitious-plan-to-developKarachi-coast
} 
and Beijing, the project is producing a heavily militarised zone, displacing locals and depriving them of economic lifelines."

It is experiences like this that have made the Baloch wary of Islamabad's promises of development. They see CPEC and its lynchpin-the Gwadar port as another 'colonial' period enabled by China. As a result, Baloch insurgents are not only targeting energy infrastructure, mainly gas pipelines and other modes of distribution, but also Chinese engineers, workers, and technicians, who are perceived as accomplices and profiteers from Pakistan's 'colonial' projects. $^{56}$

$\mathrm{CPEC}$ is seen as a particularly disruptive project -that can result in the expropriation of their resources and upend the demographic balance in the province. This has engendered deep anxieties among the local population who have responded with fear and violence. A new insurgent faction -Majeed Brigade has emerged with the stated goal of pushing the Chinese away from Balochistan. A spate of attacks against Chinese interests and personal has created jitters in Islamabad, which fears losing on the much-coveted investment from Beijing. The anxiety to protect the Chinese investment at all costs has intensified the militarisation of the province and expropriation of resources in Balochistan in the name of development and antiterrorism. And as the military further entrenches its penetration to safeguard economic assets and ward off the threat from a hostile local population, nationalists are pushing back against the intensifying control over their land and resources.

As a quintessential endpoint of CPEC, Balochistan should have indubitably been its major beneficiary. CPEC possesses an immense transformational potential for Pakistan as well as Balochistan. However, the Baloch have serious apprehensions about the implications of centrally imposed large-scale development projects. Only by fostering a sense of ownership, creating stakes for the Baloch in the projects and incentivizing their participation in harnessing and protecting their resources, can the brewing discontent be assuaged. In its current form CPEC, with minimal local control over their resources, absence in the decision making processes and an overbearing military presence, may well end up furthering the divide between Islamabad and Quetta.

\footnotetext{
${ }^{55}$ International Crisis Group. China-Pakistan Economic Corridor: Opportunities and risks. Asia Report N ${ }^{\circ} 297$, 2018, p. i-ii.

${ }^{56}$ WANI, Shakoor A. The Changing Dynamics of the Baloch Nationalist Movement in Pakistan: From Autonomy toward Secession. Asian Survey, 2016, 56(5); 807-832.
} 


\section{References}

AAMIR, Adnan. Pakistan and China unveil ambitious plan to develop Karachi coast. Nikkei Asia, 5 October 2021. https://asia.nikkei.com/Spotlight/Belt-and-Road/Pakistan-andChina-unveil-ambitious-plan-to-develop-Karachi-coast

AAMIR, Adnan. Pakistan's Gwadar loses lustre as Saudis shift \$10bn deal to Karachi. Financial Times, 23 June 2021. https://www.ft.com/content/88cfe78b-517f-41d9-97d19f7f540f517c

AAMIR, Adnan. The Balochistan Insurgency and the Threat to Chinese Interests in Pakistan. China Brief: A Journal of Analysis and Information, 2019, 19(4).

ADENEY, Katherine; BONI, Filippo. How Pakistan and China negotiate. Washington DC: Carnegie Endowment for International Peace, 2021.

AHMED, Zahid Shahab. Impact of the China-Pakistan Economic Corridor on NationBuilding in Pakistan. Journal of Contemporary China, 2018, DOI: 10.1080/10670564.2018.1542221.

AKBAR, Malik Siraj. The End of Pakistan's Baloch Insurgency?" HuffPost, 3 Nov 2014. http://shorturl.at/wFPZ8

AKHTAR, Aasim Sajjad. Balochistan versus Pakistan. Economic and Political Weekly, 2007, 42(45/46): 73-79.

AKINS, Harrison. China in Balochistan: CPEC and the Shifting Security Landscape of Pakistan. Howard H. Baker Jr. Center for Public Policy, Policy Brief 4:17, 2017, University of Tennessee.

BAQIR S. Syed. Analysis: BLA out to bleed Pakistan economy, Chinese interests. Dawn, June 30, 2020. https://shorturl.at/duxQ3.

BOKHARI, Farhan \& Stacey, Kiran. China woos Pakistan militants to secure Belt and Road projects. Financial Times, 2018. https://www.ft.com/content/063ce350-1099-11e88cb6-b9ccc4c4dbbb

BONI, Filippo. Civil-military relations in Pakistan: a Case Study of Sino-Pakistani Relations and the Port of Gwadar. Commonwealth \& Comparative Politics, 2016, 54(4): 498-517. DOI: $10.1080 / 14662043.2016 .1231665$

CHAUDHURY, Dipanjan Roy. As part of CPEC, 'Chinese only' colony coming up in Pakistan. Economic Times, 2018, 21.

DUCHÂTEL, Mathieu. The Terrorist Risk and China's Policy toward Pakistan: strategic reassurance and the 'United Front'. Journal of Contemporary China, 2011, 20(71): 543561.

ESTEBAN, M. The China-Pakistan Corridor: A Transit, Economic or Development Corridor?" Strategic Studies, 2016, 36(2): 63-74.

FAIR, Christine; HAMZA, Ali. Rethinking Baloch Secularism: What the Data Say. Peace and Conflict Studies, 2017, 24(1), Article 1. DOI: 10.46743/1082-7307/2017.1405

FARHAN Zahid, 'Baluch Raji Ajohi Sangar: Emergence of a New Baluch Separatist Alliance', The Jamestown Foundation -Terrorism Monitor, XVII(18): 7-8, 2019.

FAZL-E-HAIDER. Syed. Expansion of Saindak copper project. Dawn, 31 Oct 2005. https://www.dawn.com/news/163609

GRARE, Frederic. Pakistan: The Resurgence of Baluch Nationalism. The Carnegie Papers, 2006, No. 65, Washington, DC: Carnegie Endowment for International Peace.

HAIDER, Ziad. Baluchis, Beijing, and Pakistan's Gwadar Port. Georgetown Journal of International Affairs, 2005, 6(1): 95-103.

HAQQANI, Hussain. Pakistan: Between Mosque and Military. Lahore: Vanguard, 2005. 
HARRISON, Selig. In Afghanistan's Shadow: Baluch Nationalism and Soviet Temptations.

Washington, D.C.: Carnegie Endowment for International Peace, 1981.

HARTPENCE, Mathias. The Economic Dimension of Sino-Pakistani Relations: an overview. Journal of Contemporary China, 2011, 20(71): 581-599. DOI: 10.1080/10670564.2011.587160

International Crisis Group. China-Pakistan Economic Corridor: Opportunities and risks. Asia Report N²97, 2018.

JAVED, Umair; NABI, Ijaz. Heterogeneous fragility: The case of Pakistan. Commission on State Fragility, Growth and Development, 2018. https://www.theigc.org/wpcontent/uploads/2018/04/Pakistan-report.pdf

JAWAD, Syed. Terrorising the Belt and Road: A critical analysis of security threats to Chinese nationals and businesses in Pakistan. China Pakistan Management Initiative, LUMS Working Paper Series, 2017. http://shorturl.at/gmnHO

JETLY, Rajshree. Baluch ethnicity and nationalism (1971-81): an assessment. Asian Ethnicity, 2004, 5.1: 7-26. DOI: 10.1080/1463136032000168871

JETLY, Rajshree. The politics of Gwadar Port: Baluch nationalism and Sino-Pak relations. The Round Table, 2021, 110(4): 432-447. DOI: 10.1080/00358533.2021.1957226

KAKAR, R. China Pakistan Economic Corridor (CPEC) and Balochistan. In Maheen Hassan \& Umer Akhlaq M. (Eds), Balochistan: Challenges \& opportunities, 2018, Islamabad: UNDP.

KAPLAN, Robert. Pakistan's fatal shore. The Atlantic Monthly, 2009, 72. http://www.theatlantic.com/magazine/archive/2009/05/pakistans-fatal-shore/307385/

KHAN, Adeel. Politics of Identity: Ethnic Nationalism and the State in Pakistan. New Delhi: Sage, 2005.

KOVRIG, Michael. National Ambitions Meet Local Opposition along the China-Pakistan Economic Corridor. International Crisis Group, 2018. https://bit.ly/2tKFl8v

LIEVEN, Anatol. Pakistan: A Hard Country, New York: Public Affairs, 2011.

MARKEY, Daniel S.; WEST, James. Behind China's Gambit in Pakistan. Council on Foreign Relations, 2016. https://www.cfr.org/expert-brief/behind-chinas-gambitpakistan

MASOOD, Salman. Car Bombing, Claimed by Separatists, Kills 10 in Pakistan. The New York Times, Dec 30, 2011. https://shorturl.at/alJTZ

NABEEL, Fahad. Aslam Baloch's killing: Implications for Balochistan Insurgency. Centre for Strategic and Contemporary Research, 2018. http://shorturl.at/doLMU

NOTEZAI, Muhammad Akbar. The Saindak Files. Dawn, Jan 7, 2018. https://www.dawn.com/news/1381378

NOTEZAI, Muhammad Akbar. Why Balochs Are Targeting China. The Diplomat, 2018. https://thediplomat.com/2018/11/why-balochs-are-targeting-china/

RITZINGER, Louis. The China-Pakistan Economic Corridor: Regional Dynamics and China's Geopolitical Ambitions. The National Bureau of Asian Research, 2015.

RIZVI, Hasan A. The China-Pakistan Economic Corridor: regional cooperation and socioeconomic development. Strategic Studies, 2014, 34(4): 1-17.

SCHMIDLE, Nicholas. Waiting for the Worst: Baluchistan, 2006. Virginia Quarterly Review, 2007, 83(2).

SHEIKH, Salman Rafi. The Genesis of Baloch Nationalism: Politics and Ethnicity in Pakistan, 1947-1977. New York: Routledge, 2018. DOI: 10.4324/9781351020701

SIDDIQUE, Abubakar. Baluch Separatist Insurgency Torn by Internal Conflict over Class. Gandhara, July 04, 2020, at https://shorturl.at/jDR17

SMALL, Andrew. The China-Pakistan Axis: Asia's New Geopolitics. New York: Oxford University Press, 2015. DOI: 10.1093/acprof:oso/9780190210755.001.0001 
The Balochistan Post. Aslam Baloch-The Baloch General. 11 Feb 2020 at https://shorturl.at/otFNQ

The Balochistan Post. BLA says it does not have any representatives in London, Europe or US. 17 August 2018. http://shorturl.at/nqAD8

The Express Tribune. Saindak Copper and Gold Project: Centre refuses to hand over ownership till 2018. Nov 24, 2014, at https://bit.ly/2TrDwMe

The World Bank. Balochistan Mining and Regional Integration Policy Dialogue Paper, 2013. https://www.pakistanmdtf.org/images/stories/projectdocuments/BalochistanReport2013

TITUS, Paul; SWIDLER, Nina. Knights, not pawns: Ethno-nationalism and regional dynamics in post-colonial Balochistan. International Journal of Middle East Studies, 2000, 32.1: 47-69. DOI: 10.1017/S0020743800021048

WANI, Shakoor A. The Changing Dynamics of the Baloch Nationalist Movement in Pakistan: From Autonomy toward Secession. Asian Survey, 2016, 56(5); 807-832. DOI: 10.1525/as.2016.56.5.807

WANI, Shakoor A. The New Baloch Militancy: Drivers and Dynamics. India Quarterly, 2021, 77(3) 479-500. DOI: 10.1177/09749284211027253

YANG, Jian; RASHID A Siddiqi. About an 'All-Weather' Relationship: security foundations of Sino-Pakistan relations since 9/11. Journal of Contemporary China, 2011, 20(71): 563-579. DOI: 10.1080/10670564.2011.587159

YOUSAFZAI, Fawad. Chinese to outnumber Baloch natives by 2048. The Nation, 04 Aug, 2018. https://bit.ly/2hrYbbZ

ZAFAR, M. CM halts work on Gwadar fencing project. The Express Tribune, 2020. https://tribune.com.pk/story/2277928/cm-halts-work-ongwadar-fencing-project 


\title{
Balúčské povstání v Pákistánu a souvislost s Čínou
}

\author{
Shakoor Ahmad Wani \\ Islamic University of Science \& Technology, Awantipora, Jammu and Kashmir 192122, India \\ Email: shakoor.ahmad@live.in
}

DOI: https://doi.org/10.7160/KS.2021.170204cs

\begin{abstract}
Shakoor Ahmad Wani vyučuje mezinárodní vztahy na Islamic University of Science and Technology v Awantipoře $v$ Kašmíru. Získal doktorát $v$ oboru jihoasijských studií na Škole mezinárodních studií na Univerzitě Džaváharlála Néhrúa v Dillí v Indii.
\end{abstract}

\begin{abstract}
Abstrakt
Tento článek zkoumá vzájemný vztah mezi velkými investičními projekty financovanými čínským kapitálem a etnonacionalismem v provincii Balúčistán. Článek ukazuje, že rostoucí čínská přítomnost $\mathrm{v}$ Balúčistánu poskytla nový impuls již doutnajícímu balúčskému nacionalistickému odporu. Balúčistán disponuje rozsáhlým prŕírodním bohatstvím, avšak z jeho bohatství jeho obyvatelé neprofitují. Balúčové jsou jednou $\mathrm{z}$ nejchudších komunit $\mathrm{v}$ zemi. Všechny centrální vlády využívaly zdroje provincie ve jménu rozvoje na úkor jejích obyvatel. Vznik CPEC (China-Pakistan Economic Corridor / Čínsko-pákistánský hospodářský koridor) balúčské problémy ještě zhoršil. Balúčové se domnívají, že megalomanské rozvojové projekty, jako je přístav Gwadar, negativně ovlivní místní demografii tím, že přilákají obrovský příliv ekonomických migrantů a učiní z Balúčů menšinu v jejich vlastní zemi. Povstalecké skupiny považují Čínu za „partnera ve zločinu“ a reagují selektivními útoky na čínská aktiva a personál. Článek analyzuje povahu odporu vůči čínské př́itomnosti a měnící se způsoby jednání povstaleckých skupin. Tvrdí, že pokusy Islámábádu odvrátit útoky zesílením militarizace provincie jsou kontraproduktivní, nebot' posilují balúčský odpor vůči CPEC.
\end{abstract}

\section{Klíčová slova}

CPEC, Balúčistán, př́ístav Gwadar, demografie, vyloučení

\section{Úvod}

Pákistánská provincie Balúčistán je již téměř dvě desetiletí zmítána doutnajícím povstáním. Balúčští bojovníci, kteří jsou podněcováni historickými pocity křivdy, včetně politického opomíjení, ekonomické marginalizace a vyvlastňování zdrojů, vedou pravidelné ozbrojené boje proti autoritářskému státu. Balúčistán má bohaté přírodní zdroje, ale jeho obyvatelé z nich nemají téměř žádný užitek. Jeho zdroje, zejména zemní plyn, přispěly do státní pokladny miliardami dolarů a rozvíjely průmysl v Karáčí a centrálním Paňdžábu, ale 
provincie je stále nejchudší. Sociálně-ekonomické ukazatele jsou hluboko pod celostátním průměrem a míra gramotnosti je nejnižší v zemi. Provincii chybí základní občanská vybavenost, jako je čistá voda, elektřina a zdravotnická infrastruktura. ${ }^{1}$ V Balúčistánu je $71 \%$ domácností klasifikováno jako chudé, zatímco celostátní průměr činí $37 \%{ }^{2}$

Mnohamiliardové investice Číny do odvětví nerostných surovin, př́istavu Gwadar a nyní i do čínsko-pákistánského hospodářského koridoru / China-Pakistan Economic Corridor (CPEC) zdůraznily vnímání vykořist'ování. Ještě před CPEC se Čína podílela na různých projektech v provincii, jako je přístav Gwadar a projekt těžby mědi a zlata v okrese Čagaj. S CPEC zaznamenala čínská účast rychlý nárůst vlivu. Balúčští nacionalisté se obávají, že masivní čínské investice zvýší míru odcizování jejich zdrojů, způsobí socioekonomické rozvraty a naruší demografickou rovnováhu v provincii. Obávají se, že masový př́liv cizinců, který se odhaduje na několik milionů osob, vyvolaný projekty, jako již zmiňovaný přístav Gwadar, by mohl z města Gwadar vytvořit další Karáčí - metropoli, kde migranti převyšují počet původních obyvatel. Jediné Karáčí v rozlehlém, ale řídce osídleném Balúčistánu by znamenalo, že Balúčové by se v oblasti, kterou považují za svou historickou vlast, stali menšinou. To vyvolalo silné zděšení a odpor vůči tomu, co vnímají jako „pákistánsko-čínský neokoloniální projekt“, jehož cílem je vyvlastnit jejich zdroje.

Balúčové reagovali strachem a násilím a vystupňovali doposud latentní povstání. Zpočátku povstalci vyhazovali do povětř́i plynovody a další energetickou infrastrukturu dodávající zdroje do jiných částí Pákistánu, postupně se terčem staly rostoucí čínské investice a personál. Sporadické útoky na čínský personál zintenzivnily snahu Islámábádu ovládnout region prostř̌ednictvím rozsáhlé militarizace oblasti. To vedlo $\mathrm{k}$ prudkému nárůstu případů násilných zmizení a mimosoudních poprav.

Zhoršující se porušování lidských práv ze strany bezpečnostních složek a mizivá pozornost médií přiměly balúčské separatisty $\mathrm{k}$ většímu zviditelnění své věci tím, že zvýšili náklady Pákistánu a Číny. Doutnající povstání zůstávalo př́liš dlouho omezeno na území Balúčistánu. To se začíná měnit, protože povstalecké skupiny, zejména Balúčská osvobozenecká armáda (BLA), přehodnocují své strategie a rozšiřují oblast konfliktu.

Tento článek se zabývá čínskými investicemi v Balúčistánu a jejich interakcí s balúčským nacionalismem. Tvrdí, že CPEC a zejména stavba přístavu Gwadar posílily

\footnotetext{
${ }^{1}$ The World Bank. Balochistan Mining and Regional Integration Policy Dialogue Paper, 2013. https://www.pakistanmdtf.org/images/stories/project-documents/BalochistanReport2013.pdf, s. 28.

${ }_{2}^{2}$ JAVED, Umair; NABI, Ijaz. Heterogeneous fragility: The case of Pakistan. Commission on State Fragility,

Growth and Development, 2018. https://www.theigc.org/wp-content/uploads/2018/04/Pakistan-report.pdf, s. 25.
} 
místní vnímání vykořist'ování a vyvlastňování. Balúčové se obávají sociálně-ekonomického narušení, které megaprojekty způsobují, a proto kladou zuřivý odpor. První oddíl zasazuje balúčský nacionalismus do historického kontextu a tvrdí, že současný odpor proti čínským projektům vychází z historie vykořist’ování zdrojů těžební centrální vládou. Druhý oddíl zkoumá různé motivy, které jsou základem čínských investic v Balúčistánu. Třetí oddíl analyzuje příčiny odporu Balúčů proti čínským investicím a tvrdí, že rostoucí útoky proti čínským zájmům vedly k intenzivnímu vojenskému potlačování, což posílilo odpor proti CPEC. Čtvrtý oddíl se zaměřuje na Madžídovu (Majeed) brigádu - výrazně protičínskou povstaleckou frakci, která vznikla jako reakce na rostoucí čínskou přítomnost v Balúčistánu. Tato nová skupina přijala dosud neotřelý modus operandi a rozšírila oblast konfliktu tím, že podniká akce mimo hranice provincie. Poslední oddíl shrnuje argumenty a uzavírá je několika poznámkami o tom, aby se Balúčové stali rovnocennými účastníky CPEC.

\section{Kořeny balúčské nespokojenosti}

Balúčistán je jednou ze čtyř federativních jednotek Pákistánu. Je to rozlohou největší, ale nejméně zalidněná provincie, v níž žije přibližně šest procent obyvatel země. Z etnickojazykového hlediska je to nejrozmanitější pákistánská provincie. Dominantní etnickou skupinou jsou Balúčové, následovaní Paštuny a dalšími menšími menšinami, jako jsou Paňdžábci, Hazárové, Sindhové atd. Základem společenské struktury v Balúčistánu je kmenové uspořádání. Existuje 17 hlavních balúčských kmenových skupin a přibližně 400 podskupin, přičemž v čele každé skupiny nebo podskupiny stojí sardar (náčelník), který má na kmen značný vliv. ${ }^{3}$

Balúčové si po celou dobu své historie tvrdě střeží svou politickou nezávislost. Od invaze Afghánců až po imperiální Brity se bránili vetřelcům. Po pádu do područí Britů v roce 1839 měl Balúčistán kvazi suverénní postavení. Chán (náčelník) Kalátu - největšího knížecího státu v Balúčistánu - získal značnou volnost ve správě vnitřních záležitostí výměnou za ochranu císařských obchodních cest a přístup do Afghánistánu. Pro Brity byl Balúčistán ekonomickou pustinou, ale cenili si ho pro jeho strategický význam.

Kořeny současného nacionalistického odporu proti Islámábádu lze vysledovat v pozdější fázi britského koloniálního období. Když se blí̌̌il konec britského odchodu, tehdejší kalátský chán Mir Ahmad Jar Chán podporovaný skupinou mladých balúčských nacionalistů

\footnotetext{
${ }^{3}$ JETLY, Rajshree. Baluch ethnicity and nationalism (1971-81): an assessment. Asian Ethnicity, 2004, 5.1: 726, s. 10.
} 
organizovaných v Kalátské národní státní straně (KSNP) urychlil své aktivity s cílem vytvořit nezávislý Balúčistán. Chán se v době rozdělení postavil proti připojení k Pákistánu a 12. srpna 1947 oficiálně vyhlásil nezávislost.

Pákistán však na odpor Balúčů nebral ohled a Kalát k připojení přinutil. Poté, co pákistánská armáda potlačila počáteční vzpouru proti násilnému připojení, se balúčští vůdci, kteří byli postaveni před hotovou věc a byli si vědomi svého slabého postavení, "smíŕili s připojením k Pákistánu". ${ }^{4}$ Vůdci stojící v čele balúčského boje za nezávislost přehodnotili svůj boj na boj za federální Pákistán, který by poskytl značnou autonomii svým etnickojazykovým menšinám. ${ }^{5}$ Vládnoucí třída však pohrdala nároky menších etnických skupin na etnickou odlišnost a zavedla centralizovanou státní strukturu. Tento centralizovaný státní systém "se změnil v militaristický, autoritářský režim, který nedominantním skupinám vnutil jakýsi 'domorodý' kolonialismus". ${ }^{6} \mathrm{~V}$ důsledku toho se rodící se balúčský nacionalismus, který se objevil před rozdělením indického subkontinentu, stal mocnou silou poté, co Pákistán hrubě převálcoval jejich etno-regionální aspirace.

V důsledku neschopnosti vytvořit stabilní demokratické instituce a nástupu vojenského autoritářství vypukla v Balúčistánu v letech 1958-1962 řada povstání proti centrální vládě. ${ }^{7}$ K nejkrvavější konfrontaci došlo, když byl prezidentem Zulfikár Alí Bhutto. Ačkoli byl Bhutto demokraticky zvoleným vůdcem, sdílel se svými předchůdci mnoho autoritářských tendencí a projevoval příklon $\mathrm{k}$ silnému unitárnímu centru. Pohrdal požadavky menších etnicko-jazykových skupin na větší autonomii provincií a byl nepřátelský vůči provinčním vládám ř́zeným opozičními stranami. ${ }^{8}$ První volby v zemi na základě volebního práva dospělých v roce 1970 vynesly v Balúčistánu k moci Národní stranu Awami (NAP) vedenou horlivým nacionalistou Sardarem Ataullahem Chánem Mengalem. Bhutto nechal provinční vládu působit jen krátce, a o pouhých devět měsíců později (od 1. května 1972 do 12. února 1973) byla v provincii svržena první lidově zvolená vláda na základě pochybného obvinění z př́ípravy secesionistického spiknutí s cílem rozdělit zemi. ${ }^{9}$

\footnotetext{
${ }^{4}$ TITUS, Paul; SWIDLER, Nina. Knights, not pawns: Ethno-nationalism and regional dynamics in post-colonial Balochistan. International Journal of Middle East Studies, 2000, 32.1: 47-69, s. 48.

${ }^{5}$ Ibidem.

${ }^{6}$ SHEIKH, Salman Rafi. The Genesis of Baloch Nationalism: Politics and Ethnicity in Pakistan, 1947-1977. New York: Routledge, 2018, s. 140-141.

${ }^{7}$ WANI, Shakoor A. The New Baloch Militancy: Drivers and Dynamics. India Quarterly, 2021, 77(3) 479-500, S. 481.

${ }^{8}$ HARRISON, Selig. In Afghanistan's Shadow: Baluch Nationalism and Soviet Temptations. Washington, D.C.: Carnegie Endowment for International Peace, 1981, s. 156.

${ }^{9}$ HAQQANI, Hussain. Pakistan: Between Mosque and Military. Lahore: Vanguard, 2005, s. 94.
} 
Mengalovo bezprecedentní odvolání uvrhlo provincii do vleklého ozbrojeného boje mezi směsicí balúčských militantních skupin a vládními silami. Konflikt se táhl čtyři roky (1973-1977) a vedl k úmrtí několika tisíc Balúčů, dokud generál Zia-ul-Haq pučem nesesadil Bhutta $\mathrm{z}$ funkce. ${ }^{10}$ Zia zaujal méně konfrontační přístup, nabídl amnestii uvězněným vůdcům a poskytl provincii hospodářskou pomoc. Zijova metoda nátlaku, kooptace a ekonomické štědrosti pomohla zabránit návratu $\mathrm{k}$ násilí na více než deset let. Jeho nešt’astná smrt při leteckém neštěstí v roce 1988 zahájila desetiletí demokracie v letech 1988-1999. Během tohoto období zůstal Balúčistán převážně klidný a umírněné nacionalistické strany se podílely na obnoveném demokratickém procesu. Když se Pákistán vrátil k vojenskému autoritářství a moci se $\mathrm{v}$ roce 1999 chopil generál Parvíz Mušaraf, došlo k obnovení militantního nacionalistického odporu.

$\mathrm{Na}$ prvním místě Mušarafova programu v roce 1999 bylo podpořit "nemocnou pákistánskou ekonomiku" a za tímto účelem se "zaměřil především na megaprojekty a rozvoj infrastruktury"11 Balúčistán se svým bohatým surovinovým bohatstvím byl ideálním místem. Čína měla hrát klíčovou roli při financování mnoha velkých projektů, jako je přístav Gwadar a projekt Reko Deq na těžbu mědi a zlata. Mušarafưv velký tlak na megalomanské rozvojové projekty se setkal s tvrdým odporem místních obyvatel, kteří se obávali, že budou připraveni o svou půdu a zdroje. ${ }^{12}$ Balúčové, kteří se po léta potýkali s těžkou socioekonomickou deprivací a politickou marginalizací, jsou obezřetní vůči slibům Islámábádu o rozvoji, který místnímu obyvatelstvu přináší jen malý užitek. Snaha armády potlačit místní odpor a získat větší kontrolu nad zdroji a územím vytvořila nezbytné podmínky pro obnovení povstání v Balúčistánu. ${ }^{13}$

\section{Co dělá Čína v Balúčistánu?}

Ústředním bodem čínských zájmů v Pákistánu je přístav Gwadar. Přírodní přístavy Gwadaru po staletí přitahovaly rybáře a obchodníky, kteří pendlovali mezi jihovýchodní Asií, Blízkým východem a Afrikou. Jeho potenciálu jako hlubokomořského prŕstavu si poprvé všimli britští inženýři ve 20. letech 20. století, ale nic se nedělo, dokud Mušaraf v březnu 2002 neoznámil

\footnotetext{
${ }^{10}$ Ibidem, s. 151

${ }^{11}$ BONI, Filippo. Civil-military relations in Pakistan: a Case Study of Sino-Pakistani Relations and the Port of Gwadar. Commonwealth \& Comparative Politics, 2016, 54(4): 498-517, s. 504.

${ }^{12}$ GRARE, Frederic. Pakistan: The Resurgence of Baluch Nationalism. The Carnegie Papers, 2006, No. 65, Washington, DC: Carnegie Endowment for International Peace, s. 5.

${ }^{13}$ AKHTAR, Aasim Sajjad. Balochistan versus Pakistan. Economic and Political Weekly, 2007, 42(45/46): 7379 , s. 75
} 
plán vybudovat s pomocí Pekingu přístav v Gwadaru. ${ }^{14}$ První fáze stavby přístavu byla dokončena v roce 2006, přičemž Čína přispěla částkou 198 milionů dolarů z celkového rozpočtu 248 milionů dolarů a v roce 2007 ji pronajala na 40 let Singapurskému př́stavnímu úradu (Port of Singapore Authority - PSA). ${ }^{15}$

Gwadar má pro Pákistán i Čínu ekonomickou a strategickou hodnotu. Nachází se v ústí Perského zálivu, klíčové trasy pro celosvětové dodávky ropy, a má sloužit jako regionální centrum pro tranzit a překládku zboží pro Afghánistán, Střední Asii a Blízký východ. V Gwadaru se nachází námořní základna, která Islámábádu poskytuje strategický opěrný bod. Během války v roce 1971 byla hlavní námořní základna země v Karáčí vystavena blokádě a hrozba blokády se objevila i během války v Kargilu v roce $1999 .{ }^{16}$

Čína a Pákistán mají již po desetiletí těsné strategické vztahy, které jsou často popisovány lyrickými přívlastky jako „vyšší než hory“ a „hlubší než oceány“. Rozsah spolupráce v politické a vojenské oblasti se však nevztahoval na hospodářské vztahy. To se začalo měnit s Mušarafovou politikou liberalizace. V roce 2006 byla podepsána dohoda o volném obchodu mezi Č́nou a Pákistánem, která byla zavedena v roce $2007 .{ }^{17}$ Čína investovala velké prostředky do přístavu Gwadar, zlatých a měděných dolů Saindak v Balúčistánu a nakonec do projektu CPEC, který je největším zdrojem přímých zahraničních investic v Pákistánu. CPEC je vlajkovou lodí čínské iniciativy Pásmo a cesta (BRI) a zahrnuje 3000 km dlouhou sít' silnic, železnic a potrubí spojující Kašgar v čínské oblasti Sin-t’iang s Gwadarem v Balúčistánu. Slibuje investice přesahující 60 miliard dolarů, které by měly vyř̌šit prohlubující se nedostatky $\mathrm{v}$ oblasti energetiky a infrastruktury $\mathrm{v}$ Pákistánu. V Pákistánu, který má nedostatek peněz, je CPEC označován za nástroj, který mění pravidla hry. ${ }^{18}$

Vědci analyzovali různé faktory, které stojí za čínskými zájmy o př́ístav Gwadar, a to bez ohledu na nestabilní bezpečnostní situaci $\mathrm{v}$ provincii. Zdůrazňují strategický a hospodářský význam přístavu Gwadar pro Č́íňany, který je označován za důležitou čínskou

\footnotetext{
${ }^{14}$ SCHMIDLE, Nicholas. Waiting for the Worst: Baluchistan, 2006. Virginia Quarterly Review, 2007, 83(2).

15 JETLY, Rajshree. The politics of Gwadar Port: Baluch nationalism and Sino-Pak relations. The Round Table, 2021, 110(4): 432-447, s. 435.

${ }^{16}$ HAIDER, Ziad. Baluchis, Beijing, and Pakistan's Gwadar Port. Georgetown Journal of International Affairs, 2005, 6(1): 95-103, s. 98.

17 AHMED, Zahid Shahab. Impact of the China-Pakistan Economic Corridor on Nation-Building in Pakistan. Journal of Contemporary China, 2018, s. 5.

${ }^{18}$ RIZVI, Hasan A. The China-Pakistan Economic Corridor: regional cooperation and socio-economic development. Strategic Studies, 2014, 34(4): 1-17.
} 
energetickou přestupní stanici a nový čínský energetický kanál. ${ }^{19}$ Některé studie naznačují, že CPEC může snížit náklady na mezinárodní obchod západní a střední Číny se Střední Asií, Blízkým východem, Evropou a Afrikou a umožnit Číně ušetřit až 2 miliardy USD ročně, pokud by využila CPEC k dovozu $50 \%$ současného objemu dodávek ropy. ${ }^{20}$

Podle jiných je obchodní životaschopnost Gwadaru podezřelá a čínské investice jsou vedeny strategickými motivy. ${ }^{21}$ Blízkost Gwadaru k Perskému zálivu nabízí čínskému námořnictvu potenciální „stálé a spolehlivé zařízení pro lodě, které potřebují podpůrné body $\mathrm{v}$ blízkosti Blízkého východu, severní Afriky nebo východní Afriky““ ${ }^{22}$ Nabízí také Číně alternativní trasu pro dodávky energie z Blízkého východu do Číny, což Pekingu umožní snížit závislost na Malackém průlivu a zmírnit tak to, co se nazývá „malacké dilema“. Téměř $85 \%$ čínského dovozu ropy prochází tímto jediným kontrolním bodem, což jej činí zranitelným vůči př́ípadné blokádě ze strany Spojených států. ${ }^{23}$ I z pohledu Pákistánu je ekonomická životaschopnost Gwadaru sporná a jeho hlavní význam může spočívat v jeho strategickém významu. Hlavní průmyslová uskupení v zemi se nacházejí především v Gudžranvale, Láhauru a Fajsalábádu a tyto oblasti jsou nejblíže přístavu Karáčí, nikoli Gwadaru. $^{24}$

Tvrdí se také, že investice do Gwadaru jsou součástí čínské strategie „Otevřít západ“, jejímž cílem je snížit socioekonomickou nerovnost mezi zaostalým západním regionem Číny a jejími relativně rozvinutými pobřežními provinciemi. Rozvojem rozsáhlé dopravní infrastruktury by Gwadar mohl poskytnout západním provinciím Číny, které nemají přístup $\mathrm{k}$ moři, přístupové cesty $\mathrm{k}$ využití obchodních a investičních př́ležitostí s širším světem. Prostřednictvím této strategie Peking plánuje zklidnit Sin-t'iang - nejneklidnější západní provincii Číny, která je domovem separatistického hnutí, tím, že podpoří hospodářskou revitalizaci regionu jeho propojením s trhy v jižní Asii, na Blízkém východě a v Evropě

\footnotetext{
${ }^{19}$ DUCHÂTEL, Mathieu. The Terrorist Risk and China's Policy toward Pakistan: strategic reassurance and the 'United Front'. Journal of Contemporary China, 2011, 20(71): 543-561.

HARTPENCE, Mathias. The Economic Dimension of Sino-Pakistani Relations: an overview. Journal of Contemporary China, 2011, 20(71): 581-599.

YANG, Jian; RASHID A Siddiqi. About an 'All-Weather' Relationship: security foundations of Sino-Pakistan relations since 9/11. Journal of Contemporary China, 2011, 20(71): 563-579.

${ }^{20}$ ESTEBAN, M. The China-Pakistan Corridor: A Transit, Economic or Development Corridor?" Strategic Studies, 2016, 36(2): 63-74, s. 68.

${ }^{21}$ SMALL, Andrew. The China-Pakistan Axis: Asia's New Geopolitics. New York: Oxford University Press, 2015, s. 102.

${ }^{22}$ Ibidem, s. 103.

${ }^{23}$ MARKEY, Daniel S.; WEST, James. Behind China's Gambit in Pakistan. Council on Foreign Relations, 2016. https://www.cfr.org/expert-brief/behind-chinas-gambit-pakistan.

${ }^{24}$ BONI, Filippo. Civil-military relations in Pakistan: a Case Study of Sino-Pakistani Relations and the Port of Gwadar. Commonwealth \& Comparative Politics, 2016, 54(4): 498-517, s. 512.
} 
prostřednictvím silničních a železničních sítí. CPEC je také motivována potřebou Číny podpořit dlouhodobého spojence, který se potýká s politickou a hospodářskou nestabilitou. Stabilní a hospodářsky prosperující Pákistán by nebyl ochoten poskytovat bezpečné útočiště ujgurským militantům. Hospodářsky silný Pákistán by zároveň představoval hrozivou protiváhu sílící Indii, a fungoval by tak jako strategická pojistka. ${ }^{25}$

CPEC poskytl Pákistánu tolik vytouženou příležitost $\mathrm{k}$ restartu jeho hospodářství a infrastruktury. Jedná se o největší přímou zahraniční investici v historii Pákistánu představuje téměř pětinu jeho HDP. Mnozí jsou však skeptičtí ohledně spravedlivého rozdělení přínosů z navrhovaných projektů. Etnické rozpory jsou v Pákistánu hluboce zakořeněné a překrývají se s rozdíly mezi provinciemi, což z CPEC učinilo předmět intenzivního sporu mezi provinciemi a různými zájmovými skupinami. Menší provincie jako Balúčistán a Chajbar Paštúnchwá / Khyber Pakhtunkhwa (KP) se s Islámábádem přou o přidělování investic. Opoziční strany obvinily ústřední vládu z diskriminace a tvrdí, že rozdělování tras, služeb, průmyslových parků a zvláštních ekonomických zón upírá některým provinciím přístup $\mathrm{k}$ investičním př́iležitostem a prospívá pouze nejlidnatější pákistánské provincii Paňdžáb, v níž žije více než polovina celkové populace země. ${ }^{26}$ Nespokojenost proti CPEC je nejsilnější v Balúčistánu, kde na jedné straně umírnění profederální politici obviňují Islámábád z preferenčního zacházení a na druhé straně militantní skupiny koridor otevřeně odmítají jako neokoloniální projekt.

\section{Militarizace a odpor proti čínské přítomnosti}

Od té doby, co Peking začal v Balúčistánu intenzivně investovat, obracejí balúčští separatisté stále více svou pozornost $\mathrm{k}$ Číně, kterou vnímají jako zemi, která jde ruku v ruce s Islámábádem při využívání zdrojů a militarizaci jejich prostoru. Odsuzují, že výnosné zdroje jsou odčerpávány v rámci „rozvojových“ projektů v Balúčistánu podle známého schématu vyloučení, zpronevěry a pokřiveného poměru rozdělování příjmů. Př́kladem je projekt Saindak, v současnosti největší provozovaný důl na měd’ a zlato v Pákistánu. Čínský podnik Metallurgical Corporation of China (MCC) provozuje ziskové doly Saindak od roku 2001, ale s malým dohledem a odpovědností. ${ }^{27} \mathrm{Z}$ pracovního dokumentu předloženého funkčnímu

\footnotetext{
${ }^{25}$ RITZINGER, Louis. The China-Pakistan Economic Corridor: Regional Dynamics and China's Geopolitical Ambitions. The National Bureau of Asian Research, 2015.

${ }^{26}$ MARKEY, Daniel S.; WEST, James. Behind China's Gambit in Pakistan. Council on Foreign Relations, 2016. https://www.cfr.org/expert-brief/behind-chinas-gambit-pakistan.

${ }^{27}$ Až do roku 2012, kdy byl podíl provincie zvýšen podle 18. dodatku ústavy, dostávala federální vláda podle podmínek smlouvy $48 \%$ a MCC $50 \%$ příjmů, takže pro Balúčistán zbývala pouhá $2 \%$. MCC měla po dobu 10
} 
výboru Senátu vyplývá, že měd' vytěžená v Saindaku v letech 2003 až 2013 byla prodána za přibližně 1,6 miliardy dolarů. Pákistán a Čína získaly největší podíl, zatímco Balúčistán obdržel skromných 9 milionů dolarů. ${ }^{28}$ Projekt Saindak byl označen za loupež za bílého dne; neexistuje žádný přehled o tom, kolik stř́bra, zlata a mědi bylo od roku 2002, kdy byly doly uvedeny do provozu, vytěženo. ${ }^{29}$ Nehledě na nerovnoměrné rozdělení výnosů unikly místním obyvatelům i druhotné výhody, jako je povznesení místní oblasti, včetně pracovních př́iležitostí. Jak poznamenávají dva vědci, „Č́íñané jsou podle svého osvědčeného přístupu k řízení takových megaprojektů vysoce soběstační a nezapojili do těchto snah místní pracovní sílu“. 30

Žádný jiný projekt ovšem nezasáhl do projevů balúčského nacionalismu tolik jako př́istav Gwadar. ${ }^{31}$ Př́ístav, který je projektován jako další utopie podobná Dubaji a Šen-čenu, představuje tragický př́iběh vyloučení, vyvlastnění a vykořenění místního obyvatelstva. V roce 2013 byla práva na pronájem přístavu převedena na společnost China Overseas Port Holding Company-Pakistan (COPHC) v rámci dohody CPEC poté, co společnost PSA nesplnila své investiční závazky a rozhodla se odstoupit. Dohoda přiznává COPHC $91 \%$ zisku a Islámábádu $9 \%$ po dobu následujících 40 let, zatímco Balúčistánu upírá jakýkoli př́ijem. Př́stav byl navíc vybudován na nejlepším rybářském revíru, který se nachází podél Východního zálivu, kde je většina místních obyvatel závislá na rybářském průmyslu. Přístup k moři byl také omezen $\mathrm{z}$ bezpečnostních důvodů, což způsobilo neustálé vysídlování obyvatelstva. ${ }^{32} \mathrm{~S}$ tím, jak CPEC znovu upřel pozornost na přístav Gwadar, se vysídlování rybářů zrychlilo a federální vláda vyvlastňuje další pozemky, aby uvolnila místo pro rozvoj. ${ }^{33}$ Zabírání půdy v Gwadaru se stalo další spornou otázkou poté, co si civilní a vojenské elity z jiných provincií přivlastnily pozemky ve vlastnictví místních obyvatel, kteří k nim ovšem neměli žádné doklady. Vojsko, námořnictvo a pobřežní stráž získaly v Gwadaru prvotřídní

let platit Pákistánu 500000 dolarů měsičně a 50 procent z celkového výnosu z prodeje nerostných surovin, Balúčistán měl dostávat ročně pouhých 0,7 milionu dolarů jako licenční poplatky. Fazl-e-Haider, Syed. "Expansion of Saindak copper project", Dawn, 31 Oct 2005, https://www.dawn.com/news/163609

${ }^{28}$ The Express Tribune. Saindak Copper and Gold Project: Centre refuses to hand over ownership till 2018. Nov 24, 2014, at https://bit.ly/2TrDwMe.

${ }^{29}$ NOTEZAI, Muhammad Akbar. The Saindak Files. Dawn, Jan 7, 2018. https://www.dawn.com/news/1381378.

${ }^{30}$ FAIR, Christine; HAMZA, Ali. Rethinking Baloch Secularism: What the Data Say. Peace and Conflict Studies, 2017, 24(1), Article 1, s. 11.

${ }^{31}$ WANI, Shakoor A. The Changing Dynamics of the Baloch Nationalist Movement in Pakistan: From

Autonomy toward Secession. Asian Survey, 2016, 56(5); 807-832, s. 810.

${ }^{32}$ International Crisis Group. China-Pakistan Economic Corridor: Opportunities and risks. Asia Report №297, 2018, s. 20.

${ }^{33}$ KOVRIG, Michael. National Ambitions Meet Local Opposition along the China-Pakistan Economic Corridor. International Crisis Group, 2018. https://bit.ly/2tKFl8v 
pozemky za dumpingové ceny. ${ }^{34}$ Místní obyvatelé navíc neměli prospěch z pracovních př́ležitostí vytvořených díky CPEC, protože Čína si s sebou přivezla vlastní pracovní sílu a také místní lidské zdroje jsou př́liš málo rozvinuté na to, aby mohly konkurovat cizincům. ${ }^{35}$ Gwadar, označovaný za futuristické př́ístavní město, stále postrádá základní vybavení, jako je čistá voda, školy a nemocnice pro místní obyvatele.

Podle některých oficiálních odhadů by mělo přístavní město Gwadar po svém plném rozvoji přilákat miliony migrantů. To změní demografickou strukturu města Gwadar v čele s př́livem ekonomických migrantů z jiných zemí. Podle odhadu se počet obyvatel města Gwadar, který se v současnosti pohybuje kolem 90 000, neustále zvyšuje a město bude mít v př́štích dvou desetiletích pravděpodobně více než dva miliony obyvatel, přičemž většina z nich bude pocházet z jiných pákistánských provincií. ${ }^{36}$ Objevují se také zprávy, že ve Gwadaru budou postaveny uzavřené kolonie výhradně pro čínské odborníky. Některé zprávy dokonce odhadují, že do roku 2048 počet Číňanů převýší počet původních obyvatel. ${ }^{37}$ Tyto zprávy se sice mohou, ale nemusí stát skutečností, nicméně nahrávají obavám Balúčů z demografických změn a posilují odpor vůči přístavu Gwadar. Tento odpor vedl k cíleným útokům na čínský personál a dělníky pracující na různých projektech financovaných Č́nou v Balúčistánu. Číňané se v Balúčistánu stávají terčem útoků již od útoku v okrese Sibi v roce 2001, ale s rostoucím počtem jejich přítomnosti a investic v regionu se stávají cílem stále častějším. V letech 2001-2017 bylo podle studie zjištěno 13 takových útoků, při nichž bylo zabito 60 osob, většinou dělníků pracujících na čínských projektech, ale také někteří čínští státní příslušníci. ${ }^{38}$

Islámábád však místo toho, aby řešil nespokojenost místních obyvatel s vykořist'ováním, nespravedlivým rozdělováním zdrojů a obavami z demografických změn, reagoval zvýšeným bezpečnostním dohledem a kontrolou. ${ }^{39}$ Byly vyzkoušeny i některé další

\footnotetext{
${ }^{34}$ KAPLAN, Robert. Pakistan's fatal shore. The Atlantic Monthly, 2009, 72. http://www.theatlantic.com/magazine/archive/2009/05/pakistans-fatal-shore/307385/

${ }^{35}$ KAKAR, R. China Pakistan Economic Corridor (CPEC) and Balochistan. In Maheen Hassan \& Umer Akhlaq M. (Eds), Balochistan: Challenges \& opportunities, 2018, Islamabad: UNDP, s. 14-15.

${ }^{36}$ AHMED, Zahid Shahab. Impact of the China-Pakistan Economic Corridor on Nation-Building in Pakistan. Journal of Contemporary China, 2018, s. 10.

37 CHAUDHURY, Dipanjan Roy. As part of CPEC, 'Chinese only'colony coming up in Pakistan. Economic Times, 2018, 21.

YOUSAFZAI, Fawad. Chinese to outnumber Baloch natives by 2048. The Nation, 04 Aug, 2018. https://bit.ly/2hrYbbZ

${ }_{38}$ JAWAD, Syed. Terrorising the Belt and Road: A critical analysis of security threats to Chinese nationals and businesses in Pakistan. China Pakistan Management Initiative, LUMS Working Paper Series, 2017. http://shorturl.at/gmnHO

${ }^{39}$ KOVRIG, Michael. National Ambitions Meet Local Opposition along the China-Pakistan Economic Corridor. International Crisis Group, 2018. https://bit.ly/2tKFl8v
} 
smírčí možnosti, jak vytvořit prríznivější prostředí pro čínské investice. Například parlamentní výbor zrrízený Mušarafovou vládou v roce 2004 a balíček Aghaz-e-Huqooq-e-Balochistan (urdsky Počátek práv v Balúčistánu) z roku 2009 se pokusily vyhovět stížnostem Balúčů prostřednictvím institucionálních struktur. Tyto snahy však byly polovičaté a reformy nebyly nikdy plně realizovány. $\mathrm{V}$ rozporu s lidovými požadavky na větší kontrolu provincie nad př́istavem Gwadar a zastavení výstavby vojenských kantonů Mušarafova vláda schválila výstavbu tří nových armádních kantonů $\mathrm{v}$ některých $\mathrm{z}$ nejcitlivějších okresů $\mathrm{v}$ regionu, konkrétně v Sui, Gwadaru a Kohlu. To svědčí o snaze vlády vojensky ovládnout region, aby zajistila větší bezpečnost čínských státních př́íslušníků pracujících v oblasti. ${ }^{40}$

Vojenská „,̌̌ešení“ jsou i nadále preferovaným způsobem řešení bezpečnostních otázek v Balúčistánu před náročnými demokratickými kompromisy. Na ochranu čínských zájmů v Pákistánu byly vytvořeny 15 tisícové jednotky. ${ }^{41}$ Federální vláda rovněž plánovala vybudovat 24 km dlouhý plot, který by fyzicky uzavřel části Gwadaru a chránil investice související s CPEC před útoky povstalců. Toto rozhodnutí bylo později po protestech veřejnosti zrušeno. ${ }^{42}$ Je příznačné, že čínské úřady se zdají být citlivější vůči odporu místních obyvatel než samotný Islámábád. Postavily školu a slíbily pomoc ve výši přibližně 500 milionů dolarů na výstavbu nemocnice, vysoké školy a projektů na zásobování města pitnou vodou. ${ }^{43}$ Čínští analytici také navrhli, aby Peking zajistil místní podporu navázáním kontaktů s lokálními komunitami, a tak lépe vyhověl místním zájmům a zajistil úspěch CPEC. ${ }^{44}$ Některé zprávy naznačovaly, že Peking vede rozhovory s balúčskými povstalci, aby ochránil své investice v provincii. ${ }^{45}$ Tyto snahy však nepřinesly kýžené výsledky, o čemž svědčí následné útoky proti čínským zájmům a pracovníkům.

Uprostřed všudypřítomné militarizace a rostoucího rozčarování z vylučujícího „rozvoje“ nachází mezi stále rozčarovanějším obyvatelstvem větší odezvu apel separatismu. Úzkost z hrozícího ohrožení demografické rovnováhy vyvolala radikalizaci etnického

\footnotetext{
${ }^{40}$ BONI, Filippo. Civil-military relations in Pakistan: a Case Study of Sino-Pakistani Relations and the Port of Gwadar. Commonwealth \& Comparative Politics, 2016, 54(4): 498-517, s. 504.

${ }^{41}$ AKINS, Harrison. China in Balochistan: CPEC and the Shifting Security Landscape of Pakistan. Howard H. Baker Jr. Center for Public Policy, Policy Brief 4:17, 2017, University of Tennessee., s. 10.

${ }^{42}$ ZAFAR, M. CM halts work on Gwadar fencing project. The Express Tribune, 2020. https://tribune.com.pk/story/2277928/cm-halts-work-ongwadar-fencing-project

43 ADENEY, Katherine; BONI, Filippo. How Pakistan and China negotiate. Washington DC: Carnegie Endowment for International Peace, 2021, s. 20-21.

${ }^{44}$ NOTEZAI, M. Akbar. Why Balochs Are Targeting China. The Diplomat, 2018. https://thediplomat.com/2018/11/why-balochs-are-targeting-china/

${ }^{45}$ BOKHARI, Farhan \& Stacey, Kiran. China woos Pakistan militants to secure Belt and Road projects. Financial Times, 2018. https://www.ft.com/content/063ce350-1099-11e8-8cb6-b9ccc4c4dbbb
} 
uvědomění Balúčů, kteří vnímají vzorec př́livu cizinců jako „etnické zaplavení““46 V důsledku toho se boj za obnovení vlastnictví nad zdroji provincie stal základním kamenem balúčského ozbrojeného odporu.

\section{Madžídova brigáda: formování protičínské fronty}

Madžídova brigáda byla zformována s cílem zaměřit se na bezpečnostní síly a čínský personál a investice v regionu. Od jejího vzniku neváhali balúčští ozbrojenci přenést svůj boj mimo územní obvod Balúčistánu a podnikali útoky na pečlivě vybrané cíle mimo provincii. Tato strategie do jisté míry zviditelnila balúčský odboj, a vynutila si jeho začlenění do národního a mezinárodního diskurzu. V prosinci 2011 provedli členové Madžídovy brigády první sebevražedný útok od počátku povstání v polovině roku 2000. Auto naložené výbušninami se stalo terčem útoku údajného šéfa propákistánské milice Šafíka Mengála v jeho rezidenci v Kvétě. Výbuch zabil více než 10 lidí, ale Šafík a jeho rodina vyvázli bez zranění. ${ }^{47}$

Madžídova brigáda zůstala nečinná až do roku 2017, kdy Aslam Baloch postoupil na pozici vrchního velitele BLA (Balúčistánská osvobozenecká armáda / Baloch Liberation Army). ${ }^{48}$ Aslam skupinu přeměnil na téměř výhradně protičínskou jednotku a pod jeho vedením BLA provedla několik nejznámějších útoků na čínský personál a podniky, které podle Aslama „drancují zdroje v Balúčistánu ve jménu megaprojektů““. ${ }^{49}$ V srpnu 2018 brigáda zaútočila na autobus s čínskými inženýry v Dalbandinu. Při sebevražedném útoku byli zraněni tři čínští inženýři a pět dalších osob. Ačkoli byl sebevražedný útok úspěšný jen omezeně, stal se symbolickým projevem Aslamova závazku k cíli skupiny vyhnat Číňany, jako sebevražedného atentátníka určil svého staršího syna.

K odvážnějšímu pokusu poškodit Čínu došlo o několik měsíců později, kdy členové brigády podnikli útok na čínský konzulát v Karáčí, př̌i němž zahynulo sedm lidí včetně tří útočníků. Předem nahrané video varovalo čínské investory, aby přestali využívat zdroje Balúčistánu, jinak budou útoky pokračovat. ${ }^{50} \mathrm{O}$ několik týdnů později byl Aslam Balúč zabit při sebevražedném bombovém útoku v afghánském Kandaháru. Velitelova smrt byla těžkou ranou pro nově vznikající skupinu, jejíž organizace a struktura zůstávají mlhavé. Jeho smrt

\footnotetext{
${ }^{46}$ LIEVEN, Anatol. Pakistan: A Hard Country, New York: Public Affairs, 2011.

${ }^{47}$ MASOOD, Salman. Car Bombing, Claimed by Separatists, Kills 10 in Pakistan. The New York Times, Dec 30, 2011. https://shorturl.at/alJTZ

${ }^{48}$ The Balochistan Post. Aslam Baloch-The Baloch General. 11 Feb 2020 at https://shorturl.at/otFNQ

${ }^{49}$ AAMIR, Adnan. The Balochistan Insurgency and the Threat to Chinese Interests in Pakistan. China Brief: A Journal of Analysis and Information, 2019, 19(4).

${ }^{50}$ Ibidem
} 
však skupinu neodradila od dalších útoků a o několik měsíců později skupina zaútočila na jediný pětihvězdičkový hotel v Balúčistánu, Pearl Continental v Gwadaru, kde jsou významní čínští podnikatelé. Byli zabiti čtyři zaměstnanci hotelu a jeden člen ochranky. Také nedávný útok na pákistánskou burzu cenných papírů v červnu 2020 měl čínský podtext. V roce 2016 se Čína stala hlavním investorem na burze a zajistila si kontrolu nad vedením tím, že získala $40 \%$ jejích akcií v transakci v hodnotě 85 milionů dolarů. Akcie drží Šanghajská burza cenných papírů, Šenčenská burza cenných papírů a Čínská burza finančních futures. Dalších pět procent akcií držených místní společností je rovněž spojeno s čínskou investicí. ${ }^{51}$

Všechny výše uvedené útoky Madžídovy brigády měly velký dopad na její zviditelnění, ale nedokázaly soupeře výrazně poškodit. Útočníkům se nepodařilo vyřadit protivníka na delší dobu a některé útoky byly bleskově neutralizovány. To poukazuje na slabou organizační kapacitu skupiny, nedostatečnou připravenost, výcvik a zdroje. Především to poukazuje na absenci významné vnější pomoci nebo vedení, která by skupinu učinilo účinnější a ničivější. Tím lze rovněž vyvracet tvrzení pákistánské vlády, podle které jsou tyto útoky dílem zahraničních zpravodajských služeb.

Přesto opakované útoky odhalily zranitelnost čínských osob a omezily jejich mobilitu $\mathrm{v}$ provincii. Nemohou se volně pohybovat a musí cestovat s bezpečnostními oddíly. Útoky zvýšily náklady na bezpečnost projektu CPEC. Kromě samostatného bezpečnostního oddělení o síle 15000 osob, které bylo vytvořeno za účelem ochrany čínského personálu, si čínské firmy působící v Pákistánu najaly také soukromé bezpečnostní stráže, čímž zásadně zvýšily náklady na bezpečnost CPEC. ${ }^{52}$ Útoky na Č́ínany ze strany balúčských separatistů i extremistických skupin, jako je Tehrik-i-Taliban Pákistán (TTP) - které se kvůli pronásledování ujgurských muslimů v oblasti Sin-t’iang ze strany Pekingu začaly stále častěji zaměřovat na čínské osoby - vyvolaly otazníky nad budoucností př́ístavu Gwadar.

Již nyní dochází ke změnám a zdá se, že Gwadar ztrácí svůj význam jako megainvestiční centrum. Saúdská Arábie se rozhodla přesunout plánovanou ropnou rafinérii z Gwadaru do Karáčí. V roce 2019 se Rijád zavázal investovat 10 miliard dolarů do ropné rafinerie a petrochemického komplexu ve Gwadaru. Důvodem rozhodnutí odstoupit jsou infrastrukturní nedostatky Gwadaru, které se Pákistánu a Číně nepodařilo za posledních šest

\footnotetext{
${ }^{51}$ BAQIR S. Syed. Analysis: BLA out to bleed Pakistan economy, Chinese interests. Dawn, June 30, 2020. https://shorturl.at/duxQ3

52 AAMIR, Adnan. The Balochistan Insurgency and the Threat to Chinese Interests in Pakistan. China Brief: A Journal of Analysis and Information, 2019, 19(4).
} 
let vyřešit. ${ }^{53}$ Vzhledem $\mathrm{k}$ tomu, že bezpečnost $\mathrm{v}$ Balúčistánu nevykazuje žádné známky zlepšení, je možné, že se Čína od přístavního města Gwadar odvrátí. Jak naznačuje nedávné memorandum o porozumění podepsané mezi Pákistánem a Čínou ohledně komplexní rozvojové zóny na pobřeží Karáčí, pozornost a investice se možná přesouvají do Karáčí a od Gwadaru. ${ }^{54}$ Zatímco Č́na může i nadále investovat do přístavu Gwadar ze strategických důvodů, rozvoj futuristického přístavního města zůstane pouhým snem, protože nekončící nepokoje znemožňují trvalé investice do infrastruktury.

\section{Závěr}

Balúčistán se v současné době nachází ve druhém desetiletí doutnajícího povstání nízké intenzity, které začalo v polovině roku 2000. Ačkoli je balúčský nacionalismus založen na historicky konzistentních požadavcích na větší samosprávu, současný konflikt se vyznačuje dominantními tématy, jako je vyvlastnění, marginalizace a vykořenění. Balúčové si stále více uvědomují, jakým bohatstvím jejich země disponuje, a přesto se ocitají mezi nejchudšími v zemi. Po celá desetiletí byl Balúčistán největším producentem zemního plynu v zemi a Pákistán na něm ve velké miŕre závisel pro svou domácí spotřebu. Většina zde vytěžené energie však v Balúčistánu nezůstává, ale zásobuje nejprůmyslovější a nejlidnatější provincie státu, Paňdžáb a Sindh. Dokonce i licenční poplatky přidělované provincii federální vládou byly donedávna také nejnižší mezi pákistánskými provinciemi produkujícími plyn. Podobně tomu bylo i s rozvojem přístavu Gwadar, který měl pobřežní oblast proměnit v další Dubaj, místní obyvatelé se však opět ocitli bez jakýchkoli potenciálních výhod. Jak výstižně shrnuje jedna zpráva think-tanku, „namísto rozvoje ospalé rybářské vesnice v rušné obchodní centrum, jak slibovaly Islámábád a Peking, vytváří projekt silně militarizovanou zónu, která vysídluje místní obyvatele a připravuje je o ekonomické zázemí“. ${ }^{5}$

Právě kvůli takovým zkušenostem jsou Balúčové vůči slibům Islámábádu o rozvoji obezřetní. V CPEC a jeho piliŕri - přístavu Gwadar - vidí další koloniální období vytvořené Č́nou. Výsledkem je, že balúčští povstalci se zaměřují nejen na energetickou infrastrukturu, především na plynovody a další způsoby distribuce, ale také na čínské inženýry, dělníky a

\footnotetext{
53 AAMIR, Adnan. Pakistan's Gwadar loses lustre as Saudis shift \$10bn deal to Karachi. Financial Times, 23 June 2021. https://www.ft.com/content/88cfe78b-517f-41d9-97d1-9f7f540f517c

${ }^{54}$ AAMIR, Adnan. Pakistan and China unveil ambitious plan to develop Karachi coast. Nikkei Asia, 5 October 2021. https://asia.nikkei.com/Spotlight/Belt-and-Road/Pakistan-and-China-unveil-ambitious-plan-to-developKarachi-coast

${ }_{55}$ International Crisis Group. China-Pakistan Economic Corridor: Opportunities and risks. Asia Report N ${ }^{\circ} 297$, 2018, s. i-ii.
} 
techniky, kteří jsou vnímáni jako spoluviníci a těžaři z pákistánských „koloniálních“ projektů. ${ }^{56}$

CPEC je vnímán jako obzvláště rušivý projekt, který může vést $\mathrm{k}$ vyvlastnění jejich zdrojů a narušit demografickou rovnováhu v provincii. To vyvolává hluboké obavy místních obyvatel, kteří reagují strachem a násilím. Vznikla nová povstalecká frakce - Madžídova brigáda, jejímž deklarovaným cílem je vytlačit Č́ínany z Balúčistánu. V Islámábádu, který se obává ztráty tolik žádaných investic z Pekingu, vyvolala vlna útoků proti čínským zájmům a osobnostem nervozitu. Snaha za každou cenu ochránit čínské investice zintenzivnila militarizaci provincie a vyvlastňování zdrojů v Balúčistánu ve jménu rozvoje a boje proti terorismu. A jak armáda dále posiluje své pronikání za účelem ochrany ekonomických aktiv, aby odvrátila hrozbu ze strany nepřátelského místního obyvatelstva, nacionalisté se brání proti sílící kontrole nad jejich půdou a zdroji.

Balúčistán, který je základním koncovým bodem CPEC, měl být bezesporu hlavním př́jemcem jeho výhod. CPEC má pro Pákistán i Balúčistán obrovský transformační potenciál. Balúčové však mají vážné obavy z důsledků centrálně vnucených rozsáhlých rozvojových projektů. Rostoucí nespokojenost lze zmírnit pouze podporou pocitu odpovědnosti, vytvořením podílů Balúčů na projektech a motivací $\mathrm{k}$ jejich účasti na využívání a ochraně jejich zdrojů. V současné podobě CPEC s minimální kontrolou místních obyvatel nad jejich zdroji, absencí rozhodovacích procesů a př́lišnou vojenskou př́itomností může nakonec ještě více prohloubit rozpory mezi Islámábádem a Kvétou.

\footnotetext{
${ }^{56}$ WANI, Shakoor A. The Changing Dynamics of the Baloch Nationalist Movement in Pakistan: From Autonomy toward Secession. Asian Survey, 2016, 56(5); 807-832.
} 


\section{Seznam použitých zdrojů}

AAMIR, Adnan. Pakistan and China unveil ambitious plan to develop Karachi coast. Nikkei Asia, 5 October 2021. https://asia.nikkei.com/Spotlight/Belt-and-Road/Pakistan-andChina-unveil-ambitious-plan-to-develop-Karachi-coast

AAMIR, Adnan. Pakistan's Gwadar loses lustre as Saudis shift \$10bn deal to Karachi. Financial Times, 23 June 2021. https://www.ft.com/content/88cfe78b-517f-41d9-97d19f7f540f517c

AAMIR, Adnan. The Balochistan Insurgency and the Threat to Chinese Interests in Pakistan. China Brief: A Journal of Analysis and Information, 2019, 19(4).

ADENEY, Katherine; BONI, Filippo. How Pakistan and China negotiate. Washington DC: Carnegie Endowment for International Peace, 2021.

AHMED, Zahid Shahab. Impact of the China-Pakistan Economic Corridor on NationBuilding in Pakistan. Journal of Contemporary China, 2018, DOI: 10.1080/10670564.2018.1542221.

AKBAR, Malik Siraj. The End of Pakistan's Baloch Insurgency?” HuffPost, 3 Nov 2014. http://shorturl.at/wFPZ8

AKHTAR, Aasim Sajjad. Balochistan versus Pakistan. Economic and Political Weekly, 2007, 42(45/46): 73-79.

AKINS, Harrison. China in Balochistan: CPEC and the Shifting Security Landscape of Pakistan. Howard H. Baker Jr. Center for Public Policy, Policy Brief 4:17, 2017, University of Tennessee.

BAQIR S. Syed. Analysis: BLA out to bleed Pakistan economy, Chinese interests. Dawn, June 30, 2020. https://shorturl.at/duxQ3.

BOKHARI, Farhan \& Stacey, Kiran. China woos Pakistan militants to secure Belt and Road projects. Financial Times, 2018. https://www.ft.com/content/063ce350-1099-11e88cb6-b9ccc4c4dbbb

BONI, Filippo. Civil-military relations in Pakistan: a Case Study of Sino-Pakistani Relations and the Port of Gwadar. Commonwealth \& Comparative Politics, 2016, 54(4): 498-517. DOI: $10.1080 / 14662043.2016 .1231665$

CHAUDHURY, Dipanjan Roy. As part of CPEC, 'Chinese only' colony coming up in Pakistan. Economic Times, 2018, 21.

DUCHÂTEL, Mathieu. The Terrorist Risk and China's Policy toward Pakistan: strategic reassurance and the 'United Front'. Journal of Contemporary China, 2011, 20(71): 543561.

ESTEBAN, M. The China-Pakistan Corridor: A Transit, Economic or Development Corridor?" Strategic Studies, 2016, 36(2): 63-74.

FAIR, Christine; HAMZA, Ali. Rethinking Baloch Secularism: What the Data Say. Peace and Conflict Studies, 2017, 24(1), Article 1. DOI: 10.46743/1082-7307/2017.1405

FARHAN Zahid, 'Baluch Raji Ajohi Sangar: Emergence of a New Baluch Separatist Alliance', The Jamestown Foundation -Terrorism Monitor, XVII(18): 7-8, 2019.

FAZL-E-HAIDER. Syed. Expansion of Saindak copper project. Dawn, 31 Oct 2005. https://www.dawn.com/news/163609

GRARE, Frederic. Pakistan: The Resurgence of Baluch Nationalism. The Carnegie Papers, 2006, No. 65, Washington, DC: Carnegie Endowment for International Peace.

HAIDER, Ziad. Baluchis, Beijing, and Pakistan's Gwadar Port. Georgetown Journal of International Affairs, 2005, 6(1): 95-103.

HAQQANI, Hussain. Pakistan: Between Mosque and Military. Lahore: Vanguard, 2005. 
HARRISON, Selig. In Afghanistan's Shadow: Baluch Nationalism and Soviet Temptations.

Washington, D.C.: Carnegie Endowment for International Peace, 1981.

HARTPENCE, Mathias. The Economic Dimension of Sino-Pakistani Relations: an overview. Journal of Contemporary China, 2011, 20(71): 581-599. DOI: 10.1080/10670564.2011.587160

International Crisis Group. China-Pakistan Economic Corridor: Opportunities and risks. Asia Report $\mathrm{N}^{\circ} 297,2018$.

JAVED, Umair; NABI, Ijaz. Heterogeneous fragility: The case of Pakistan. Commission on State Fragility, Growth and Development, 2018. https://www.theigc.org/wpcontent/uploads/2018/04/Pakistan-report.pdf

JAWAD, Syed. Terrorising the Belt and Road: A critical analysis of security threats to Chinese nationals and businesses in Pakistan. China Pakistan Management Initiative, LUMS Working Paper Series, 2017. http://shorturl.at/gmnHO

JETLY, Rajshree. Baluch ethnicity and nationalism (1971-81): an assessment. Asian Ethnicity, 2004, 5.1: 7-26. DOI: 10.1080/1463136032000168871

JETLY, Rajshree. The politics of Gwadar Port: Baluch nationalism and Sino-Pak relations. The Round Table, 2021, 110(4): 432-447. DOI: 10.1080/00358533.2021.1957226

KAKAR, R. China Pakistan Economic Corridor (CPEC) and Balochistan. In Maheen Hassan \& Umer Akhlaq M. (Eds), Balochistan: Challenges \& opportunities, 2018, Islamabad: UNDP.

KAPLAN, Robert. Pakistan's fatal shore. The Atlantic Monthly, 2009, 72. http://www.theatlantic.com/magazine/archive/2009/05/pakistans-fatal-shore/307385/

KHAN, Adeel. Politics of Identity: Ethnic Nationalism and the State in Pakistan. New Delhi: Sage, 2005.

KOVRIG, Michael. National Ambitions Meet Local Opposition along the China-Pakistan Economic Corridor. International Crisis Group, 2018. https://bit.ly/2tKFl8v

LIEVEN, Anatol. Pakistan: A Hard Country, New York: Public Affairs, 2011.

MARKEY, Daniel S.; WEST, James. Behind China's Gambit in Pakistan. Council on Foreign Relations, 2016. https://www.cfr.org/expert-brief/behind-chinas-gambitpakistan

MASOOD, Salman. Car Bombing, Claimed by Separatists, Kills 10 in Pakistan. The New York Times, Dec 30, 2011. https://shorturl.at/alJTZ

NABEEL, Fahad. Aslam Baloch's killing: Implications for Balochistan Insurgency. Centre for Strategic and Contemporary Research, 2018. http://shorturl.at/doLMU

NOTEZAI, Muhammad Akbar. The Saindak Files. Dawn, Jan 7, 2018. https://www.dawn.com/news/1381378

NOTEZAI, Muhammad Akbar. Why Balochs Are Targeting China. The Diplomat, 2018. https://thediplomat.com/2018/11/why-balochs-are-targeting-china/

RITZINGER, Louis. The China-Pakistan Economic Corridor: Regional Dynamics and China's Geopolitical Ambitions. The National Bureau of Asian Research, 2015.

RIZVI, Hasan A. The China-Pakistan Economic Corridor: regional cooperation and socioeconomic development. Strategic Studies, 2014, 34(4): 1-17.

SCHMIDLE, Nicholas. Waiting for the Worst: Baluchistan, 2006. Virginia Quarterly Review, 2007, 83(2).

SHEIKH, Salman Rafi. The Genesis of Baloch Nationalism: Politics and Ethnicity in Pakistan, 1947-1977. New York: Routledge, 2018. DOI: 10.4324/9781351020701

SIDDIQUE, Abubakar. Baluch Separatist Insurgency Torn by Internal Conflict over Class. Gandhara, July 04, 2020, at https://shorturl.at/jDR17

SMALL, Andrew. The China-Pakistan Axis: Asia's New Geopolitics. New York: Oxford University Press, 2015. DOI: 10.1093/acprof:oso/9780190210755.001.0001 
The Balochistan Post. Aslam Baloch-The Baloch General. 11 Feb 2020 at https://shorturl.at/otFNQ

The Balochistan Post. BLA says it does not have any representatives in London, Europe or US. 17 August 2018. http://shorturl.at/nqAD8

The Express Tribune. Saindak Copper and Gold Project: Centre refuses to hand over ownership till 2018. Nov 24, 2014, at https://bit.ly/2TrDwMe

The World Bank. Balochistan Mining and Regional Integration Policy Dialogue Paper, 2013. https://www.pakistanmdtf.org/images/stories/projectdocuments/BalochistanReport2013

TITUS, Paul; SWIDLER, Nina. Knights, not pawns: Ethno-nationalism and regional dynamics in post-colonial Balochistan. International Journal of Middle East Studies, 2000, 32.1: 47-69. DOI: 10.1017/S0020743800021048

WANI, Shakoor A. The Changing Dynamics of the Baloch Nationalist Movement in Pakistan: From Autonomy toward Secession. Asian Survey, 2016, 56(5); 807-832. DOI: 10.1525/as.2016.56.5.807

WANI, Shakoor A. The New Baloch Militancy: Drivers and Dynamics. India Quarterly, 2021, 77(3) 479-500. DOI: 10.1177/09749284211027253

YANG, Jian; RASHID A Siddiqi. About an 'All-Weather' Relationship: security foundations of Sino-Pakistan relations since 9/11. Journal of Contemporary China, 2011, 20(71): 563-579. DOI: 10.1080/10670564.2011.587159

YOUSAFZAI, Fawad. Chinese to outnumber Baloch natives by 2048. The Nation, 04 Aug, 2018. https://bit.ly/2hrYbbZ

ZAFAR, M. CM halts work on Gwadar fencing project. The Express Tribune, 2020. https://tribune.com.pk/story/2277928/cm-halts-work-ongwadar-fencing-project 


\title{
Zachování etnické identity a kultury Jezídů v Německu
}

\author{
Preservation of ethnic identity and culture of Yazidis in Germany
}

Natalia Doboš

Fakulta sociálních věd Univerzity Karlovy

Email: nata.dobos@seznam.cz

DOI: https://dx.doi.org/10.7160/KS.2021.170205

\begin{abstract}
This paper deals with an ethnic-religious minority whose members call themselves Yazidis. The aim of the work is to examine how the adaptation of the Yazidis emigrating to Germany, the process of integration into the majority society seems to be successful and how, despite their will to integrate, they try to guard and preserve their ethnic identity and culture. The theoretical part contains a branch anchoring of the topic and an explanation of key concepts such as ethnic identity, diaspora, Yazidism and etymology of the word. The practical part acquaints the reader more closely with the mysterious and closed society after centuries, which begins to reveal itself to the world only in the last decade. In the practical part of the work are interpreted qualitative data collected from field research, which the author carried out in two trips to Germany at the end of September 2020 and early January 2021. For data collection was used the method of qualitative research. The method of participatory observation was applied to data collection, in which the researcher lived in a traditional Yazidi family and participated in daily routine.
\end{abstract}

Keywords

Yazidis, Germany, ethnic identity, diaspora, genocide, migration, integration

\section{Klíčová slova}

Jezídi, Německo, etnická identita, diaspora, genocida, migrace, integrace

\section{Úvod}

Jezídové jsou etnicko-náboženskou minoritou, která byla až do roku 2014 pro evropského člověka téměř neznámá. Nejpočetnější skupina Jezídů žila do daného roku v severním Iráku poblíž města Mosul. Bohužel toto etnikum se dostalo do širšího povědomí odborníků a veřejnosti až na základě masakru, který na Jezídech spáchala teroristická organizace Islámský stát, která působí na Blízkém východě od roku 2014 prakticky do současnosti. Specifické náboženství a také způsob uspořádání jezídské společnosti dělá z Jezídů jednu z nejméně 
probádaných minorit na Blízkém východě. Současně patří i mezi nejohroženější, když se podle OSN stala obětí genocidy provedené již výše zmíněnou teroristickou organizaci. ${ }^{1}$

Kromě Iráku žije menšina Jezídů také v Turecku, Sýrii, Gruzii a Arménii. Komunita Jezídů, žijící v Rusku a na Kavkazu zde vznikla v 19. století, kdy Jezídové emigrovali z Osmanské říše, kde se je Osmani snažili masově likvidovat či donutit ke konverzi k islámu. Během devadesátých let 20. století vznikla větší jezídská diaspora v Německu, která se významně rozrostla v minulém desetiletí v průběhu masového exodu v letech 2014-2016. V dnešní době jezídská diaspora v Německu tvoří přes 200000 lidí. $^{2}$ Největší část z nich tvoří Jezídi, kteří mají svůj původ v Iráku a Sýrii. Žije zde ale i část kavkazských Jezídů, především z Arménie. Jezídská komunita je velice uzavřená a soudržná, a proto se i v diaspoře soustřed'uje do několika málo měst.

Tato práce se snaží zachytit změny, s nimiž se musí jezídská komunita vyrovnat po emigraci do Evropy, převážně do Německa. Jezídové se snaží své kulturní hodnoty chránit a zachovat si svou identitu. Rodinné hodnoty jsou pro Jezídy velice důležité. Badatelé si všímají toho, že i po emigraci do Evropy alespoň první i druhá generace žijí v tradičních rodinách, kdy žena má na starost domácnost a výchovu děti, zatímco manžel pracuje a snaží se uživit rodinu. Někteří z azylantů si přivezli do Německa jednoho ze svých rodičů, zpravidla se jedná o matky, které bývají vdovami. Již ted’ je patrné, že následujícím generacím se bude dařit hůře udržovat svou identitu, když důvodů je hned několik. Prvním je skutečnost, že tyto generace vyrůstají nebo se již rovnou narodily v Německu, což znamená, že nastoupí do školek a do škol již zde a budou tu trávit víc času než doma. Navážou kontakty s německými dětmi a jinými emigranty a časem dospějí ke kritickému myšlení, když si budou pokládat nové otázky. Je pravděpodobné, že některé zvyky a tradice se jim v kontextu evropské kultury budou zdát bizarní nebo přinejmenším jiné.

Cílem práce je zkoumat adaptaci Jezídů v Německu, proměnu způsobu života této etnické minority po emigraci do Německa, průběh procesu integrace do majoritní společnosti a míru zachování vlastní kultury a identity v kontextu života v Evropě. K dosažení cíle byly stanoveny následující výzkumné otázky:

- Jak vznikla jezídská diaspora v Německu?

- Jaké jsou hlavní příčiny emigrace Jezídů do Evropy?

- Jak si udržují Jezídi svou kulturu mezi německou majoritou?

\footnotetext{
${ }^{1}$ ČERNÝ, Karel. Jezídové - komunita na útěku. Praha: Lidové noviny, 2016.

${ }^{2}$ PETERMANN, A. Jesiden in Deutschland oragnisieren sich. [online]. Deutschlandfunk: 2017. [cit. 2021-02-

12]. Dostupné z: https://www.deutschlandfunk.de
} 
- Jsou nějakým způsobem Jezídové diskriminování při hledání práce v Německu?

- Kým jsou sponzorované vzniklé jezídské spolky?

- Jaké jsou hlavní atributy jezídské identity?

Pro sběr dat byla využitá metoda polostrukturovaného rozhovoru, kdy se autorka snažila dávat prostor respondentům k volnému, ale věcnému vyprávění. Bylo provedeno 6 rozhovorů, přičemž u jednoho rozhovoru byla přítomná celá rodina, což umožnilo částečně využít metodu focus group. Praktická část dále vychází z terénního výzkumu v německých oblastech, kde žije větší část jezídské diaspory. V daném případě se jedná o město Gladenbach, které se nachází na západě okresu Marburg-Biedenkopf v Hesensku a dále v Severním Porýní-Vestfálsku o město Oerlinghausen, kde Jezídi žijí ve čtvrti Lippe. Terénní výzkum trval celkem 19 dní, přičemž autorka po celou dobu žila v jezídské rodině pocházející z Iráku. V rámci výzkumu byly uskutečněny dva výjezdy do Německa.

\section{Literární rešerše}

Jezídskou minoritu jako takovou popisuje narativním způsobem ve své knize The Yezidis autor Birgül Açikyildiz. Kniha poskytuje komplexní a srozumitelný úvod do jezídské historie, původu etnika, kultury, jejich náboženského vyznání a společnosti. Jelikož je tato komunita po dlouhá staletí ve stínu jiných náboženství a etnických menšin, jako je islám a Kurdové, tato publikace přináší jako první výsledky výzkumu celého historického a geografického rozsahu jezídismu. Ten je rozšířen nejen v severním Iráku, odkud Jezídové hlavně odvozují svůj původ, přičemž regionem, kde se nachází nejsvatější jezídská poutní místa, je údolí Láliš, ale žijí také v Turecku, Sýrii a na Kavkazu. Publikace také popisuje roli žen v jezídské společnosti a vztahy mezi Jezídy a jinými komunitami, jako jsou Asyřané, muslimští Kurdové nebo křest’ané. Publikace nabízí komplexní popis náboženských prvků, které činí jezídismus samostatným a jedinečným náboženstvím, které je často pro islámský svět nepochopitelné. ${ }^{3}$

S jezídskou komunitou dobře seznamuje čtenáře kniha Nadii Murad Poslední dívka. Jedná se o svědectví mladé ženy, která přežila jezídskou genocidu v Iráku z roku 2014. Po zničení rodné vesnice byla dívka prodaná jako sexuální otrokyně pro bojovníky Islámského

\footnotetext{
${ }^{3}$ AÇIKYILDIZ, B. The Yezidis. 1. vydání. I. B. Tauris, 2014.
} 
státu, odkud se jí časem podařilo utéct. Nadia se dostala do Německa, kde se stala aktivistkou i bojovnicí za práva jezídské populace. ${ }^{4}$

Problematikou důvodů emigrace uprchlíků této pronásledované skupiny do Evropy se zabývá autor Karel Černý ve své knize Jezídové - komunita na útěku. Příčin emigrace existuje hned několik. Největším impulsem pro přesídlení Jezídů z Iráku byla genocida spáchaná Islámským státem, kdy více jak půl milionů Jezídů uprchlo na území Kurdistánu a několik desítek tisíc osob emigrovalo do Německa nebo do Švédska. Jezídské obyvatelstvo usazené na území Kurdistánu má většinou čtyři možnosti, jak dále žít. Může emigrovat do Evropy, vrátit se do Iráku do Sindžáru nebo Bahzání, případně začít nový život a snažit se asimilovat na území Kurdistánu, anebo jen vyčkávat v nesnesitelných podmínkách v uprchlických táborech. Jeden z největších problémů v uprchlických táborech je nedostatečná infrastruktura, dále se uprchlíci vyrovnávají s absencí vody, toalet a sprch. Také se zde lidé potýkají s nedostatkem služeb a životních př́iležitostí, jelikož se většinou tábory nacházejí daleko od okolní společnosti, služeb a pracovních příležitostí.

Je tu pozorovatelný fenomén, kdy se jedna vlna uprchlictví stává spouštěčem pro další. Jak již bylo uvedeno výše, dochází k fenoménu zvanému únik mozků, což znamená, že jako první emigrují učitelé, lékaři a střední třída. Tato vrstva počítá s tím, že díky vzdělání a finančním možnostem se na novém místě lépe a rychleji přizpůsobí. Kvưli odchodu střední třídy dochází k redukci služeb a generování pracovních př́iležitostí pro zbytek komunity, která pak kvůli zhoršující se ekonomické situaci přemýšlí také o emigraci, a to i přesto, že původně chtěla zůstat ve svých domovech. Dochází také k demonstračnímu efektu jiných skupin migrantů, kdy se často Jezídi inspirují syrskými uprchlíky, kteří například utíkali do severního Iráku, tam se pár měsíců zdržovali v uprchlických táborech a pak dále mírili do Evropy. Sledovatelný je i proces zvaný řetězová migrace, kdy uprchlíci emigrují již ke svému př́ibuzenstvu, které je $\mathrm{v}$ Evropě usazeno, a pomáhají si navzájem informacemi, ale i finančními prostředky nebo hledáním pracovních míst.

Centrem jezídské diaspory se od devadesátých let stalo Německo. Podle odhadu z roku 2016 zde v této době žilo přes 60 tisíc Jezídů pocházejících z Turecka, Arménie a Iráku. O tom, jak se snaží Jezídi integrovat a zároveň chránit si svou kulturu, vypraví kapitola věnovaná Jezídům v knize Ve stínu islámu - menšinová náboženství na Blízkém východě od Jiř́ho Gebelta a kolektivu autorů. Jezídové zakládají spolky, které zajišstují kulturní a

\footnotetext{
${ }^{4}$ MURÁdOVÁ, N. Poslední dívka. 1.vyd. Ikar, 2018.
} 
náboženské aktivity, ale i komunikaci s úřady a médii. Po roce 2014 se spolky také snaží zajistit psychologickou péči ženám, které byly drženy v sexuálním otroctví Islámským státem.

Jezídismus není pouhým náboženstvím, ale celkově definuje jezídskou minoritu jako takovou. Nejedná se o misijní náboženství, a proto členové nemají zájem o jeho šírení. Toto náboženství je velice spjaté s geografickou polohou, takže kvůli intenzivní migraci Jezídů v posledních letech může dojít k postupnému oslabení víry ze strany mladší generace Jezídů, která se již narodila anebo minimálně vyroste v Evropě. Otázkou rozdílů ve vnímání náboženství mezi jezídskými migranty, kteří vyrostli ve vlasti, a těmi, kteří byli převážně socializovaní v diaspoře, se zabývá Greyenbroek ve své práci Yezidism in Europe: Different Generations Speak about their Religion. ${ }^{5}$

Jezídská víra od poloviny 19. století fascinovala a dráždila řadu západních učenců, ale skutečné znalosti jezídské tradice zůstaly relativně omezené. Na konci 20. století vyšla sbírka jezídských posvátných hymnů, které byly dřive předávány ústně a $\mathrm{v}$ písemné formě neexistovaly až do konce 70. let. Texty obsažené v díle Philipa Greyenbroeka Yezidism - Its Background, Observances and Textual Tradition nabízejí podrobnější pohled na víru, její pozadí a dodržování. První polovina svazku analyzuje dřívější práce o jezídismu a přináší náhled do historie náboženství íránských národů. Druhá část se skládá z překladů 19 jezídských hymnů s komentářem k filologickým a teologickým bodům. ${ }^{6}$

\section{Jezídismus}

Jezídské náboženství bylo přenášeno ústně a jeho charakteristické prvky vycházejí z jeho orální povahy. Mýty, lidové legendy a chvalozpěvy byly předávány po staletí náboženskými autoritami a kawály (náboženští hudebníci) z generace na generaci. Přestože některé posvátné texty byly poprvé publikovány na počátku 20. století a z některých arabských a syrských zdrojů vyplývají odkazy na události v době, kdy se poprvé objevila jezídská komunita, o historii a víře prvních Jezídů není zaznamenáno téměř nic. ${ }^{7}$

\section{Etymologie}

Etymologie slova „Jezíd“ (v angličtině „,Yazidi“) je svým způsobem sporná. Někteří vědci se domnívají, že slovo pochází ze středoperského a kurdského Jazadu, což znamená „Bůh“,

\footnotetext{
${ }^{5}$ GREYENBROEK, P. G. Yezidism in Europe: Different Generations Speak about their Religion. 1. vydání. Wiesbaden, Germany: Otto Harrassowitz GmbH \& Co., 2009.

${ }^{6}$ GREYENBROEK, P. G. Yezidism - Its Background, Observances and Textual Tradition. 1. vydání. Edwin Mellen Pr, 1995.

${ }^{7}$ AÇIKYILDIZ, B. The Yezidis. 1. vydání. I. B. Tauris, 2014, s. 35.
} 
nebo „Izid / Izad“ což znamená v nové perštině „Anděl“. Slovní kořen „Jaz“ znamená „uctívat“, „ctít“ a stává se podstatným jménem ,jazata“ - „bytost hodná uctívání“ nebo „svatá bytost“ nebo „bytost hodná oběti““. Někteří vědci si myslí, že Jezídové odvozují své jméno od zoroastriánského města Yazd v Íránu, kde se dodnes uctívá oheň, odkaz na „Ahura Mazda“ či „Ohrmazd“", princip dobra v opozici k „Angra Mainyu či Ahriman“", princip zla. ${ }^{8}$

Další teorie mluví o tom, že Jezídové pocházejí od umajjovského chálify Jazída ibn Mu'awiya, který vládl v letech 680 až 683 n. 1. a zabil vnuka proroka Mohameda Husajna ibn Alího. Po pádu umajjovského chalífátu v roce 750 n. 1. uprchli potomci královské rodiny a další umajjovští sympatizanti do kurdských hor před konkurenčním abbasovským chálifátem. Tam je přivítali Kurdové, kteří jim přísahali věrnost. Tato teorie dospěla k závěru, že umajjovští uprchlíci uzavírali sňatky s Kurdy a společně oslavovali Jazida ibn Mua'wiyaha jako jejich předka a bývalého vládce. ${ }^{9}$

Jezídové si říkají Ezid, Ezi nebo Izid, stejně jako Dasini nebo Dasin, což je údajně spojuje s nestoriánskými křest’anskými diecézemi Daseni nebo Dasaniyat. Další křest'anská tradice naznačuje, že Jezídové byli původně křest’any, ale jejich víra se změnila. Existují zásadní důkazy o vzniku jezídismu z křest’anství, protože určité jezídské rituály pocházejí z křest’anských tradic, např́iklad křest nebo konzumace alkoholu. Na podporu svých tvrzení místní obyvatelé tvrdí, že šejkem Adim byl Addai - legendární křest'anský apoštol Mezopotámie. Tato myšlenka odkazuje na fakt, že svatyně šejka Adiho v Lalíši byl původně klášter. ${ }^{10}$ Nejčastější verzí, kterou je možné slyšet od jezídské veřejnosti, je ta, která tvrdí, že jezídismus je nejstarší náboženství na Blízkém východě. Jezídové tvrdí, že celá kurdská populace byli kdysi Jezídové, dokud je represe a masakry nedonutily konvertovat k islámu. Jen malý počet lidí odolal a zůstal věrný svému původnímu náboženství - jezídismu.

\section{Etnická identita}

Termín etnická identita se používá k vyjádření stejnosti, podoby a jednoty. Přesněji řečeno, identita znamená ,podobnost osoby nebo věci za všech okolností; podmínka nebo skutečnost, že osoba nebo věc je sama sebou, a ne něčím jiným."11 Etnická identita je typicky afiliativní konstrukt, kdy se na jednotlivce nahlíží jako na příslušníka konkrétní etnické nebo kulturní

\footnotetext{
${ }^{8}$ AÇIKYILDIZ, B. The Yezidis. 1. vydání. I. B. Tauris, 2014, s. 35.

${ }^{9}$ EISLUND, S. Yazidism. [online]. Ancient History Encyclopedia: 2019. [cit. 2021-02-11]. Dostupné z: https://www.ancient.eu/Yazidism/.

${ }^{10}$ AÇIKYILDIZ, B. The Yezidis. 1. vydání. I. B. Tauris, 2014, s. 36.

${ }^{11}$ SIMPSON, J. A., WEINER, E. S. (1989). The Oxford English dictionary (2nd ed., Vol. VII). Oxford:

Clarendon Press, 1989, s. 620.
} 
skupiny. Příslušnost může být ovlivněna rasovými, natálními, symbolickými a kulturními faktory. ${ }^{12}$ Etnická identita Jezídů je definovaná zejména náboženskou příslušností a přísnou endogamií.

Diaspora. Jeden z následků emigrace, difúze kulturních prvků a globalizačních procesů je vznik diaspor po celém světě. Diaspora označuje etnickou skupinu lidí, kteří z určitého důvodu emigrují z domovského státu, přitom se ale snaží zachovat svou kulturu a kořeny. ${ }^{13}$ Až do 80. let 20. století byl pojem diaspora asociován s negativními následky, které byly způsobeny donucenou migrací. Od 80. let se postupně opouští od percepce diaspory, jež byla formována na základě násilného exilu způsobeného vnějšími faktory. ${ }^{14}$ Prvotní teorie o diasporách tvrdily, že po přestěhování se natrvalo migranti ztrácí své vazby na domovskou zemi. ${ }^{15}$ Moderní pojetí naopak počítá se zachováním etnických identit a s trvalým spojením s mateřskou zemí. V současnosti v důsledku globalizace vznikají diaspory založené na etnické identitě, které mají často uzavřený charakter. Neexistují ale žádné hranice stanovující, kolika generacemi by měl člověk dokázat svůj etnický původ, aby se kvalifikoval jako člen diaspory, a proto je sebeidentifikace často považována za dostatečnou.

\section{Historie}

Na světě existuje jen málo národů, jejichž historie sahá několik tisíciletí nazpět. Jedním z těchto národů jsou právě Jezídové. Původ Jezídů je doposud pro vědce nejednoznačný. Existují tři hlavní verze: - Jezídové - přímí potomci Babyloňanů; - Jezídové - přímí potomci Sumerů; - Jezídové - přistěhovalci z Indie, kteří emigrovali na sever Iráku. Je třeba poznamenat, že žádná z verzí není podložena vědeckými důkazy. Avšak odborná literatura za jejich vlast převážně považuje oblasti Mosulu a Sindžáru v severním Iráku, kde žila donedávna většina Jezídů. ${ }^{16}$

\section{Jezídové v Iráku a Turecku}

První zmínky o Jezídech se objevují v kronikách až ve 12. století. Současník šajcha Adího, Kitab al-Ansab zmiňuje komunitu zvanou al-Jezídiya v severním Mosulu. ${ }^{17}$ Ve 12 . století se ocitl šajch Adi se svými stoupenci z bratrstva Adawíje na severu Iráku, kde objevil rolnickou

\footnotetext{
${ }^{12}$ CHEUNG, Yuet W. Approaches to ethnicity: Clearing roadblocks in the study of ethnicity and substance use. International journal of the addictions, 1993, 28.12: 1209-1226.

${ }^{13}$ The Cambridge dictionary of sociology. Cambridge: Cambridge University Press: 2006.

${ }^{14}$ HANUS, Lukášs. "Nové diaspory"- diaspora jako transnacionální moment. AntropoWebzin, 2009, 5.2-3: 13-17.

${ }^{15}$ MCLOUGHLIN, Seán. Religion, religions, and diaspora. A Companion to Diaspora and Transnationalism, 2013, 125-138.

${ }^{16}$ GAZARYAN, A. Jezidy. Kto oni / Езиды. Кто они? [online]. Noev kovcheg: 2013. [cit. 2021-02-20]. Dostupné z: https://noev-kovcheg.ru/mag/2013-05/3749.html

${ }^{17}$ AÇIKYILDIZ, B. The Yezidis. 1. vydání. I. B. Tauris, 2014, s. 37.
} 
komunitu, jejîž víra byla směsí starověkých íránských věr typu zoroastrastrismu a manicheismu. Tito lidé uctívali chalífu Jazída ibn Mu'awiyu. Postupem času byli místní ovlivněni učením šajcha Adího a jeho řádu, ale i víra a praktiky Jezídů se začaly promítat do učení řádu Adawíje, jehož členové původně vyznávali islám. Pokračující synkretismus mezi súfijským islámem a starodávným íránským náboženstvím vyústil do jakési syntézy víry, která definitivně oddělila náboženství stoupenců šajcha Adího od ortodoxního islámu.

Ve čtrnáctém století se jezídismus šiřil přes oblast Sulejmánia dnes patřící pod Kurdistán až na západ k Antalyi v Turecku. Jezídismus se stal oficiálním náboženstvím polonezávislého knížectví Jazíra. Jak politická síla Jezídů na počátku patnáctého století rostla, stali se muslimové krutějšími vůči následovníkům šajcha Adího, které považovali za odpadlíky a uctívače Jazída. Povinná konverze k islámu a zmasakrování těch, kteří se postavili na odpor, se stala běžnou záležitostí.

Na rozdíl od třináctého a čtrnáctého století, kdy byli jednotní a mocní, od patnáctého století Jezídové přežívali jako malé kmenové skupiny, kdy někteří důležití náčelníci jezídských kmenů byli násilně donuceni ke konverzi k islámu a moc Jezídů rychle slábla. ${ }^{18}$

Od druhé poloviny devatenáctého století zahájili Osmané rozsáhlé pronásledování nemuslimských komunit. Velké množství Jezídů z Karadagu a Rumkaly proto uprchlo a připojilo se $\mathrm{k}$ jezídské populaci v severní Sýrii a Iráku. Arménští křest’ané a křest’ané z východních církví uprchli do provincie Sindžár, kde hledali útočiště u Jezídů. ${ }^{19}$

Po vyhlášení kurdské autonomie v roce 1992 se Jezídové začali integrovat do širší kurdské společnosti s podporou obou hlavních kurdských stran - Kurdské demokratické strany Iráku a Vlastenecké unie Kurdistánu, které Jezídům daly jakousi symbolickou svobodu vyznání jakožto př́ivržencům původního kurdského náboženství. Například kulturní centrum Láliš bylo založeno v roce 1993 v Duhoku. Jezídové dostali možnost vydávat několik časopisů s historickou, kulturní a náboženskou tématikou. Na školách se začalo vyučovat jezídské náboženství. Komunita obnovuje starobylé jezídské památky a staví nové. Mnoho Jezídů je však nespokojeno se současnou kurdskou vládou, protože věří, že kurdské strany Jezídy uznávají jen proto, aby prosazovaly své vlastní politické zájmy. ${ }^{20}$

\footnotetext{
${ }^{18}$ AÇIKYILDIZ, B. The Yezidis. 1. vydání. I. B. Tauris, 2014, s. 48.

${ }^{19}$ AÇIKYILDIZ, B. The Yezidis. 1. vydání. I. B. Tauris, 2014, s. 56-57.

${ }^{20}$ AÇIKYILDIZ, B. The Yezidis. 1. vydání. I. B. Tauris, 2014, s. 61-63.
} 


\section{Jezídové v Sýrii}

Jezídové žijí ve dvou oblastech v severní Sýrii kolem města Afrin a Jebel Simán a Jazira s hlavními městy Qamišli a al-Hasakah. V těchto oblastech žijí pouze Jezídi nebo směsice Jezídů a muslimských Kurdů.

Vzhledem k nedostatku historických pramenů je obtížné do dnešního dne dějiny Jezídů v Sýrii dokumentovat. Lze však předpokládat, že jejich přítomnost v této oblasti sahá až do časů počátků prrítomnosti Jezídů v Sindžáru a turecké Jazíře, tedy do dvanáctého století. Dnes žije v Sýrii podle odhadů mezi 160000 Kurdů a asi 5000 Jezídů, kteří jsou na průkazech totožnosti označováni jako cizí státní příslušníci. ${ }^{21}$

\section{Jezídové v Arménii}

Přítomnost Kurdů na Kavkazu sahá až do konce desátého století, kdy v celém regionu vládly dvě kurdské dynastie Šaddadi (951-1199) a Rawwadi (955-1227). Během mongolské invaze ve třináctém století se kurdské kmeny přestěhovaly do Arménie, konkrétně na jih Karabachu. Dnes je velká část jezídské populace v Arménské republice soustředěna kolem hory Aragac. Během devatenáctého století došlo ke konfliktu mezi Osmanskou ř́̌ší a Ruskem. Kvưli kurdské vzpouře proti Osmanům se muselo kurdské obyvatelstvo, jak muslimové, tak Jezídové, kvůli bezpečnosti odstěhovat do carského Ruska, které je uvítalo jako potenciálně užitečný nástroj v boji proti Osmanům. ${ }^{22}$

$\mathrm{Na}$ konci třicátých let a po druhé světové válce se mnoho arménských Jezídů přestěhovalo do Gruzie a na jiná místa v Sovětském svazu. Kupř́ikladu ve městě Novosibirsk vznikla větší komunita Jezídů. V padesátých a šedesátých letech se Jezídové nadále stěhovali do velkých gruzínských měst, zejména do Tbilisi a Telavi kvůli práci a lepšímu životu.

\section{Sindžárský masakr}

Masakr začal 3. srpna 2014, když teroristé z Islámského státu napadli jezídskou sídelní oblast kolem pohoří Sindžár a okolní města. Několik týdnů předtím IS dobyl iráckou metropoli Mosul. Milice kurdské vlády zvané pešmerga slíbili Jezídům, že je budou chránit, jenže evakuovaly své pozice ještě předtím, než se skupiny teroristů dostaly do oblasti Sindžáru. Zločiny spáchané IS na jezídské populaci zahrnovaly zabíjení, sexuální otroctví, zotročení a mučení; aplikaci nástrojů, které vedou $\mathrm{k}$ pomalé smrti; zavedení opatření k zabránění jezídským dětem v narození, včetně nucené konverze dospělých, oddělení jezídských mužů a žen a přemístění jezídských dětí z jejich rodin do výcvikových táborů IS, čímž se teroristi

\footnotetext{
${ }^{21}$ AÇIKYILDIZ, B. The Yezidis. 1. vydání. I. B. Tauris, 2014, s. 66.
}

${ }^{22}$ AÇIKYILDIZ, B. The Yezidis. 1. vydání. I. B. Tauris, 2014, s. 68. 
snažili odříznout je od praktikování své víry, oddělit od vlastní komunity a vymazat jejich etnickou identitu. $^{23}$

Přes 50000 Jezídů bylo uvězněno na hoře Sindžár, kam utekli před pronásledováním vojáků, kteří je obklopili ze 4 stran bez možnosti úniku. Stovky Jezídů zemřely na hoře, bez jídla a vody, na vyčerpání vysokými teplotami. Během těchto dní přiletělo několik vrtulníků s vodou a potravinami, jenže jelikož byly lahve házeny ze vzduchu, často se rozbily, a pomoc tak byla neúčinná. Hosni vzpomínal, „že viděl u jednoho mladého kluka vodu a nabídl mu za to tisíc dolarů, protože celá rodina umírala žizní, jenže chlapec nabídku odmítnul, jelikož v daný moment nikomu nešlo o peníze, ale o přežití v horních podmínkách. "Pomoc Jezídům do hor přišla až po 12 dnech, kdy jim jednotky PKK (Strana kurdských pracujících) dokázaly uvolnit jednu cestu, kudy se Jezídové spustili z hor a utekli do iráckého Kurdistánu, kde byli ubytováni v uprchlických táborech. Téměř všechny vesnice byly evakuovány do 3 dnů po útoku. Výjimkou se stála vesnice Kojo, která čelila útoku až do 15. srpna, respektive byla obklopena ze všech stran a vesničané byli drženi jako rukojmí ve vlastních domech. Pokud se někdo pokoušel uniknout autem nebo pěšky, ihned byl zastřelen. Vesnice Kojo se stala symbolem jezídské genocidy. Přes 3000 jezídských mužů bylo zavražděno a pohřbeno v masových hrobech, přes 7000 žen a dětí bylo uneseno a prodáno do otroctví, polovina těchto lidí se stále pohřešuje. ${ }^{24}$ Jen pár tisíc Jezídů mělo to štěstí, že se prostřednictvím humanitárního kontingentu dostalo do bezpečné země typu Německa. Dnes žije přes 300000 Jezídů v uprchlických táborech v severním Iráku v kurdské autonomní oblasti, hodně z nich se nemohlo nebo si netroufá do Sindžáru vrátit, protože jim byl zničen všechen majetek a bezpečnostní situace v oblasti je stále nestabilní. Počet kladně vyřízených žádostí o azyl v Německu klesá.

\section{Emigrace Jezídů do Evropy}

Jezídové začali emigrovat do Evropy, a to zejména do Německa, již v šedesátých letech 20. století. První př́íchozí Jezídi pocházeli z Turecka. Hodně z nich se usadilo ve městě Celle v Dolním Sasku. ${ }^{25}$ Aby mohli v Německu pracovat, museli být jako gastarbeitři naprosto

\footnotetext{
${ }^{23}$ YAZIDI CULTURAL HERITAGE PROJECT: Recent History. [online]. 2019. [cit. 2021-03-05]. Dostupné z: https://www.yazidiculturalheritage.com/recent-history/

${ }^{24}$ MURÁDOVÁ, N. Poslední dívka. 1.vyd. Ikar, 2018.

${ }^{25}$ TAZ.de: Die zweite Heimat. [online]. Jesiden in Norddeutschland, 2014. [cit. 2021-02-24]. Dostupné z: https://taz.de/Jesiden-in-Norddeutschland/!5035368/
} 
zdraví a gramotní. Příchozí Jezídi pracovali v Turecku především v zemědělství, většina z nich pocházela $\mathrm{z}$ chudšího sociálního prostř̌edí a nebyla příliš vzdělána. ${ }^{26}$

Jezídské ženy byly většinou negramotné. Existují pro to dva hlavní důvody. Jeden z nich je, že jejich rodiny je ze strachu z únosu neposílaly do školy, a druhým je situace na Blízkém východě, kde je zvykem, že dívky jsou méně vzdělané kvůli tomu, že jejich rolí ve společnosti je hlavně pečovat o domácnost a o děti. První generace Jezídů tedy měla do konce 80. let velmi nízkou úroveň vzdělání. Teprve druhá generace využila vzdělávacích př́iležitostí v Německu. Pro většinu Jezídů žijících v Německu je dnes kvalifikované vzdělání pro jejich děti velmi důležité, protože jim umožňuje integraci do německé společnosti i př́stup na německý trh práce. ${ }^{27}$ Často př́slušníci této generace mají již vlastní podniky a hodně se zapojují do činností jezídských spolků.

Druhou největší skupinu Jezídů žijících v Německu tvoří Jezídové pocházející ze Sýrie. Největší migrační vlny této skupiny Jezídů probíhaly v letech 1980-1990²8, další potom po roce 2011, kdy začala občanská válka v Sýrii.

Největší vlna stěhování Jezídů do Německa nastala po výše představených událostech v Sindžáru. Jen v roce 2015 uprchlo do Německa přes 75000 Jezídů pocházejících z Iráku a přes 10000 Jezídů ze Sýrie. ${ }^{29}$

Před rokem 2014 žilo v severním Iráku okolo 600000 Jezídů a v diaspoře v Německu okolo 100000 členů této menšiny. Podle Ústřední rady Jezídů žije na území Německa přes 150000 Jezídů. Žijí hlavně v Dolním Sasku a v Severním Porýní-Vestfálsku. V rámci projektu přijalo Bádensko-Württembersko přibližně 1000 týraných žen a dívek, které se staly obět'mi IS. Spolu s univerzitou v Dohuku země zř́idila institut psychoterapie v severním Iráku, který by měl pomoci traumatizovaným lidem přímo na místě. ${ }^{30}$ Všichni moji respondenti přijeli do Německa až po roce 2015 a většina $\mathrm{z}$ nich žila nějakou dobu v uprchlických táborech v Kurdistánu, následně se někdo dostal do Evropy z Turecka přes Řecko, někdo jinou cestou. Např́iklad Hussein vyprávěl, že se se svým strýčkem dostal do Německa přes Bulharsko, Srbsko, Mad’arsko, Slovinsko a Rakousko. Hosni strávil v Řecku 3 roky, přičemž dva roky pracoval $\mathrm{v}$ uprchlickém táboře jako dobrovolník $\mathrm{v}$ mezinárodní

\footnotetext{
${ }^{26}$ TAGAY, S. a ORTAÇ, S. Die Eziden und das Ezidentum: Geschichte und Gegenwart einer vom Untergang bedrohten Religion. 1. vydání. Landeszentrale für politische Bildung, Hamburg, 2016.

${ }^{27}$ TAGAY, S. a ORTAÇ, S. c. d., s. 96.

${ }^{28}$ GREYENBROEK, P. G. Yezidism in Europe: Different Generations Speak about their Religion. 1. vydání. Wiesbaden, Germany: Otto Harrassowitz GmbH \& Co., 2009, s. 42.

${ }^{29}$ VON HEIN, M. Die Jesiden fünf Jahre nach dem Genozid. [online]. DW made for minds: 2019. [cit. 2021-0224]. Dostupné z: https://www.dw.com/de/die-jesiden-f\%C3\%BCnf-jahre- nach-dem-genozid/a-49839355

${ }^{30}$ WELT KOMPAKT. 150000 Jesiden leben in Deutschland. [online]. 2016. [cit. 2021-02-24]. Dostupné z: https://www.welt.de/print/welt_kompakt/article158992066/150-000-Jesiden- leben-in-Deutschland.html
} 
organizaci Lifting Hands International, kde působil ve skladě s oblečením, pracoval s dětmi a také tlumočil z angličtiny do rodného jazyka kurmandží, jelikož byl jeden z mála, kteří se za krátkou dobu naučili poměrně dobře komunikovat v angličtině. Tím často zajistil komunikaci mezi ostatními uprchlíky a dobrovolníky a sponzory působícími v táboře. Často se stává, že rodiny přijedou postupně, například nejdříve přijedou mladší členové či muži, teprve pak za nimi přijedou jejich rodiny anebo si přivezou i starší rodiče. Pro starší generace je proces integrace těžší, a proto někteří starší lidé zůstávají v Iráku, a to hlavně když jim tam zůstane někdo z rodiny.

\section{Kultura a tradice}

Jezídové mají bohatou kulturu a tradice obsahující mnoho prvků z jiných blízkovýchodních kultur. Jedinečnými je však dělá jejich spojení s přírodou. Npříklad duben je pro ně nejdůležitější měsíc v roce, protože ožívá příroda. Tento měsíc je Jezídy považován za nový začátek ve všech oblastech života. Hlavním elementem v jezídismu je Slunce, symbol, který dělá Jezídy jedinečnými. Slunce jako symbol jezídismu se objevuje v jezídských chrámech, v kulturních centrech i na náhrobcích.

\section{Svátky}

Jezídové mají v celém roce hodně svátků, o kterých mladí lidé ani nevědí. Většinu ale slaví jen málo nebo vůbec. Jezídské svátky jsou převážně spojeny s př́rodou, mají rysy starodávných íránských náboženství a slaví se v odlišných ročních obdobích.

Svátek batzmi a pletené nitě basmbari. Oslava batzmi se týká ale pouze jedné malé skupiny Jezídů, kteří patří do klanu Jelka. Kořeny tohoto svátku sahají tisíce let zpátky a také se mu říká Eid Sarsal, Taus Melek, nebo Eid Pir Alí. Pir Alí oživil tento svátek mezi syny klanů Jelky a doporučil svým následovníkům, aby jej každoročně oslavovali. Tento svátek připadá na poslední týden v prosinci a slaví se sedm dní. Jezídové v diaspoře jej však kvůli práci a škole někdy oslavují o týden dříve nebo později. Oslavu připravují pouze Jezídé z kmene Jelka, ale navštěvují je Jezídé a př́ibuzní i z jiných kmenů a kast. Na každý den trvání svátku jsou připravené jiné rituály.

Jedno z nejdůležitějších rituálů během tohoto svátku je výroba a darování basmbari, což je pojem, který má v jezídské kultuře několik významů. Basmbari (v několika zdrojích je uvedený tento název, ale Jezídové spíše používají název dazoki piriali) je vlákno vyrobené během svátku batzmi ze dvou barevných nití, které symbolizují milenecký vztah, jelikož jsou k sobě propletené. Basmbari se proplétá šestý den svátku dřevěným nástrojem zvaným ta shi; 
červená nit se nazývá ezdani soor a bílá tausi melek. Bílá barva jako přirozená barva světla a červená jako začátek jeho jasu při východu slunce, což je pro Jezídy nejposvátnější čas, je svázána v podobě límce nebo kruhu, který představuje sluneční tvar.

Po jeho dokončení jsou nitky rozřezané na menší kusy a darovány lidem a př́ibuzným, kteří přijdou na návštěvu poslední den svátku. Propletené nitky se nosí na rukou nebo krku, nosí je dospělí i děti, mají údajně schopnost ochránit před nemocemi, zlými duchy a závistivýma očima. Při nasazení basmbari by si člověk měl něco v duchu přát. Mezi Jezídy existuje pověra, že komukoli, kdo nosí nit basmbari na krku nebo na zápěstí po celý rok, aniž by se přeřízla, bude jeho přání splněno.

Rojeet Ezi. Tento svátek připadá na první pátek v prosinci. Předchází mu tř́ídenní půst, jediný půst, který Jezídové dodržují. Půst začíná od východu slunce a trvá až do západu, kdy nastává čas hodování a veselí. Půst je jako v jiných kulturách čas modlitby a spojení s Bohem. Půst je podle Jezídů rituál, který existuje již více než 3500 let na počest narození boha světla a ochránce pravdy Mithra, jak je zachyceno i ve sbírce Rgvéda. Náboženství Mithraitů, si tento obřad stále udržuje a bude i nadále předávat z generace na generaci. (informátor Farhad) Půst je podle Jezídů náboženskou a morální povinností každého Jezída před Bohem. Pojem Rojeet Ezi by se doslovně překládal jako „boží svátek“ nebo „Svátek Všemohoucího“ Rojeet Ezi se slaví v prosinci a v roce 2020 připadl na 18. prosince.

Sere Sal neboli Nový rok. Jezídský Nový rok se slaví první středu v dubnu. Tento svátek je také známý jako svátek Anděla Páva nebo jako Červená stř̌eda. Slaví se doma v rodinném kruhu. V této době jsou obětovaná zvířata, domy jsou zdobeny jarními květinami, barví se vajíčka a také se peče speciální chleba, kterému se říká sawuk. Podle jezídské víry Bůh stvořil svět ve tvaru vajíčka $v$ kameni. Na začátku byla údajně země pokryta ledem. Bůh poslal Anděla Páva, aby prolomil led, aby byla Země obyvatelná pro Adama a Evu. Po rozbití ledu Páví anděl ozdobil Zemi květinami a rostlinami. Sere Sal tedy symbolizuje den, kdy Anděl Páv rozbil led a přinesl na Zemi jaro. Z tohoto důvodu dnes Jezídové rozbíjejí barevná vajíčka a zdobí je i červenými máky. ${ }^{31}$ Podle jezídské tradice barvy vajec představují duhu, kterou vytvořil Anděl Páv, když sestoupil do údolí Láliš, aby požehnal Zemi plodností a každoroční obnovou.

Důležitý aspekt svátku Sere Sal je motiv ohně, slunce a návratu zesnulých předků, zejména samotného Tause Meleka (Anděla Páva). Jezídové věří, že duchové mrtvých se každý rok vrací ke svému pozemskému tělu do hrobů na Červenou středu s úmyslem oslavit s

\footnotetext{
${ }^{31}$ AÇIKYILDIZ, B. The Yezidis. 1. vydání. I. B. Tauris, 2014, s. 108.
} 
živými Sere Sal. Proto Jezídové v tento den navštěvují hřbitovy a hroby svých blízkých s cílem pozdravit je, sdílet s nimi pokrmy a oslavit společně tento jarní svátek. V noci Sere Salu se v údolí Láliš rozdělá velký oheň, který podle tradic má přitahovat Anděla Páva, aby se vrátil v podobě Slunce. Oheň je v tomto případě považovaný za posvátný element jako pozemská forma ohnivého Anděla Páva. Vaření vajec na Sere Sal symbolizuje rovněž proměnu Země, která na začátku měla tekutou formu, až později se stala pevnou. V diaspoře spíše mizí náboženské tradice, ale barví se vajíčka a zdobí se byty, také lidé navštěvují jezídské hřbitovy, pokud mají někoho pohřbeného ve státě, kam se odstěhovali. Organizují se oslavy v jezídském domě, kde se může zpívat a tančit.

Khydr Aylas. Jeden z dalších svátku, který slaví Jezídi po celém světě, je náboženský svátek „Khidr Nabi a Khidr Aylas“ věnovaný svatým Khidrovi a Aylasovi. Podle jezídského náboženství jsou svatí patrony milenců a činiteli tužeb. Tento svátek se vždy slaví během prvního únorového pátku. Z pohledu Jezídů jsou Khidr Nabi a Khidr Aylas dva jezdci na bílém koni (Xidir Nebî û Xidir Eylas siyarê hespêd boz). První je činitelem tužeb a patronem milenců a druhým je patronem těch, kteří cestují po moři.

Svátku předchází třídenní půst (rojî). Vstávají brzy ráno před úsvitem a po modlitbě se najedí. Jídlu říkají pašiv (paşîv). Až do východu slunce se nic nejí a nepije. Předtím, než zapadne slunce, věřící provedou umytí rukou a obličeje, modlí se a poté si dají večeři, kterou nazývají fitar. V těchto dnech se jídla připravují z rostlinných produktů, tj. pšenice, mouky a mléčných výrobků. Předpokládá se, že Khidr Nabi a Khidr Aylas nepřijímají oběti. Během těchto dnů Jezídé mají zakázáno lovit a cestovat, protože Khidr Nabi a Khidr Aylas se sami vydávají na lov a neměli by být rušeni.

\section{Kuchyně}

Jezídská kuchyně zahrnuje širokou škálu ovoce a zeleniny. Nejoblíbenějším druhem masa je ovčí, jehněčí a kuřecí. Jídla jsou většinou podobná jako u ostatních národů na Blízkém východě a jsou si velice blízká s kurdskými specialitami. V rodině, kde autorka bydlela, byla dotazovaná paní domu „Chutná ti kurdské jídlo?“, zde záleží opět na určitém národním cítění, kdy někteří říkají určitým druhům jídla, že jsou jezídská jídla, ačkoli jsou totožná s kurdským jídlem. Slaná jídla se podávají obvykle s rýží nebo s chlebem zvaným naan, který je podobný tortile. Jedno z častých běžných jídel je eprah, pokrm z plněných vinných listů. Plnící směs se obvykle skládá z bulguru, mletého masa, mrkve, rajčete, papriky a cibule, eprah má podobu menšího závitku. Často je eprah je součástí jídla zvaného dolma, což je kombinace s lehce 
smaženými bramborovými plátky a pečeným masem. Všechny tři pokrmy se uvaří zvlášt', nakonec se všechno zamíchá dohromady a podává na velkém podnosu.

Dalším pokrmem je biryani, což je pokrm z rýže, masa a zeleniny, který je ochucený kořenicí směsi. Jezídové s oblibou přidávají do biryani arašídy a rozinky. Kotilk je druh plněných knedlíků a jedná se o typický kurdský pokrm. Tyto knedlíky jsou plněny mletým masem a podávají se jak uvařené, tak i smažené v kombinaci s různými omáčkami. Marigha Bamia je blízkovýchodní jehněčí dušené maso s okrou a rajčaty. ${ }^{32}$

Jeden z nejoblíbenějších dezertů je pokrm zvaný kuliča, což je sušenka plněná datlovou pastou, zavařeninou, nebo směsí vlašských ořechů a cukru. Tradičně se kuliča peče při náboženských svátcích nebo oslavách, a to ve velkém množství.

\section{Sakrální předměty}

Jako v každém náboženství i v jezídismu existuje několik sakrálních předmětů, které mají čestné místo a nesmí chybět v žádné domácnosti. Tyto předměty zdobí byty i $\mathrm{v}$ diaspoře, přičemž mají kromě náboženského i kulturní význam. Jeden z těchto předmětu je barát neboli al-barat.

Al-Barat je posvátný jezídský symbol, který se po celou historii vyrábí v Láliši v noci na Shiv Barat, která byla pro starověké mithraisty nejdelší nocí roku. Barát má tvar zrna a velikost ořechu. Symbolizuje Zemi, která se má znovu zrodit. Barát vytváǎí šamsáni, což jsou mladé neprovdané dívky a chlapci, kteří slouží ve svatyni v Láliši a dobrovolně se vzdali možnosti uzavírat sňatek. Používá se voda ze svatého pramenu Kania Spi. ${ }^{33}$ Dívky přinášejí hlínu z jeskyně Barat poblíž Láliše. Baba čáwiš, duchovní sloužící v Láliši, přináší posvátnou vodu z Kania Spi (bílý pramen). Voda se míchá s hlínou, do směsi se přidá trošku mléka, vytvoří se malé kuličky a nechají se na slunci vyschnout. Barát je tedy symbolem Země a zrození přírody. Každý Jezíd, který cestuje, musí mít s sebou kuličku barátu, aby byl chráněný před zlem. Každý Jezíd musí políbit barát každé ráno před snídaní, během půstu a je zakázáno, aby jej muž předal své ženě nebo snoubence přímo a naopak, protože je symbolem smlouvy, přísahy a bratrství. V důsledku předání by se žena stala jeho sestrou. Toto gesto autorka pozorovala při návštěvě jezídské rodiny, kdy hospodyně domu ukazovala, jak vypadá barát. Dala jej políbit všem přítomným kromě svého manžela s vysvětlením, že se to nesmí, jelikož by se z nich stali bratr a sestra. Je to předmět př́isahy a známka poctivosti a loajality.

\footnotetext{
${ }^{32}$ YEZIDIS INTERNATIONAL: Yezidi food. [online]. 2015. [cit. 2021-02-18]. Dostupné z: http://www.yezidisinternational.org/abouttheyezidipeople/yezidi-food/

${ }^{33}$ ČERNÝ, Karel. Jezídové - komunita na útěku. Praha: Lidové noviny, 2016, s. 30.
} 
Není přípustné s rukou na něm falešně př́isahat. Jezídové používají barát k uzavření dohod a k prř́sahám.

Barát souvisí také s halátem neboli bohčekem (Jezídové po domácku spíše používají výraz bohček). Jedná se o ručně vyrobenou tašku nebo kapsu z látky a nití, k níž lze připevnit kruhový kovový náramek (uzavřený kruh označuje uzavření jezídského náboženství). V bohčeku se uchovávají posvátné př̀dměty.

\section{Rodinná obřadnost}

Svatba. Jezídové se obvykle berou mladí, často $\mathrm{v}$ patnácti letech. Manželství běžně domlouvají rodiče mladého páru. Mladý pár by neměl být do manželství nucen. Manželství by se mělo uzavírat na základě souhlasu obou partnerů. Rodina budoucího ženicha musí zaplatit cenu nevěsty, která závisí na její kráse a společenské pozici její rodiny v rámci kmene. Přestože se od této tradice malinko upustilo, stále se praktikuje. Cena za nevěstu, kterou musí rodina manžela zaplatit před svatbou, dosahuje v německých diasporách až 70000 eur. ${ }^{34}$ Podle informace od respondenta v Iráku cena za nevěstu může začínat od 1000 eur. Pokud rodiny nesouhlasí se sňatkem, mladý pár někdy uteče na pár dní do vedlejší vesnice nebo k jiným př́ibuzným. V takovém př́ípadě rodiny již musejí souhlasit, jelikož tímto činem pár dává jasně najevo, že chce být spolu za každou cenu. Tento zvyk je podobný jako v některých muslimských komunitách na Blízkém východě.

Den před svatbou je nevěsta připravena na svou henovou noc, sheva desthineye. Dává si horkou koupel, obléká se a poté dorazí do místnosti, kde jsou hosté. Její ruce a ruce družiček jsou natřeny henou. Následujícího dne je nevěsta oblečena do svatebních šatů a červeného pásu na břiše, který jí připevňuje její sestra. Manželský obřad začíná doprovodem nevěsty z domu jejího otce do domu ženicha. U dveří je obětována ovce. Pokud jde o ženicha, během svatby ho doprovází jeho bratr. V dnešní době Jezídové, kteří žijí ve městech, obvykle pořádají svatební hostiny ve svatebních sálech. V diasporách se svatby konají rovněž zde. Svatby v diaspoře mají všeobecně velký význam. Pozná se to podle toho, že Jezídové si často pouštějí svatby nahrané na Youtube a s oblibou se na ně dívají v televizi. Např́klad televizní kanál Ezidxan TV má zvláštní rubriku svatby, kde jsou nahrané různé svatební filmy, ve kterých se hodně tančí. V Německu v dnešní době nabízí své služby hodně jezídských hudebníků - na jezídských svadbách totiž musí hrát živá hudba. Podle jezídské tradice musí

\footnotetext{
${ }^{34}$ GREYENBROEK, P. G. Yezidism in Europe: Different Generations Speak about their Religion. 1. vydání. Wiesbaden, Germany: Otto Harrassowitz GmbH \& Co., 2009, s. 46-48.
} 
nevěsta po svatbě zůstat doma u svých rodičů ještě sedm dní, až potom se přestěhuje do domu svého manžela.

Jezídové dbají na endogamní manželství. Polygamní manželství není zakázané, ale není v komunitě př́liš vítané, $\mathrm{v}$ diaspoře se téměř nevyskytuje. Existuje mnoho pravidel a zákazů týkajících se manželství. Manželství s příslušníky jiných etnických skupin je zakázané. Pokud se Jezídka vdá za „nejezída“, konverze k jezídismu není možná, automaticky konvertuje k náboženství svého partnera a je exkomunikován rodinou a kmenem. V komunitě je navíc zakázáno i manželství mezi kastami a kmeny. ${ }^{35}$

Pohřeb. Smrt pro Jezídy znamená oddělení duše a její převtělení do nového těla. Jezídové věří v reinkarnaci i v existenci ráje a pekla. Po Soudném dni se duše znovu objeví v novém těle a nepamatuje si na svůj předchozí život. Proto není odpovědná za své dřívější špatné činy.

Tělo mrtvého je umyto horkou vodou. Zemřelého musí umýt šajch, birájé áchiraté, což představuje vybraného bratra pro onen svět. Respondent Farhad říká, že někteří učenci se snaží tento zvyk vědecky vysvětlit. Podle nich se používá horká voda pro případ, že by nebožtík nebyl mrtvý a horká voda by ho přivedla k vědomí. Poté, co šajch umyl zesnulého, je tělo zabaleno do bílého pláště zvaného kifin a poté je uloženo do rakve. Do úst je zesnulému vložen kousek barátu. Zemřelý je následně odvezen na hřbitov, kde je již připravený vykopaný hrob. Hlava zesnulého je umístěna směrem na východ, tedy k východu Slunce. U hrobu v oblasti hlavy je ponechaný otvor, aby duše zesnulého mohla opustit tělo. ${ }^{36}$

Průvod na hřbitov je tichý. Výjimku představují duchovní, kteří zpívají hymny v př̀ední části průvodu. Ženy pláčou a bijí se dlaněmi do prsou. Ve stejný den je pořádaná hostina na památku zemřelého. $\mathrm{V}$ diaspoře se hostina pořádá často $\mathrm{v}$ jezídském kulturním domě, jelikož je zde více prostoru. Může se jí někdy zúčastnit přes 100 lidí.

V Německu jezídské hřbitovy vznikly na konci 90. let. Na začátku bylo Jezídům přiděleno určitě místo na křest’anských hřbitovech, později si jezídské komunity zakládaly již vlastní hřbitovy. V diaspoře odpadá řada rituálů během pohřbu. Jeden z nich je ten, že pokud zemře manžel, tak vdova si ostříhá vlasy a pověsí je manželovi na hrob nebo na náhrobní

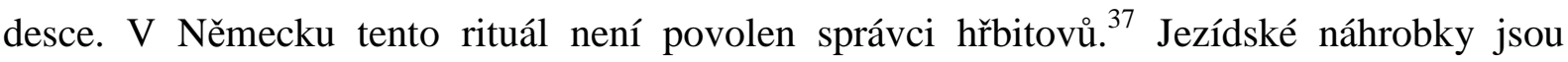
zdobeny jezídskými symboly, jako je slunce, páv či obraz svatyně Láliš. Nad jménem je často

\footnotetext{
${ }^{35}$ ISSA, C. Das Yezidentum: Religion und Leben. Oldenburg: Dengê Êzîdiyan, 2007, s. 105.

${ }^{36}$ TAGAY, S. a ORTAÇ, S. Die Eziden und das Ezidentum: Geschichte und Gegenwart einer vom Untergang bedrohten Religion. 1. vydání. Landeszentrale für politische Bildung, Hamburg, 2016, s. 82.

${ }^{37}$ GREYENBROEK, P. G. Yezidism - Its Background, Observances and Textual Tradition. 1. vydání. Edwin Mellen Pr, 1995, s. 161.
} 
nadepsána etnická př́íslušnost „Êzîdî“, „Yezidi““ nebo „Yezide“ někdy spolu se jménem př́slušné kasty. ${ }^{38}$

Mor Kirin neboli křest. Jezídové si po tisíce let udržovali mnoho nábožensko-kulturních rituálů a zvyků, které se nezměnily ani v rámci nepřátelských reforem. Mor kirin neboli křest lze považovat za jeden $\mathrm{z}$ nejdůležitějších rituálů praktikovaných řadou náboženství včetně jezídismu. V jezídismu se křtí pouze vodou z pramenu Kanya Spi, který se nachází v údolí Láliš. Tento pramen symbolizuje spojení člověka s přírodou. V Německu se tento rituál provádí v jezídském kulturním domě, provádí ho vrchní duchovní, který je v Německu určený a schválený bába šéchem. Pan Naíf říká, že se používá voda z pramenu Kanya Spi, která se posílá z Iráku. Někteří Jezídové jsou toho názoru, že pokud se křest neprovádí přímo v Láliši u pramene řeky Kanya Spí, nemůže se mluvit o pravém mor kirinu.

Obřízka. Jezídští chlapci jsou obřezáni obvykle 20 dní po křtu. Podobně jako v křest’anství rodiče si vybírají pro své dítě kmotra zvaného kerif. Mezi rodinami dítěte a kmotra vzniká pokrevní pouto. Tyto dvě rodiny nesmějí uzavírat sňatky mezi sebou po sedm dalších generací. Proto se kerif obvykle vybírá záměrně ze skupiny, se kterou i tak není možné uzavírat sňatek, což znamená, že kerif bude pocházet z jiné kasty nebo z muslimské rodiny, často z kurdské, kvůli zlepšení vzájemných vztahů. Obřad probíhá obvykle doma, v dnešní době je ale stále častěji zákrok provedený v nemocnici kvůli hygieně a zdraví dítěte, obzvlášt' pak v diaspoře, kde dodržování tradic je oslabené. ${ }^{39}$

\section{Hierarchická společnost}

Jezídská společnost je rozdělená do tří kast a každá z nich má určité místo ve společnosti, své povinnosti. Kromě toho, že Jezídům je zapovězeno uzavírat sňatky s nejezídy, je zakázáno také uzavírat sňatek s příslušníky jiných kast. Nejvýše postavenou kastou jsou šéchové, kteří představuji něco jako aristokracii jezídské společnosti, dále jsou pírové, kteří patří do sociální vrstvy duchovních. Třetí kastou jsou mirídové, do této kasty patří většina Jezídů. Šajchové a pírové tvoří pouze $5 \%$ populace Jezídů. Jezídové věří, že členy těchto dvou kast jsou potomci posvátných bytostí jezídské mytologie. ${ }^{40}$

Hierarchický systém je přenášený i do Německa, kdy pro mladší generace může být problémem najít vhodného partnera ze své kasty. Sufyan tvrdí, „že pro něj bude složitější najít

\footnotetext{
${ }^{38}$ TAGAY, S. a ORTAÇ, S. Die Eziden und das Ezidentum: Geschichte und Gegenwart einer vom Untergang bedrohten Religion. 1. vydání. Landeszentrale für politische Bildung, Hamburg, 2016, s. 82.

${ }^{39}$ AÇIKYILDIZ, B. The Yezidis. 1. vydání. I. B. Tauris, 2014, s. 100.

${ }^{40}$ ČERNÝ, Karel. Jezídové - komunita na útěku. Praha: Lidové noviny, 2016, s. 31.
} 
nevěstu v Německu, než kdyby žil v Iráku, ale pořád je situace lep̌̌́ než v 90. letech, když byla jezídská diaspora menší.“ Někteří Jezídové situaci řeší tak, že si sňatky domlouvají v Iráku. Většinou to dělají rodiny ženicha, potom se snaží přivést manželku do Evropy.

\section{Jazyk}

Většina Jezídů považuje za svůj rodný jazyk kurmandží, což je dialekt kurdštiny. Pouze malá část Jezídů hovoří arabsky a jen někteří kurmandží neovládají. Jedná se o Jezídy žijící ve městech Bahzáné a Bašiqa. V oblasti Kavkazu se začalo mluvit o jazyce zvaném jezdiki, což je také dialekt kurdštiny. Termín jezdiki je často odmítán v jezídských kruzích inteligence, které se považují za etnické Kurdy. Naopak jezdiki používají Jezídové, kteří kategoricky odmítají skutečnost, že by Jezídové a Kurdové byli jeden a tentýž národ. V diskusích lze pozorovat, že odpůrci termínu jezdiki nerozlišují jazyk na jedné straně a glosonymum na straně druhé. Často Jezídové přichází s odporujícími si tvrzeními, že jezdiki je jiný jazyk než kurdština, případně, že jezdiki neexistuje jako jazyk, že existuje pouze kurdština. Problémem je, že samotný kurdský jazyk je těžce definovatelný, protože má několik dialektů. Kurmandží a ezdiki jsou ve skutečnosti glosony, což jsou názvy stejných jazyků, ale pojmenované různými národy odlišně. Jeden jazyk může mít různé glosony, stává se to obvykle v důsledku nacionalistických tendenci, což je př́klad kurdských dialektů, nebo z hlediska jazykovědy či fonetiky, kdy vzniká potřeba jazyk nějakým způsobem pojmenovat.

Kurdská abeceda má 23 souhlásek a 8 samohlásek, rozlišuje krátké a dlouhé samohlásky. Osmdesát procent všech Kurdů mluví dialektem kurmándží. Dnes se latinská abeceda používá pro kurdštinu v Turecku a Sýrii, v Íránu a Iráku se používá pro psanou kurdštinu arabské písmo a v bývalém Sovětském svazu se používá azbuka. ${ }^{41}$

\section{Náboženství}

Jezídové tvrdí, že mají nejstarší náboženství na světě, zdůvodňují to podobou svého kalendáře. Jejich náboženský kalendář má přes 6764 let, čímž se rok 2020 n. 1. stal rokem Jezídů roku 6776. Ve vztahu k některým dalším významným náboženstvím je jezídský kalendář o 4750 let starší než křest’anský nebo gregoriánský kalendář, o 990 let starší než židovský kalendář a je o 5329 let starší než muslimský kalendář. Jezídi věří v nadpřirozeného Boha zvaného Xwede, stvořitele vesmíru. Dříve než Bůh stvořil člověka, stvořil sedm andělů, kteří byli jeho zjevením. Po stvoření světa Bůh seslal anděly na zem, aby se klaněli Adamovi

\footnotetext{
${ }^{41}$ KUBÁLEK, P. Kurdština, její dialekty a média. [online]. Kurdové a Kurdistán: 2002. [cit. 2021-03-05]. Dostupné z: https://kurdove.ecn.cz/jazyk.shtml
} 
jako nejdokonalejšímu božskému vynálezu. Všichni andělé uposlechli, pouze Taus Melek se odmítnul před Adamem poklonit s argumentem, že jediný, před kým se bude sklánět, je Bůh, nikoli člověk. Tímto si Bůh ověřil jeho věrnost a jako odměnu mu svěřil osud světa a moc nad ním vládnout. Od tohoto př́íběhu je odvozen zákaz říkat nahlas slovo šajtan (Satan). Když se Taus Melek nesklonil před prvním člověkem na světě, Adam se rozezlil a nazval Tause Meleka satanem. Proto Jezídové dodnes považují toto slovo za urážku Pavího Anděla. ${ }^{42}$

Přestože se jezídské náboženství předává ústně, existují v jezídismu dvě svaté knihy, Kitêba Cilwe (Kniha zjevení) a Mišefa Reš (Černá kniha). Rukopisy obou knih byly publikovány v letech 1911 a 1913, ale zjistilo se, že to byly padělky napsané západními cestovateli, kteří se zajímali o jezídské náboženství. Ř́ká se, že materiál v nich odpovídá autentickému textu jezídských hymnů. Nyní se komunita snaží tyto hymny shromáždit a sepsat je do jedné sbírky, aby se zachovaly, což může do budoucna proměnit jezídismus v biblické náboženství. Černá kniha popisuje stvoření světa, jak Bůh vytvořil bílou perlu a jak z ní vzešel Taus Melek. Dále popisuje, jak byli stvořeni Adam a Eva a zbytek světa. Kniha končí pojednáním o tabuizovaných věcech v jezídismu. ${ }^{43} \mathrm{~V}$ Knize zjevení jsou napsaná boží slova v první osobě, jako kdyby promlouval k lidem sám Bůh, oproti tomu Černá kniha je napsaná v 3. osobě. Jezídská kniha zjevení má pět kapitol, píše se v ní o božích skutcích a velikosti jeho moci, o tom, že Bůh nepotřebuje svatou knihu k předání svých slov a také varuje před lidmi jiných kultur. Nabádá Jezídy, at’ nikoho nepřijímají do svých náboženských skupin a zachovají věrnost svému náboženství. ${ }^{44}$

\section{Vztah k politice}

Výběr jezídského prince. Pro všechny Jezídy na světě existuje jediná světská autorita, což je princ zvaný mír, který sídlí vždy v Iráku. Podle zvyků, které Jezídové dodržují, musí být mír vybrán ze stejné rodiny jako jeho předchůdce. Rodina předchozího míra nominuje jednoho, dva nebo tři lidi, poté se Duchovní rada a významné jezídské klany společně rozhodnou zvolit jednoho z kandidátů jako jezídského míru, aby vystřídal zesnulého.

Mír je vedoucím Nadace pro správu jezídských věcí, členem Duchovní rady Jezídů. Tato nadace zahrnuje Bábu šécha a šajchského ministra. Všechna rozhodnutí, která se týkají jezídské komunity, jsou vydávána touto institucí. Tentokrát volba nového míra byla politicky

\footnotetext{
${ }^{42}$ GEBELT, J. a kol. Ve stínu islámu - Menšinová náboženství na Blízkém východě. 1. vyd. Vyšehrad, 2016.

${ }^{43}$ THORNTON, D. The Yazidi Religion. [online]. Dthorntonapgeo: 2016. [cit. 2021-03-05]. Dostupné z: https://dthorntonapgeo.weebly.com/

${ }^{44}$ ISSA, C. Das Yezidentum: Religion und Leben. Oldenburg: Dengê Êzîdiyan, 2007.
} 
ovlivněná ze strany Kurdské demokratické strany a Vlasteneckého svazu Kurdistánu. Došlo k situaci, že Jezídové z oblastí Sindžáru a ostatní Jezídové z jiných zemí si prááli odlišného kandidáta z rodiny, jenže rodina míra žije na území iráckého Kurdistánu a nový mír je členem Kurdské demokratické strany, která je nejsilnější politickou stranu v regionu. Nový mír měl podporu této politické strany, a byl vybrán. Ostatní Jezídové mimo území Kurdistánu ho nechtějí kvůli tomu, že je prokurdsky nakloněný a Jezídové po Sindžárském masakru ztratili důvěru ke kurdské vládě a chtějí se od ní co nejvíce distancovat, což je téměř nemožné, jelikož všechny jezídské autority žijí v oblasti Šejchanu na území autonomního Kurdistánu. Svou nevoli Jezídové ze Sindžáru dávají najevo tím, že si sami vybrali dalšího míra, kterého vyznávají, což vedlo $\mathrm{k}$ situaci, že momentálně Jezídové mají dva míry, kteří vládnou. Oficiálně je podle všech náležitosti právoplatným mírem ten, který sídlí v Šejchanu. (informátor Farhad)

Zde vzniká otázka, jak se tato situace dotýká ostatních Jezídů kupř́ikladu z diaspor či z oblasti Kavkazu? Dotýká se primárně etnické identity, když všichni Jezídi pochází původně ze severního Iráku, a proto by chtěli, aby v této oblasti nebyly konflikty jakéhokoliv rázu. Podle respondenta Hosniho „,ždycky byla tendence ze strany irácké vlády Jezídy arabizovat anebo je donutit ke konverzi k islámu. Kurdové dávaji Jezídưm víceméně volnost vyznávat své náboženství, ale tvrdí, že Jezídové jsou Kurdové, s čímž Jezídové nesouhlasí.“ Tento výrok ukazuje snahu nutit Jezídy k asimilaci do majoritní společnosti Kurdů. Pravý jezídský nacionalismus začal paradoxně v Gruzii a Arménii a tito Jezídové rozhodně nesouhlasí s politikou, která vede k postupnému ztracení jezídské identity.

Výběr duchovní autority Baby Šécha. Duchovní rada Jezídů si po konzultaci s jezídským mírem a řadou náboženských vůdců podle řady podmínek a zvláštních postupů vybere zástupce pro řešení náboženských záležitostí. Baba Šéch je považován za duchovního vůdce jezídského náboženství, když je pokaždé vybrán nástupce 40 dní po smrti předchozího Baba Šécha. Khartu Hajj Ismail plnil funkci Baby Šécha do své smrti. Zemřel 1. října ve věku 87 let v nemocnici v Erbilu poté, co se jeho zdravotní stav zhoršil.

Kandidát na místo Baby Šécha je po hodnocení Duchovní radou podroben raadě zvláštních postupů a musí splnit několik podmínek. Musí pocházet z rodiny Baba Šécha, ale nemusí to být syn, může to být synovec, bratranec apod. Musí znát a správně praktikovat jezídské náboženství. Šéchova rodina odvozuje svůj původ od šajcha Fakhri Adia, což byl jezídský učenec, filozof a duchovní, který zemřel před stovkami let, přičemž jeho rodina je jednou ze známých a vlivných rodin mezi Jezídy. (informátor Farhad) 


\section{Adaptace Jezídů v novém prostředí}

V Německu se Jezídové soustředí hlavně ve spolkových zemích Dolní Sasko a Severní Porýní-Vestfálsko s hlavními sídly v Gelle, Hannoveru a Bielefeldu.

Jezídové se v Německu adaptují poměrně rychle, když velkou roli tu hraje i věk migrantů, mladí lidé jsou více přizpůsobiví a otevřenější ke změnám. Pro starší generace proces integrace trvá déle a je komplikovanější. Jeden z důvodů je ten, že starší nevyužívají všechny možnosti integračního programu. Např́íklad pan Khalil tvrdí, „že kvůli tomu, že neovládá dobře němčinu, není snadné si najít práci. Když potřebuje vyřizovat některé věci na úřadé, pomáhá mu devítiletá dcera, která chodí do školy a německý jazyk ovládá dobře." Dalším faktorem, proč hodně migrantů, kteří imigrovali v posledních pěti letech do Německa nepracuje, je systém sociálního zabezpečení v Německu. Ten je nastavený tak, že větším rodinám se vyplatí pobírat sociální dávky, místo toho, aby rodiče byli zaměstnáni. Ženy navíc často nemají dokončenou ani základní školu a tím, že mají několik dětí, se musejí starat o domácnost. Je na manželovi, aby pracoval, když mu jako nekvalifikovanému pracovníkovi bude vyplacená nižší mzda, obvykle do 1,5 tisíce euro. (informace od respondenta) V případě žadatelů o azyl finanční pomoc ze strany státu činí okolo 340-350 euro měsíčně na osobu. ${ }^{45}$ V př́ípadě, že alespoň manžel začíná pracovat, se sociální dávky zkrátí anebo dokonce přestávají být úplně vypláceny. Proto je pro rodiny s 5 dětmi a více, výhodnější pobírat sociální pomoc i nadále.

Jezídská komunita $\mathrm{v}$ posledních deseti letech prochází velmi zásadními transformačními procesy. Pro Jezídy život $\mathrm{v}$ diaspoře znamená svobodu, ve které mohou praktikovat své náboženství beze strachu, že budou pronásledováni. Jezídi v Německu již nemusí skrývat své náboženství a popírat svou etnickou identitu. Svoboda v diaspoře umožňuje Jezídům otevřít se světu jako jedna z nejstarších etno-náboženských skupin, která má co nabídnout ze své kultury. Dlouhá historie pronásledování a utrpení ovlivňuje kolektivní trauma Jezídů a jezídskou identitu i v diaspoře. Na pozadí sindžárské genocidy je otázka identity velmi aktuální a je předmětem kontroverzního diskurzu v umění, literatuře a filozofii, ale také v religionistice. Byla zakládaná jezídská kulturní centra, která se stávají těžištěm kulturního dění $\mathrm{v}$ jezídské společnosti. Vydávají se časopisy s tématy jezídismu, jsou vytvářena diskusní fóra, ve kterých se probírají nejaktuálnější témata. Postupně se opouští od ústní tradice předávání kultury, jezídské časopisy a fóra se pokoušejí všechno již písemné

\footnotetext{
${ }^{45}$ IDNES.CZ, Přehledně: Kolik berou žadatele o azyl v zemích Evropské unie. [online]. 2018. [cit. 2021-03-16]. Dostupné z: https://www.idnes.cz/zpravy/zahranicni/azyl-eu-kolik-berou- zadatele-migrant-prispevek
} 
zachytit, hlavně co se týče kulturního dědictví. „Nový jezídismus“ již není zaměřený výhradně na posvátné místo Láliš, přestože toto místo zůstává „domovem“ všech Jezídů na světě. ${ }^{46}$

Přestože Jezídi si mohou $\mathrm{v}$ diaspoře uchovávat kulturu a náboženství, vzniká zde několik problémů. Jedním z nich je jako skoro v každé soudobé společnosti mezigenerační konflikt, kdy se mladí lidé distancují názorově od starších. Podobně jako u jiných skupin migrantů dochází ke střetu zájmů mezi staršími lidmi, pro které je těžké zůstat v diaspoře, a mladšími, pro které se hostitelský stát stál domovem. Kontext migrace s jejími aspekty urbanizace a gramotnosti vytváŕí zejména pro mladší generace nová omezení v legitimaci a vede k potřebě přeformulování teologického konceptu. Např́íklad pro mladé lidi, kteří získali vzdělání v evropských školách, kde se klade důraz na kritické myšlení, je obtížné dodržovat tabu nebo je pro ně obtížně pochopit tradiční hymny (qewly), jelikož v nich nemohou nalézt racionální vysvětlení. Dalším problémem je neochota mladých Jezídů akceptovat manželské partnery vybrané jejich rodiči. Preference tradičního uzavírání manželství ze strany starších generací a vysoké ceny za nevěsty vytváří ekonomickou propast a můžou do budoucna rozdělit jezídskou komunitu $\mathrm{v}$ Německu. V rodinách dochází ke konfliktům a mladí lidé odchází z domova. Dále se začíná porušovat přísné pravidlo endogamie a roste emancipace žen.

Na druhou stranu mohou Jezídové poprvé za celou historii svobodně slavit své svátky a svatební oslavy. Mají př́ležitost německé majoritě ukázat své tradice prostřednictvím pozvání na různé akce. ${ }^{47}$

\section{Jezídské organizace v Německu a ve světě}

Již od počátku 90. let 20. století se centrem diaspory stalo Německo. Imigrace Jezídů do Německa ovlivnila jejich náboženský a kulturní život. ${ }^{48}$ Jezídismus je náboženství spjaté s místem vzniku, a proto bylo nutné hodně tradic přizpůsobit možnostem, které hostitelský stát nabízí. Jezídská společnost již nemohla zůstávat nadále uzavřenou. Musela se světu otevřít a zároveň hledat způsob, jak svou identitu uchránit a předat další generaci. Zakládání kulturních sdružení, vydávání časopisu a sdružení laických spolků bylo prvním znakem sociální změny, které diaspora čelila. Jezídská diaspora je konfrontována s novými výzvami, k nimž patří

\footnotetext{
${ }^{46}$ ACKERMANN, Andreas. Yeziden in Deutschland. Von der Minderheit zur Diaspora. Paideuma, 2003, 157177.

${ }^{47}$ AFFOLDERBACH, M., GEISLER, R. Die Yeziden. Berlin: Evangelische Zentralstelle für Weltanschauungsfragen: 2007.

${ }^{48}$ GEBELT, J. a kol. Ve stínu islámu - Menšinová náboženství na Blízkém východě. 1. vyd. Vyšehrad, 2016.
} 
zachování etnické identity, praktikování vlastního náboženství a snaha o zachování zvyků a tradic. Pro zachování své identity v západních podmínkách, Jezídové musí přizpůsobit svou náboženskou praxi a dodržování tradic, musí dosáhnout rovnováhy mezi starými tradicemi a moderním životem v diasporách. Je třeba, aby přešli od ústního předávání náboženských textů k písemnému zachycení a také by měli akceptovat individualistický způsob života místo kolektivistického. Právě kvůli těmto faktorům vznikly první jezídské organizace v diaspoře. Organizace mají za úkol pomoct Jezídům $\mathrm{s}$ adaptací $\mathrm{v}$ novém prostředí, při řešení administrativních záležitostí s úřady a poskytnout jim prostor pro upořádání akcí a oslav. Kulturní centra jsou určena i mladým Jezídům, když se tu mohou kulturně seberealizovat. Jezídské organizace se snaží u mladé generace posílit její identitu. Často je nabízena výuka náboženství a historie jezídismu. ${ }^{49}$ Většina organizací je financována z darů sponzorů a drobných dárců, na regionální úrovni organizace mohou zažádat o dotace $\mathrm{k}$ financování konkrétních projektů. Níže jsou jmenovány pouze některé z nich.

Mezi prvními a nejaktivnějšími organizacemi bylo Jezídské fórum založené v roce 1993. ${ }^{50}$ Jezídské fórum vzniklo z iniciativy několika jezídských rodin z Oldenburku. Původním cílem zakladatelů bylo udržovat a předávat náboženské a kulturní hodnoty a zvyky mladé generace Jezídů. Od svého založení se práce sdružení neustále rozšiřovala do různých oblastí, jako je například pomoc novým jezídským imigrantům s administrativou na úradech a také nabízí psychologickou a sociální pomoc. Zásadní je i pomoc s integrací mladým lidem, kteří vyrůstají mezi dvěma kulturami. Dalším úkolem je pomoc jezídským ženám se lépe integrovat do německé majority a nabídka vzdělávání a zapojení se do aktivit v jezídském fóru. $^{51}$

Další organizaci je Jezídská akademie (Ezidische Akademie). Jedná se o vzdělávací instituci, která sídlí v Hannoveru. Organizace se zabývá současnou situací jezídských menšin. Mezi hlavní cíle instituce patří podpora soudržnosti uvnitř komunity, odstranění bariér mezi minoritou a německou majoritou, PR, vydávání titulu „Zeitschrift der Ezidische Akademie“ o jezídském náboženství a kultuře, podpora rodin a jejich dětí při vzdělávaní v německých školách. ${ }^{52}$ Za zmínku stojí také Společnost jezídských akademiků (Gesellschaft Ezidischer AkademikerInnen, zkratka GEA). GEA je největší jezídská akademická organizace na světě.

\footnotetext{
${ }^{49}$ TAGAY, S. a ORTAÇ, S. Die Eziden und das Ezidentum: Geschichte und Gegenwart einer vom Untergang bedrohten Religion. 1. vydání. Landeszentrale für politische Bildung, Hamburg, 2016, s. 138-141.

${ }^{50}$ GEBELT, J. a kol. Ve stínu islámu - Menšinová náboženství na Blizkém východě. 1. vyd. Vyšehrad, 2016.

${ }^{51}$ YEZIDEN.DE: Integrationsarbeit - Herausforderungen im Home-Schooling. [online]. 2020. [cit. 2021-0316]. Dostupné z: www.yeziden.de

${ }^{52}$ THE CONGRESS OF EZIDIS WORLDWIDE: About. [online]. 2021. [cit. 2021-03-16]. Dostupné z: https://www.ezidi-worldcongress.com/en/about/
} 
Cílem sdružení je přeshraniční a interdisciplinární vědecká spolupráce, podpora mezikulturního porozumění, otázka lidských práv, práce žen a mládeže, jakož i udržování jezídské kultury a víry. ${ }^{53}$

Ústřední rada Jezídů v Německu je sdružení se sídlem v Bielefeldu, které zastupuje zájmy Jezídů v Německu a paralelně funguje jako zastřešující organizace pro dalších 29 dílčích jezídských organizací v Německu. Ústřední rada Jezídů v Německu byla založena 29. ledna 2017. Cílem Ústřední rady Jezídů v Německu je zastupovat Jezídy v jejich tradičních sídelních oblastech i v diaspoře v Německu. Organizace sleduje náboženské cíle typu ochrany jezídismu, přiznání jezídské menšiny podle mezinárodního práva, zavedení jezídského náboženství do výuky ve školách, ale i politické cíle jako uznání jezídské genocidy, poskytnutí pomoci jezídským uprchlíkům, pomoc při rekonstrukci poničených měst Sindžár a Láliš a dalších kulturních památek nacházejících se ve sporných oblastech v severním Iráku. ${ }^{54}$

Kromě organizací v Německu existují jezídské organizace i v jiných zemích, některé z nich působí mezinárodně. Kupříkladu Národní svaz Jezídů Arménie byl založen v roce $1989 \mathrm{v}$ Arménii. Jedním z hlavních cílů této organizace sjednocení Jezídů a snaha rozvíjet jezídskou národní kulturu všude na světě. V posledních letech tato organizace pomáhá i Jezídům z Iráku, kteří byli vystaveni pronásledování a cílené likvidaci. Národní svaz Jezídů Arménie vyvíjí velké úsilí, aby pomohl arménským Jezídům a Jezídům z jiných států s vyřešením sociálních problémů a s kulturním rozvojem a pomohl s otevřením několika jezídských škol a se zavedením výuky kurmándží v jezídských třídách.

Další mezinárodní organizace je Free Yezidi Foundation, což je politicky nezávislá nezisková organizace, která má pomáhat Jezídům v nouzi. Byla založená v roce 2015 krátce poté, co se teroristé v srpnu 2014 v Iráku pokusili vyhladit jezídskou populaci. Nadace se zabývá humanitárními službami pro přeživší genocidu, a to zejména pro jezídské ženy a děti, se zvláštním zaměřením na zotavení z traumatu a poskytuje psychologické služby. Free Yezidi Foundation se snaží realizovat projekty na ochranu a podporu členů jezídské komunity, kteří se nachází v nepř́iznivé situaci. ${ }^{55}$

Jedna z nejznámějších neziskových organizaci na pomoc Jezídům je organizace Yazda, což je nadnárodní jezídská organizace založená v návaznosti na jezídskou genocidu v roce

\footnotetext{
${ }^{53}$ GEA: Über uns. [online]. Gesellschaft Ezidischer AkademikerInnen: 2021. [cit. 2021-03-16]. Dostupné z: https://www.gea-ev.net/\%C3\%BCber-die-gea/

${ }^{54}$ ZED: Ziele. [online]. Zentralrat der Êzîden in Deutschland: 2021. [cit. 2021-03-16]. Dostupné z: http://www.zentralrat-eziden.com/ziele/

${ }^{55}$ FREE YEZIDI FOUNDATION: Our Mission. [online]. FYF: 2015. [cit. 2021-03-16]. Dostupné z:

https://www.freeyezidi.org/about-us/
} 
2014 za účelem podpory jezídské etnicko-náboženské menšiny a dalších utlačovaných menšin. Organizace vznikla ve Spojených státech v Nebrasce. První misí Yazdy bylo poskytnutí humanitární pomoci během útoku IS na Sindžár v roce 2014. Pomoc byla poskytnutá ve formě jídla a vody přibližně 60000 Jezídům, kteří byli okolo 10 dnů obklíčeni Islámským státem na hoře Sindžár. Dalším cílem mise bylo osvobodit jezídské ženy a dívky, z nichž více než 3200 bylo prodáno do sexuálního otroctví a některé jsou dosud drženy v zajetí IS. ${ }^{56}$ Posláním Yazdy je podpora Jezídů, psychologická pomoc obětem genocidy, zdravotní péče přeživším, kteří byli vystaveni těžkému traumatu a distribuce humanitární pomoci $\mathrm{v}$ uprchlických táborech. Mezi další cíle organizace patří zvýšení povědomí o otázkách lidských práv, odhalení zločinů teroristické organizace IS, usilování o uznání genocidy Jezídů vládami jiných států, podpora aktivistek za lidská práva, také sběr a dokumentace důkazů o genocidě, snaha dostát pachatele před mezinárodní soud. Jedním z realizovaných projektů v letošním roce byla pomoc při organizaci pohřbů 104 obětí jezídské genocidy ve vesnici Kodžo. Pohřební ceremoniál proběhl 6. února $2021 .^{57}$

\section{Vztah Jezídů s německou majoritou}

Na otázku, jaké mají vztahy s německou majoritou, všichni respondenti odpověděli kladně. S Němci údajně vychází dobře a zatím se nikdo z nich nesetkal s nacionalistickým postojem ze strany Němců. Mladší respondenti dokonce tvrdili, že mají i německé přátele. Z odpovědí vyplývá, že neexistuje mezi nimi žádný konflikt. Pravdou však je existence jakési bariéry, která se dá vypozorovat z toho, že typické jezídské rodiny se stýkají s jezídskými rodinami a přátelí se spíše s lidmi pocházejícími také z Blízkého východu, v př́ípadě Jezídů z bývalého SSSR s Rusy nebo s jinými národnostmi z bývalého Sovětského svazu. Dá se říct, že si rozumějí nejlíp s lidmi, s nimiž je pojí podobný osud nebo alespoň stejná historická minulost. Pravděpodobně jen málo lidí starší generace by si pozvalo k sobě na návštěvu Němce. Nejedná se o nenávist k majoritě, naopak německý stát přijal uprchlíky, německy lid si již zvyknul na multikulturalismus, který jej obklopuje, problémem zde je fakt, že tyto dva národy se tolik kulturně odlišují, že je malá pravděpodobnost, aby se sblížily. Druhý faktor je jazyková bariéra, kdy starší generace Jezídů často špatně ovládá německy jazyk. V Německu je dnes rozdělená společnost, na jedné straně stojí Němci jako „My“, ti, kteří jsou „,doma“ a

\footnotetext{
${ }^{56}$ WHEELER, S. Yezidi Women After Slavery Trauma. [online]. Human Rights Watch, 2016. [cit. 2021-03-16]. Dostupné z: https://www.hrw.org/news/2016/04/18/yezidi-women-after- slavery-trauma

${ }^{57}$ YAZDA GLOBAL ORGANISATION: About Yazda. [online]. 2015. [cit. 2021-03-16]. Dostupné z: https://www.yazda.org/about-us
} 
přijímají migranty, a na druhé straně stojí „Oni““, migranti, kteří se pomalu integrují do německé společnosti, ale také ti, kteří se snaží si zachovávat i svou kulturu a náboženství, tím, že si sebou přenesli některé zvyky a tradice, kuchyni a další prvky své kultury.

Německo vede př́znivou migrační politiku a je jednou z nejčastějších destinací pro imigranty ze třetích zemí. Od roku 2014 poskytlo azyl skoro dvěma milionům uprchlíků, mezi něž patří i tisíce Jezídů pocházející hlavně z Iráku a Sýrie. Německý stát se snaží pomáhat jezídskému obyvatelstvu nejen v diaspoře, ale i v Iráku. Nejvíce jezídských neziskových organizací sídlí v Německu, což souvisí s tím, že se zde nachází největší jezídská diaspora. Ačkoli Německo nabízí v rámci Národního integračního plánu přes 400 návrhů opatření k vytvoření nových př́ležitostí pro cizince a podporu jejich integrace a dále Jezídům pomáhají jezídské spolky a svazy, někteří z nich mají obavy, že jim Německo neprodlouží azyl a budou ho muset opustit. „...Německo kdykoliv může posoudit, že nám již nehrozí nebezpečí, a tudiž není důvod nám nadále prodloužit azyl. Osobně znám jednu mladou rodinu i s dětmi, kterou německý stát vrátil do Iráku a žili zde již 6 let, byli to slušní lidé, neporušovali zákony... nevím, proč se jim to stalo. “, říká s obavami respondent Hosni. Přestože se situace v severním Iráku uklidnila, podle Jezídů tam již nikdy nebude bezpečně. Pořád se tam provádějí občasné atentáty, únosy a stále se tisíce Jezídů pohřešují. Politická situace je nestabilní, ukázkou je vláda dvou mírů, což je v jezídské historii bezprecedentní. Dalším důvodem, proč je pro Jezídy nebezpečně se do sporné oblasti Sindžáru vrátit, je věčný konflikt mezi iráckou a kurdistánskou vládu o tom, komu Sindžár patří. Vždy to dopadne tak, že pokud začíná nějaký válečný konflikt, Jezídům ze Sindžáru se nedostává pomoci ani ze strany irácké vlády, ani z té kurdské.

Případy, kdy Spolková republika navrátila zpátky celé rodiny, bývají výjimečné a nebývá to bez přičiny. $\mathrm{V}$ poslední době se ale $\mathrm{v}$ médiích začíná mluvit o případech, kdy jezídské rodiny se samy vracejí např́íklad do uprchlických táborů do Kurdistánu kvůli tomu, že se nemohou v Německu integrovat. Objevilo se několik případů, kdy se zpátky do Iráku vrátilo několik dívek, obětí sexuálního otroctví, které v Německu potkaly své trýznitele. Bohužel mezi statisíci uprchlíků, kteří utíkali před válkou, se do Evropy dostáli i radikálové a vojáci IS, kteří se ukrývají pod statutem „uprchlík“, a nedaří se zajistit, aby i oni nepřekračovali hranice EU. 


\section{Závěr}

Jezídi jsou etnikem, které po staletí vedlo uzavřený způsob života uvnitř své skupiny. Setkávali si často s útlakem ze strany majoritních skupin pod záminkou náboženské jinakosti. Do druhé poloviny 20. století emigrace probíhala většinou v rámci Blízkého východu, a to například z Turecka do Sýrie, z Iráku do Sýrie nebo do Arménie. Až v 90. letech 20. století začala migrace Jezídů do Evropy, nejčastěji do Německa. Jezídi začali masově emigrovat do Německa hlavně v roce v roce 2014 na základě genocidy, kterou na nich spáchala teroristická organizace IS. Od tohoto roku bylo v Německu zřízeno několik jezídských kulturních domů v regionech, kde se jezídská menšina usadila. Nové prŕíchozí Jezídi měli výhodu v tom, že spousta jezídských spolků zde již fungovala, například Jezídské fórum bylo založené v roce $1993{ }^{58}$ Tyto jezídské spolky se snaží zajistit Jezídům kulturní a náboženské aktivity a snaží se jim pomáhat i v jiných sférách, aby se lépe integrovali do majoritní skupiny. Spolky jsou zakládané Jezídy, kteří žijí již delší dobu v Německu, někdy ve spolupráci s některou neziskovou organizací. Většinou jsou sponzorovány movitějšími Jezídy z diaspory či ze zahraničí, např́íklad z Arménie anebo z poskytnutých dotací na lokální úrovni.

Německo se stává cílovým státem pro mnoho imigrantů, jelikož tento stát byl a dodnes je lákavý pro cizince hned z několika důvodů. Zaprvé se Německo dokázalo poměrně rychle ekonomicky zvednout po obou světových válkách. Zadruhé je zde vysoká životní úroveň, dobrý systém zabezpečení při nezaměstnanosti a celkově má stát př́iznivý vztah k migrantům. V Německu je aplikovaný Národní integrační plán, který obsahuje přes 400 návrhů vytvořených pro vhodné př́ležitosti pro imigranty a $\mathrm{k}$ podpoře jejich integračního procesu. Integrační politika je založená na poskytování integračních kurzů, které zahrnují kurzy německého jazyka a získání znalostí zákonů a německých reálií. Projekty jsou soustředěny na předškolní výchovu, zaměstnávání odborníků migrantského původu, k nimž patří např́íklad učitelé, lékaři apod., zprostř̌edkovávání lepší zdravotní a sociální péče a na zmenšení bariér mezi členy různých kultur. ${ }^{59}$

Jezídi mají pestrou škálu tradic a svátků, které se snaží dodržovat i v diasporách. Většina svátků se zakládá na pohostinnosti, navštěvování se navzájem, na přípravě jídel. Díky tomu, že jezídské ženy mají na starost domácnost a výchovu děti, i dodržování svátků je snazší, jelikož ženy jsou doma a mají čas věnovat se těmto přípravám. V diaspoře se mění

\footnotetext{
${ }^{58}$ GEBELT, J. a kol. Ve stínu islámu - Menšinová náboženství na Blízkém východě. 1. vyd. Vyšehrad, 2016.

${ }^{59}$ PORSCHE, S. Kulturní, historické a sociální souvislosti migrace. 1. vydání. ZSF JU v Českých Budějovicích: 2009, s. 44.
} 
spíše duchovní stránka těchto oslav, jelikož některé svátky podle jezídských tradic mají být provázené určitými rituály vykonávanými jezídskými duchovními, kteří v Německu chybí, a proto jsou vynechány. Například svátek probíhá beze zpěvu hymnů qewály, jelikož v Německu qewálové nejsou, anebo oslava je menší, jelikož ve městě v bytě se nemůže shromáždit tolik lidí jako v domech na vesnici v Iráku.

Přestože se nabízí několik integračních programů pro nové př́íchozí imigranty, pro hodně z nich je těžké si najít práci. Existuje ještě velký počet negramotných lidí, kteří nevyužívají ani jazykový kurz, následně se potýkají s jazykovou bariérou a zaměstnavatelé nemají zájem je zaměstnat. Také migrantům chybí kvalifikace, např́íklad několik z nich má dokončenou jen základní školu a nemá žádnou profesi. Zde je velký rozdíl mezi Jezídy pocházejími z Iráku či Sýrie a Jezídy kteří mají svůj původ v Zakavkazsku. Posledně jmenovaní většinou mají lepší vzdělání, které je i středoškolské a vysokoškolské. Další výhodu, kterou mají Jezídové pocházející z bývalých států SSSR, je ovládání ruského jazyka, což jim dává větší šanci se někde uplatnit, jelikož v Německu je mnoho firem, které mají za majitele Rusy či Němce původem z Kazachstánu. Tito podnikatelé většinou berou do svých firem hodně zaměstnanců z východu, jelikož jsou pro ně levnější pracovní sílou. Tímto způsobem lidé mluvící rusky mohou začínat svou kariéru, časem se mohou dopracovat i na vyšší pozice. Pro Jezídy z Blízkého východu se na druhou stranu objevují príiležitosti k zaměstnání v podnicích gastronomického typu, jako jsou restaurace s kebabem nebo kiosky s potravinami. Jejich majiteli jsou zpravidla Turci nebo Kurdové, kteří Jezídy mohou zaměstnávat, jelikož zde hlavně mizí jazyková bariéra. V oblastech, kde je soustředěná jezídská populace, jako např́klad Hannover, Bielefeld, Oldenburg, mají Jezídové, kteří tu často žijí déle než pět let nebo ti, kteří přijeli v 90. letech, už vlastní podniky, které převážně působí rovněž v gastronomickém sektoru.

Kromě německých programů určených $\mathrm{k}$ integraci imigrantů existují jezídské laické spolky, které se snaží pomáhat nově příchozím Jezídům s adaptací, s vyřízením úkonů na úřadech, někdy s nabídkou práce a zapojením se do kulturních aktivit. Tyto spolky jsou zakládané Jezídy, kteří žijí v Německu déle, jsou plně integrováni a zároveň nechtějí ztratit svou etnickou identitu. Jezídské organizace jsou sponzorovány dary ze strany movitějších Jezídů, také pro větší projekty například na pomoc obětem jezídské genocidy jsou vytvořeny fondy, na regionální úrovni jsou k určitým projektům využívány dotace a granty. Někteří jednotlivci jsou velice aktivní. Např́iklad ve městě Oerlinghausen existuje menší uprchlický tábor a respondent Hosni s jeho rodinou pravidelně tento tábor navštěvuje. Zjišt’ují, jestli 
přišla do tábora nějaká nová rodina a případně se jí snaží pomoci finančně či materiálně ve formě dětského oblečení nebo potravin. Jezídové si jsou vědomi toho, že jsou malou etnickou menšinou, a proto jsou k sobě velice solidární a pomáhají si.

Jezídskou identitu tvoří dva hlavní atributy, které se doplňují navzájem, přičemž ztráta jednoho z nich zapř́ičiňuje, že jedinec ztrácí svou etnickou identitu a prrízeň celé komunity. Prvním atributem je etnická čistota udržovaná pomoci endogamních sňatků. Uzavření sňatku mimo jezídské komunity je $\mathrm{v}$ jezídském náboženství zapovězeno. $\mathrm{S}$ tím je spojeno také uzavření manželství pouze $v$ rámci své kasty. V dnešní době je větší šance, že Jezíd uzavře manželství s prř́slušníkem jiného náboženství, než by uzavřel manželství s jezídským př́slušníkem jiné kasty. Sňatky uzavírané pouze v rámci své kasty jsou přísně dodržovány i v diasporách. Porušení tohoto zákazu vede k exkluzi jedince nebo párů z jezídské společnosti. Pokud by Jezíd uzavřel manželství s př́íslušníkem jiného náboženství, automaticky přijímá vyznání svého partnera, nemůže to být naopak. Druhým atributem je nemožnost konverze k jezídismu. Jezídem se člověk pouze narodí, k jezídské komunitě se nelze přidávat. Jezídismus je nemisijní náboženství a nikdy nebyla snaha jej předávat „nejezídům“. Jezídismus obsahuje prvky několika náboženství, což z něj dělá speciální náboženství mnohými nepochopené a odsouzené k zániku. Jestliže Jezídové a Kurdové mají společný původ, stejný jazyk, podobný tanec, kuchyň a způsob oblékání, tak přesně náboženství a endogamie jsou hlavní faktory, které je navzájem odlišují. Také jezídské symboly, jako jsou Slunce a podoba Anděla Páva, odlišují Jezídy od všech ostatních etnicko-náboženských komunit. Veškeré tyto atributy tvoří společně jezídskou identitu, která představuje jednu z nejstarobylejších etnicko-náboženských skupin na světě. 


\section{Seznam použitých zdrojů}

AÇIKYILDIZ, B. The Yezidis. 1. vydání. I.B. Tauris, 2014, 283 s., ISBN: 978-1-78453-2161.

ACKERMANN, Andreas. Yeziden in Deutschland. Von der Minderheit zur Diaspora. Paideuma, 2003, 157-177.

AFFOLDERBACH, M., GEISLER, R. Die Yeziden. Berlin: Evangelische Zentralstelle für Weltanschauungsfragen: 2007.

ČERNÝ, Karel. Jezídové - komunita na útěku. Praha: Lidové noviny, 2016.

EISLUND, S. Yazidism. [online]. Ancient History Encyclopedia: 2019. [cit. 2021-02-11]. Dostupné z: https://www.ancient.eu/Yazidism/.

FREE YEZIDI FOUNDATION: Our Mission. [online]. FYF: 2015. [cit. 2021-03-16]. Dostupné z: https://www.freeyezidi.org/about-us/

GAZARYAN, A. Jezidy. Kto oni / Езиды. Кто они? [online]. Noev kovcheg: 2013. [cit. 2021-02-20]. Dostupné z: https://noev-kovcheg.ru/mag/2013-05/3749.html

GEA: Über uns. [online]. Gesellschaft Ezidischer AkademikerInnen: 2021. [cit. 2021-03-16]. Dostupné z: https://www.gea-ev.net/\%C3\%BCber-die-gea/

GEBELT, J. a kol. Ve stínu islámu - Menšinová náboženství na Blízkém východě. 1. vyd. Vyšehrad, 2016, 440 s. ISBN: 978-80-7429-692-5.

GREYENBROEK, P. G. Yezidism - Its Background, Observances and Textual Tradition. 1. vydání. Edwin Mellen Pr, 1995, 349 s. ISBN 0-7734-9004-3.

GREYENBROEK, P. G. Yezidism in Europe: Different Generations Speak about their Religion. 1. vydání. Wiesbaden, Germany: Otto Harrassowitz GmbH \& Co., 2009, 246 s. ISBN 978-34-47060-60-8.

GREYENBROEK, P. G., RASHOW, K. J. God and Sheikh Adi are Perfect. Sacred Poems and Religious Narratives from the Yezidi Tradition. Wiesbaden, Germany: Otto Harrassowitz GmbH \& Co., 2005, 435 s. ISBN 978-3-447-05300-6.

HANUS, Lukáš. " Nové diaspory"-diaspora jako transnacionální moment. AntropoWebzin, 2009, 5.2-3: 13-17.

CHEUNG, Yuet W. Approaches to ethnicity: Clearing roadblocks in the study of ethnicity and substance use. International journal of the addictions, 1993, 28.12: 1209-1226. DOI: 10.3109/10826089309062185.

IDNES.CZ, Přrehledně: Kolik berou žadatele o azyl v zemích Evropské unie. [online]. 2018. [cit. 2021-03-16]. Dostupné z: https://www.idnes.cz/zpravy/zahranicni/azyl-eu-kolikberou- zadatele-migrant-prispevek.

ISSA, C. Das Yezidentum: Religion und Leben. Oldenburg: Dengê Êzîdiyan, 2007, ISBN 978-3-9810751-4-4.

KUBÁLEK, P. Kurdština, její dialekty a média. [online]. Kurdové a Kurdistán: 2002. [cit. 2021-03-05]. Dostupné z: https://kurdove.ecn.cz/jazyk.shtml

MCLOUGHLIN, Seán. Religion, religions, and diaspora. A Companion to Diaspora and Transnationalism, 2013, 125-138. DOI: 10.1002/9781118320792.ch7

MURÁdOVÁ, N. Poslední dívka. 1.vyd. Ikar, 2018, 344 s. ISBN: 978-80-249-3523-2.

PETERMANN, A. Jesiden in Deutschland oragnisieren sich. [online]. Deutschlandfunk: 2017. [cit. 2021-02-12]. Dostupné z: https://www.deutschlandfunk.de

PORSCHE, S. Kulturní, historické a sociální souvislosti migrace. 1. vydání. ZSF JU v Českých Budějovicích: 2009, 91 s. ISBN 978-80-7394-751-4.

SIMPSON, J. A., WEINER, E. S. (1989). The Oxford English dictionary (2nd ed., Vol. VII). Oxford: Clarendon Press, 1989, 384 s. ISBN: 978-01-986-1299-5 
TAGAY, S. a ORTAÇ, S. Die Eziden und das Ezidentum: Geschichte und Gegenwart einer vom Untergang bedrohten Religion. 1. vydání. Landeszentrale für politische Bildung, Hamburg, 2016, 217 s. ISBN 978-3-946246-03-9.

TAZ.de: Die zweite Heimat. [online]. Jesiden in Norddeutschland, 2014. [cit. 2021-02-24].

Dostupné z: https://taz.de/Jesiden-in-Norddeutschland/!5035368/

The Cambridge dictionary of sociology. Cambridge: Cambridge University Press: 2006. 688 s. ISBN 9780521540469.

THE CONGRESS OF EZIDIS WORLDWIDE: About. [online]. 2021. [cit. 2021-03-16]. Dostupné z: https://www.ezidi-worldcongress.com/en/about/

THORNTON, D. The Yazidi Religion. [online]. Dthorntonapgeo: 2016. [cit. 2021-03-05]. Dostupné z: https://dthorntonapgeo.weebly.com/

VON HEIN, M. Die Jesiden fünf Jahre nach dem Genozid. [online]. DW made for minds: 2019. [cit. 2021-02-24]. Dostupné z: https://www.dw.com/de/die-jesiden-f\%C3\%BCnfjahre- nach-dem-genozid/a-49839355

WELT KOMPAKT. 150000 Jesiden leben in Deutschland. [online]. 2016. [cit. 2021-02-24]. Dostupné z: https://www.welt.de/print/welt_kompakt/article158992066/150-000Jesiden- leben-in-Deutschland.html

WHEELER, S. Yezidi Women After Slavery Trauma. [online]. Human Rights Watch, 2016. [cit. 2021-03-16]. Dostupné z: https://www.hrw.org/news/2016/04/18/yezidi-womenafter- slavery-trauma

YAZDA GLOBAL ORGANISATION: About Yazda. [online]. 2015. [cit. 2021-03-16].

Dostupné z: https://www.yazda.org/about-us

YAZIDI CULTURAL HERITAGE PROJECT: Recent History. [online]. 2019. [cit. 2021-0305]. Dostupné z: https://www.yazidiculturalheritage.com/recent-history/

YEZIDEN.DE: Integrationsarbeit - Herausforderungen im Home-Schooling. [online]. 2020. [cit. 2021-03-16]. Dostupné z: www.yeziden.de

YEZIDIS INTERNATIONAL: Batzmi -Yazidi Holiday. [online]. 2015. [cit. 2021-02-18]. Dostupné z: http://www.yezidisinternational.org/batzmi-yezidi-holidays/

YEZIDIS INTERNATIONAL: Yezidi food. [online]. 2015. [cit. 2021-02-18]. Dostupné z: http://www.yezidisinternational.org/abouttheyezidipeople/yezidi-food/

ZED: Ziele. [online]. Zentralrat der Êzîden in Deutschland: 2021. [cit. 2021-03-16]. Dostupné z: http://www.zentralrat-eziden.com/ziele/ 


\title{
Základní vojenská služba po roce 1968 jako nástroj výchovy $k$ občanství: indoktrinace a ideologizace $v$ narativní reflexi ${ }^{1}$
}

\section{Compulsury military service after 1968 as citizenship education: indoctrination and ideology in narrative reflection}

Jiří Hlaváček

\author{
Ústav pro soudobé dějiny AV ČR, v. v. i., Vlašská 355/9, 11800 Praha \\ Email: hlavacek@usd.cas.cz
}

DOI: https://doi.org/10.7160/KS.2021.170206

\begin{abstract}
The aim of this study is to analyse the narratives of conscripts focused on the relationship between the army and ruling ideology between 1968 and 2004. The first part is devoted to the reflection of various forms of interaction between the army and ideology at the level of official and public discourse. The second part is focused on the mapping of specific forms and narratives related to the phenomenon of compulsory military service, including the question of its importance for conscripts. The main sources of analysis are narrative and semistructured oral history interviews with 100 conscripts, who had experience with compulsory military service between 1968 and 2004.
\end{abstract}

\section{Keywords}

army, society, ideology, oral history, interview, military, socialism, democracy

\section{Klíčová slova}

armáda, společnost, ideologie, orální historie, rozhovor, armáda, socialismus, demokracie

\section{Úvod}

Primárním účelem armády je boj, a to bez ohledu na povahu vládnoucího režimu, který je aktuálně u moci. V čem se však jednotlivé typy společenského uspořádání ve vztahu k nasazení ozbrojených sil liší, jsou zdroje, z nichž armáda jako instituce historicky čerpá svou legitimitu. Nový způsob válčení, stejně jako délka a rozměr válečných konfliktů během 19. a 20. století, si postupně vyžádaly potřebu rozvíjet nejen bojové, ale i ideové a morálně volní kvality vojáků (tj. dát jejich počínání vyšší smysl). ${ }^{2}$ Nizozemský sociolog Jacques van Doorn v polovině 70 . let minulého století v jedné ze svých publikací věnované

\footnotetext{
${ }^{1}$ Tato studie je výstupem projektu č. 410/19-19311S Armáda jako nástroj socializace: reflexe fenoménu základní vojenské služby v českých zemích (1968-2004) podpořeného Grantovou agenturou České republiky.

${ }^{2}$ KOLDINSKÁ, Marie; ŠEDIVÝ, Ivan. Válka a armáda v českých dějinách. Sociohistorické črty. Praha, Nakladatelství Lidové noviny 2008, s. 134.
} 
civilně-militárním vztahům konstatoval, že zatímco masové armády totalitního typu se opírají zpravidla o politickou ideologii s internacionálním přesahem, demokratické ozbrojené síly tradičně vycházejí spíše z nacionalistických pohnutek. ${ }^{3}$ Součástí snah o vybudování efektivní branecké armády se tak zejména od počátku 20. století stalo intenzivní ideologické působení, tj. proces indoktrinace a vytváření pozitivního vztahu branců k vládnoucí moci a státnímu zřízení během absolvování povinné základní vojenské služby (ZVS).

Patriotismus či nacionalismus představoval ve většině případů prvotní a nejsilnější impuls, na jehož základě měli být občané podléhající branné povinnosti v průběhu posledního staletí mobilizováni k boji. Politický entuziasmus však neměl představovat efektivní náhradu disciplíny, ale měl být spíše jejím užitečným doplňkem. Důkazem může být idea politické národní armády z období Francouzské revoluce, která se odvolávala na představu politického vojáka, formovaného a motivovaného uvědomělým vyznáváním komunistických idejí. Současně je však třeba mít na paměti, že politicky uvědomělá armáda byla od počátku moderních dějin vždy spíše jen ideálem než dlouhodobě udržitelným faktem a samotné aktivní zapojení do boje bylo zpravidla následně zapř́íčiněno zcela jinými faktory. ${ }^{4}$

Rusko v tomto ohledu dodnes považuje institut ZVS za významný nástroj k posílení vlastenectví a utváření pozitivního vztahu veřejnosti k armádě, což potvrzují i výsledky evropských průzkumů veřejného mínění z posledních let. ${ }^{5}$ Za typický př́klad armády budované na občanském principu pak lze považovat německý Bundeswehr, který zavedl povinnou vojenskou službu v roce 1956 a k jejímu zrušení přistoupil teprve v roce 2011. Spolková republika Německo se v polovině 50. let vydala cestou intelektuální, politické a morální reformy armády, jejímž cílem byl „myslící voják - občan v uniformě“ sám sebou i společností považovaný za prŕíslušníka svobodného národa stojícího na straně svobody. Prostřednictvím ZVS byl armádní kolos pod permanentním dozorem společnosti, což mělo zabránit tomu, aby se opakovala situace z 20. a 30. let minulého století (výmarská republika,

\footnotetext{
${ }^{3}$ DOORN, Jacques van. The Soldier and Social Change. Londýn, Sage 1975, s. 98.

${ }^{4}$ KILIAS, Jaroslaw. Válka, armáda, stát a národ. Byrokracie, disciplína a nacionalismus. In: Historická sociologie, č. 1 (2009), s. 54.

${ }^{5}$ Více než $60 \%$ Rusů v roce 2017 podporovalo stávající roční ZVS a projevilo ochotu bojovat za národní zájmy, ve Spojených státech to byla necelá polovina obyvatel a ve státech západní Evropy, kde již byla ve většině případů ZVS definitivně zrušena, dokonce méně než třetina. Vyššího výsledku dosáhlo v obdobném průzkumu v roce 2015 pouze Finsko (74 \%), což lze přičíst historicky nepřerušené tradici branné povinnosti a současně bohatým zkušenostem s obranou vlastního území v prvních desetiletích existence samostatného finského státu. Viz BARNDOLLAR, Gil. The Best or Worst of Both Worlds? Russia's Mixed Military Manpower System. In: CONLEY, Heather et al. The Diversity of Russia's Military Power: Five perspectives (Research Report).

Washington D. C., Center for Strategic and International Studies 2020, s. 21-22.
} 
třetí ř́ı̌se), kdy se z armády stal de facto „stát ve státě“. ${ }^{6}$ Současný trend profesionálních ozbrojených sil, pokud jde o vztah k vlastenectví, je však spíše opačný a potvrzuje, že od konce studené války se globalizovaný svět (až na několik výjimek v podobě autoritativních režimů) zásadním zpo̊sobem proměnil. Vzhledem ke globalizaci, transnacionalizaci a internacionalizaci již vojenská služba nespočívá primárně v patriotismu a povinnosti vůči národu, ale vychází spíše z určitého druhu humanitárního kosmopolitismu, který národním zájmům neodporuje, ale přesahuje je. Nutným předpokladem pro uplatnění této nové vize v kontextu profesionálních armád je pak schopnost sebereflexe a porozumění vojenské kultuře ,druhých“. 7

Pro studenoválečný svět od konce 40. let do počátku 90. let minulého století nicméně Doornova teorie nepochybně zůstává v platnosti a v případě československé armády po roce 1948 lze dokonce hovořit o specifickém legitimizačním mixu, který v sobě (pod vlivem politické diskontinuity 20. století) kombinuje národovecké tradice prvorepublikové armády s marxisticko-leninskými principy sovětského totalitárního systému. V československé armádě byla totiž již od jejího počátku (v důsledku první světové války) pevně zakořeněna myšlenka státní a národní existence, která byla po francouzském vzoru úzce navázána právě na koncept obrany vlasti. Nastupující komunistické garnituře po vítězném únoru tedy stačilo tento po tři dekády umně budovaný patriotismus pouze převzít a zasadit do marxistickoleninského rámce. ${ }^{8}$ Místo původního Masarykova hesla „odrakouštěni““ armády dosadili komunisté „politickou očistu“ a konformní osvětu nahradili politickou indoktrinací. V důsledku těchto změn byl francouzský vzor po roce 1948 postupně definitivně nahrazen tím sovětským. ${ }^{9}$

\footnotetext{
${ }^{6}$ LONGHURST, Kerry. Bezpečnostní kultura a branná povinnost v Německu. In: Mezinárodní vztahy, č. 3 (1998), s. 31-32.

${ }^{7}$ ECHTERNKAMP, Jörg; MACK, Hans-Hubertus (eds.). Déjiny bez hranic? Evropské dimenze vojenských dějin od 19. století po dnešek. Praha, Academia 2019, s. 13-16.

${ }^{8}$ Podle marxismu-leninismu je armáda ozbrojenou organizací státu na ochranu zájmů určité tř́ídy, přičemž po provedení socialistické revoluce vytvářejí dělníci a rolníci armádu nového typu - třídní armádu. Viz KOLDINSKÁ, Marie; ŠEDIVÝ, Ivan. Válka a armáda v českých dějinách, s. 172.

${ }^{9}$ Vnímání armády jako záležitosti politického režimu, důraz na její výchovnou úlohu i silná vazba na francouzský vzor významně usnadnily infiltraci a ovládnutí československé armády komunisty po roce 1945. Viz KŘÍŽ, Zdeněk. Civilní řizení a demokratická kontrola armády v České republice. Peripetie transformace vojensko-civilních vztahů po roce 1989. Brno, Masarykova univerzita v Brně 2004, s. 51.
} 


\section{Ideologický rozměr povinné vojenské služby v letech 1968-}

\section{9}

Chceme-li plně pochopit ideologický rozměr ZVS jako prostředku záměrné socializace - tj. výchovy $\mathrm{k}$ (socialistickému) občanství $\mathrm{v}$ období normalizace -, nesmíme opominout předcházející společenský vývoj 50. let, který byl ukotven v diskursech „budování socialismu“ a utváření „nového socialistického člověka“. ${ }^{10}$ Charakteristickým rysem československé poválečné éry byl všudypř́ítomný tlak na militarizaci společnosti. Důraz měl být kladen na moderní racionalizaci, mobilizaci a disciplinaci, přičemž bojovný slovník komunistického hnutí často odkazoval právě ke světu vojenské morálky. Komunistická strana Československa (KSČ) a její členové měli proto v souladu s Leninovým učením hledat inspiraci v armádě. ${ }^{11}$ Není proto překvapivé, že propagace armády představovala od konce 40. do konce 60. let jeden z hlavních piliřru ideologické propagandy. Typickým dobovým obrazem se stal obyčejný voják (vojín, málokdy důstojník) se zbraní v pohotovostní poloze, který byl zobrazován často ve společnosti sovětského vojáka nebo v typické kombinaci s dělníkem a rolníkem. ${ }^{12}$

ČSLA měla být garantem nových společenských pořádků a KSČ se v tomto ohledu mohla opřít nejen o vysoké procento straníků (tj. politicky spolehlivých jedinců) v řadách vojáků z povolání, ale také o vlastní politická pracoviště (od roku 1950 v čele s Hlavní politickou správou) na různých úrovních armádního organismu, která měla dohlížet na politickou osvětu důstojnického sboru, vojáků základní služby i občanských zaměstnanců armády. ${ }^{13}$ Po celou dobu komunistického panství v Československu tak v armádě existovala vedle služební linie také linie politická, která vytvářela jakousi paralelní mocenskou strukturu,

\footnotetext{
${ }^{10}$ Viz NEČASOVÁ, Denisa. Nový socialistický člověk. Československo 1948-1956. Brno, Host 2018.

${ }^{11}$ Komunistické strany byly na počátku studené války popisovány jako „bojové štáby úderné brigády dělnického hnutí složené z obětavých a nadšených vojákư“. Viz KAŠKA, Václav. Neukáznění a neangažovaní. Disciplinace členů Komunistické strany Československa v letech 1948-1952. Praha, Conditio humana - Ústav pro studium totalitních režimů 2014, s. 47-48.

12 KABÁT, Jindřich. Psychologie komunismu. Praha, Práh 2011, s. 303.

${ }^{13}$ V roce 1968 bylo mezi vojáky z povolání přes $76 \%$ straníků, poté následoval krátkodobý pokles, ale v polovině 70. let to bylo již opět $75 \%$ a na podzim 1989 bylo v KSČ organizováno dokonce $82 \%$ důstojnického sboru (a v praporčickém sboru to bylo ,jen“ necelých $35 \%$ ). Viz TOMEK, Prokop. Československá armáda v čase sametové revoluce. Proměny ozbrojených sil na přelomu osmdesátých a devadesátých let. Cheb, Svět křídel 2019, s. 32.
} 
mnohdy nadřazenou vojenským řádům a předpisům. ${ }^{14}$ Za ojedinělý pokus zvrátit mocenskou převahu KSČ v armádě lze označit snad jen demokratizační proces v období pražského jara, kdy část důstojníků otevřeně kritizovala politický aparát v armádě, ale následující okupace Československa vojsky Varšavské smlouvy v čele se sovětskou armádou jakékoliv snahy o narovnání mocenských poměrů na další dvě desetiletí ukončila.

Poměry $\mathrm{v}$ armádě $\mathrm{v} 70$. letech byly (obdobně jako ve zbytku společnosti) poznamenány nástupem tzv. normalizace. Utužení komunistického režimu v Československu šlo paradoxně ruku v ruce s celkovým uvolněním mezinárodního napětí (politika détente) v období studené války. Konsolidovaná lidová armáda se tak po stranických prověrkách na začátku 70. let opětovně stává oddaným politickým nástrojem, jehož cílem je demonstrovat loajalitu vưči vládnoucí moci (resp. KSČ a Sovětskému svazu). ${ }^{15}$ Velitelé sice formálně stále velí, ale je to především komunistická strana (resp. politický aparát), která po následující dvě dekády rozhoduje o podstatných záležitostech armády, což se zřetelně odráží také v rovině tehdejšího oficiálního diskurzu: „Československá lidová armáda je rozhodující složkou ozbrojených sil ČSSR určená k obraně socialistické vlasti a společně se Sovětskou armádou a ostatními armádami Varšavské smlouvy $k$ obraně západních hranic socialistického společenství. (...) Základním principem výstavby a organizační činnosti ČSLA je vedoucí úloha KSČ. Strana je základem její politické pevnosti, vysoké bojeschopnosti a zárukou toho, že armáda se ctí splní svoje vlastenecké a internacionální poslání. “16

Mladý muž, jemuž se nepodařilo po roce 1968 vyhnout odvodu, tak byl v podmínkách relativní izolace armádního prostředí během ZVS dlouhodobě (po dobu dvou let, výjimečně pěti měsíců nebo jednoho roku v případě vysokoškoláků), nepřetržitě a jednotně vystavován ideovému a pedagogickému působení důstojnického sboru, jenž tak dostal jedinečnou př́ležitost vytvořit z něj uvědomělého socialistického občana, obránce vlasti. ${ }^{17}$ Vojenská služba tak měla představovat důležitou etapu socializace, během níž se mladý člověk stává

\footnotetext{
${ }^{14}$ Výsadní postavení KSČ v armádě bylo včleněno přímo do stanov komunistické strany a stranické organizace měly svou každodenní činností zajišt'ovat plnění politiky strany v ozbrojených silách. Viz Stanovy Komunistické strany Československa. Praha, Ústř̌ední výbor KSČ, 1966, kap. IX, čl. 71-72.

${ }^{15}$ Do konce roku 1973 bylo v rámci stranických čistek vyloučeno nebo vyškrtnuto z KSČ přes 7000 vojáků z povolání. Viz Zásady třídně politického zpevnění velitelského sboru ozbrojených sil ČSSR ze dne 29. 3. 1974, Národní archiv, fond Předsednictvo ÚV KSČ, sv. 112, aj. 114, bod 15.

${ }^{16}$ SVOBODA, Oldřich a kol. Stručný slovník vojenství. Praha, Naše vojsko 1984, s. 60.

${ }^{17}$ SKALKA, Jaromír. Sebeuvědomování socialistické vojenské pedagogiky. In: Pedagogika, č. 5 (1969), s. 735.
} 
členem třídně politické ozbrojené organizace socialistické společnosti - vojákem ČSLA -, dotváří se řada jeho osobnostních kvalit, čímž dochází k jeho politickému dozrávání. ${ }^{18}$

Zatímco západní státy v této době (zejména po neúspěšném americkém vojenském angažmá ve Vietnamu) stále častěji uvažují o nahrazení branecké armády poloprofesionálními či plně profesionálními ozbrojenými silami, státy Varšavské smlouvy naopak své indoktrinační praktiky dále zintenzivňují. ${ }^{19} \mathrm{~V}$ rámci boje s nepřátelskou ideologií jsou pak soustavně administrativně potlačovány všechny projevy nemarxistického myšlení, zvláště náboženství (včetně pronásledování věřících). Právě s ohledem na výchovně-vzdělávací a formativní funkci armády se většina předlistopadových vojenských normativů neomezuje pouze na definici všeobecných práv a povinností vojáků, ale pozornost věnuje také jejich ideálně-typickým charakterovým vlastnostem: „,Voják ozbrojených sil ČSSR je obráncem své vlasti. (...) Je osobně odpovědný za obranu své vlasti; povinen důsledně a neochvějně zachovávat československé zákony a vojenskou př́sahu. Být ukázněný, čestný, pravdomluvný, smělý. Nešetřit svých sil ani života při plnění vojenských povinností. Bez odmluvy se podřizovat velitelưm/náčelníkům a bránit je v boji. “20

Zvláštní pozornost byla $\mathrm{v}$ tomto ohledu věnována kádrovým profilům branců, a to dokonce ještě před jejich samotným nástupem k výkonu ZVS. Kádrové materiály, které byly průběžně vypracovávány bezpečnostními a stranickými orgány, měly v ideálním případě reflektovat politický a morální profil branců, jejich zájmy, schopnosti a sklony využitelné v ozbrojených silách, ale i další důležité skutečnosti (včetně rodinných poměrů) a tělesný, zdravotní a duševní stav. ${ }^{21} \mathrm{Na}$ základě těchto podkladů - které však v praxi (s ohledem na časovou i personální náročnost jejich podrobného vypracování) trpěly pro komunistický režim typickým schematismem a málokdy zahrnovaly skutečně relevantní a komplexní informace měli být branci zařazováni do funkcí a $\mathrm{k}$ jednotlivým útvarům. K přednostně doplňovaným útvarům ČSLA, včetně útvarů zvláštní důležitosti (zahrnující např. Pohraniční stráž a útvary vojska Ministerstva vnitra), tak např. nebylo možné zařazovat brance, u nichž byly zjištěny

\footnotetext{
${ }^{18}$ STRUHOVSKÝ, Václav. Hlavní činitelé utváření vztahu vojáků k vojenské službě. In: Historie a vojenství, č. 4 (1985), s. 87.

${ }^{19}$ Př́ičinou západních diskusí byl zejména nový komplikovanější způsob válčení a také stále častější uplatňování globálních národních zájmů, které ztěžovalo mobilizaci občanů k aktivní účasti na vojenských akcí daleko od vlastních hranic. Viz KOLDINSKÁ, Marie; ŠEDIVÝ, Ivan. Válka a armáda v českých déjinách, s. 185-186.

${ }^{20}$ VALEŠ, Jan; VESELÝ, Mirko. Základní řády. Řád vnitřní služby ozbrojených sil ČSSR. Praha, Státní pedagogické nakladatelství 1980, s. 16.

${ }^{21}$ Smérnice pro hodnocení branců a vojáků v záloze a pro jejich zar̆azování $k$ útvarům ozbrojených sil. Vojenský ústřední archiv - Vojenský historický archiv, f. Nařízení náčelníka generálního štábu, č. 04, 31. 3. 1981, s. 4.
} 
státobezpečnostní závady (protistátní činnost), podezření na trestnou činnost, evidence mezi kriminálně závadovými osobami, pokus(y) o útěk do ciziny nebo návštěvu zahraničí bez povolení prŕíslušných úřadů, udržování osobního nebo písemného styku s cizinci z kapitalistických států. Překážku pro výkon služby představovali také rodiče a blízcí př́ibuzní, kteří emigrovali v letech 1968-1969 nebo se podíleli na reakční politice, popř. byli sledováni Státní nebo Veřejnou bezpečností. A konečně, u těchto útvarů také nesměli sloužit branci žijící v silně náboženských rodinách nebo tzv. náboženští fanatici (členové náboženských sekt apod.). ${ }^{22}$

\section{Demokratizační proces po roce 1989 v rovině (ne)nucené}

\section{indoktrinace}

Po roce 1989 se československá, posléze česká armáda pokusila v rovině ideového působení navázat na prvorepublikové tradice, které zdůrazňovaly demokratický princip fungování ozbrojených sil a jejich apolitičnost. Cílem těchto snah mělo být mimo jiné také posílení národní identity a utváření společných hodnot u vojáků základní služby. Úkolem byla pověřena nejprve Správa výchovy a kultury Federálního ministerstva národní obrany, která v lednu 1990 nahradila dosavadní politický aparát, od roku 1993 se pak tato problematika stala součástí agendy Správy sociálního řízení Ministerstva obrany České republiky. Ani nově budovaná armáda na počátku 90. let v období celospolečenských změn tedy nerezignovala na péči o morální a volní kvality vojáků základní služby, spíše naopak. Upřednostňován měl být smysl pro povinnost, odpovědnost, čestnost, vytrvalost, houževnatost, kamarádství a tělesná zdatnost. Tehdejší vojenští didaktici nicméně jedním dechem dodávali, že výchovněvzdělávací funkci armády nelze oddělit od působení civilních institucí. Armáda tak měla v tomto ohledu pouze navázat na výchovné působení rodiny, školy, zájmových organizací i dalších formálních a neformálních skupin, případně občanských iniciativ. ${ }^{23}$

Bezprostředně po vzniku Armády České republiky (AČR) v roce 1993 byla u vybraných útvarů též experimentálně zaváděna obdoba občanské nauky pod názvem vojensko-občanská př́íprava, která měla do určité míry substituovat předlistopadové politické

\footnotetext{
${ }^{22}$ Tamtéž, s. 6-7.

${ }^{23}$ CVRČEK, Jaromír. Vzájemné vztahy společnosti a armády (teoreticko-empirická studie). Praha, Správa sociálního řízení FMO 1992, s. 46-47.
} 
školení mužstva, tentokrát však již v demokratickém gardu. ${ }^{24}$ Podle autorů tohoto ambiciózního projektu, mezi něž patřila řada rehabilitovaných vojáků (tzv. osmašedesátníků), mělo být hlavním smyslem přípravy ovlivňování vědomí a jednání vojáků v základní službě. Jejich ztotožnění s principem občanů ve zbrani (přijetí odpovědnosti za obranu vlasti a národních zájmů); utváření postojů v souladu s vojenskými hodnotami a tradicemi (ideálem byl sebevědomý, statečný, ctnostný a důstojný voják-občan-demokrat) a v neposlední řadě kultivování lidského faktoru v armádě. ${ }^{25} \mathrm{~K}$ plošné realizaci této iniciativy nicméně nakonec nikdy nedošlo, což potvrzují rovněž př́ručky pro brance z pozdějších let, které formou odpovědí na často kladené otázky řeší již pouze praktické aspekty ZVS a na jakékoliv snahy o aktivní výchovné působení v občanské rovině rezignují. ${ }^{26}$ Od roku 1995 úlohu každodenní péče o lidský faktor $\mathrm{v}$ armádě převzala tzv. humanitní služba, jejíž personál tvořili psychologové, sociální pracovníci, duchovní a vybraní právníci. ${ }^{27} \mathrm{Na}$ konci milénia se nicméně jedinou alternativní formou k výchovně-vzdělávací funkci armády stala Duchovní služba AČR, mezi jejíž úkoly patří mimo jiné také podpora vojáků při řešení osobních krizí, rozvoj a prohlubování demokratických tradic a vytváření podmínek pro naplňování ústavou zaručených lidských práv. ${ }^{28}$

Myšlenka nepřímého pozitivního ideového působení na mladou generaci mužů prostřednictvím institutu povinné služby $\mathrm{v}$ armádě nicméně zůstává přinejmenším v rovině oficiálního diskurzu nadále živá a stává se jeho imanentní součástí až do jejího zrušení, což dosvědčují také výsledky armádních dotazníkových šetření z druhé poloviny 90 . let a bezprostředně před koncem milénia. Podle jejich závěrů výkon ZVS nepůsobí pozitivně jen na vztah branců k instituci armády, ale také na některé vyšší, celospolečenské hodnoty (např. hrdost na občanskou př́slušnost a obětavý vztah k vlasti a národu) a rovněž dochází k posilování hodnot mezilidského porozumění, vzájemné pomoci a národnostní tolerance. Tento účinek se však podle autora závěrečné zprávy z výzkumu Jiřího Hendrycha výrazně projevuje teprve až s časovým odstupem - v době, kdy se bývalí vojáci plně adaptují na

\footnotetext{
${ }^{24}$ O povaze chystané vojensko-občanské přípravy si lze udělat komplexní představu z vybraných ročníků (19931994) sešitů Dialog, které v 90 . letech vydávala Správa sociálního MO ČR. Jednotlivé sešity byly zamýšleny jako tematická skripta pro výuku, včetně časové dotace.

${ }^{25}$ Tematika vojensko-občanské př́pravy pro povolance. In: Dialog, č. 1 (1993), s. 20-21.

${ }^{26} \mathrm{Tj}$. specifikum, vojenského prostředí, základní práva a povinnosti vojáků základní služby, znění vojenské přísahy, riziko šikany, zásady bezpečného sexu, důležitá telefonní čísla apod. Srv. např. MAJER, Petr. Vojna do kapsy. Praha, Ministerstvo obrany C̆R - AVIS 1999.

${ }^{27}$ LAŠTAVKOVÁ, Jitka; BRNULA, Peter. Sociální práce v armádě - možnosti a výzvy v českém prostoru. In: Vojenské rozhledy č. 1 (2017), s. 44.

${ }^{28}$ Duchovní služba v AČR. Ministerstvo obrany ČR. [online] [2021-10-10]. https://www.mocr.army.cz/informa cni-servis/zpravodajstvi/duchovni-sluzba-v-acr-64633.
} 
civilní život a pracovní zařazení. ${ }^{29}$ Závěry longitudinálního výzkumu nicméně působí značně rozporuplně, protože jak Hendrych sám o několik stran dále konstatuje, při porovnání výsledků šetření hodnotové orientace branců s kontrolním vzorkem „nevojáků“ v téže věkové kohortě lze v dlouhodobém horizontu nalézt jen zanedbatelné diference. ${ }^{30}$ Rekonfigurace hodnot tak může být zapř́činěna zcela jinými kolektivně sdílenými faktory v období dospívání, než je povinné absolvování ZVS.

\section{Pamětnická reflexe vojáků základní služby v orálně-}

\section{historických rozhovorech}

$\mathrm{V}$ rovině indoktrinace existoval mezi oficiálním (řády, předpisy apod.) a zkušenostním diskurzem (aktérská reflexe) evidentní rozpor, pokud jde o očekávání pamětníků a následnou realitu, a to bez ohledu na konkrétní časové období v rozmezí let 1968-2004. V tomto textu vycházíme z (re)konstruovaných narativů, které napříč orálně-historickými polostrukturovanými rozhovory se 100 absolventů povinné vojenské služby nějakým způsobem reflektují problematiku vlastenectví, občanství a vztahu ke státu či k ideologii. Tyto rozhovory byly pořízeny v rámci grantového projektu, na jehož řešení se v letech 2019-2021 podílely dva ústavy Akademie věd České republiky (Ústav pro soudobé dějiny a Etnologický ústav). Všechny rozhovory byly uskutečněny v souladu se zavedenými metodologickými a etickými standardy metody orální historie, která si klade za cíl prohloubit poznání minulosti prostřednictvím analýzy a interpretace vzpomínek pamětníků a pamětnic. ${ }^{31}$ Respondenti (výhradně muži) byli vybíráni na základě kombinace otevřené výzvy, cíleného výběru a náhodného vzorkování takovým způsobem, aby pokud možno rovnoměrně pokryli nejen časový záběr celého výzkumu napříč jednotlivými dekádami (tj. rozmezí let 1968-2004), ale i různé druhy vojsk tehdejší československé/české armády (pozemní vojsko, letectvo, protivzdušná obrana státu), včetně běžných, specializovaných i elitních typů konkrétních vojenských útvarů. Do výzkumného vzorku bylo také cíleně zahrnuto několik současných příslušníků Aktivních záloh AČR a vojenských reenactorů (tj. členů různých zájmových uskupení - typicky klubů vojenské historie -, která se ve svém volném čase věnují zpřítomňování historických bitev či každodenního života vojáků v různých historických obdobích). Zvolený způsob vzorkování pak mimo jiné nabízí také reflexi zkoumaného

\footnotetext{
${ }^{29}$ HENDRYCH, Jiří. Voják v míru. Praha, Ministerstvo obrany ČR - AVIS 1998, s. 55-56.

30 Tamtéž, s. 59.

${ }^{31}$ Viz ABRAMS, Lynn. Oral History Theory. New York, Routledge 2010.
} 
fenoménu napříc různými profesními a sociálními skupinami. Posledním významným kritériem vzorkování pak bylo dosažené vzdělání pamětníků v době odvodu, od něhož se až do roku 1989 odvíjela délka povinné vojny (rok či dva). ${ }^{32}$

Než přistoupím k samotné interpretaci rozhovorů, je nutné uvést několik důležitých analytických poznatků. Za prvé, všechny narativy vztahující se k tomuto tématu s ohledem na svou četnost naznačují, že indoktrinační nebo ideologickou funkci ZVS je možné v kontextu připisovaných významů (na rozdíl od roviny socializace a disciplinace) v aktérské zkušenosti považovat za naprosto marginální. Za druhé, část výzkumného vzorku zahrnující pozdější vojáky z povolání, příslušníky aktivních záloh nebo příznivce reenactmentu tvoří specifickou skupinu, jejíž vztah k pojmům jako vlast, stát nebo národ lze obecně hodnotit jako pozitivní (v některých př́padech až nekritický), jakkoliv je těžké odlišit, nakolik zde reálně sehrává roli celkové osobnostní naladění jedince, jeho zkušenost se ZVS nebo případné pozdější angažmá v armádě či zapojení do různých militárních aktivit. Za třetí, u pamětníků, kteří získali vysokoškolské vzdělání (lhostejno zda před ZVS nebo po jejím absolvování), můžeme identifikovat převažující sklon bagatelizovat jakékoliv snahy o výchovně-vzdělávací působení armády v ideologické rovině. Za čtvrté, krátkodobé pozitivní konotace v rovině očekávání lze vysledovat u respondentů, kteří absolvovali ZVS v rozmezí let 1990-1993, což lze přičíst na vrub dobovým referenčním rámcům (proces konstituování nové občanské společnosti v podmínkách liberální demokracie). A konečně, s ohledem na výše uvedené vycházím v následující části nikoliv z reprezentativních, ale naopak převážně z okrajových pamětnických narativů, jejichž smyslem je ilustrovat různorodé vnímání politickoideologického působení ve vojenském prostředí.

\section{Patriotismus a vztah k národu}

Interpretačně obtížně uchopitelné, až téměř fluidní téma představuje v rozhovorech zejména otázka vztahu mezi institutem povinné vojenské služby a vlastenectvím chápaným v rovině budování pozitivního vztahu k vlasti jakožto geografickému prostoru a současně souboru společensky žádoucích hodnot. V rámci otevřené otázky tázající se přímo po osobní reflexi významu ZVS byl patriotismus explicitně zmíněn pouze v jednom príípadě ze sta (navíc se jednalo o respondenta, který se po vojně dobrovolně stal vojákem z povolání a po odchodu do

\footnotetext{
${ }^{32}$ Pro podrobnější informace k teoreticko-metodologickému ukotvení výzkumu viz HLAVÁČEK, Jiří. Vojna stejná, a přece jiná. Narativní (re)konstrukce základní vojenské služby po roce 1968 v multigenerační perspektivě. In: Národopisný věstník, č. 2 (2020), s. 5-26.
} 
civilu příslušníkem aktivních záloh). V kontextu jejího případného znovuzavedení patřilo toto téma sice již mezi častější, nicméně stále se objevuje pouze u necelé desetiny pamětníků.

Typickým př́kladem může být vojenská přísaha, která - jakkoliv se jedná o deklarativní akt par excellance - pro drtivou většinu respondentů retrospektivně nepředstavovala nijak ideově signifikantní závazek (byla dalece vzdálena původnímu významu veřejného stvrzení věrnosti a statečného chování, které bylo v armádě uplatňováno již v době římských legiî́). Její vykonání bylo chápáno převážně čistě pragmaticky v intenci nutného předpokladu pro to, aby se pamětníci po několika týdnech fyzického a psychického strádání znovu mohli, byt' jen na krátkou chvíli, setkat se svými blízkými a opustit prostor kasáren. ${ }^{33}$ Za výjimku potvrzující pravidlo lze považovat jediného narátora, nynějšího aktivního reenactora, který absolvoval ZVS v druhé polovině 90. let u útvaru protivzdušné obrany. Jeho narativ se svým pozitivním zabarvením vymyká všem ostatním, současně však také v poslední větě odráží převažující sdílenou reflexi napříč výzkumným vzorkem: ,Já jsem to [př́sahu] bral vážně, pro mě to byl opravdu akt cti. A byla zima, my jsme to nacvičovali neustále dokolečka jak pitomci. Myslím si, že jsme to měli i hezký. A musím říct, že opravdu i ten poslední blb, i takovej ten nejvíc tupej kluk, kterej na útvaru byl, tak to bral s nějakou hrdostí. Nebylo tam, že by někdo dělal posměšky nebo ponižoval ten akt. (...) Všichni jsme se těšili na rodiče a holky, co tam přijedou. “34

Vlastenecký étos je ve spojitosti s vojnou do pamětnických narativů vnášen jen minimálně a zpravidla teprve ad hoc. Často se stává prostředkem pro vyjádření nespokojenosti aktérů s aktuálním stavem společnosti, v němž jsou individuální hodnoty upřednostňovány před těmi kolektivními. Dochází tak $\mathrm{k}$ paradoxní situaci, kdy narátoři (zejména ti, kteří mají zkušenost se socialistickou armádou), ač v rámci vlastních vzpomínek vliv jakékoliv užitečné indoktrinace během nuceně strávené doby ve vojenském stejnokroji vehementně popírají, ve spojitosti se současnou mladou generací naopak vkládají naděje právě do možného znovuzavedení ZVS (př́ípadně do její alternativy v podobě povinné národní služby): ${ }^{35}$ „Po těch letech jsem si udělal uvědomění, že v podstatě $v$ tom kolektivu

\footnotetext{
${ }^{33}$ Význam vojenské prŕísahy se tak v případě branců, kteří jsou odvedeni v době míru, významně liší od reflexe vojenských profesionálů, př́ípadně branců, kteří rukují do války. Viz HOLMES, Richard. Obrazy války. Chování člověka v bitvě. Praha, Nakladatelství Lidové noviny 2011, s. 36-37.

${ }^{34}$ Rozhovor s M. A. vedl Petr Wohlmuth, 14. 7. 2019. Ústav pro soudobé dějiny, Centrum orální historie, sbírka Rozhovory (dále jen „ÚSD COH, Rozhovory“).

35 „Co je otázka, jestli by neměla být nějaká občanská služba. Povinnost odsloužit něco v rámci státních nebo veřejných úkolů, jo? S tím, že mně by se líbilo, kdyby byla paleta nějak rozprostřená, a ti lidi by dostali fakt dobrý výcvik v nějakém krátkém rozsahu časovém. (...) Třeba at’ to má v tom vojenském režimu nebo jde pracovat někam s postiženými, do důchod’áku nebo výcvik pro krizové režimy, povodně nebo k hasičům něco
} 
[vojáků ZVS], když by k něčemu došlo a vyř́dí si tu šikanu ty jednodušši lidi, tak prece jenom dojde k tomu stmelení a určitýmu principu lásky k tý vlasti. A to si myslím, že dneska ti mladý taky nemají, jsou daleko sobečtější. “36

V ojedinělých prrípadech pak představuje patriotismus pro pamětníky jednu z možných forem legitimizace, jež má ospravedlnit službu v armádě před rokem 1989 z ideologického hlediska. ${ }^{37}$ Podobné narativy nasvědčují, že kolektivně sdílené předpoklady o ZVS jakožto prostředku občanské a vlastenecké výchovy jsou v oficiálním a veřejném diskurzu natolik silně zakořeněny, že s odstupem času dokážou upozadit i zcela protichůdné individuální aktérské zkušenosti. ${ }^{38}$ Někteří narátoři tak od současné či budoucí armády očekávají něco, co jim tehdejší armáda podle jejich názoru v minulosti měla poskytnout, ale nedokázala to, protože systém ZVS nebyl nastaven správně (at' už jde o formu, délku či konkrétní obsah povinné vojny). ${ }^{39}$

\section{Politické školení mužstva a jeho (chybějící) alternativa}

Základní prostř̌edek př́imé indoktrinace a ideologizace vojáků základní služby před rokem 1989 představovalo politické školení mužstva (PŠM), jehož prováděním byli pověřeni osvětoví političtí pracovníci (politruci), instruktoři Svazu socialistické mládeže, řadoví vojáci z povolání a v některých případech dokonce i vojáci druhého ročníku z řad absolventů (vysokoškoláků). Dobové řády stanovovaly rozsah PŠM v délce čtyř hodin jednou týdně, a to vždy na začátku denního zaměstnání vojáků ve formě přednášky, samostudia, besedy nebo semináře. Oficiálně mělo být cílem politického školení: „,...vyzbrojit vojáky v základní službě základy vědeckého světového názoru marxismu-leninismu, formovat a upevňovat jejich komunistické přesvědčení, vyhraněný třídní postoj a morálně-politické, bojové a psychologické vlastnosti, upevňovat jejich socialistické vlastenectví a proletářský

\footnotetext{
takového pro obě pohlaví, aby bylo.“ Viz Rozhovor s J. TE. vedl Petr Wohlmuth, 20. 6. 2020. ÚSD COH, Rozhovory.

${ }^{36}$ Rozhovor s V. V. vedl Jiří Hlaváček, 20. 8. 2019. ÚSD COH, Rozhovory.

37 „My jsme tu vojnu nebrali, že bráníme socialismus nebo nějaké takové, my jsme opravdu byli vychovaní v tom, že bráníme vlast, hotovo, tím to končilo.“ Viz Rozhovor s P. G. vedl Jiří Hlaváček, 9. 7. 2019. ÚSD COH, Rozhovory.

${ }^{38}$ Poměrně častá byla v tomto ohledu argumentace zahraničím: „Zajímavá je zkušenost, kterou jsem udělal ve Švýcarsku, kdy jsem se bavil s generálním ředitelem jedné nadnárodní firmy a on mi říkal, že tady když jste nebyl v armádě, tak nedostanete slušný zaměstnání, protože o tom člověku je okamžitě jasno, že nemá dobrý poměr ke státu. To je pohled Švýcarů.“"Viz Rozhovor se Z. Z. vedl Jiří Hlaváček, 17. 4. 2019. ÚSD COH, Rozhovory.

${ }^{39}$ Typické je to zejména pro současné př́íslušníky Aktivních záloh AČR nebo stoupence vojenského reenactmentu.
} 
internacionalismus. Prohlubovat jejich oddanost komunistické straně a lidu, zodpovědnost za obranu své země a světového socialistického společenství, posilovat jejich bdělost, ostražitost a uvědomělou třídní nenávist vưči nepřátelưm socialismu. "40

Těmto cílům odpovídalo také obsahové zaměření PŠM, které mělo během pravidelného dvouletého cyklu vojáky postupně seznámit nejen s dějinami KSČ a rozdíly mezi dvěma světovými společenskými soustavami (socialismem a kapitalismem), ale také s významem komunistické strany při obraně vlasti a úlohou ČSLA v rámci Varšavské smlouvy. Jednou týdně měla být navíc povinně věnována hodina společnému sledování pořadu Kompas, publicistickému a dokumentárnímu cyklu Československé televize účelově určenému k lidově politické, vojenské a branné vlastenecké výchově vojáků. A dvakrát týdně (ve dnech, kdy neprobíhalo PŠM) měla být před začátkem dopoledního zaměstnání uskutečňována politická informace (aktualita) v rozsahu nejméně půl hodiny. Ani tím však politicko-výchovná funkce ČSLA zdaleka nekončila. Významnou součást ideového působení tvořila také masová politická práce, která měla být realizována převážně v hodinách osobního volna vojáků a zahrnovala schůze, besedy, názorné agitace nebo práci s tiskem, rozhlasem a televizí. $^{41}$ Snaha o politickou indoktrinaci tak byla před rokem 1989 v armádě prakticky všudypřítomná.

Negativní postoj respondentů k PŠM, nejčastěji vyjadřovaný ironií či sarkasmem, proto představuje ideální příklad, na němž lze ilustrovat stav, kdy se oficiální diskurzivní model dostává do konfliktu s každodenní žitou zkušeností. Zatímco oficiálně mělo být PŠM pro každého vojáka prioritou (jeho prostř̌ednictvím měla být zvyšována efektivita práce a bojová připravenost, přičemž jeho neuskutečnění bylo dle dobových předpisů dokonce považováno za mimořádnou událost), v praxi tomu bylo přesně naopak. Politická výchova, obdobně jako fenomén socialistického soutěžení, většinu důstojnického sboru (s výjimkou politického aparátu) i vojáků základní služby zdržovala od výcviku a školení se tak zúčastňovali z prosté povinnosti než pro nějaké skutečné ideologické nadšení. Ačkoliv ve výjimečných případech nelze popřít, že u některých jedinců z řad vojáků základní služby mohlo - vzhledem $\mathrm{k}$ jejich nízkému věku při nástupu ZVS - PŠM skutečně vést k určité indoktrinaci, většina respondentů jej považovala za zbytečnou ztrátu času, který byl navíc vyplněn (retrospektivně) absurdní propagandou: ${ }^{42}$ Politický školení mužstva, tam byla

\footnotetext{
${ }^{40}$ NĚMEČEK, Zděnek (ed.) Základní vojenská příručka. Praha, Naše vojsko 1986, s. 313.

${ }^{41}$ Tamtéž, s. 312-313.

42 „Tenkrát [70. léta] to bylo tak, že jsme si mysleli, že ten [komunistický] režim bude navždycky tady. To je první pohled. Druhej pohled je, že jsme slyšeli o armádách NATO [Severoatlantická aliance], který jsou
} 
desetiminutovka, kde jsi shrnoval nějaký politický události, jako že byl sjezd strany nebo že horníci překročili plán na 120 procent nebo že už proběhly žně a že bude hodně chleba. Takovýhle blbosti. A potom tam politruci a jejich poskoci mluvili o Varšavský smlouvě, o potřebě mladé generace, která by měla po vojně (...) zưstat u vojska. Dělali takový nábory nenápadně. (...) Ale my jsme leželi na těch lavicích a poslouchali jsme nebo spali a někdo mluvil, mluvil, mluvil a pak řekli - „konec“. ${ }^{43}$

Školení nabývalo v narativech různých nových (především však vyloženě neideologických) významů a pro vojáky prvního ročníku v70. a 80. letech mnohdy představovalo okamžiky vytouženého odpočinku, kdy bylo možné načerpat fyzické a psychické síly potřebné pro zdárné zvládnutí základního výcviku a každodenního střetávání s neoficiálním (mazáckým) řádem. Způsob, jímž se pamětníci vztahovali ke komunistické ideologii a indoktrinačním praktikám v tomto kontextu vykazuje nápadnou paralelu s procesy hypernormalizace a performativní změny, které popsal ruský sociální antropolog Alexej Jurčak pro fungování společnosti $\mathrm{v}$ období pozdního socialismu v Sovětském svazu. ${ }^{44}$ Pamětnické narativy současně dokládají, že praxe PŠM se mohla útvar od útvaru významně lišit. Čas vymezený na indoktrinaci mužstva tak mohl být v některých př́ípadech neoficiálně využíván k různým jiným ryze nevojenským činnostem (od hraní karet přes sledování zábavných pořadů až po neformálně vedené rozhovory a diskuze, které mohly - zejména pokud bylo PŠM vedeno vojáky absolventy - dokonce názorově odporovat původnímu ideologickému záměru).

Připočteme-li k tomu skutečnost, že také řada dalších politicko-ideových nařízení byla v praxi na různých úrovních naplňována často jen formálně, zatímco obsahově byla spíše obcházena, a to i samotnými příslušníky z řad důstojnického sboru, vyvstává před námi obraz normalizační armády, jejíž pamětníci komunistickou ideologii retrospektivně vnímají jako

připravený sem vtrhnout, takže jsme se snažili ty naše rodiny chránit. A další věc byla, že jako kluci jsme se snažili tou vojnou procpat, abysme co nejdřív byli doma. Ta doba prostě byla taková a ta ideologie docela dobře propracovaná, takže jste těm věcem a zprávám věřil, protože bylo těžký najít oponenta, (...) kterej by vysvětlil, že tak to není." Viz Rozhovor s J. TER. vedl Petr Drož, 7. 8. 2019. ÚSD COH, Rozhovory.

${ }^{43}$ Rozhovor s M. V. vedl Jiří Hlaváček, 5. 4. 2019. ÚSD COH, Rozhovory.

44 Jurčak přichází s tezí, že normalizované a neměnné diskurzivní struktury od poloviny 50. do poloviny 80 . let postupně znehybněly a beze změny začaly být opakovány v různých kontextech, což se projevilo nejen na úrovni textů, ale také ve vizuálním diskurzu ideologie (plakáty, filmy, pomníky, architektura), v rituálním diskurzu (schůze, rezoluce, institucionální praxe, slavnosti) a v množství centralizovaných „formálních struktur“ každodenní praxe (školní osnovy, ceny zboží, uspořádání městského prostoru a času apod.). Tato opakování se nakonec stala sama o sobě konečným účelem a konstativní významy diskurzivních forem postupně zmizely. Tato performativní změna byla centrálním principem, skrze nějž autoritativní diskurz v pozdně socialistickém období fungoval, reprezentoval a organizoval každodenní život. Viz JURČAK, Alexej. Bylo to na věčné časy, dokud to neskončilo. Praha, Karolinum 2018, s. 41-42. 
nedílný a neměnný dobový referenční rámec každodenního fungování. ${ }^{45}$ Jeho nerespektování sice mohlo mít pro některé jedince fatální následky (jak ukázaly politické čistky mezi vojáky z povolání po roce 1968), ale současně bylo do určité míry také nutně tolerováno, jak dokládá př́íklad již zmiňovaného personálního doplňování vojáků u jednotlivých útvarů. Mezi pamětníky tak nalezneme jedince, kteří v průběhu 70. a 80. let absolvovali ZVS u útvarů, které předpokládaly ,,vysokou ideovou pevnost a politicko-morální uvědomělost““ (raketové vojsko, Pohraniční stráž), a to i přes vlastní nevyhovující kádrový profil (příbuzní v emigraci nebo disentu, nevhodný třídní původ apod.).

Pro celá 90. léta je pak - i přes rychlé zrušení politického aparátu po sametové revoluci - příznačná určitá neformální setrvačnost „starých pořádků“ a současné tápání v podmínkách nového, demokratického režimu ze strany armádního velení, pokud jde o žádoucnost př́mého ovlivňování občanských postojů vojáků základní služby: „V těch 90. letech se armáda snažila, ještě před tou duchovenskou službou faráṛ̛̆, nastavit takzvanou humanitní službu s tou vizí jako pečovat o takový lidství. (...) No, a právě ten plukovník (...) musel odejít po roce 1968 z armády, ale měl nějakou vizi tohle uplatnit, takže on si vyhmátl mě plus další čtyři vysokoškoláky, učitelé (...) s humanitním vzděláním. (...) Takže my jsme byli v pěti lidech v Praze, Českých Budějovicích, Kroměřiži, Ostravě, Náměšti a vlastně jsme zjistili, že nikde se nic moc neděje. (...) To bylo rozvrženo na pět týdnů, ve kterých jsme prakticky skoro nic nedělali, jenom jsme si jezdili po služebních cestách, vlastně v té době, kdy všichni z přijímače nastupovali na útvary, tam byli zavření, že jo, a zakoušeli tu první srážku s mazáckou vojnou nebo prímo s šikanou, tak my jsme spali v bílých postelích v Praze, jo? [smích] (...) Ono to pak šlo do ztracena. Nevím, co se s tou institucí stalo, vím, že oni se cítili silně ohroženi duchovenskou službou. "46

Zatímco vysoká míra ideologizace armády před rokem 1989 byla narátory vnímána negativně, její odideologizování (resp. absence jakékoliv snahy o výchovu k občanství) je zpětně v některých případech považováno taktéž za chybu (resp. promarněnou př́ležitost navázat na předcházející historické tradice), což je reflexe typická zejména pro pamětníky, kteří absolvovali ZVS již v demokratických podmínkách. ${ }^{47}$

\footnotetext{
${ }^{45}$ Tato reflexe současně tvoří pomyslný svorník mezi narativy pamětníků z řad vojáků základní služby a vzpomínkami vojáků z povolání před rokem 1989. Srv. HLAVÁČEK, Jiří. Vzestup a pád ČSLA? Vojenská profese v kolektivní paméti důstojnického sboru (1960-1970). Praha, Karolinum 2019, s. 57.

${ }^{46}$ Rozhovor s J. TE. vedl Petr Wohlmuth, 20. 6. 2020. ÚSD COH, Rozhovory.

47 „Co se týče té přidané hodnoty [indoktrinace], tak já jsem něco takového trochu očekával. (...) Po tom 90. roce jsem očekával, že bude nějakej návrat někam, že i ta armáda se nějak změní a přiblíží tomu, co tady za první republiky fungovalo. Myslím si, že to je takovej ideál, že v těch 30. letech lidi tady byli s armádou ztotožněný. (...) Ale tomu ideálu se to asi po tom roce 1989 nepřiblížilo, protože ta armáda neměla kde brát.
} 


\section{Závěrem o postupné generační deideologizaci povinné vojenské}

\section{služby}

Osobní vztah kideologii nebo politickým preferencím nebyl v rozhovorech pamětníky zpravidla zmiňován, což může být do značné míry způsobeno tematicky úzce vymezeným výzkumem zaměřeným na konkrétní fenomén, jehož součástí nebyla ambice získat ucelené biografie narátorů, včetně jejich politické orientace. Nelze tedy posoudit či komparovat př́mý vliv ZVS na utváření jejich tehdejšího či současného světonázoru. V rámci zkoumaného období je však možné $z$ dílčích zmínek vysledovat ve vzpomínkách trend postupné deideologizace povinné vojny na všech úrovních, což lze ilustrovat na již zmiňovaném neúspěšně budovaném patriotismu, který lze považovat (na rozdíl od převážně politického působení v masových armádách totalitních států) za žádoucí výsledek indoktrinace v rámci národních armád. Zdá se, že tím skutečným motivem, který by přiměl pamětníky k boji, tedy není ochrana státní suverenity (,rodná vlast“), státních zájmů, společenských hodnot, ba dokonce ani spoluobčanů, ale - vedle již zmiňované mikrosolidarity v rámci jednotky především prostý fakt, že na území ohroženého státu se nachází jejich rodina, příbuzní, přátelé nebo majetek (komunitní rozměr a osobní zájmy zde nahrazují vyšší ideologické či metafyzické cíle).

U pamětníků, kteří absolvovali ZVS na konci 60. let (s výjimkou př́ímé zkušenosti s okupací v srpnu 1968) otevřené zmínky o vlastenectví prakticky nenajdeme a podobně je tomu i v případě reflexe 70. let. Příčinu tohoto stavu lze spatřovat jednak v radikální ideologizaci na úrovni oficiálního diskurzu v důsledku normalizace, jejíž dopad na každodenní praxi měl u většiny obyvatelstva za následek postupnou ztrátu důvěry v komunistické ideály (na rozdíl od milieu 50. let), která vyvrcholila na začátku 80. let, ale také v negativních důsledcích „dočasného“ rozmístění sovětských vojsk na československém území po roce $1968 .{ }^{48} \mathrm{Na}$ druhou stranu v mnoha narativech absolventů povinné vojny ze 70 . let je vlastenecký étos přítomen skrytě v podobě jakéhosi nepsaného a nezpochybnitelného

Myslím si, že všecko je v lidech, a že ten pozůstatek bolševický vojny si bohužel v sobě pořád nese i ta současná armáda. Je to dědictví, kterého se ani po těch třiceti letech úplně nemůžeme zbavit."Viz Rozhovor s J. P. vedl Jiří Hlaváček, 25. 6. 2019. ÚSD COH, Rozhovory.

${ }^{48}$ KABÁT, Jindřich. Psychologie komunismu, s. 171. 
předpokladu, jehož součástí je nedůvěra k profesionální armádě, což lze částečně připsat $\mathrm{i}$ důsledku širší socializace a ideologického působení v období před nástupem k výkonu ZVS. ${ }^{49}$

Následující dekáda se již nesla ve znamení totální deziluze a nihilismu v důsledku mezinárodního vývoje, ale i politické a ekonomické stagnace, pro niž byla typická ztráta jakékoliv víry $\mathrm{v}$ principy a cíle socialistické občanské společnosti. V individuálních narativech bychom proto konkrétní zmínky o přímých (výchovných) metodách, jejichž prostřednictvím by armáda reálně (nikoliv pouze oficiálně) a úspěšně podněcovala či posilovala vlastenectví a pozitivní vztah ke státnímu zřízení u vojáků základní služby hledali jen marně. Naopak, aktivně uplatňované nástroje, např. PŠM, měly opačný efekt a u pamětníků vedly spíše k prohlubování jejich individuálního odporu či apatie vůči komunistické ideologii. ČSLA proto bývá v rozhovorech obecně kritizována za svou př́ilišnou ideologičnost a politizaci, což se projevovalo např. v podobě povinně organizované volební účasti příslušníků vojenských útvarů po celé normalizační období. ${ }^{50}$

Většina „pozitivně“ míněné indoktrinace, připustíme-li možný reálný dopad ZVS v tomto ohledu, by tak musela probíhat kolektivně neprrímo a spíše podprahově, např. v podobě každodenního vztyčování státní vlajky při nástupu, účasti na slavnostních přehlídkách či oslavách, pocitu hrdosti na historické tradice československé armády apod. Podobné vzpomínky se však v rozhovorech prakticky nevyskytují a nenajdeme je ani v rozsáhlé memoárové literatuře věnované (zpravidla humorně laděným) vzpomínkám na vojnu před rokem 1989. Potenciál pro rehabilitaci vlasteneckých myšlenek a ideálů v armádním prostředí podle pamětníků představovala 90. léta. K naplnění těchto ambicí nicméně vlivem nízké adaptability důstojnického sboru a přetrvávajících „,socialistických pořádků“ nedošlo a postupné směřování k profesionalizaci armády na konci milénia pohřbilo i veškerá pamětnická očekávání v tomto ohledu. Indoktrinační funkce ZVS v rozhovorech téměř nefiguruje a „domnělé“ vlastenectví lze připisovat spíše vlivu předcházející socializace před nástupem na vojnu, případně jej můžeme chápat jako výsledek skupinového semknutí a vzdoru vůči nucené disciplinaci ze strany nadřízených (at' už v rovině oficiálního, či neoficiálního disciplinačního řádu).

\footnotetext{
49 „Každej chlap od určitého do určitého věku je ve státě pro to, aby ho bránil. At' už to bylo dřív s kopím či mečem v ruce, nebo dneska se samopalem, ale jako nechat se bránit dneska víceméně hrstkou - promiň, ale bůhví jak vychovanejch - profesionálů?“ Viz Rozhovor s J. HU vedl Petr Wohlmuth, 15. 7. 2019. ÚSD COH, Rozhovory.

${ }^{50}$ Rozhovor s P. T. vedl Jiř́ Hlaváček, 16. 5. 2019. ÚSD COH, Rozhovory.
} 


\section{Seznam použitých zdrojů}

ABRAMS, Lynn. Oral History Theory. New York, Routledge 2010. DOI: 10.4324/9780203849033

BARNDOLLAR, Gil. The Best or Worst of Both Worlds? Russia's Mixed Military Manpower System. In: CONLEY, Heather et al. The Diversity of Russia's Military Power: Five perspectives (Research Report). Washington D. C., Center for Strategic and International Studies 2020, s. 17-22.

CVRČEK, Jaromír. Vzájemné vztahy společnosti a armády (teoreticko-empirická studie). Praha, Správa sociálního řízení FMO 1992.

DOORN, Jacques van. The Soldier and Social Change. London, Sage 1975.

Duchovní služba v AČR. In: Ministerstvo obrany ČR. [online] [2021-10-10]. https://www.mocrarmy.cz/informacni-servis/zpravodajstvi/duchovni-sluzba-v-acr64633.

ECHTERNKAMP, Jörg; MACK, Hans-Hubertus (eds.): Dějiny bez hranic? Evropské dimenze vojenských dějin od 19. století po dnešek. Praha, Academia 2019.

HENDRYCH, Jiří. Voják v míru. Praha, Ministerstvo obrany ČR - AVIS 1998.

HLAVÁČEK, Jiř́i. Vojna stejná, a přece jiná. Narativní (re)konstrukce základní vojenské služby po roce 1968 v multigenerační perspektivě. In: Národopisný věstník, č. 2 (2020), s. 5-26.

HLAVÁČEK, Jiří. Vzestup a pád ČSLA? Vojenská profese v kolektivní paměti důstojnického sboru (1960-1970). Praha, Karolinum 2019.

HOLMES, Richard. Obrazy války. Chování člověka v bitvě. Praha, Nakladatelství Lidové noviny 2011.

JURČAK, Alexej. Bylo to na věčné časy, dokud to neskončilo. Praha, Karolinum 2018.

KABÁT, Jindřich. Psychologie komunismu. Praha, Práh 2011.

KAŠKA, Václav. Neukáznění a neangažovaní. Disciplinace členů Komunistické strany Československa v letech 1948-1952. Praha, Conditio humana - Ústav pro studium totalitních režimů 2014.

KILIAS, Jaroslaw. Válka, armáda, stát a národ. Byrokracie, disciplína a nacionalismus. In: Historická sociologie, č. 1 (2009), s. 45-64. DOI: 10.14712/23363525.2017.52

KOLDINSKÁ, Marie; ŠEDIVÝ, Ivan. Válka a armáda v českých dějinách. Sociohistorické črty. Praha, Nakladatelství Lidové noviny 2008.

KŘÍŽ, Zdeněk. Civilní řízení a demokratická kontrola armády v České republice. Peripetie transformace vojensko-civilních vztahů po roce 1989. Brno, Masarykova univerzita $\mathrm{v}$ Brně 2004.

LAŠTAVKOVÁ, Jitka; BRNULA, Peter. Sociální práce v armádě - možnosti a výzvy v českém prostoru. In: Vojenské rozhledy č. 1 (2017), s. 40-51. DOI: 10.3849/23362995.26.2017.01.040-051

LONGHURST, Kerry. Bezpečnostní kultura a branná povinnost v Německu. In: Mezinárodní vztahy, č. 3 (1998), s. 29-36.

MAJER, Petr. Vojna do kapsy. Praha, Ministerstvo obrany ČR - AVIS 1999.

NEČASOVÁ, Denisa. Nový socialistický člověk. Československo 1948-1956. Brno, Host 2018.

NĚMEČEK, Zděnek (ed.). Základná vojenská příručka. Praha, Naše vojsko, 1986.

Rozhovor s J. HU vedl Petr Wohlmuth, 15. 7. 2019. ÚSD COH, Rozhovory.

Rozhovor s J. P. vedl Jiř́ Hlaváček, 25. 6. 2019. ÚSD COH, Rozhovory.

Rozhovor s J. TE. vedl Petr Wohlmuth, 20. 6. 2020. ÚSD COH, Rozhovory. 
Rozhovor s J. TER. vedl Petr Drož, 7. 8. 2019. ÚSD COH, Rozhovory. Rozhovor s M. A. vedl Petr Wohlmuth, 14. 7. 2019. ÚSD COH, Rozhovory. Rozhovor s M. V. vedl Jiř́i Hlaváček, 5. 4. 2019. ÚSD COH, Rozhovory. Rozhovor s P. G. vedl Jiř́i Hlaváček, 9. 7. 2019. ÚSD COH, Rozhovory. Rozhovor s V. V. vedl Jiř́i Hlaváček, 20. 8. 2019. ÚSD COH, Rozhovory. Rozhovor se Z. Z. vedl Jiří Hlaváček, 17. 4. 2019. ÚSD COH, Rozhovory.

SKALKA, Jaromír. Sebeuvědomování socialistické vojenské pedagogiky. In: Pedagogika, č. 5 (1969), s. 725-749.

Směrnice pro hodnocení branců a vojáků v záloze a pro jejich zařazování k útvarům ozbrojených sil. Vojenský ústřední archiv - Vojenský historický archiv, f. Nařízení náčelníka generálního štábu, č. 04, 31. 3. 1981.

Stanovy Komunistické strany Československa. Praha, Ústřední výbor KSČ, 1966.

STRUHOVSKÝ, Václav. Hlavní činitelé utváření vztahu vojáků k vojenské službě. In: Historie a vojenství, č. 4 (1985), s. 75-92.

SVOBODA, Oldřich a kol.. Stručný slovník vojenství. Praha, Naše vojsko 1984.

Tematika vojensko-občanské přípravy pro povolance. In: Dialog, č. 1 (1993), s. 20-21.

TOMEK, Prokop. Československá armáda v čase sametové revoluce. Proměny ozbrojených sil na přelomu osmdesátých a devadesátých let. Cheb, Svět křídel 2019.

VALEŠ, Jan; VESELÝ, Mirko. Základní řády. Řád vnitřní služby ozbrojených sil ČSSR. Praha, Státní pedagogické nakladatelství 1980.

Zásady tř́idně politického zpevnění velitelského sboru ozbrojených sil ČSSR ze dne 29. 3. 1974, Národní archiv, fond Předsednictvo ÚV KSČ, sv. 112, aj. 114. 


\section{Studentská sekce}




\title{
Starobylá Arménie aneb krásy Kavkazu
}

\author{
Karel Jílek, Kateřina Mlázovská
}

Země (ne)známá pro svou starobylou historii a krvavou minulost. Země nespočtu chrámů a klášterů, jež berou dech. Země, jejíž břehy neomývá moře, a přesto ho v ní najdeme. Země chudoby a pohostinnosti. Země výborného jídla a skvělého vína. Země kontrastů, krás, tajů a dálav. Tahle země byla v červnu 2021 cílem naší cesty.

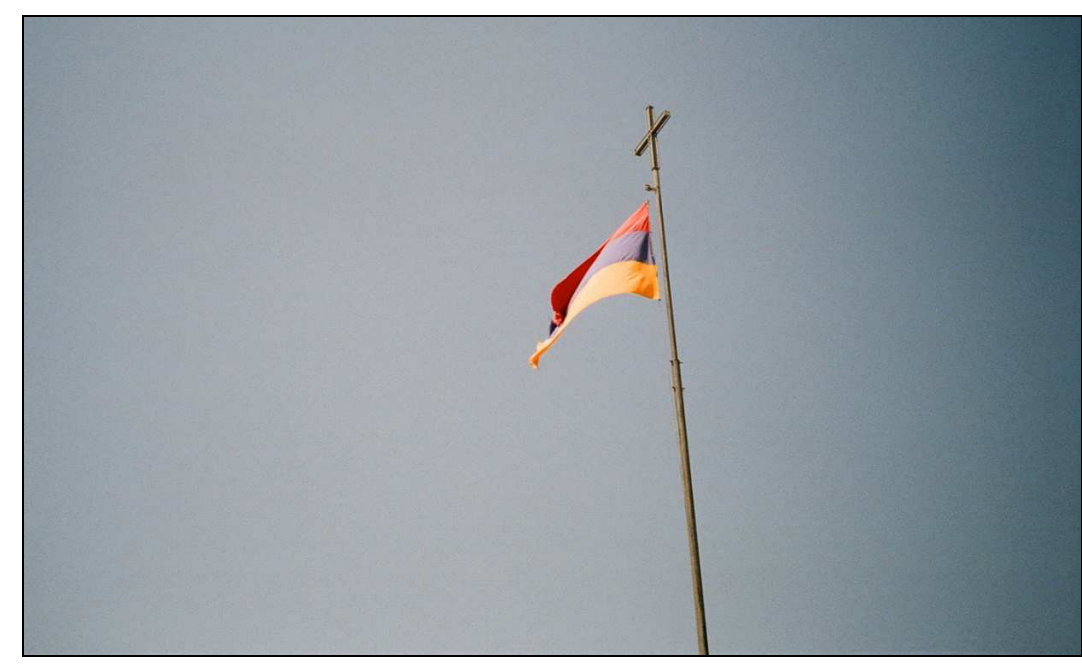

Obrázek 1. Státní vlajka Arménie.

\section{Přípravy}

Když jsme dva měsíce před samotným odjezdem hovořili o možnosti navštívit společně s Arménií také Gruzii a Ázerbájdžán, vypadalo to minimálně na měsíční výlet. My na to měli deset dnů a bylo jasné, že bychom za tu dobu prakticky nic pořádně neviděli. Navíc probíhala pandemie COVID-19, která by nám kvůli testování a karanténním opatřením stěžovala přejezdy, proto jsme se nakonec rozhodli „pouze“ pro Arménii. Nutno dodat, že v této fázi plánování jsme ani pořádně nevěděli, zda vůbec někam pojedeme a co nás tam bude čekat. Většina členů expedice se navíc kvůli distanční výuce trvající skoro rok vůbec neznala. Jako správní dobrodruzi jsme se ovšem nenechali zastrašit černými myšlenkami a skupinově zakoupili letenky. Jak jinak se totiž co nejlépe seznámit s novými lidmi? No přeci..., jet s nimi do Arménie! 


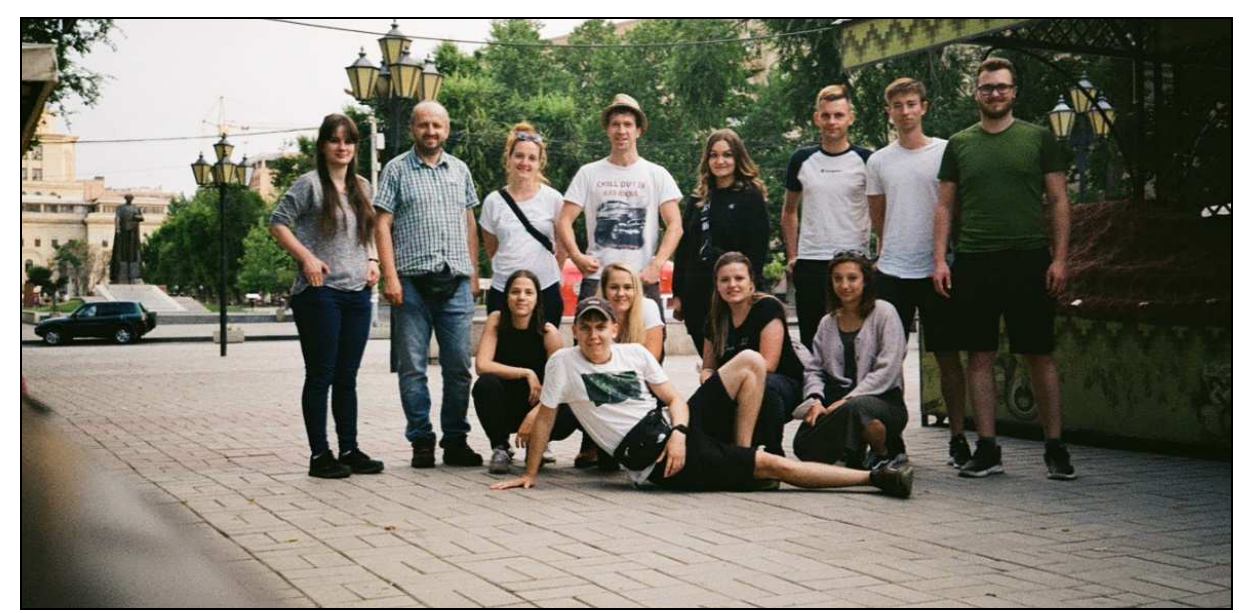

Obrázek 2. Společná fotka při příjezdu do Jerevanu.

\section{První kontakt}

Třrináct statečných ${ }^{1} \mathrm{v}$ čele $\mathrm{s}$ panem docentem Kokaislem se pár měsíců poté, 14. 6. ve večerních hodinách, odlepuje od země a na palubě letadla Embraer ERJ-175 mírí spokojeně do Varšavy, odkud s menší pauzou na přsstup vyráží přímo do Jerevanu. Naštěstí nad námi během celé naší cesty držel svatý Kryštof ochrannou ruku a my jsme tak mohli stanout v cíli. Na letišti jsme si hned prozíravě koupili SIM karty² a než jsme se nadáli, hlasití arménští taxikáři nás za brzkého rána za zvuků ruštino-arménštiny a hlasitého smíchu všechny naládovali do tří aut a vydali se s námi do hloubi arménského hlavního velkoměsta. Jízda, která by byla v ČR minimálně „o papíry“, nám tak dala první cestovatelský zážitek. První zkušenost. To jsme chtěli. Proto jsme tady.

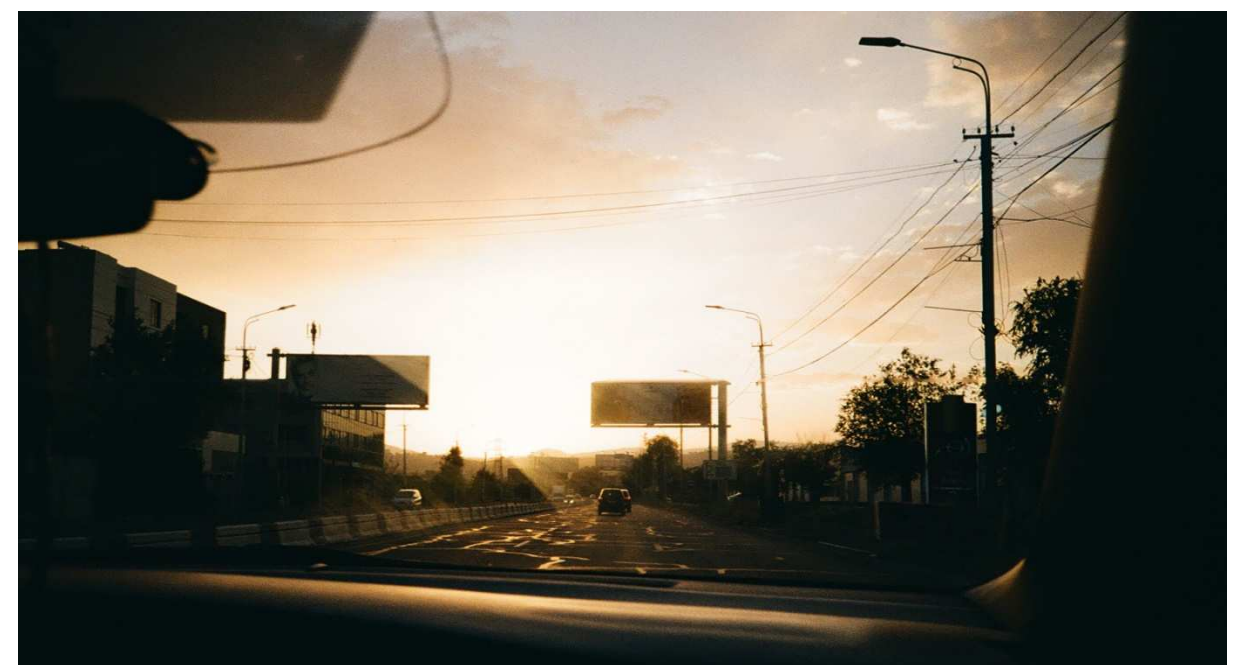

Obrázek 3. První fotka v Arménii. Sedadlo spolujezdce v taxi z letiště.

\footnotetext{
${ }^{1}$ Málem nás odlétlo pouze dvanáct. Jeden z členů expedice totiž cestoval pravděpodobně od letiště místo na letiště. Naštěstí nad nástrahami MHD úspěšně zvítězil a skupina se tak mohla vydat na výpravu.

${ }^{2}$ Pokud člověk cestuje po Arménii, je určitě výhodné si hned na letišti zakoupit SIM kartu. Balíček s 6 GB + 100 minut vyjde jednoho na $6 \$$.
} 


\section{Jerevan - město ve stínu hory}

Jerevan je s milionem obyvatel hlavním městem Arménie. Základy města byly položeny okolo pevnosti Erebuni kolem roku 783 př. n. 1., což činí z Jerevanu dokonce staršího bratra samotného Říma, který vznikl o 30 let později. Město samotné je plné více či méně patrných kontrastů. Je to vidět zejména na architektuře z dob socialismu, která se prolíná s moderní. Každého návštěvníka z centrální Evropy jistě překvapí pítka s vodou na každém rohu, ale také truchlící ženy na hlavních třídách, které žádají o peníze se slovy o svých padlých synech ve válce v Karabachu. ${ }^{3}$

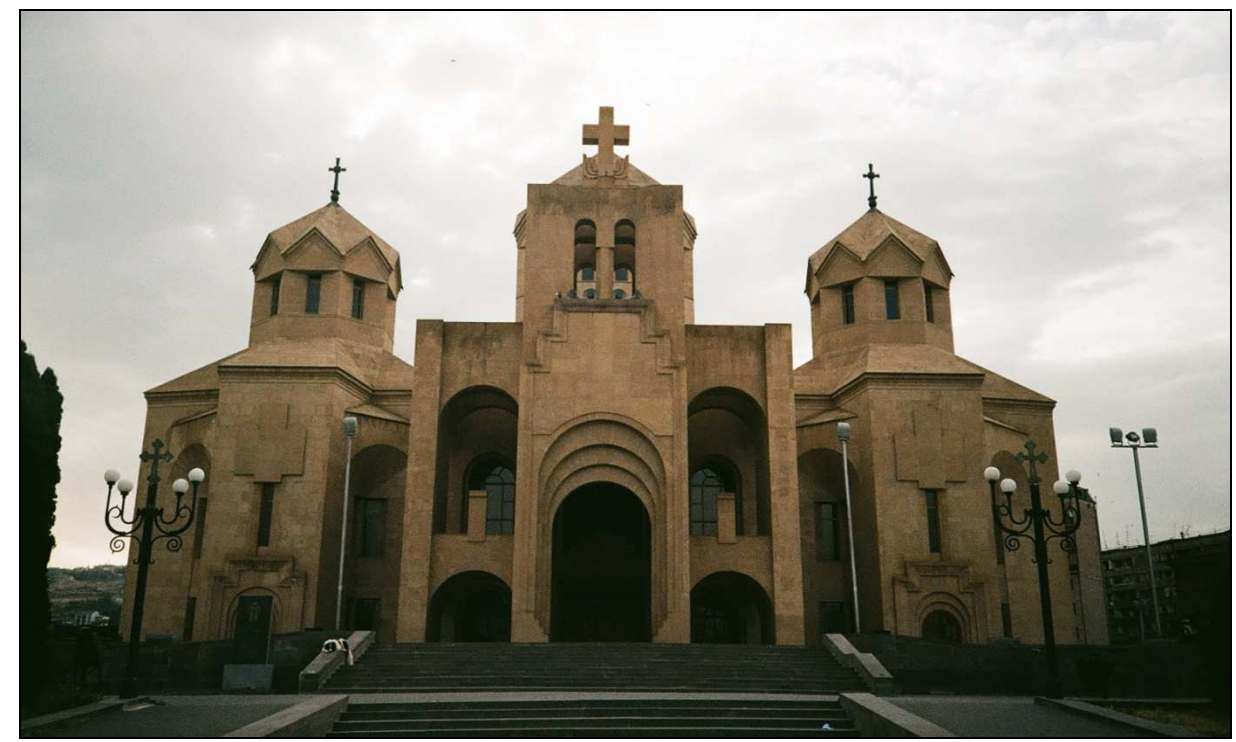

Obrázek 4. Kostel sv. Řehoře Osvětitele.

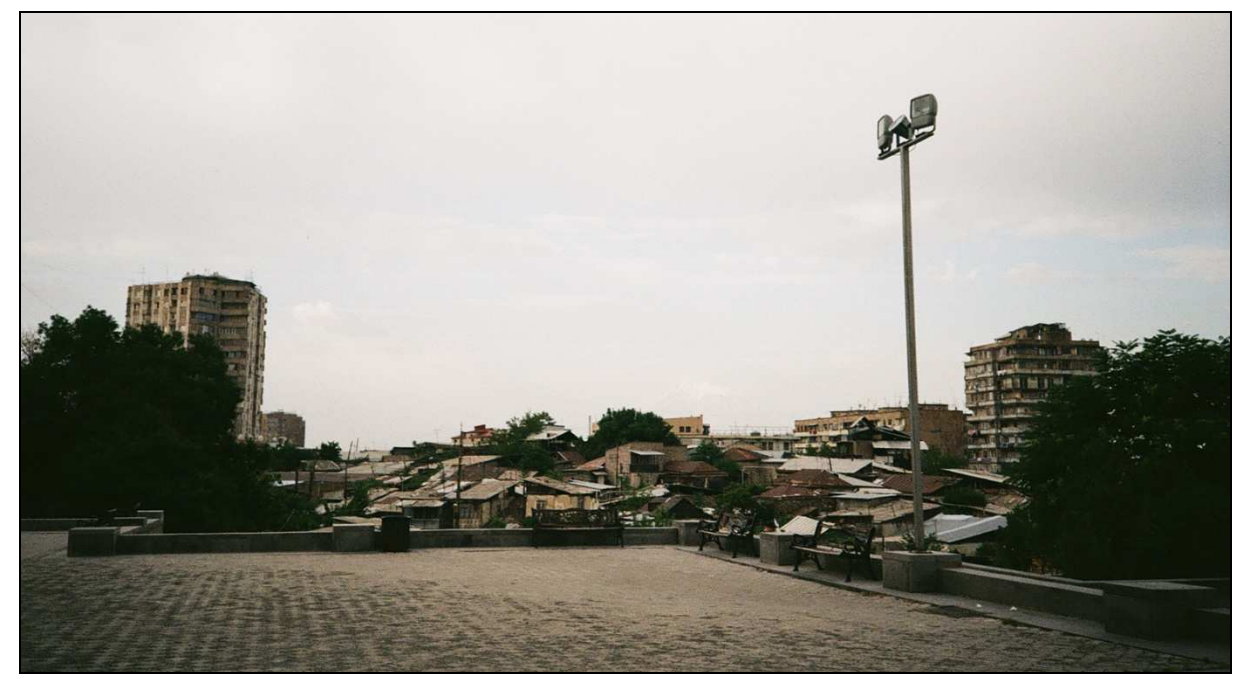

Obrázek 5. Pohled směrem od kostela sv. Řehoře.

\footnotetext{
${ }^{3}$ Spory o Náhorní Karabach se táhnou několik desítek let do minulosti. Po rozpadu SSSR chtěli Azerové připojit území Karabachu obývané především Armény k Ázerbájdžánu. V oblasti Karabachu (v překladu znamená: černá zahrada) žili ale od nepaměti většinou Arméni. V celém sporu figurovaly také sliby sovětských vůdců o územních reformách, které ale nebyly dodrženy. Vypukla tak válka, ve které zahynulo přes 30 tisíc lidí.
} 
Na každodenní život obyvatel Jerevanu dohlíží, společně s monumentální sochou Matky Arménie, z výšky 5000 m n. m. posvátná hora Ararat. Ten jsme měli všichni poprvé možnost spatřit při zběsilé jízdě z letiště. Zasněžený vrcholek zprvu připomínal mrak, ale při delším zkoumání člověk opravdu rozpoznal zasněžený vršek hory. Ararat, na jehož vrcholku prý podle pověsti stanul během ,potopy světa“ Noe se svou archou, je od hlavního města vzdálen něco málo přes $50 \mathrm{~km}$. Tím pádem bychom ho už nehledali v Arménii, ale v Turecku. Tento geografický fakt ovšem nebrání Arménům horu považovat za posvátnou a sobě vlastní. S tím by jistě souhlasil i pán, na kterého jsme narazili v bývalém hlavním městě, Ečmiadzinu. Ten nám vyprávěl, že v mládí na vrcholcích Araratu jezdil na lyžích a že je hora jejich. Arménská. Dotyčný, takový milý starší pán, měl s sebou tašku plnou jídla a po prvním rozhovoru s námi zůstal skoro celý den. Zatímco se dobrovolně pasoval do role průvodce, skupinově jsme usoudili, že jeho rodina bude dnes zřejmě bez večeře.
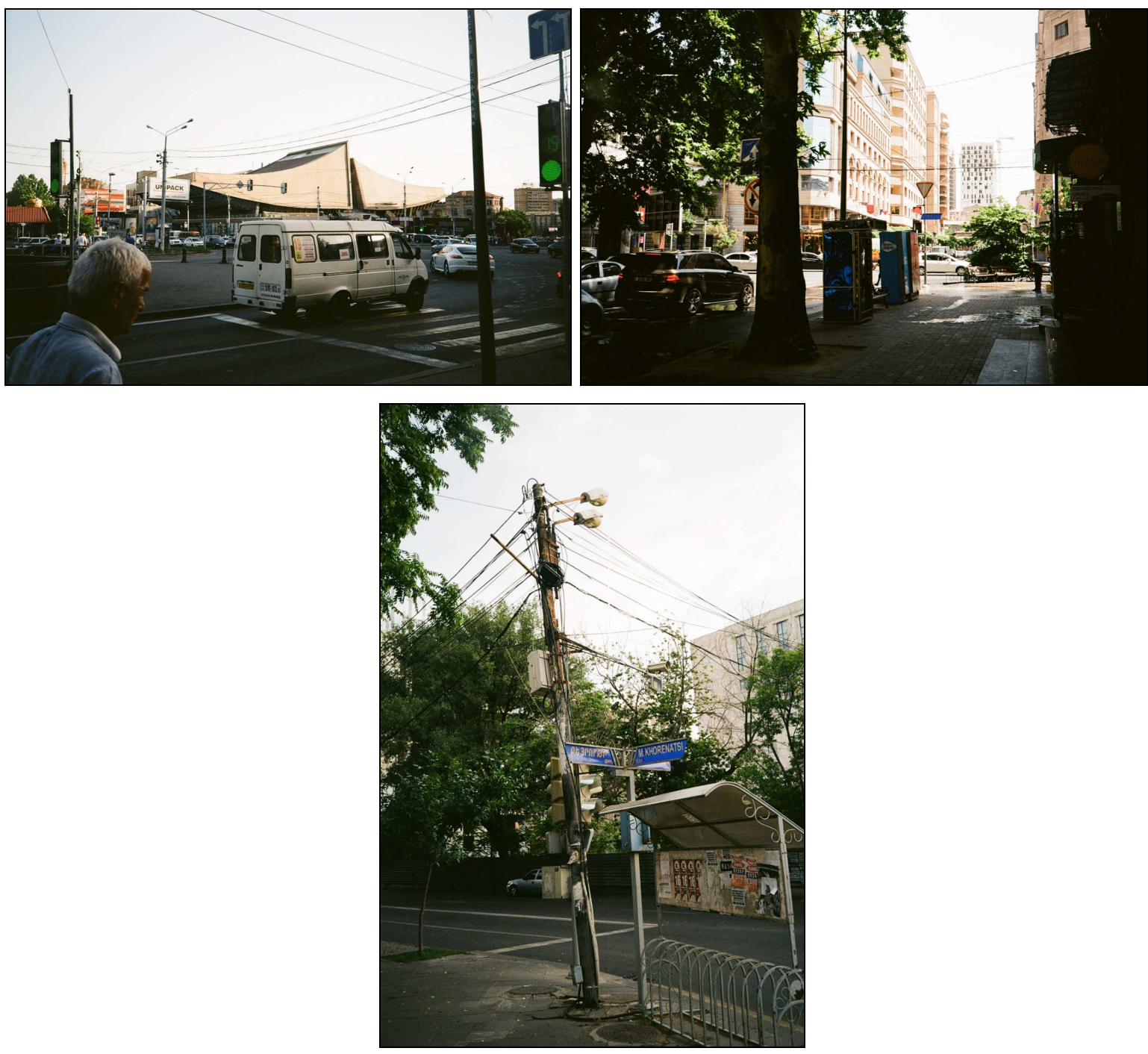

Obrázek 6, 7, 8. Ulice Jerevanu. 


\section{„Jak? Kudy? Kam?““ - Doprava}

Během naší expedice jsme hojně využívali místní dopravu. At’ už se jednalo o linkové autobusy, taxikáře nebo řidiče maršrutek. ${ }^{4}$ Řidiče je možné stopnout prakticky kdekoliv a pro cestovatele tak není problém se dostat, kam zrovna potřebuje. Nám se např́klad podařilo uplatit řidiče linkového autobusu, aby nás vozil podle našeho přání celý den. Zde musím říct, že mám možná lehce zkreslenou představu. Ačkoliv jsem byl po celou dobu výletu stále mile překvapený, že nám pořád každý staví a chce nás svézt, zpětně mi došlo, že řidiči místním asi tak horlivě nestaví. Přikládám to vztahu turista=peníze.

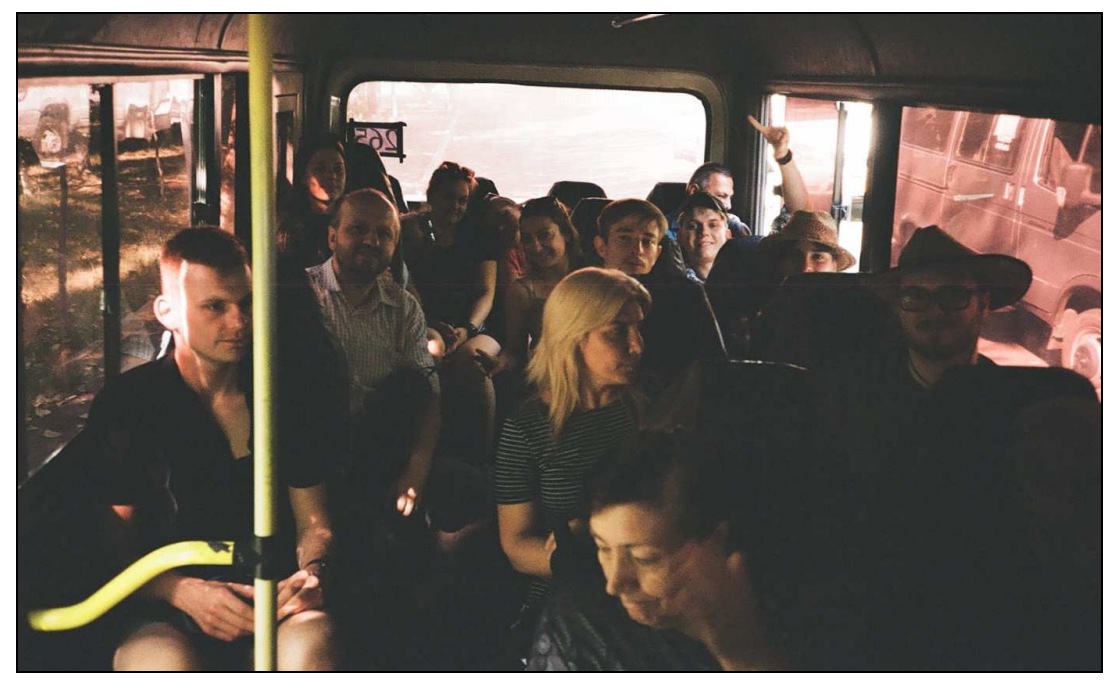

Obrázek 9. Čekání na plné obsazení maršrutky.

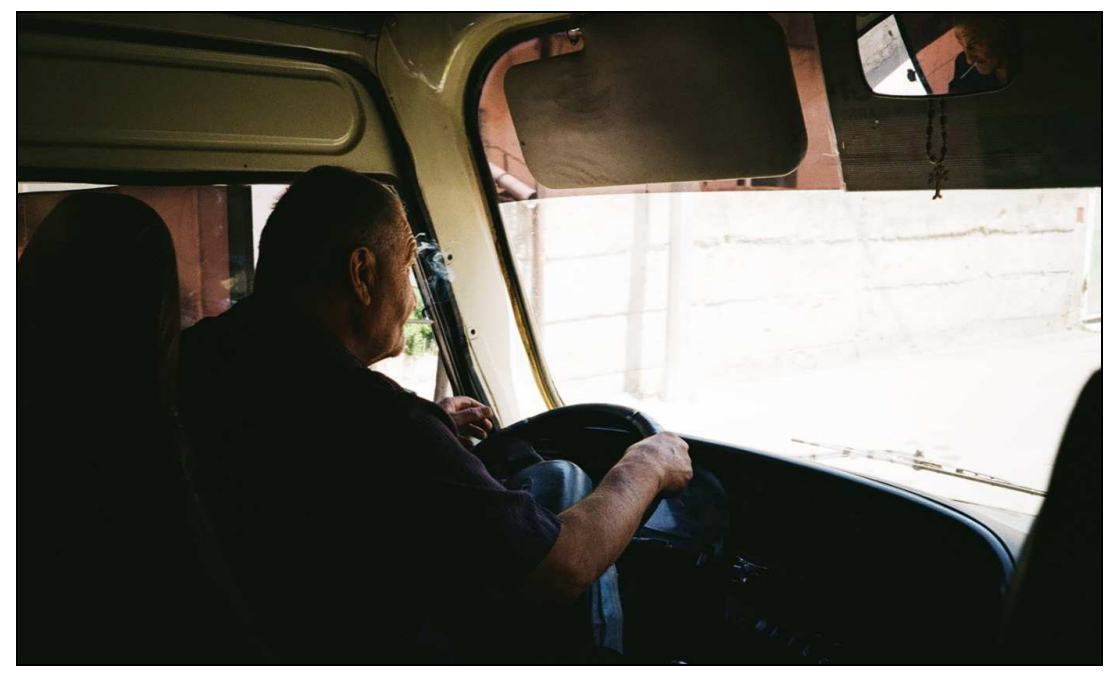

Obrázek 10. Řidič linkového autobusu, kterého jsme uplatili.

\footnotetext{
${ }^{4}$ Maršrutka je takový menší autobus sloužící jako jeden z druhů veřejné dopravy v postsovětských zemích. Tyto maršrutky jezdí, na rozdíl od normálních linkových autobusů, v nepravidelných intervalech a častokrát jen tehdy, než jsou zcela naplněné. Maršrutky nejezdí pouze ve větších městem, ale v celé Arménii.
} 


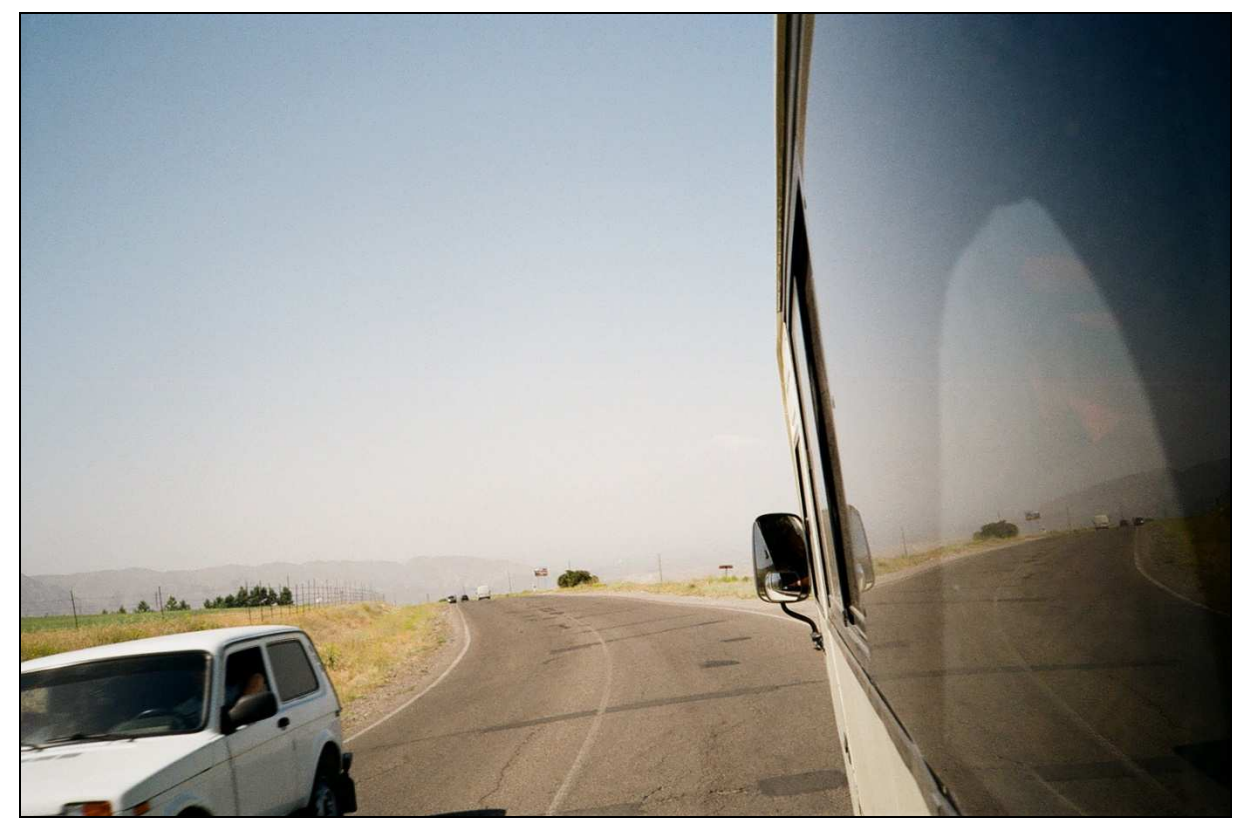

Obrázek 11. Na cestě.

V Jerevanu mají také metro. Sice pouze jednu linku o 10 zastávkách, ale i tak to byl zajímavý zážitek. Metro lehce připomínalo normální vlakové nádraží, akorát pod zemí. Proč? Každá stanice má svého výpravčího. Ten hezky každou vlakovou soupravu odmávne a ta poté na znamení mizí v tunelu.

\section{Ztraceni v překladu}

Jediný, kdo uměl z naší skupiny dobře rusky, byl pan docent Kokaisl. Když se tak vydal společně se třemi odvážnými studenty do horských masivů hledat starobylou etnickonáboženskou komunitu Jezídů, ostatní jsme si kladli otázku: Jak se dostaneme do Jerevanu, který je asi $60 \mathrm{~km}$ daleko? Nervozitu jsme rychle zahnali zmrzlinou z překvapivě umístěného obchodu ve vesnici Aknalich a pohledem na zádumčivý Ararat. Venku bylo přes 38 stupňů ve stínu, na slunci jsme se neodvažovali ani hádat. Pomalu jsme se rozpouštěli společně s našimi zmrzlinami a očekávali blížící se konec. Opak byl pravdou! Ani ne po minutě a půl stopovacího procesu nám zastavil Mercedes-Benz Sprinter... s klimatizací! „Jerevan, prosím, paka, paka... Jerevan...pažalsta...zděs děngi...“ spustili jsme s nadějí. Řidiči se z naší kombinace polštiny, slovenštiny a češtiny zřejmě udělalo nevolno. Chvilku váhal, ale nakonec se nad námi smiloval a vpustil nás do svého lesknoucího se vozu. 


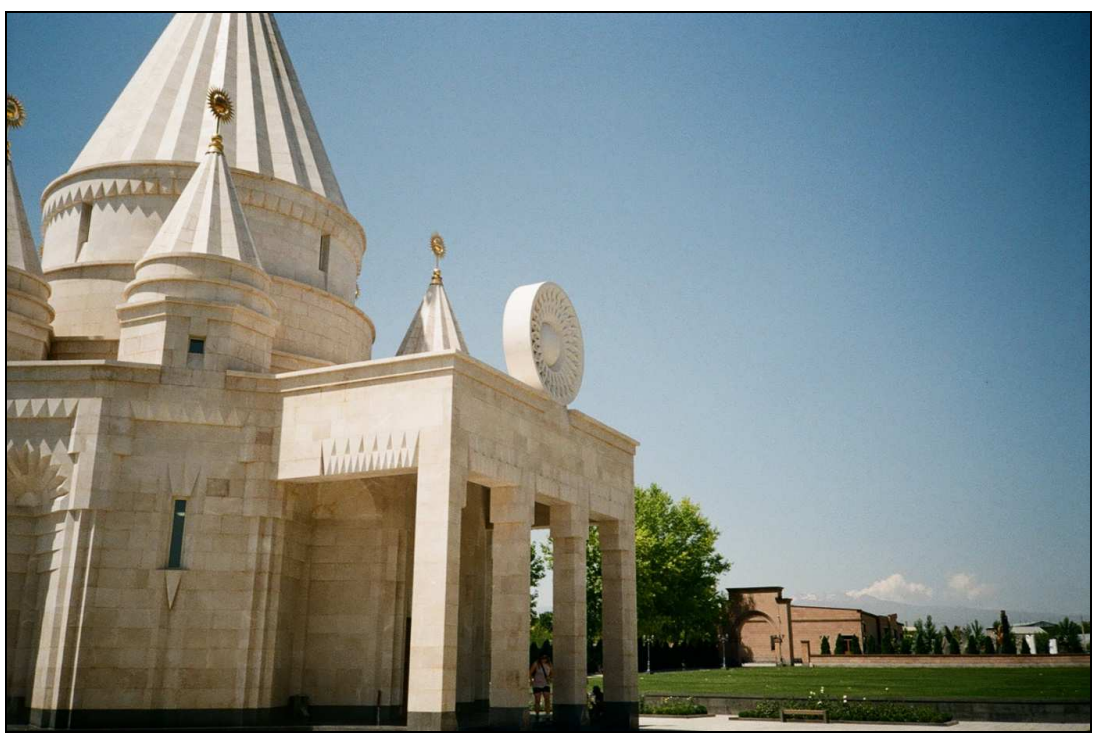

Obrázek 12. Jezídský chrám ve vesnici Aknalič.

Poučení pro budoucí dobrodruhy na cestě do Arménie. Dobré je mít alespoň elementární znalost ruštiny. Případně polštiny. S angličtinou zde moc nepochodíte. Hovoří jí spíše mladí, je občas slyšet v restauracích nebo na recepcích hotelů. Pravdou je, že jsme se dokázali domluvit povětšinou vždy. Pokud došly všechny nápady, tak „rukama a nohama“ se člověk domluví vždy a všude.

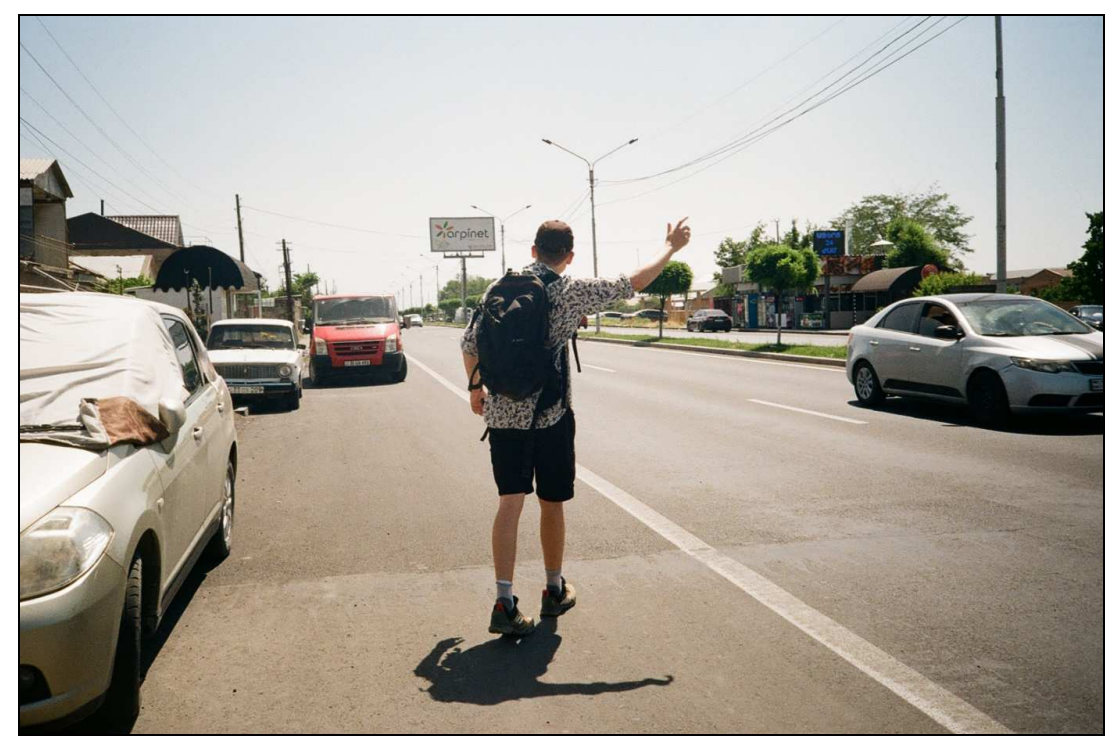

Obrázek 13. Stopujeme!

\section{„Arménské moře“" - Sevan}

Po několika dnech v Jerevanu město za rozbřesku opouštíme a vydáváme se na sever směrem k ledovcovému jezeru Kari, které se nachází ve výšce kolem 3500 m n. m. ${ }^{5}$ Dalším cílem bylo

\footnotetext{
${ }^{5} \mathrm{Z}$ rozpáleného města jsme za necelé 2 hodiny chodili po sněhových plotnách na úbočí kopce nad jezerem. Teplota se přitom změnila o zhruba 20 stupňů.
} 
sestoupit z hor směrem k jezeru Sevan. Jezero je obrovské a my hned pochopili, proč je také někdy označováno jako arménské moře. Centrum zde leží ve stejnojmenném městě, které je pro svůj klášter Sevanavank oblíbeným turistickým střediskem. Turisté zde mají možnost vyhlídkové cesty lodí (kterou jsme si vyzkoušeli na vlastní kủži) nebo adrenalinovou jízdu na vodním skútru (pro tu se odhodlala pouze jedna členka výpravy). Ubytování jsme měli v nedalekém hostelu, jehož majitel byl více než vstřícný, a to i navzdory faktu, že jsme mu nedopatřením vypili všechny zásoby ovocného červeného vína po jeho dědečkovi. Př́ijemný bonus tohoto místa byly dechberoucí výhledy z podivně vzhlížející stavby př́pomínající žraločí ploutev, stojící za hostelem. Ty mě ještě dnes budí ze spaní.

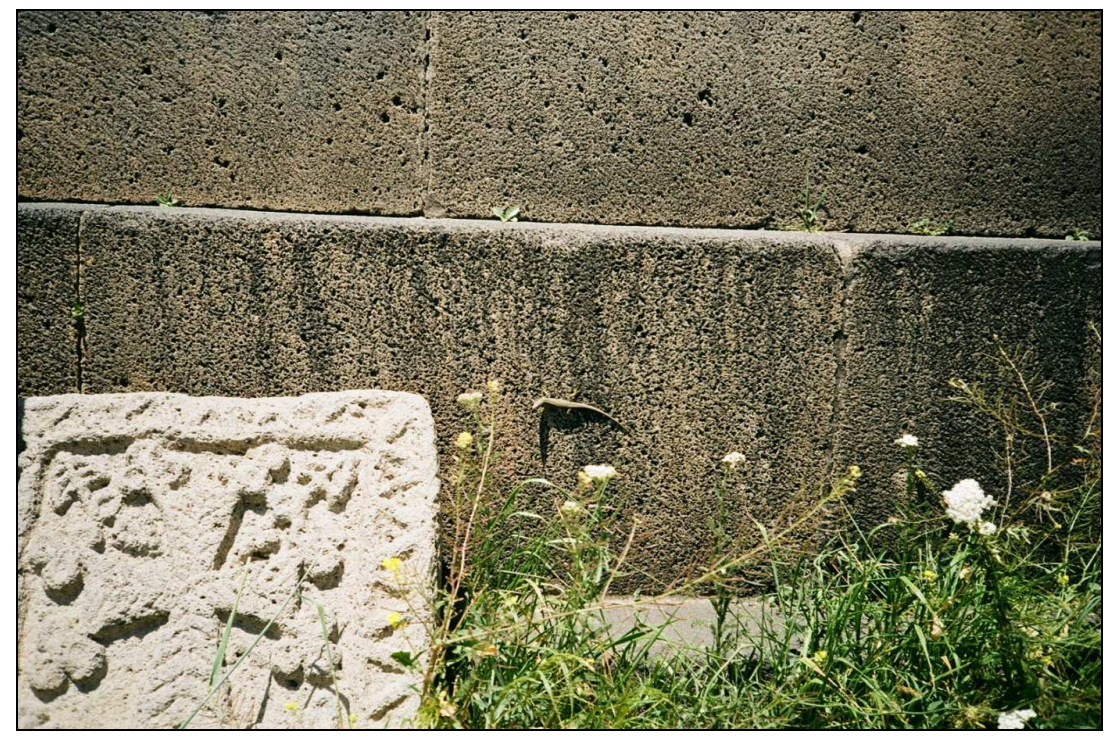

Obrázek 14. Fauna.
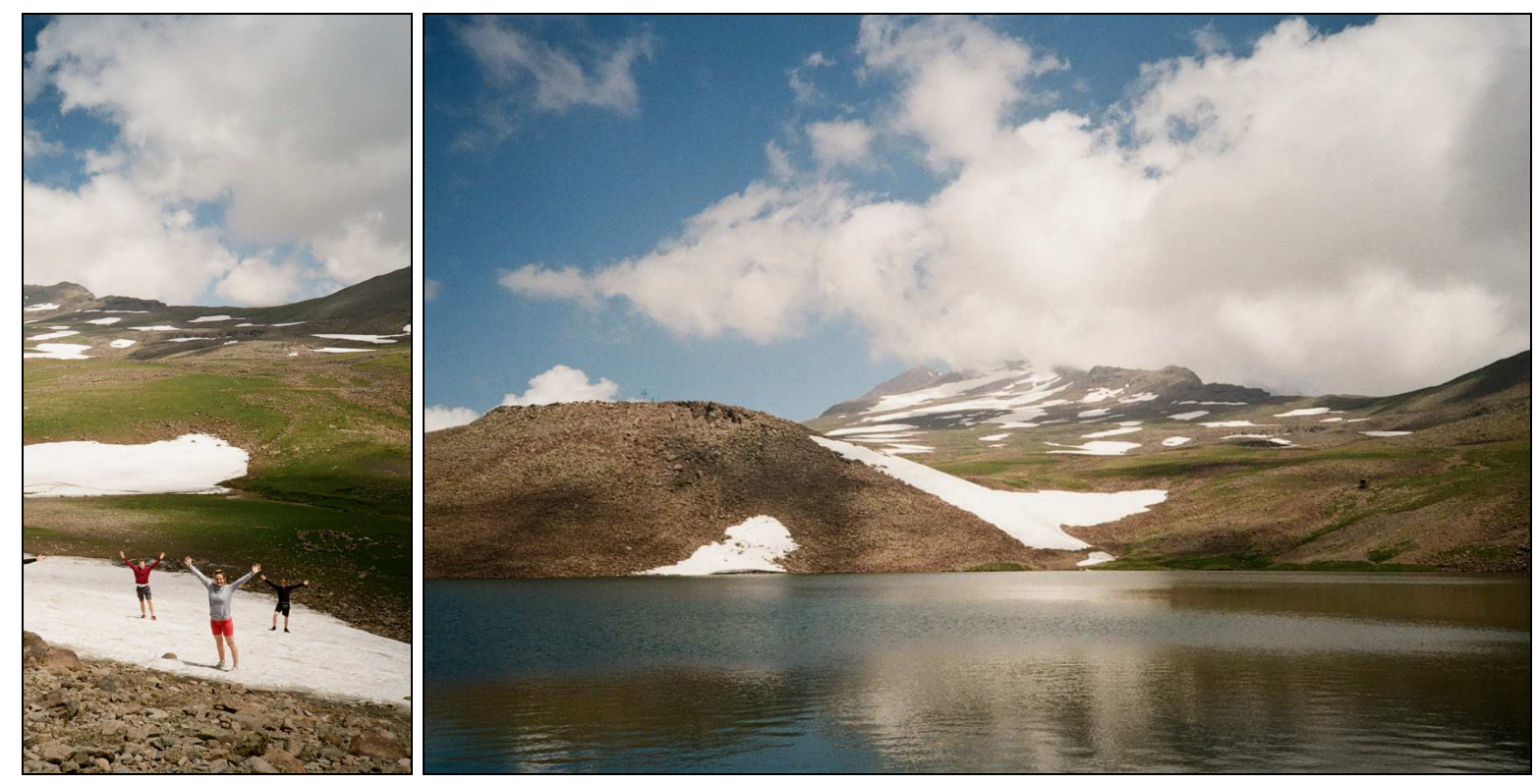

Obrázek 15, 16. Pozdravy s nejvyšší horou Arménie Aragacem v pozadí. Ledovcové jezero Kari. 

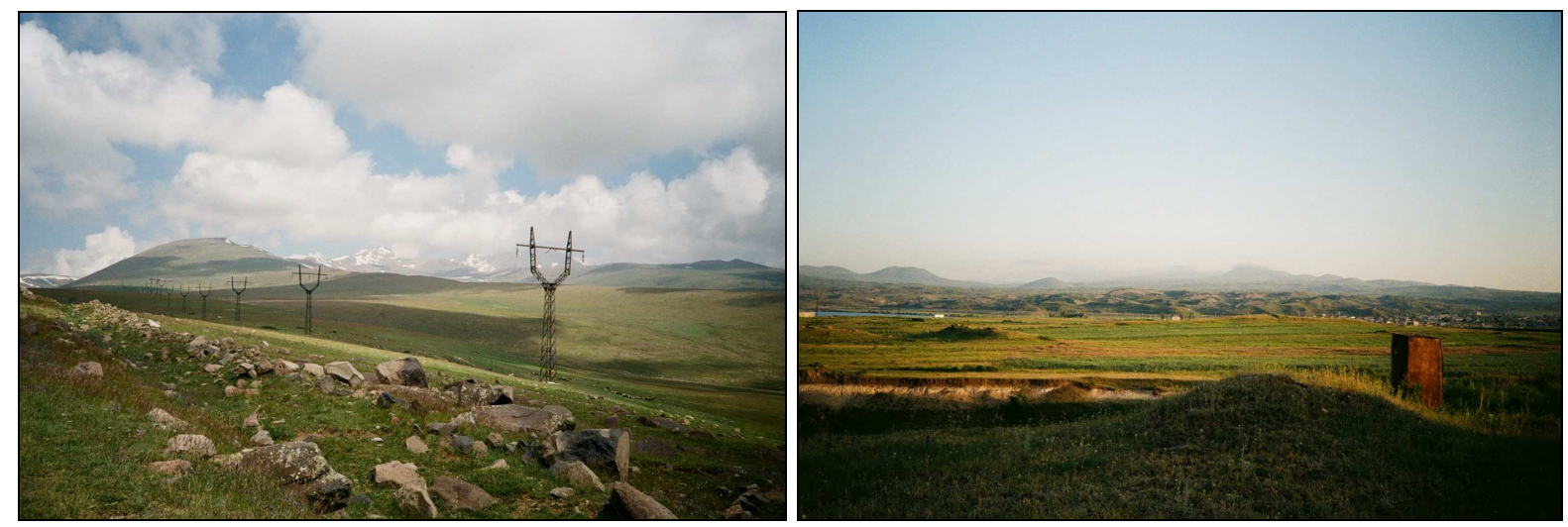

Obrázek 17, 18. Dálava.
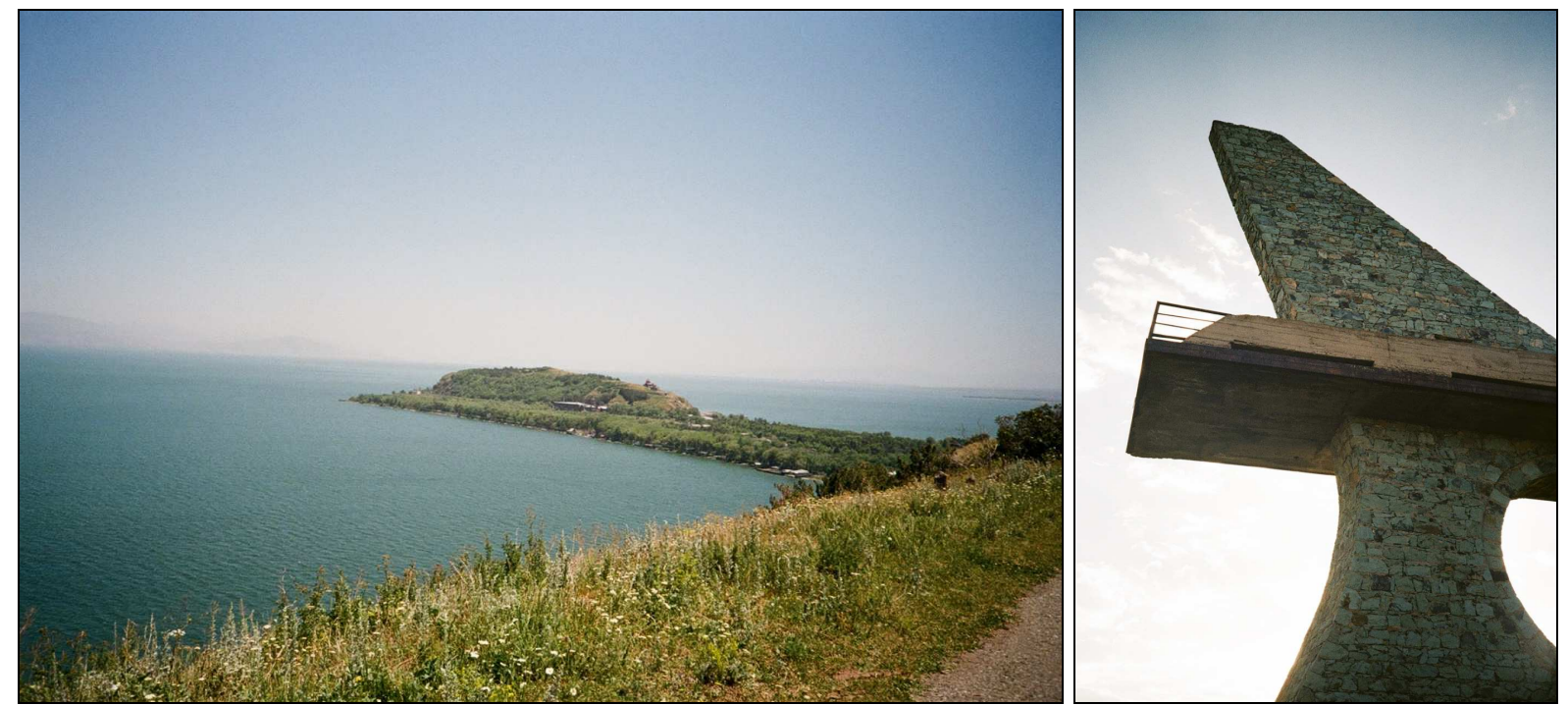

Obrázek 19, 20. Jezero Sevan a stejnojmenný poloostrov. „Žraločí ploutev““.

\section{Němé chrámy}

Arménie je zemí chrámů. Na naší cestě jsme jich navštívili hned několik. At' už se nacházely v horách, u jezera, na rovině nebo ve městě, ... pokaždé z nich výrazným způsobem sálal genius loci. Navštívili jsme jediný antický chrám nejen v Arménii, ale v celém bývalém SSSR - Garni. Na chrám Haghardzin se bylo potřeba posunout několik kilometrů od Sevanu do národního parku Dilidžan, do klášteru Tatev jsme dokonce podnikli cestu nejdelší obousměrnou lanovkou na světě - Wings of Tatev. Měli jsme možnost vidět i starodávný hotel, ve kterém prý spával samotný Čingischán a na závěr jsme se vypravily do kláštera Chor Virap známého $\mathrm{z}$ arménských pohlednic pro úchvatnou scenérii $\mathrm{s}$ výhledem na Ararat v pozadí. 

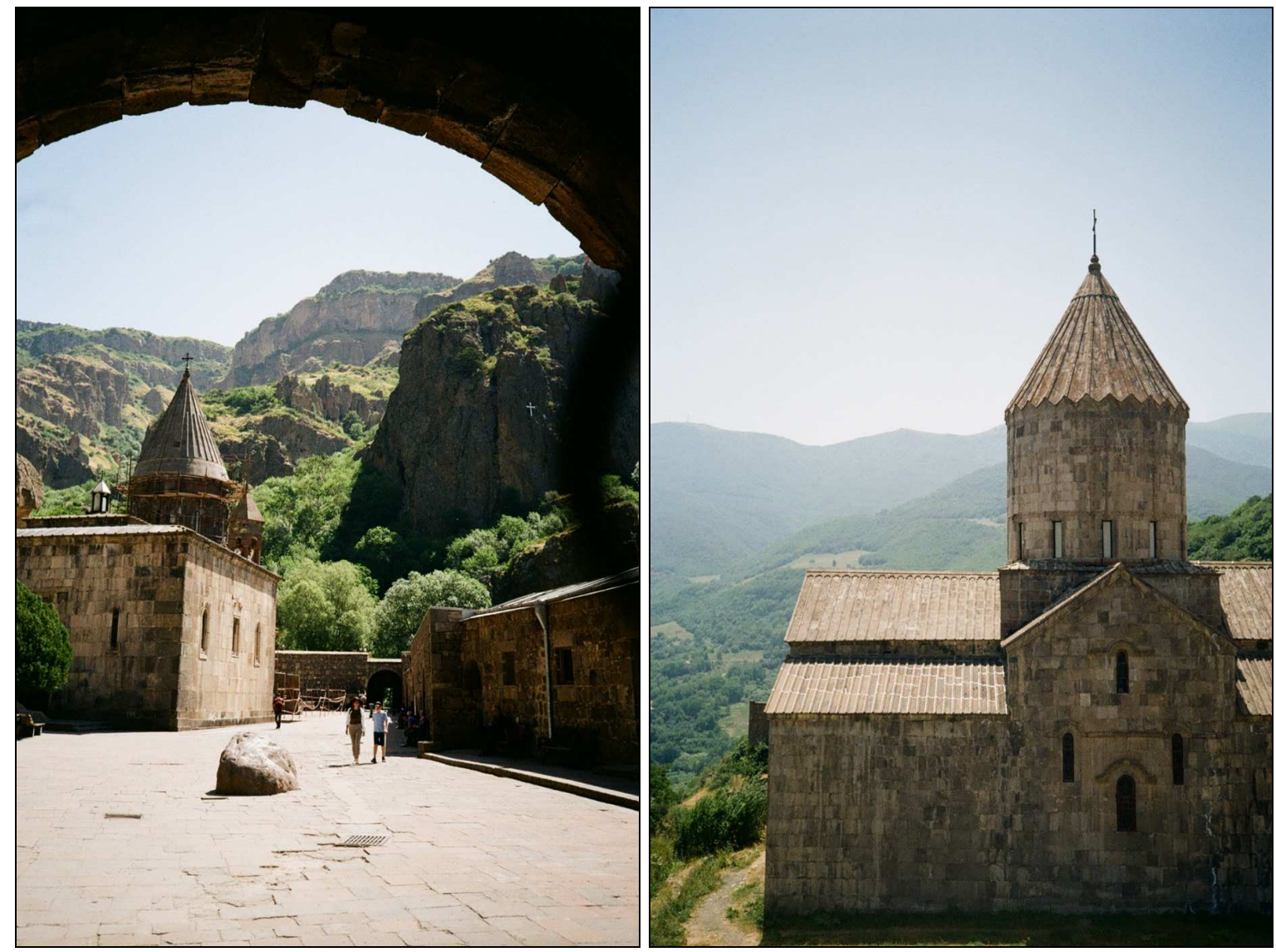

Obrázek 21, 22. Klášter Geghard a Tatevský klášter.

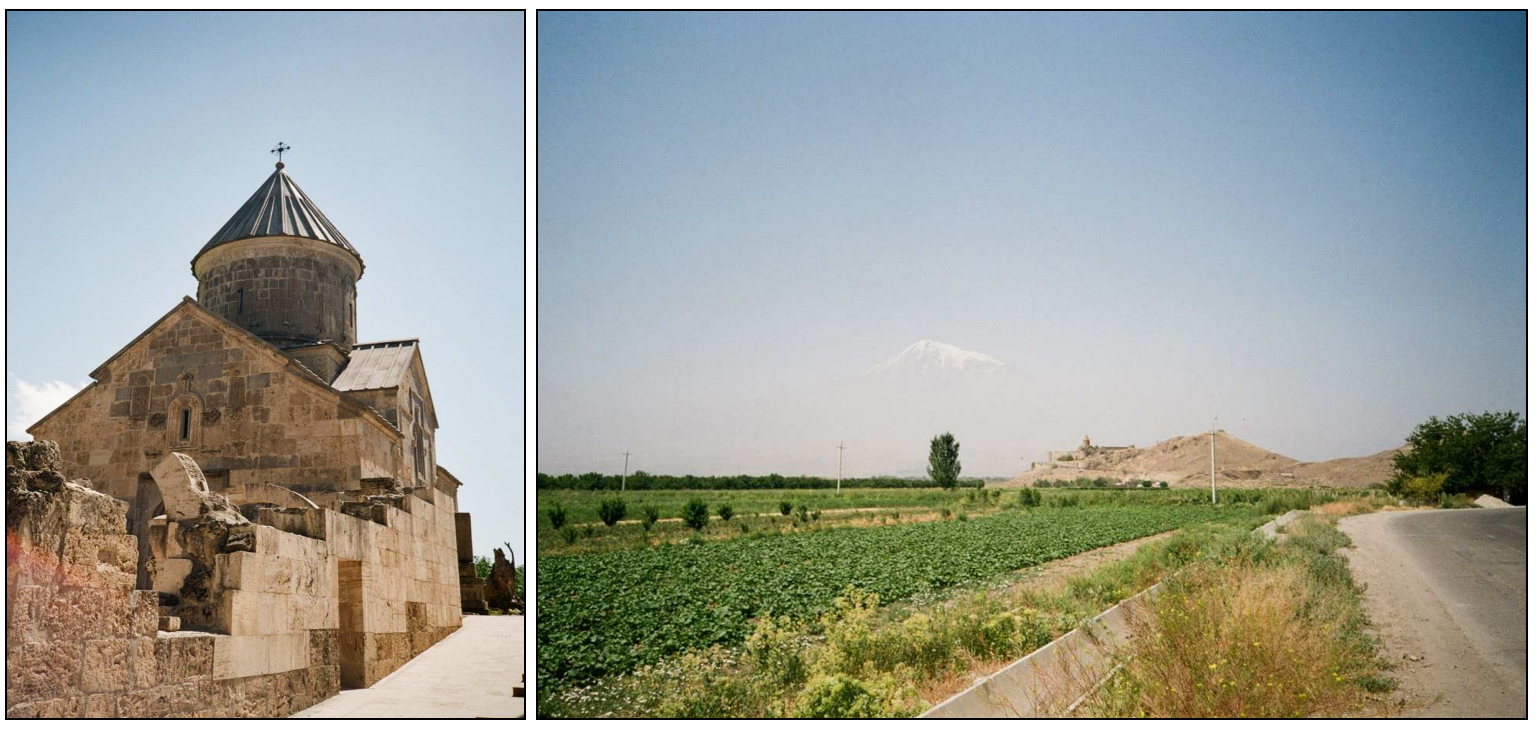

Obrázek 23, 24. Klášter Haghartsin. Klášter Chor Virap (v pozadí Ararat). 


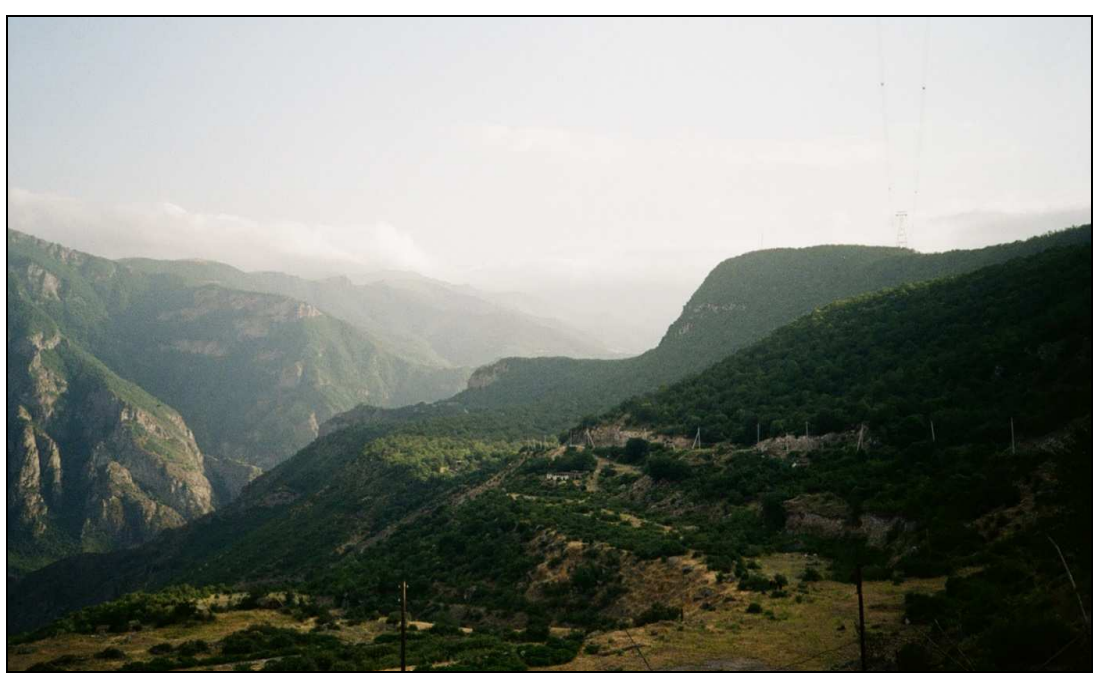

Obrázek 25. Údolí pod lanovkou Wings of Tatev.

Pro důkladnější studium historie všech těchto památek by člověku nestačily snad ani 2 životy. S údivem, pokorou a vděkem jsme si proto mlčky společně užívali sílu míst, která ožívala v našich představách.

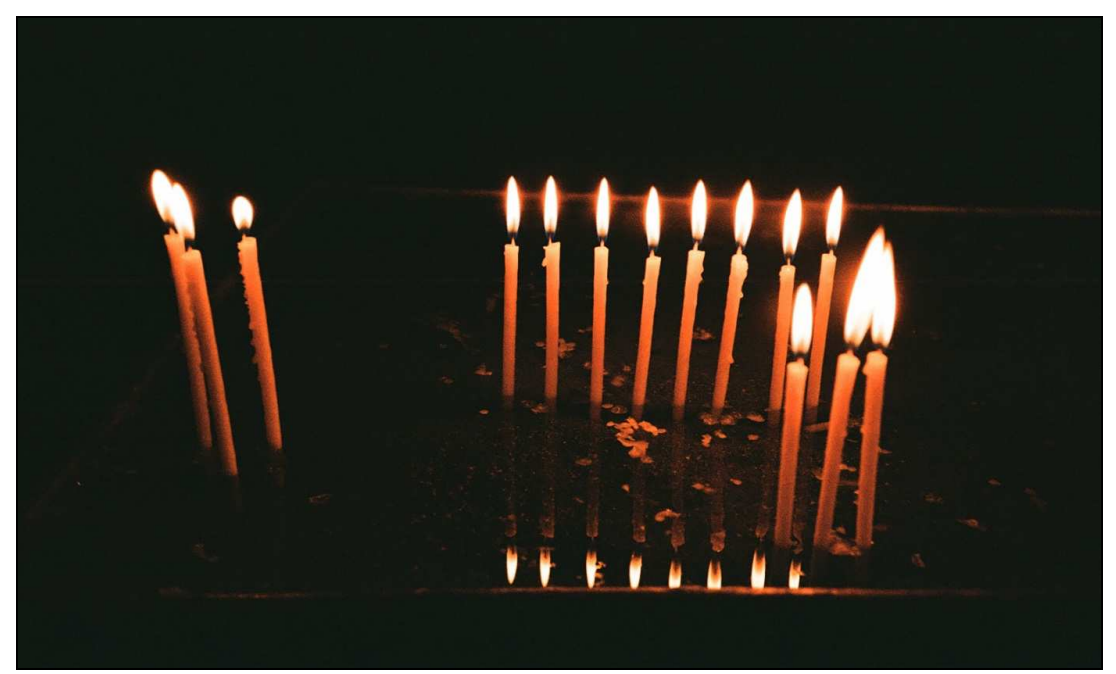

Obrázek 26. Svíce.

\section{Arménská pohostinnost a kuchyně}

O pohostinnosti obyvatel kavkazských zemí jsme před naší výpravou slyšeli hodně. Společně s kuchyní to byly mj. důvody, kvůli kterým jsme se chtěli do Arménie podívat a zjistit, zda tomu tak opravdu je. Při první příležitosti jsme v Jerevanu hned první noc okusili pravou arménskou kuchyni v příznačném podniku Tavern Yerevan. Doporučit můžeme jistě pověstné chačapuri. Tato placka z kynutého těsta plněná sýrem a dalšími ingrediencemi - v závislosti dle regionu - je na území Arménie a Gruzie tak rozššřená, že s pomocí tzv. „chačapuri 
indexu“ měří ekonomové na univerzitě v Tbilisi inflaci v zemi. ${ }^{6}$ Dále bychom mohli určitě doporučit základ arménské kuchyně, kterým je lavaš (nekynutý měkký chléb) nebo arménské národní jídlo, polévku harisu. Výborné mají také červené víno a proslulý koňak s originálním názvem Ararat.
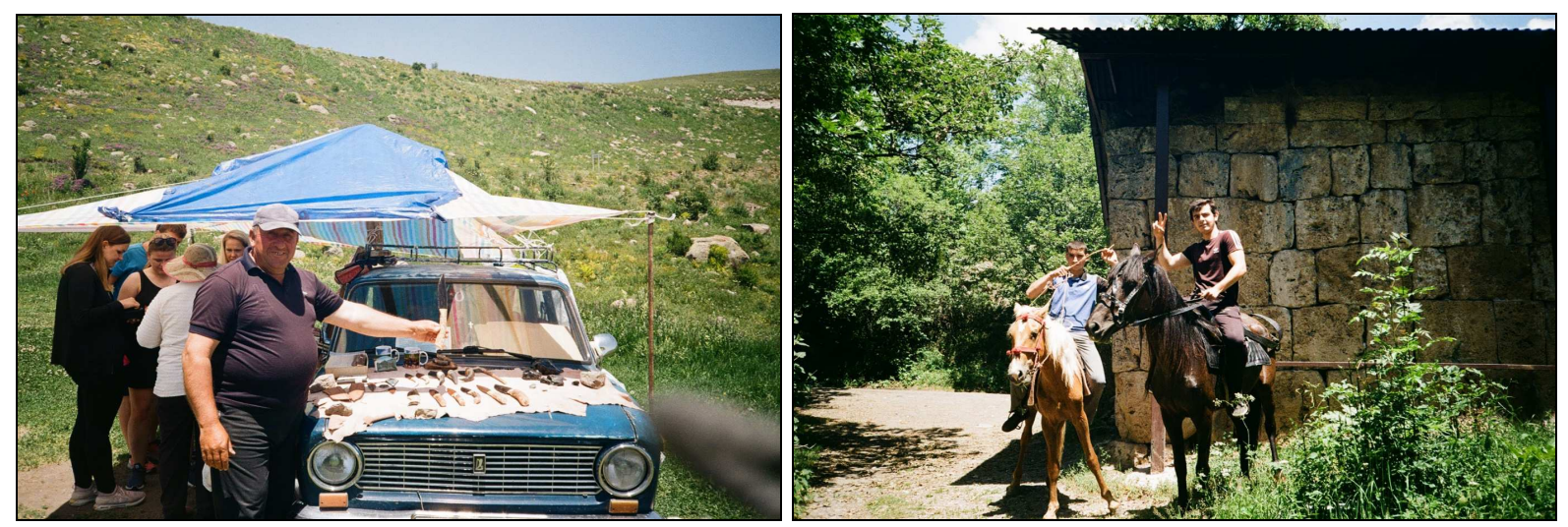

Obrázek 27, 28. Lidé.

Další důkaz pohostinnosti jsme zažili na konci naší cesty. Poslední den našeho pobytu v Jerevanu jsme si zamluvili skromný hotel, který vedl mladík jménem Tigran. Problém byl v tom, že podle pravidel bychom museli hotel opustit druhý den ještě před obědem. To by ovšem znamenalo pobyt uprostřed rozžhaveného Jerevanu celý den až do půlnoci se všemi věcmi na zádech. Letadlo zpět do Varšavy nám totiž letělo až v ranních hodinách. Po snídani jsem se dal s Tigranem do řeči, a nakonec z toho byl několikahodinový př́ijemný hovor. Dokonce nás u sebe nechal celý den (zadarmo) až do večera, kdy nám zavolal transport př́ímo na letiště. Tigran byl velmi milý mladík, který Prahu v minulosti navštívil a jednoho dne by se sem chtěl se svojí budoucí ženou vrátit. Vyměnili jsme si kontakty, a přitom žasli nad jednoduchostí mezinárodního (multikulturního chcete-li) spojení, které není limitováno kilometry, kulturou, náboženstvím nebo nepřízní počasí. Tigran nám moc pomohl a na dálku mu tímto chci ještě jednou poděkovat.

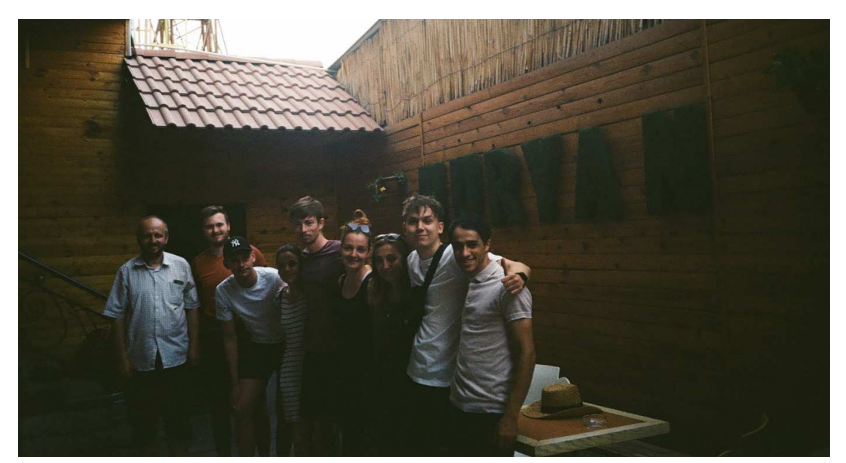

Obrázek 29. Fotka s majitelem hotelu, Tigranem.

\footnotetext{
${ }^{6}$ ZIBURA, Ladislav. Už nikdy pěšky po Arménii a Gruzii. 2. vydání. Brno: BizBooks, 2020, s. 67.
} 


\section{Něco končí, něco začíná}

Myslím, že můžu mluvit za všechny, když řeknu, že jsme si výlet všichni moc užili. Chtěli bychom moc poděkovat panu docentu Kokaislovi za to, že s námi byl ochotný výlet absolvovat. Byla to pro nás neopakovatelná zkušenost. Krok do neznáma a zároveň správným směrem. Poznali jsme tamní zem tak, jak jen to za 10 dnů jde, a přtom jsme se všichni dokázali vrátit zpátky domů. $\mathrm{V}$ jednom kuse. Vrátit se totiž není ostuda, ostuda je se nevrátit. I když jsme možná ze začátku měli obavy z naší cesty a moc jsme nevěděli co čekat, myslím, že všechny tyto pocity jsou přirozené, normální. Ve finále se nebylo vůbec čeho bát. Dobrý člověk totiž všude bratra má.

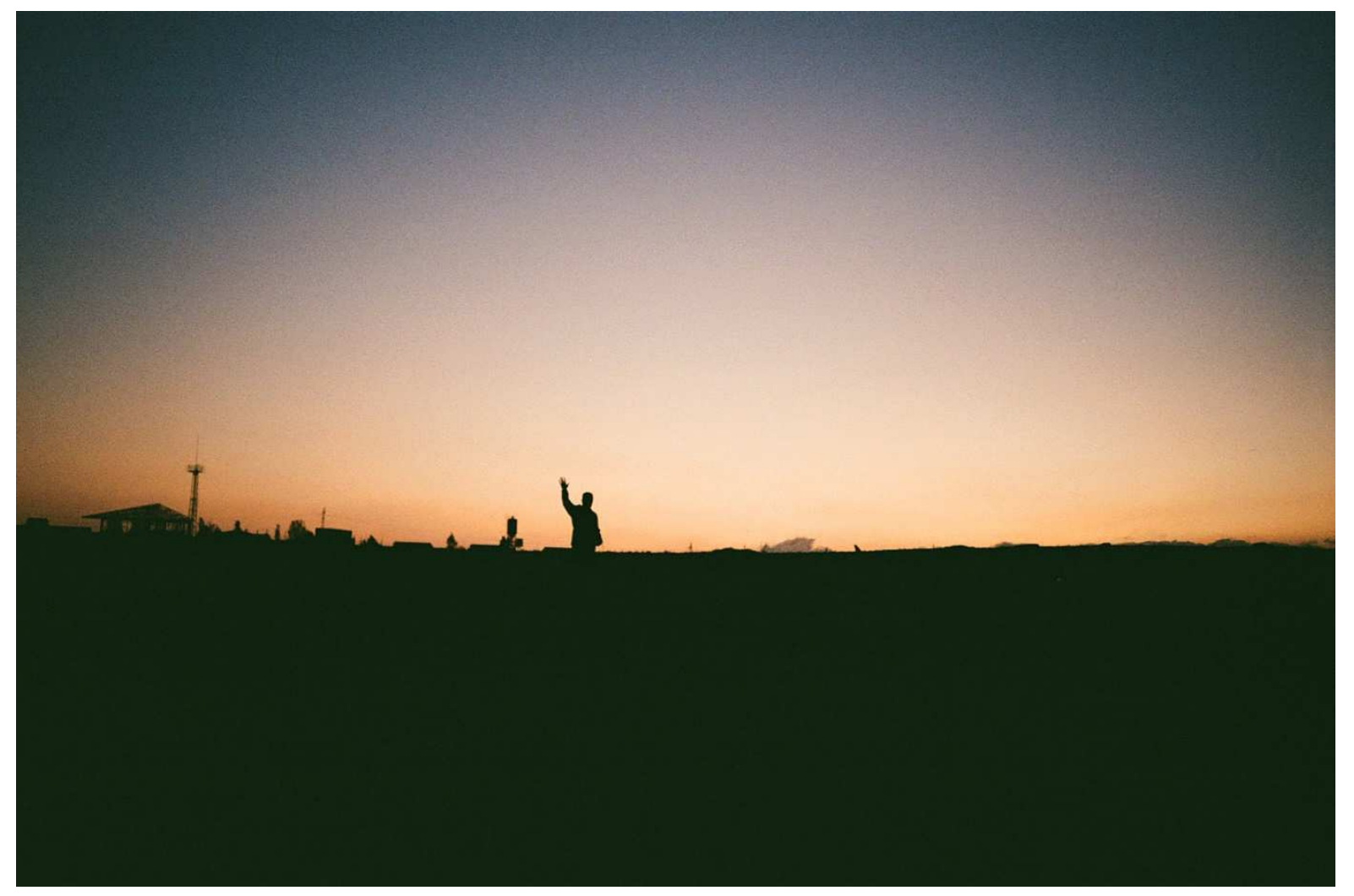

Obrázek 30. - konec. 


\title{
Kyrgyzstán - nomádem na tř̆i týdny
}

\author{
Michaela Lederová, Tomáš Matz
}

Kyrgyzstán se v posledních letech stává pro Čechy stále atraktivnější lokalitou, speciálně díky svým nádherným horám. Když jsem doma oznámila, že jedu na letní školu do Kyrgyzstánu, stejně jsem se setkala s klasickými neznalostmi a obavami - kde se vlastně země nachází? Někde u těch okolních ,stánư‘“? A je tam bezpečno? A co tam vlastně budu dělat? Nebylo by lepší jet někam jinam? Přes všechny tyto chytrá doporučení jsem na letní školu stejně odjela a vydala jsem se poznávat nepoznané. Bylo to přínosné nejen pro mě, ale i pro mé okolí, jelikož jsem po návratu byla schopná rozmetat jejich pokroucené představy a předat jim něco o místních i jejich zemi.

Měli jsme možnost se dovědět o historii a kultuře, navíc jsme ji během třech týdnů mohli i sami pozorovat. Mně samotné třeba přišel velký rozdíl mezi obyvateli města, kterým jsme zřejmě většinou překáželi, nebo je zdržovali a občas byli lehce nevrlí a mezi obyvateli na venkově, kteří byli pohostinní a přátelští. Často za námi někdo přišel a ptal se, odkud jsme, k našemu překvapení často znali Česko. Dalším překvapivým jevem bylo, že alespoň ve městě všude pobíhaly děti, ale nikdy jsme okolo neviděli rodiče. Bylo to jako by o ně nikdo neměl strach. Co se týče bezpečnosti, nikdy jsme neměli žádný problém. Pohybovali jsme se po městě i v nočních hodinách a všechno proběhlo hladce. Dalším zajímavým objevem byla místní cenová hladina. Jelikož bylo všechno velmi levné, mohli jsme jíst a pít a užívat si různé atrakce a zábavu bez přemýšlení. Po třech týdnech se to stalo lehce návykové. Návrat do Česka byl celkově těžký, ale vyšší ceny tomu jistě nepomohly. Jedinečné bylo i řízení místních. Vzhledem k levným cenám jsme si často objednávali taxi. Místní řidiči jsou šílenci, jinak to popsat ani nejde. Navíc má většina z nich nějaké staré polorozbité auto, a když říkám staré, myslím opravdu staré. Každá jízda tak byla dobrodružstvím s nejistým koncem.

Při pohledu zpět na mou letní školu v Kyrgyzstánu se mi těžko hledá pár nejdůležitějších momentů. Celé tři týdny, jež jsme v Kyrgyzstánu strávili, byly po okraj (občas až přes) naplněné zážitky, zkušenostmi. Vše zkrátka nějak plynulo a nebyl moc čas přemýšlet nad tím proč a jak. Až při zpětném pohledu si uvědomuji, jaké jsme měli štěstí, že jsme podobné věci mohli zažívat. Ne že bych si jedinečnost zážitků neuvědomovala v daný moment, ale při zpětném pohledu se jaksi zvýrazní. Bylo to jako být na tři týdny odtržen od 
reality a uzavřen v cestovatelské bublině, kde nemusíte řešit plno věcí, které nám obtěžují každodenní život. Například mobilní telefony na mnoha místech neměly signál (přestože jsme měli místní sim kartu), proto jsme po čase telefon prostě odložili a sloužil spíš jako fot’ák než cokoliv jiného.

Začátky letní školy byly z mé strany velmi nejisté. Rozhodla jsem se cestovat sama, a tak jsem se musela začlenit mezi dvacet nových lidí. Bylo to velké vystoupení z mé komfortní zóny a jsem za něj velmi ráda. Všichni studenti v Kyrgyzstánu byli přátelští a každý člověk trochu jiný. Bylo pro mě zajímavé poznávat každého jednotlivce. Letní školu jsme začali v Biškeku - hlavním městě Kyrgyzstánu. V Biškeku jsme chodili do školy celý první týden. Ve škole jsme měli předměty zaměřující se na historii, politiku, ekonomii, kulturu Kyrgyzstánu a okolních středoasijských zemí, jejich vývoj. Mimo jiné jsme také měli hodiny ruštiny, které byly velmi intenzivní. Mimo školu jsme v prvním týdnu poznávali město a taky jeden druhého.

První víkend jsme měli výlet na tři dny. Jeli jsme se podívat $\mathrm{k}$ jednomu z větších jezer v Kyrgyzstánu, k jezeru Son-Kul. Bylo to poprvé, kdy jsme vyrazili mimo město a měli jsme možnost poznat místní kulturu blíže a v přirozenějším prostředí. Bydleli jsme př́imo u jezera v tradičních obydlích - jurtách. Jurty byly nádherné a celý výlet měl lehce dobrodružněromantický nádech. Během výletu jsme jezdili po místních pláních na koních, zdolávali okolní kopce, nebo vstávali na východ slunce. Každý z uvedených zážitků a jedinečných momentů se mi vryl hluboko do paměti. Jízda na koních po místních pláních byla obzvlášt' zajímavá. Vzhledem k tomu, že mnoho z nás na koni sedělo poprvé, nebo podruhé v životě, koně si také často dělali, co sami chtěli. Přinutit je k poslušnosti byl většinou nadlidský výkon. Přesto, nebo snad právě proto, byla jízda velký zážitek. Mimo jízdu na koních jsme u jezera Son-Kul měli první delší pěší výlet po okolí. Příroda a hory v Kyrgyzstánu jsou dechberoucí, a byl to neskutečný odpočinek.
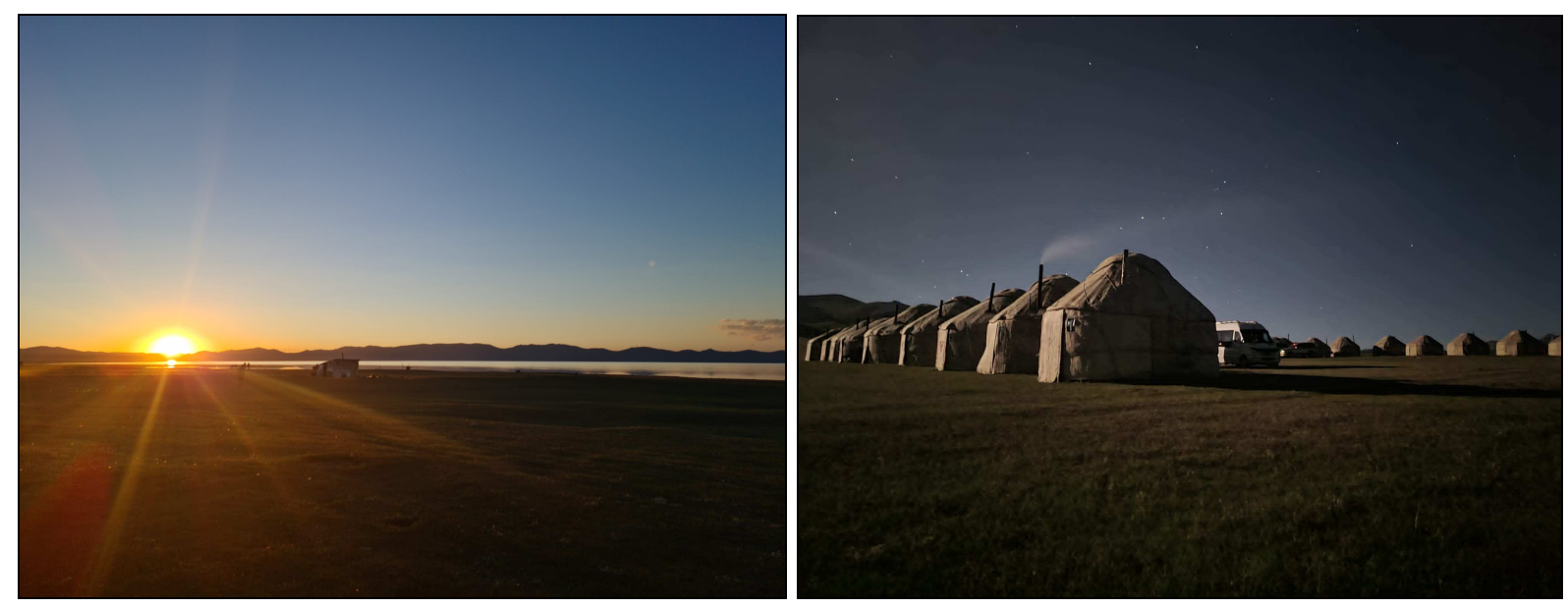

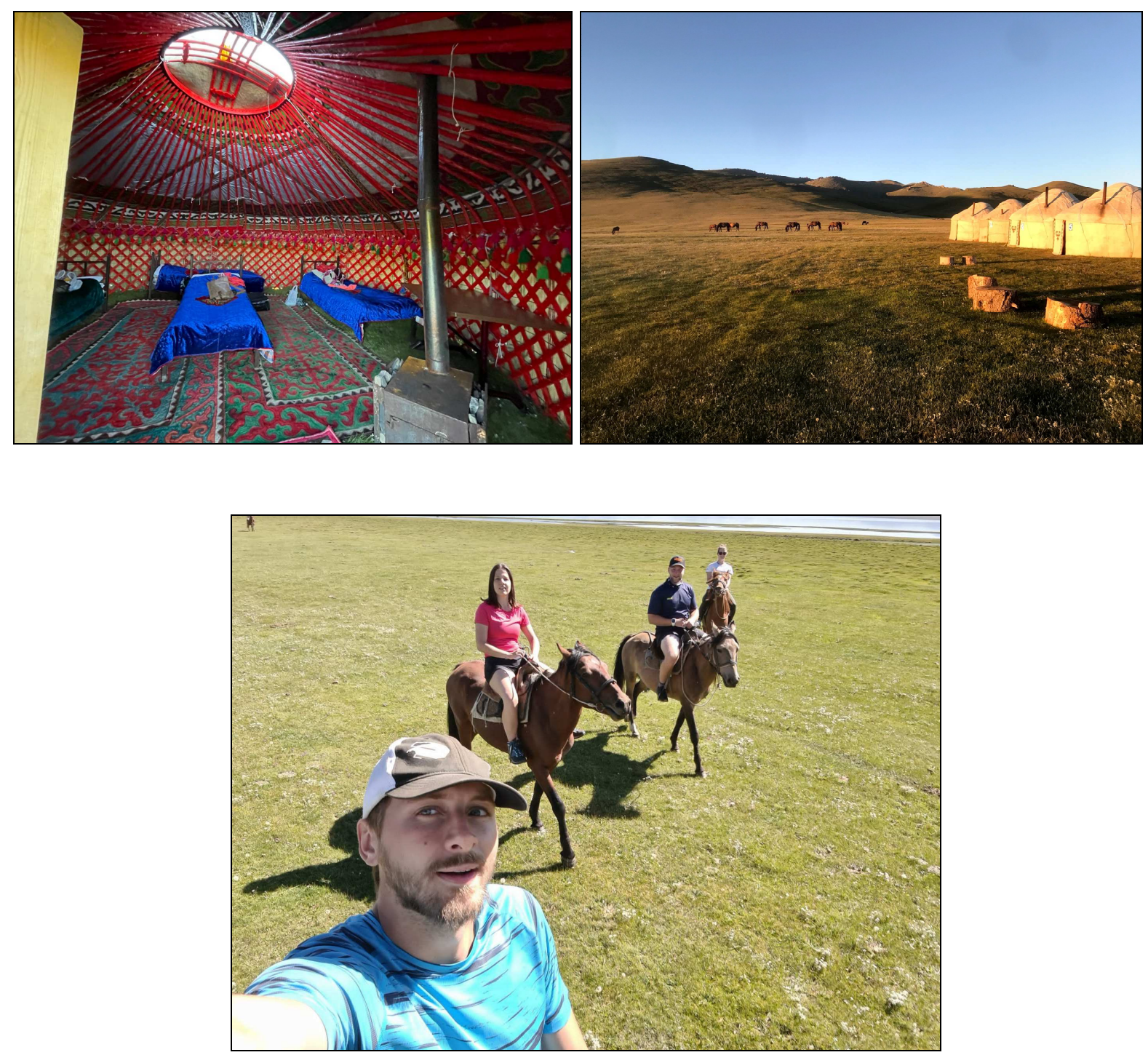

Při cestě zpět od jezera Son-Kul jsme si dopřáli ještě trochu adrenalinu (aby toho nebylo málo). Sjeli jsme kus řeky na raftech. Domluvit se s místním průvodcem na pokynech na raftu bylo samo o sobě velmi zajímavé. Nakonec jsme to zvládli, ale stejně většinou alespoň pár lidí (většinou já) pádlovalo v protisměru, nebo mimo rytmus.

Po výletě u jezera jsme se vrátili zpět do Biškeku a čekali nás dva dny školy, po kterých následoval druhý větší výlet na šest dnů. Výlet byl kolem největšího kyrgyzského jezera Issyk-Kul. První den u jezera byl ve znamení dovolené v Chorvatsku. Byli jsme v celkem pěkném hotelovém komplexu, který ústil na pláž a do jezera. Hned po př́ijezdu jsme se převlíkli do plavek a šli jsme si užít pláže a pěkného počasí. 

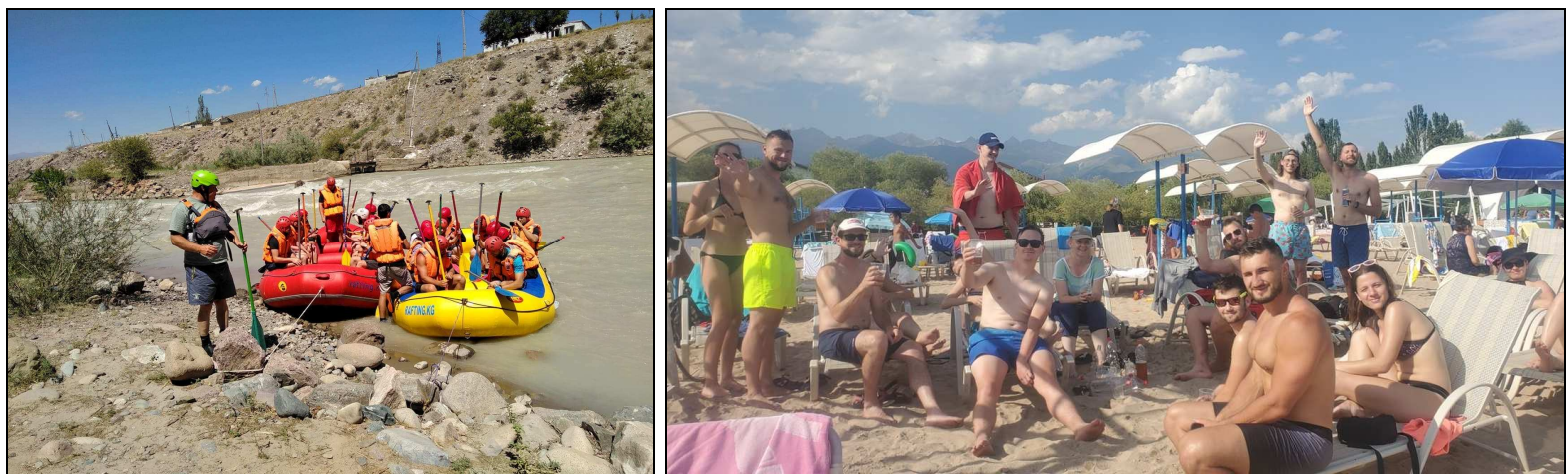

Během našeho druhého výletu nás čekal i náš nejdelší trek. Z původních $11 \mathrm{~km}$ to nakonec bylo $25 \mathrm{~km}$. I to se stává. V podstatě jsme celý den strávili v horách a údolích s občasnými přestávkami na oběd nebo svačinu. Příroda, a hlavně hory, v Kyrgyzstánu jsou opravdu nádherné a učarovali mě na první, druhý i třetí pohled.
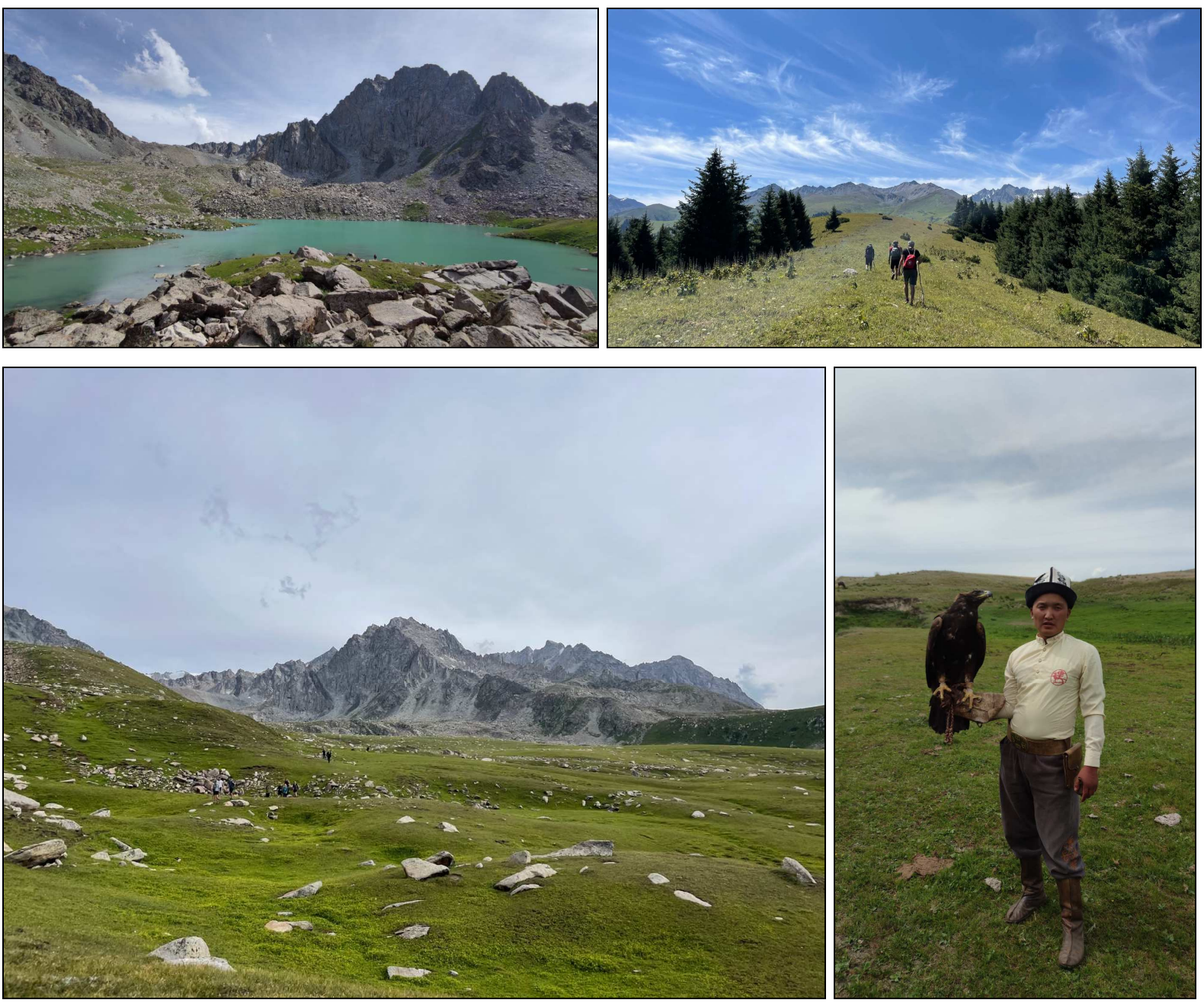

Během výletu jsme také měli možnost vidět sokola, který loví králíka. I když sokol byl celkem zlenivělý a pravděpodobně zvyklý na turisty, nakonec se mu králíka ulovit podařilo. 
V hlavním městě jsme také navštívili místní trhy. Přišlo mi to jako svět ve světě. Město mimo trh zmizelo a vy jste bloudil uličkami přeplněnými různými předměty. Každý nákup byl předmětem dvoustranného smlouvání.
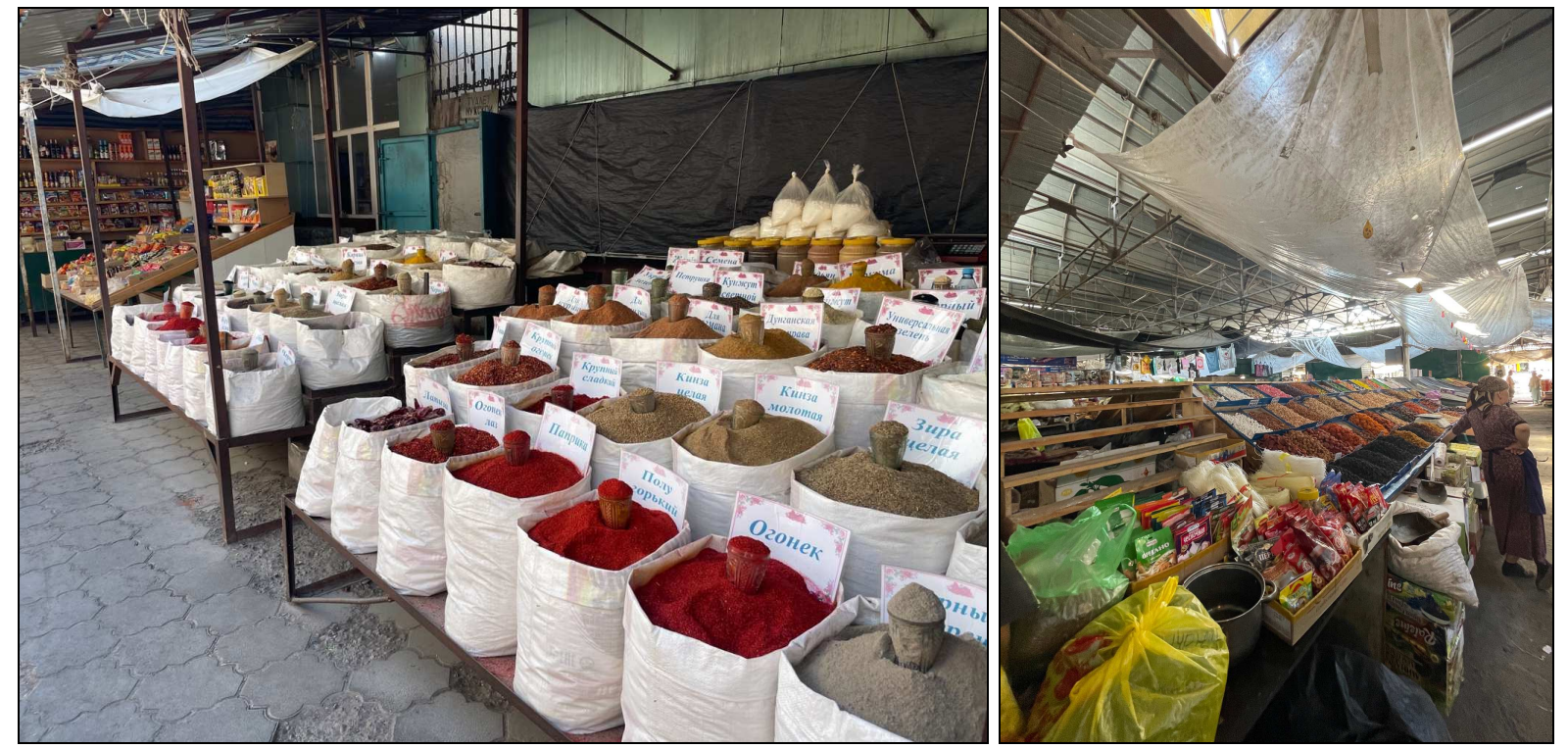

Jelikož jsme byli v Kyrgyzstánu na přelomu července a srpna, tedy v době největších veder, jedno odpoledne jsme se rozhodli i navštívit místní aquapark. I to byla velmi zajímavá zkušenost. Doted' si nejsem jistá, jestli jsem věřila místním konstrukcím tobogánu a skluzavek, ale všichni jsme ve zdraví přežili. Navíc jsme si užili spoustu legrace.
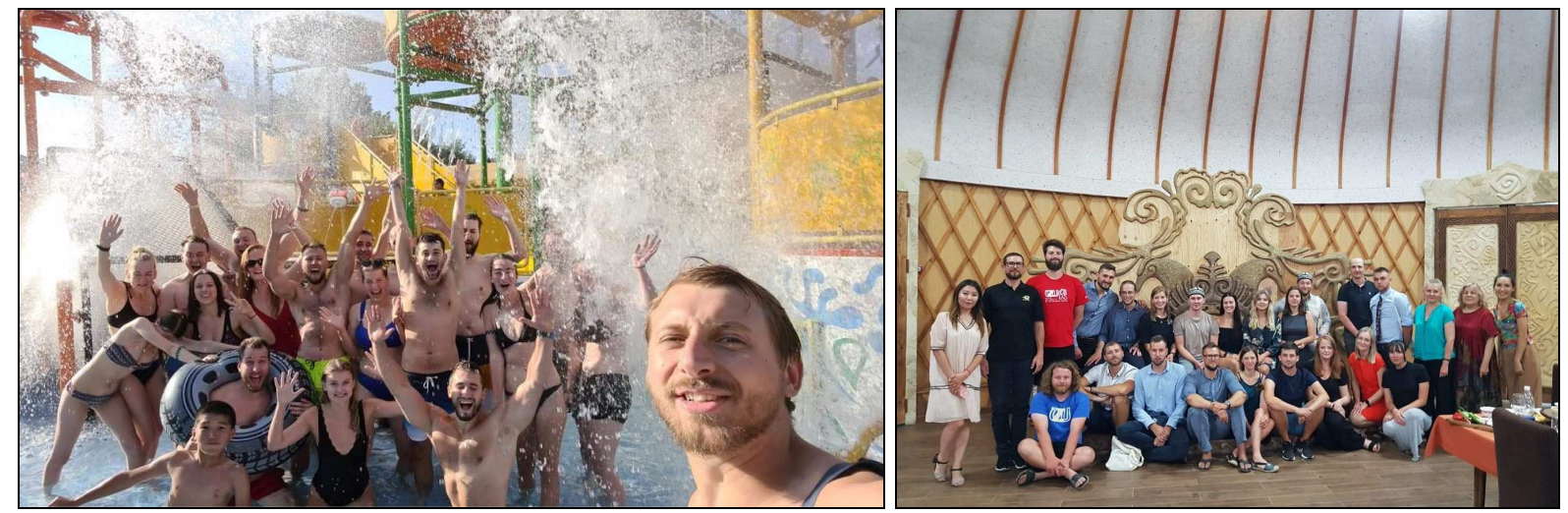

Na poslední společný večer jsme měli pro všechny uspořádanou společnou večeři, na kterou se přidali i někteří naši učitelé, či organizátoři z místní školy. Restaurace byla na nádherném místě a večeřeli jsme v místnosti, která připomínala obrovskou jurtu. 


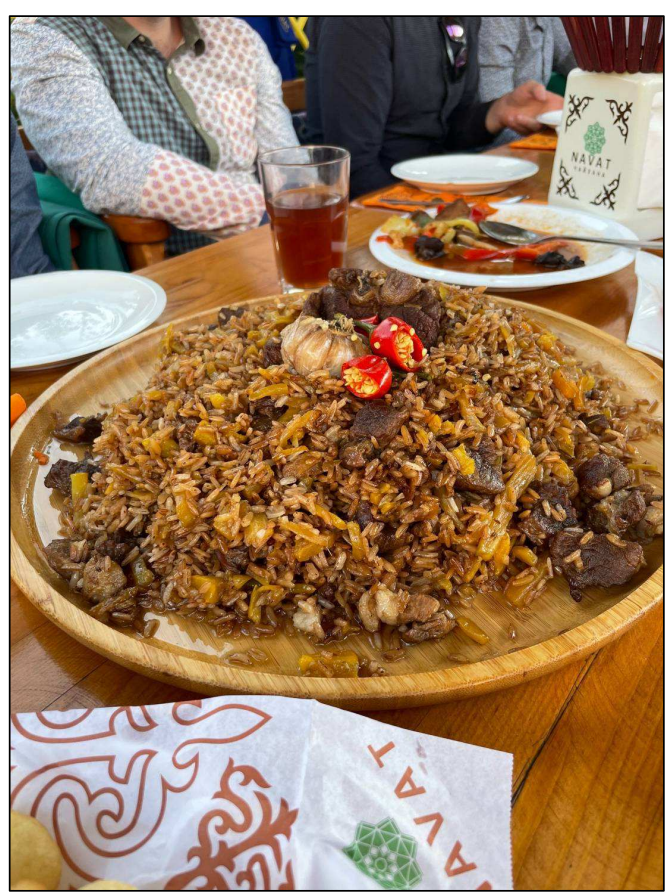

A když už jsme u jídla, jedno z mých oblíbených jídel v Kyrgyzstánu byl „,plov“. Šlo o rýži s masem a zeleninou. O jídlo jsme celkově neměli nouzi. Místní byli velmi pohostinní a několikrát se nám stalo, že jsme měli oběd zařízený př́ímo u někoho doma.

Kyrgyzstán je pro mě země mnoha tváří. Rozhodně se jedná o zajímavou různorodou zemi, kterou bych každému doporučila navštívit. Já na letní školu vzpomínám ráda a do Kyrgyzstánu se rozhodně ještě někdy podívám! 


\section{Obsah}

$\underline{\text { Recenzované články: }}$

150 LET ANTROPOLOGIE: TYLOR, MORGAN A MIKLUCHO-MAKLAJ ANEB KULTURA, KOMPARACE A TERÉNNÍ VÝZKUM ROKU 1871

Martin Soukup DOI: https://dx.doi.org/10.7160/KS.2021.170201

WOMEN'S VEILING: EVERYDAY AND CEREMONIAL PRACTICES OF CENTRAL-ASIAN PEOPLES

Tereza Hejzlarová, Olga Viktorovna Starostina DOI: https://dx.doi.org/10.7160/KS.2021.170202

«СКРЫВАНИЕ» ЖЕНЩИНЫ: ПОВСЕДНЕВНАЯ И ОБРЯДОВАЯ ПРАКТИКА У НАРОДОВ СРЕДНЕЙ АЗИИ

Tereza Hejzlarová, Olga Viktorovna Starostina DOI: https://dx.doi.org/10.7160/KS.2021.170202ru 41

POLITICAL INVENTION OF THE WORLD NOMAD GAMES IN KYRGYZSTAN

Arzuu Sheranova DOI: https://doi.org/10.7160/KS.2021.170203

THE BALOCH INSURGENCY IN PAKISTAN AND THE CHINESE CONNECTION

Shakoor Ahmad Wani DOI: https://doi.org/10.7160/KS.2021.170204 82

BALÚČSKÉ POVSTÁNÍ V PÁKISTÁNU A SOUVISLOST S ČÍNOU

Shakoor Ahmad Wani DOI: https://doi.org/10.7160/KS.2021.170204cs. 100

ZACHOVÁNÍ ETNICKÉ IDENTITY A KULTURY JEZÍDŮ V NĚMECKU

Natalia Doboš DOI: https://dx.doi.org/10.7160/KS.2021.170205 118

ZÁKLADNÍ VOJENSKÁ SLUŽBA PO ROCE 1968 JAKO NÁSTROJ VÝCHOVY K OBČANSTVÍ: INDOKTRINACE A IDEOLOGIZACE V NARATIVNÍ REFLEXI

Jiří Hlaváček DOI: https://doi.org/10.7160/KS.2021.170206. 150

Studentská sekce:

STAROBYLÁ ARMÉNIE ANEB KRÁSY KAVKAZU

Karel Jílek, Kateřina Mlázovská.

KYRGYZSTÁN - NOMÁDEM NA TŘI TÝDNY

Michaela Lederová, Tomáš Matz 183 